The copyright $\odot$ of this thesis belongs to its rightful author and/or other copyright owner. Copies can be accessed and downloaded for non-commercial or learning purposes without any charge and permission. The thesis cannot be reproduced or quoted as a whole without the permission from its rightful owner. No alteration or changes in format is allowed without permission from its rightful owner.

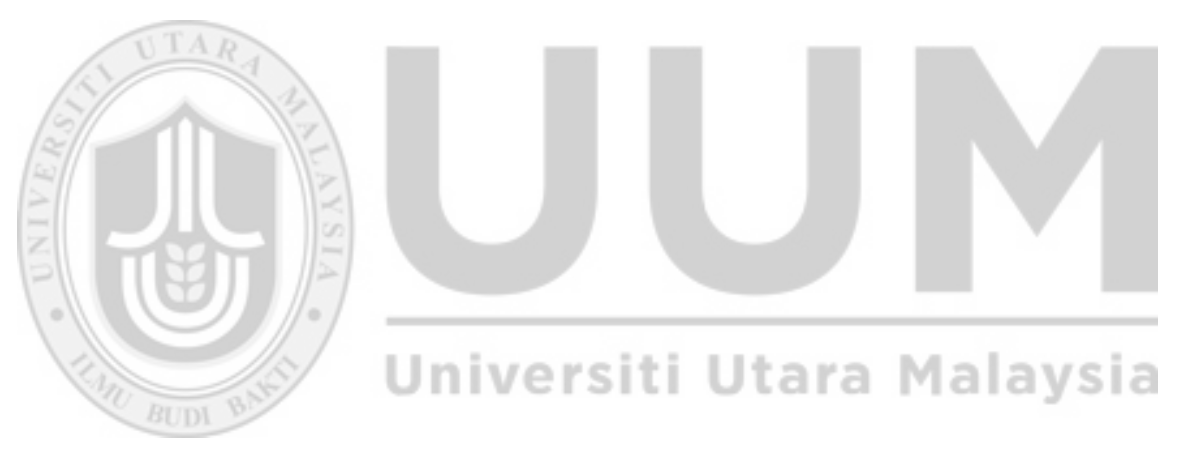


IMPACTS OF PUBLIC PARTICIPATION ON PUBLIC BUDGETING PROCESS OF KURDISTAN

NABAZ NAWZAD ABDULLAH (95531)

DOCTOR OF PHILOSOPHY

UNIVERSITI UTARA MALAYSIA

August 2016 


\section{IMPACTS OF PUBLIC PARTICIPATION ON PUBLIC BUDGETING PROCESS OF KURDISTAN}

NABAZ NAWZAD ABDULLAH (95531)

A Thesis submitted to Ghazali Shafie Graduate School of Government in fulfilment of the requirements for the Doctor of Philosophy Universiti Utara Malaysia 


\section{PERMISSION TO USE}

In presenting this thesis in fulfilment of the requirements for a postgraduate degree from Universiti Utara Malaysia, I agree that the Universiti Library may make it freely available for inspection. I further agree that permission for the copying of this thesis in any manner, in whole or in part, for scholarly purpose may be granted by my supervisor(s) or, in their absence, by the Dean of Ghazali Shafie Graduate School of Government. It is understood that any copying or publication or use of this thesis or parts thereof for financial gain shall not be allowed without my written permission. It is also understood that due recognition shall be given to me and to Universiti Utara Malaysia for any scholarly use which may be made of any material from my thesis.

Requests for permission to copy or to make other use of materials in this thesis, in whole or in part, should be addressed to:

Dean of Ghazali Shafie Graduate School of Government

UUM Collage of Law, Government, and International Studies

Universiti Utara Malaysia

06010 UUM Sintok

Malaysia 


\begin{abstract}
ABSTRAK
Kajian ini adalah bagi mengenal pasti hubungan di antara aspek penyertaan awam dan proses belanjawan modal. Objektif kajian ini adalah untuk mengenal pasti faktor-faktor yang menyebabkan kurangnya keterlibatan orang awam dalam sistem belanjawan negara di Kurdistan. Ia juga bertujuan untuk mengenal pasti kesan aspek sistem penyampaian belanjawan, komunikasi dan maklumat ke atas proses belanjawan modal. Bagi memperoleh hasil kajian, kajian ini telah mengedar 465 borang soal-selidik dan menemubual 11 pakar belanjawan dan pegawai-pegawai kerajaan. Pekali korelasi dan regresi berganda digunakan untuk mengkaji hubungan kedua-dua aspek ini. Dapatan kajian menunjukkan korelasi positif yang kuat antara perbincangan, komunikasi, maklumat, dan proses belanjawan modal. Analisis regresi berganda juga mendapati bahawa penyertaan awam menyumbang kesan yang signifikan dalam proses belanjawan modal. Kajian ini turut mendapati bahawa faktor-faktor utama yang menyebabkan kurangnya keterlibatan masyarakat awam dalam sistem penyampaian belanjawan ialah masalah kewangan, campur tangan parti-parti politik, rasuah, kelemahan organisasi masyarakat sivil, ketidaksalingpercayaan, serta pemakaian sistem kewangan yang ketinggalan zaman.. Kajian ini juga menunjukkan bahawa komunikasi bajet merangsang proses belanjawan modal secara berkesan. Selain itu, akses kepada maklumat bajet menggalakkan tadbir urus yang baik, mengurangkan rasuah serta mengurangkan penyalahgunaan bajet awam terutamanya berkaitan projek-projek palsu. Ia juga turut merangsang kepada pelaksanaan pelbagai pendekatan bagi menggalakkan penglibatan rakyat dan dengan ini dapat mewujudkan masyarakat yang aktif dan bermaklumat. Untuk itu, bagi mengurangkan ketidakpuasan hati orang ramai terutama terhadap masalahmasalah sistem penyampaian perkhidmatan, rasuah, keraguan keputusan belanjawan, penyalahgunaan bajet awam, kerajaan Kurdistan perlu melibatkan rakyat dalam proses pembuatan keputusan melalui pelbagai sistem informasi, perbincangan, serta perundingan. Kajian ini diharap dapat menyumbang serta memberi implikasi polisi yang baik bagi meningkatkan sistem belanjawan negara di Kurdistan.
\end{abstract}

Kata Kunci: Proses Belanjawan Modal, Perbincangan awam, Maklumat Awam, Komunikasi, Kurdistan. 


\begin{abstract}
This study examines the relationship between approaches of public participation and capital budgeting process. The objective of this study is to determine factors that have caused the lack of public deliberation in Kurdistan budgeting system. It also aims to identify the impacts of deliberation, communication, and information in capital budgeting process. The study administered 465 questionnaires and interviewed 11 budget experts and government officials. The correlation coefficient and regression analysis used to examine relationships. The findings indicated strong positive correlations between deliberation, communication, information and capital budgeting process. The regression analyses demonstrated a unique significant contribution of public participation in capital budgeting process. This study revealed the leading factors that caused lack of deliberation embraces money shortages, political parties interference, corruption, weakness of civil society organizations, lack of trust, and the deployment of classical financial system. The study also revealed that budget communication effectively stimulates capital budgeting process. Additionally, access to budget information promotes good governance, minimizes corruption and the misuse of public budget. It also facilitates the implementations of other participatory approaches and creates an informed and active citizenry. To alleviate public dissatisfaction, service problems, corruption, illegitimate budget decisions, and the misuse of public budget, the Kurdistan government must involve citizens in decisions making through informed, deliberative, and consultative programs. This study becomes a notable policy implication to improve Kurdistan budgeting system.
\end{abstract}

Keywords: Capital Budgeting Process, Public Deliberation, Public Information, Communication, Kurdistan. 


\section{ACKNOWLEDGEMENT}

First of all, I would like to thank Almighty God for giving me good health and hope in completing this thesis.

This thesis would not have been possible without guidance and help of several individuals who in one way or another contributed and extended their valuable assistance in preparation and completion of this study.

I would like to thank my supervisor, Dr. Mohd Fitri Abdul Rahman for his constant encouragement, inspiration and constructive guidance, ideas, feedback, critical review and examination of the thesis have been enormous help. Words alone can not express my greatest appreciation and gratitude to him.

I would like to give a high appreciation to the University of Utara Malaysia who gave me scholarship to complete my doctorate study. That was a big support that inspired me to study harder in order to prove myself. Also, my appreciation goes to Professor Ravindra Nath Vyas and Dr. Sherko Kirmanj who become guarantor for my doctorate study and the scholarship.

Finally, the long standing importance for my thesis is the kind love and support from my family including my parents, siblings and my wife who believed me enough as I embarked on the graduate study. Without their kind love and support I would not be able to finish this thesis. Their supports have made me work harder and so proudly get my dreams come true. 


\section{TABLE OF CONTENTS}

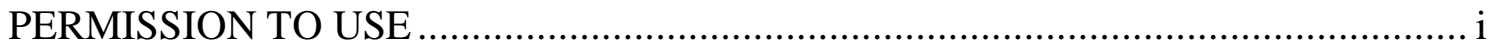

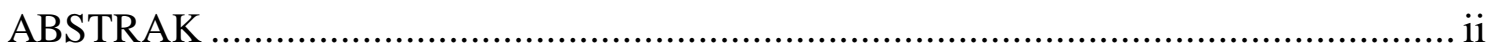

ABSTRACT ……........................................................................................

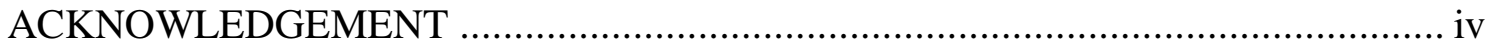

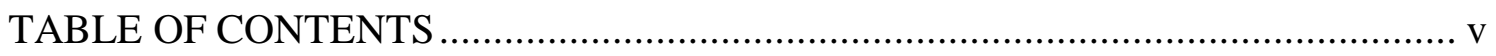

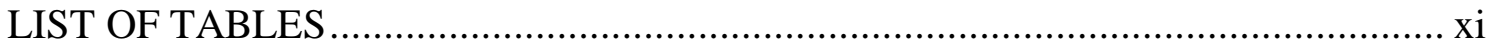

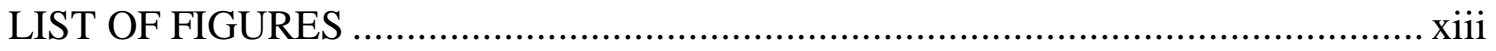

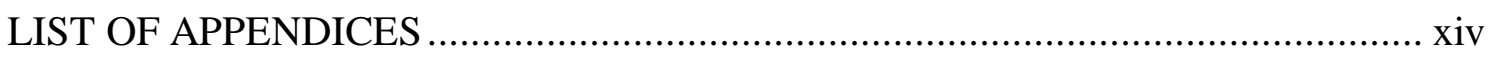

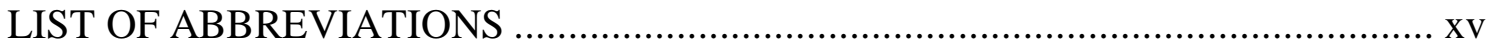

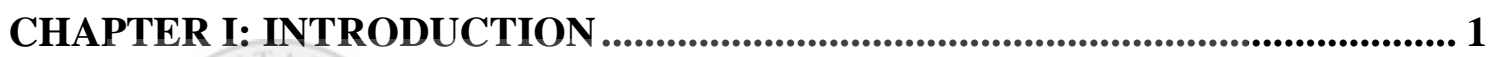

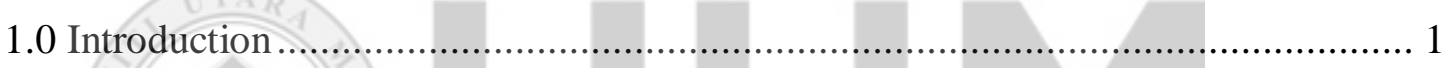

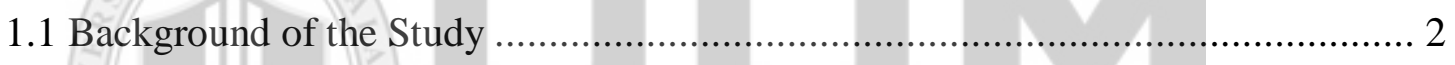

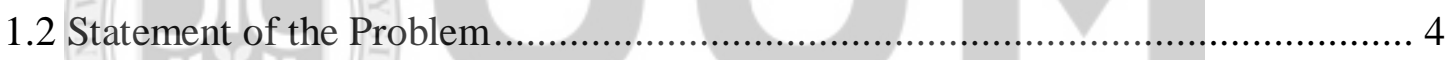

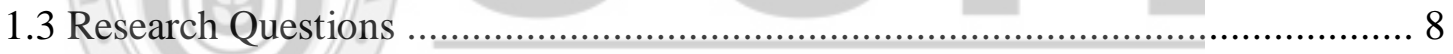

1.4 Objectives of the Researchi.........iti............................................ 8

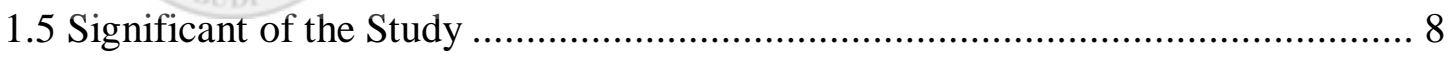

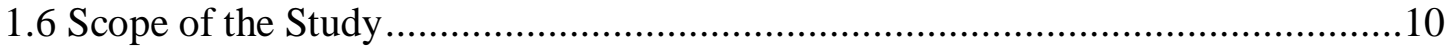

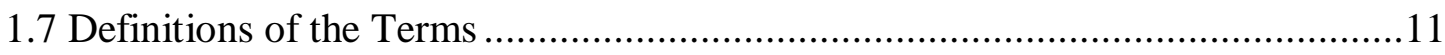

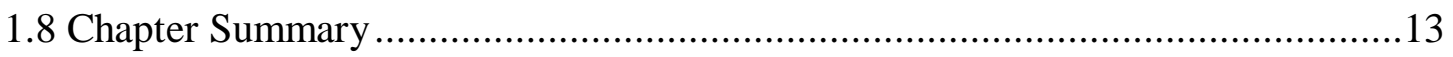

CHAPTER II: BUDGETING PROCESS .................................................................... 14

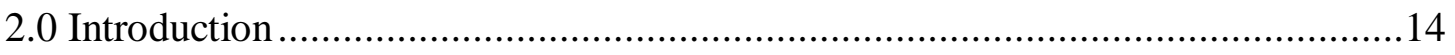

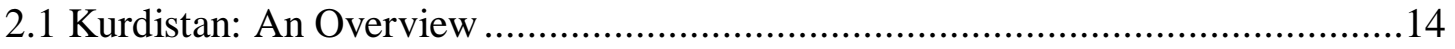

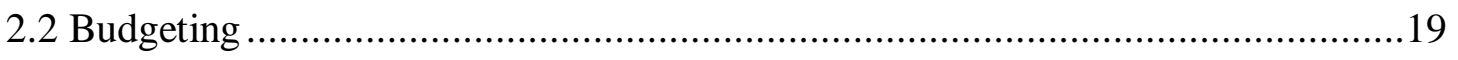

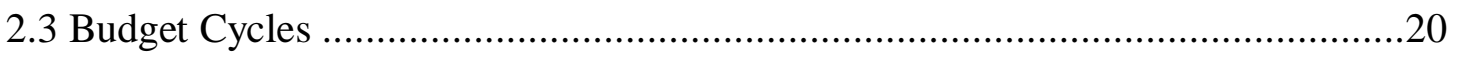

2.4 Public Expenditure and Redistribution of Resources ............................................23

2.5 Budgeting Process in Kurdistan ....................................................................24

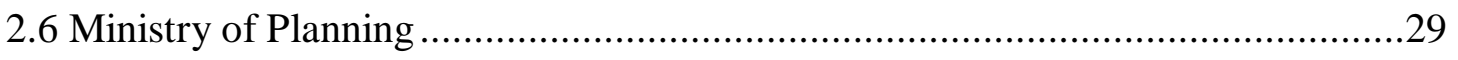


2.7 Consultative Service Delivery Program ………………......................................30

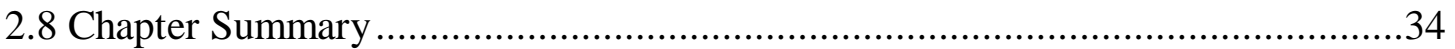

CHAPTER III: LITERATURE REVIEW ................................................................ 36

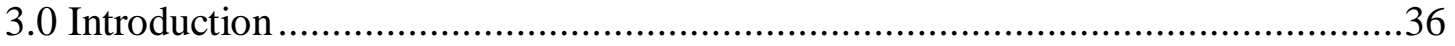

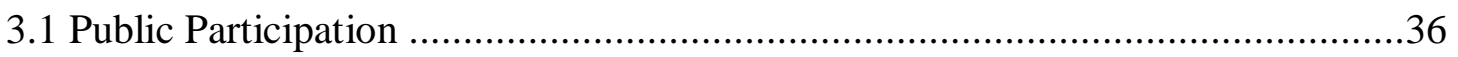

3.1.1 Public Participation and Delivery of Public Services ....................................39

3.1.2 Issues and Solutions of Public Participation..................................................42

3.1.3 Arguments against Public Participation ......................................................45

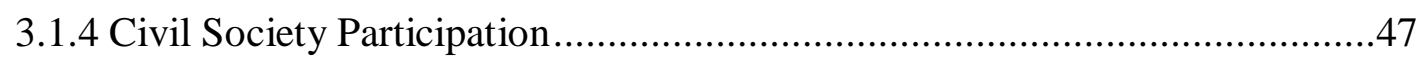

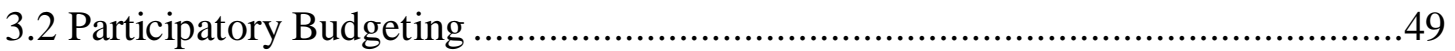

3.2.1 Outcomes of Participatory Budgeting …………….................................52

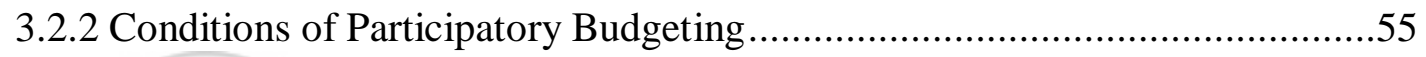

3.2.3 When Participatory Budgeting is more influential? .....................................58

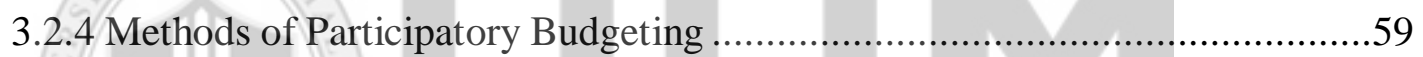

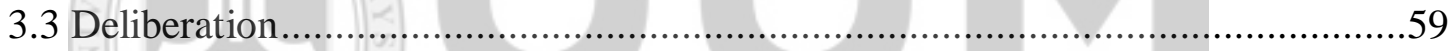

3.3.1 Definitions of Public Deliberation ..............................................................61

3.3.2 The Value of Deliberate on Public Policy Process .......................................62

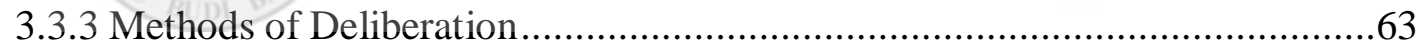

3.3.4 The Preliminary Elements of Effective Deliberation.....................................64

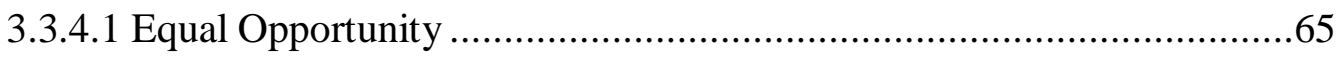

3.3.4.2 Respect to Participants...................................................................66

3.3.4.3 Availability of Information to Participants ...........................................66

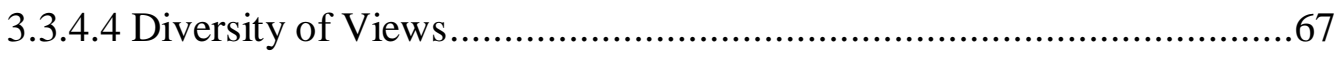

3.3.4.5 Preserving Participants Interest ........................................................67

3.3.4.6 Participate in Coordination with Policy Makers ………………….......68

3.3.4.7 Public Deliberation Predicament...........................................................68

3.3.4.8 Learning and Responsiveness .........................................................

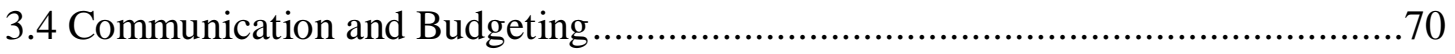

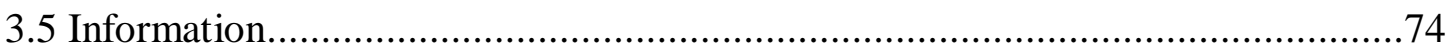

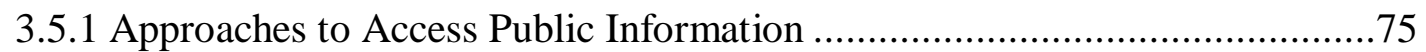




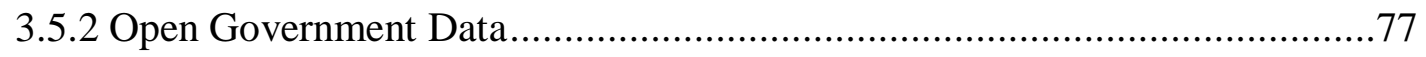

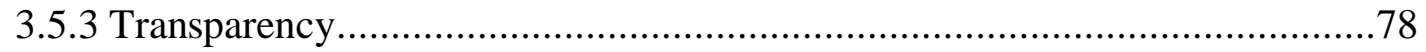

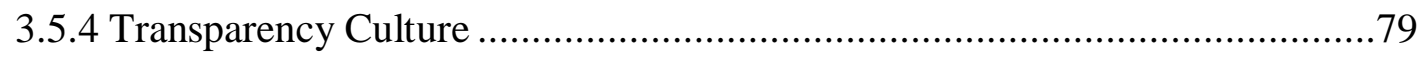

3.5.5 Information and Public Policy Participation ...............................................8

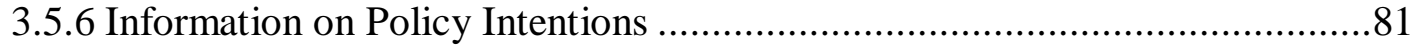

3.5.7 Public Access to Government Information Law............................................83

3.5.8 Citizens' Access to Government Information in Kurdistan ............................84

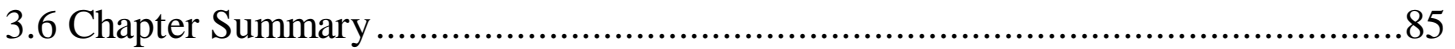

CHAPTER IV: METHODOLOGY …........................................................................ 86

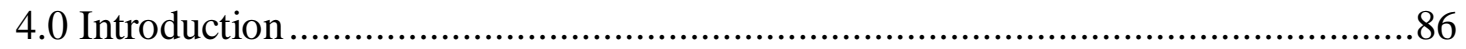

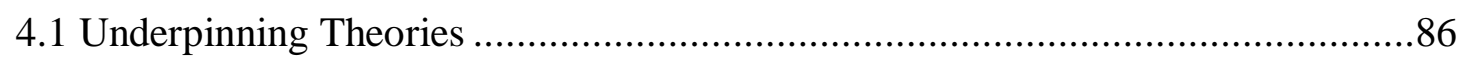

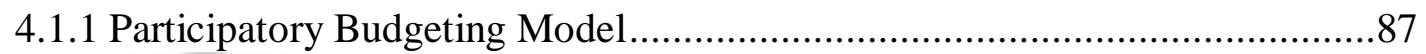

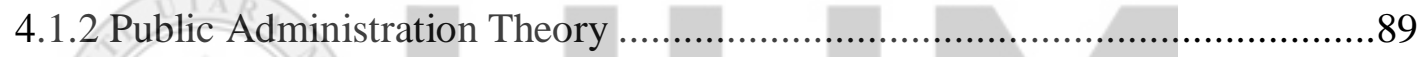

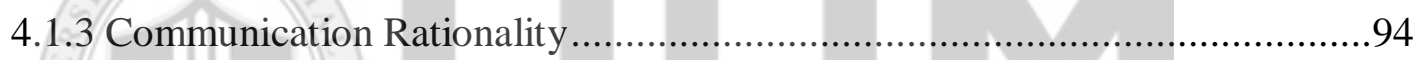

4.1.4 Deliberative Democracy Theory ...............................................................98

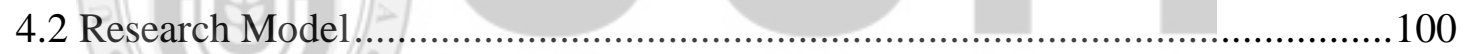

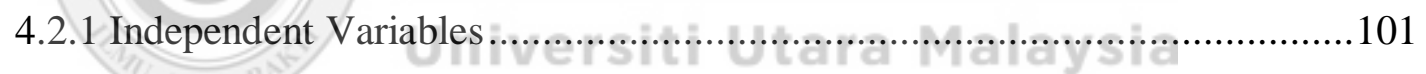

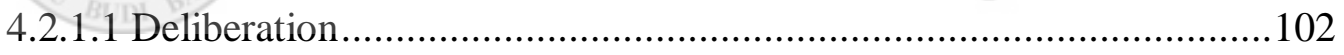

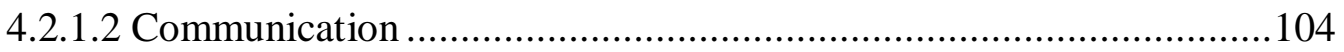

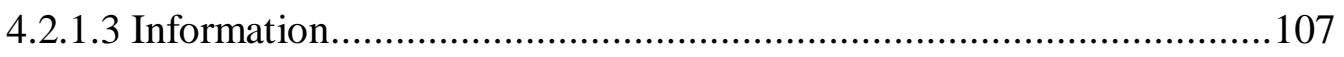

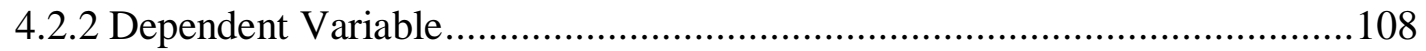

4.2.2.1 Capital Budgeting process ................................................................108

4.2.3 Conceptual Framework …………………….....................................112

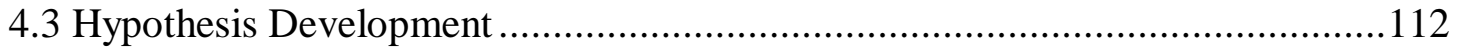

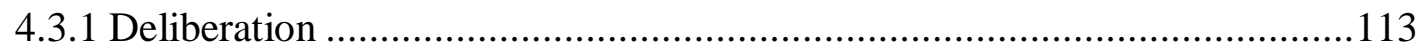

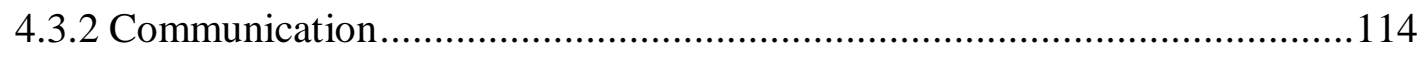

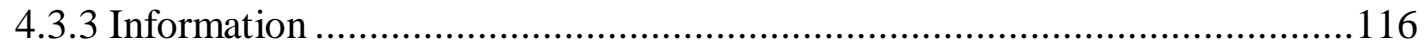

4.3.4 Research Hypothesis .......................................................................118

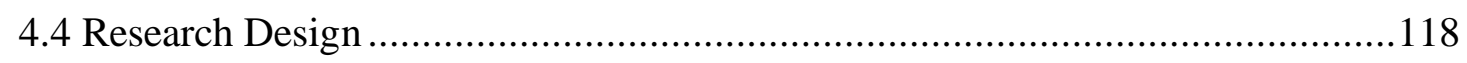

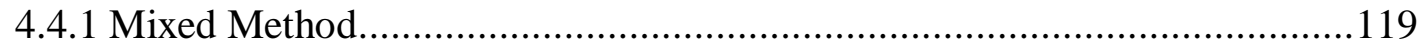




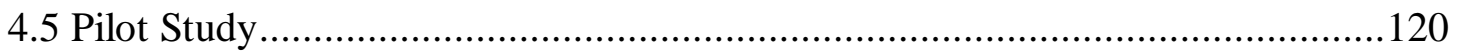

4.5.1 Reliability and Validity ...................................................................120

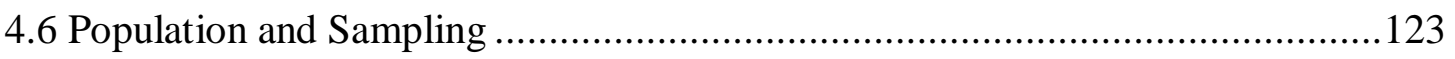

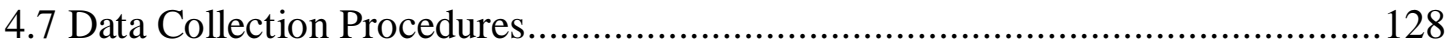

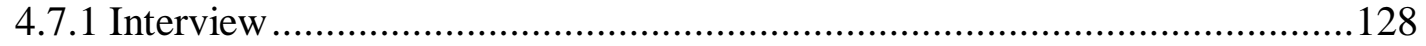

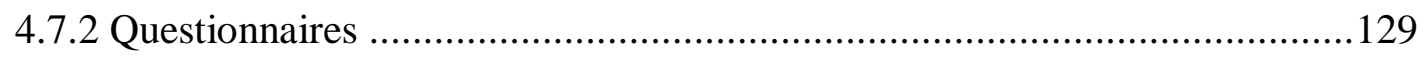

4.7.2.1 Survey Design ...............................................................................130

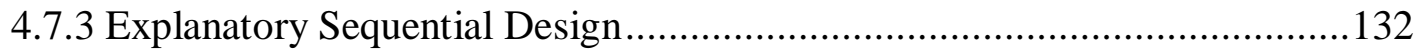

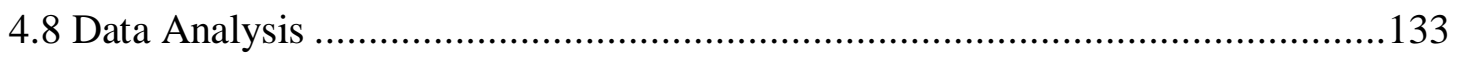

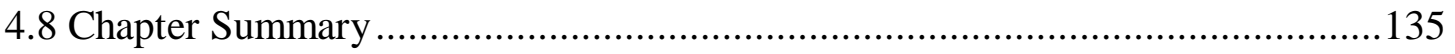

CHAPTER V: QUANTITATIVE FINDINGS...........................................................136

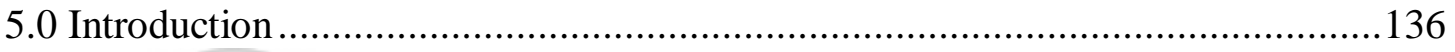

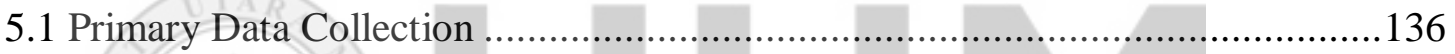

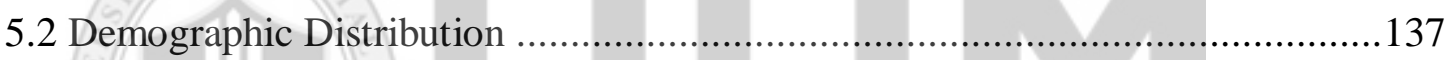

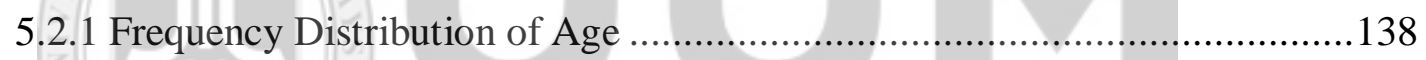

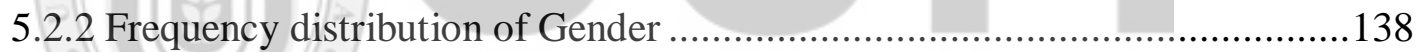

5.2.3 Frequency Distribution of Occupation ..................................................139

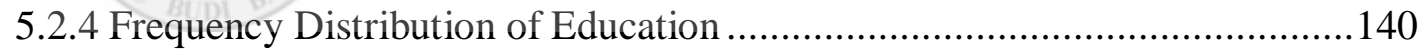

5.2.5 Frequency Distribution of Governorate ....................................................141

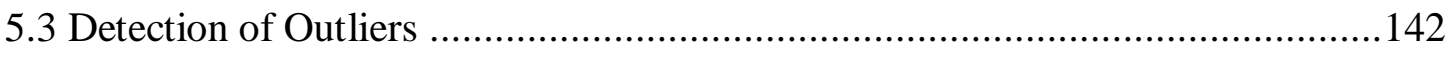

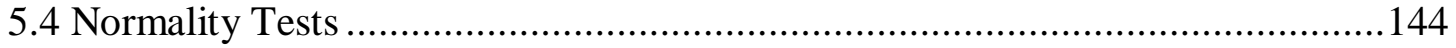

5.4.1 Kolmogorov-Smirnov and Shapiro-Wilk .................................................. 144

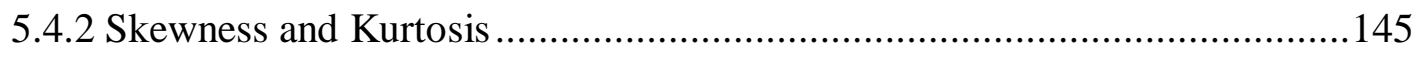

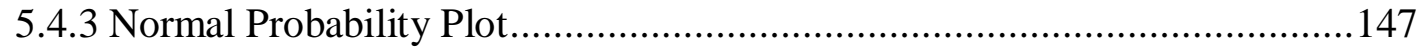

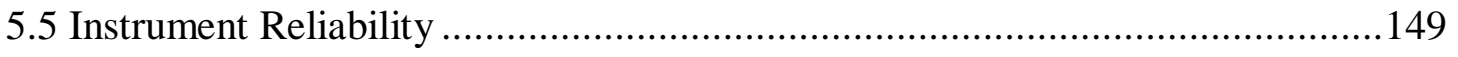

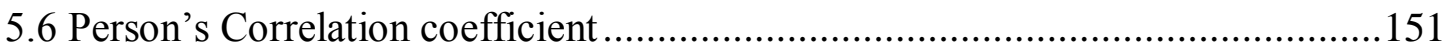

5.6.1 Correlation: Deliberation and Capital Budgeting Process ............................152

5.6.2 Correlation: Communication and Capital Budgeting Process .......................153

5.6.3 Correlation: Information and Capital Budgeting Process ..............................154

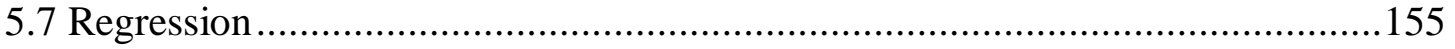




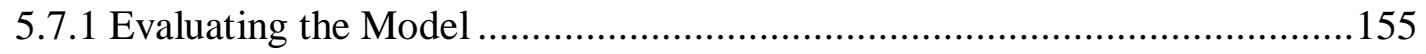

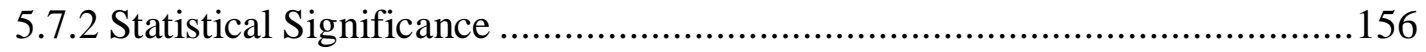

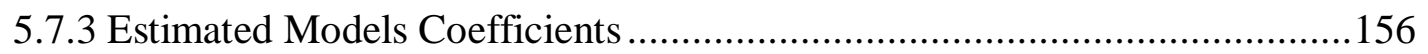

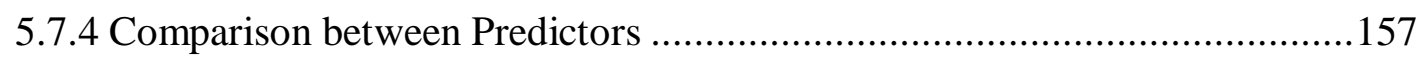

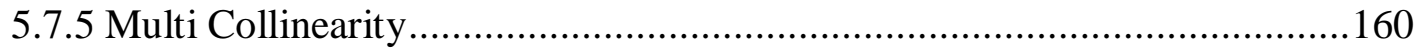

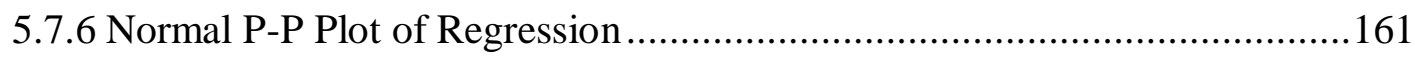

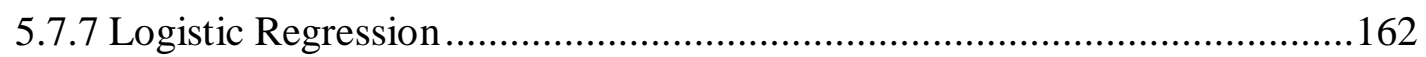

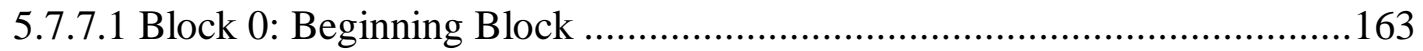

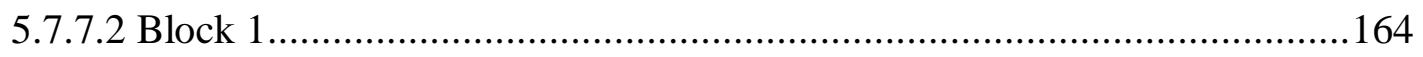

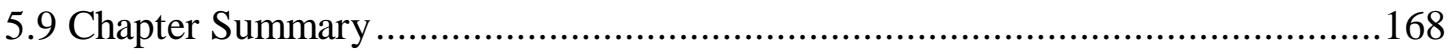

CHAPTER VI: QUALITATIVE FINDINGS ................................................169

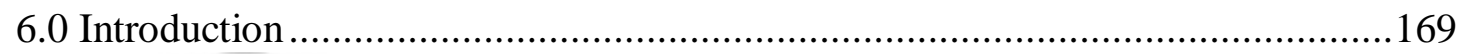

6.1 The Extent of Public Participation in Kurdistan. ............................................172

6.2 Setting Budget Priorities in Kurdistan's Public Budget ...................................175

6.3 Factors that Caused the Lack of Public Budget Deliberation ..............................178

6.3.1 The Absence of Good Financial System ....................................................178

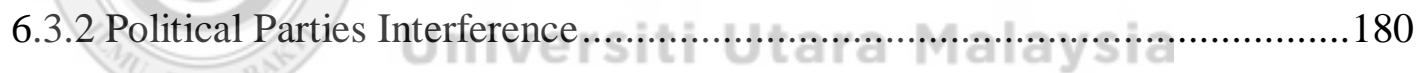

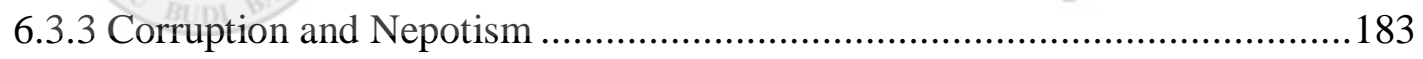

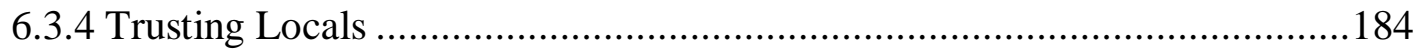

6.3.5 The Weakness of Civil Society Organizations ...........................................186

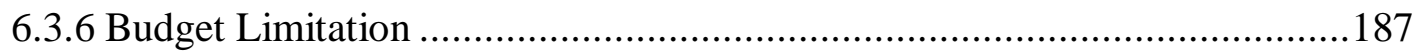

6.4 The Positive Outcomes of Budget Communication ..............................................191

6.5 The Influence of Information over Budget Decision ........................................194

6.6 Budget Decision in the Absence of Citizens' Participation ...................................197

6.7 Increasing Public Satisfaction and Better Services through PB ...........................199

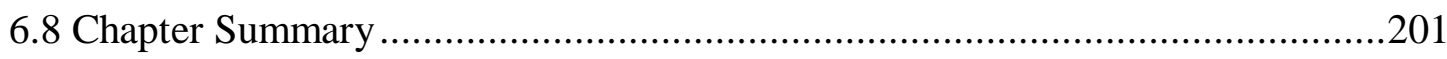

CHAPTER VII: DISCUSSION AND CONCLUSION..............................................202

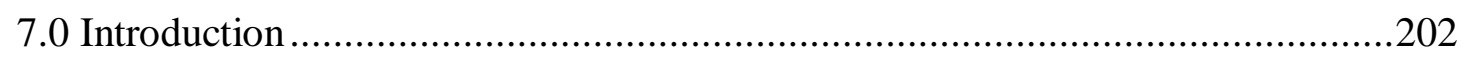

7.1 Public Deliberation and Capital Budgeting Process........................................203 
7.2 Factors of the Lack of Public Deliberation in Kurdistan .................................206

7.3 Communication and Capital Budgeting Process .............................................2211

7.4 Information and Capital Budgeting Process ...............................................214

7.5 Influence of Public Participation in Capital Budgeting Process ........................218

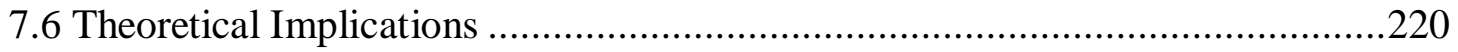

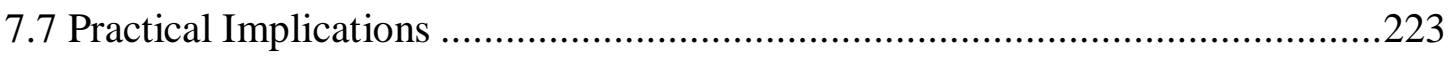

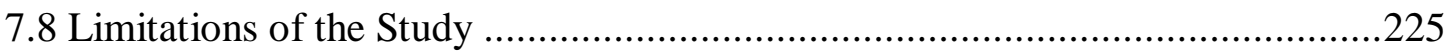

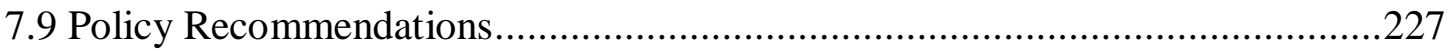

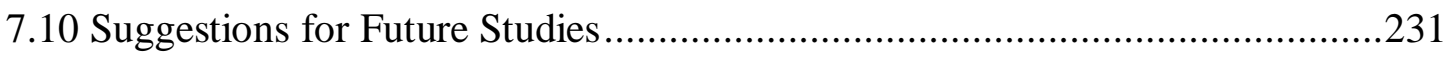

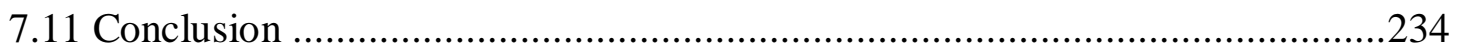

REFERENCES ...................................................................................................246

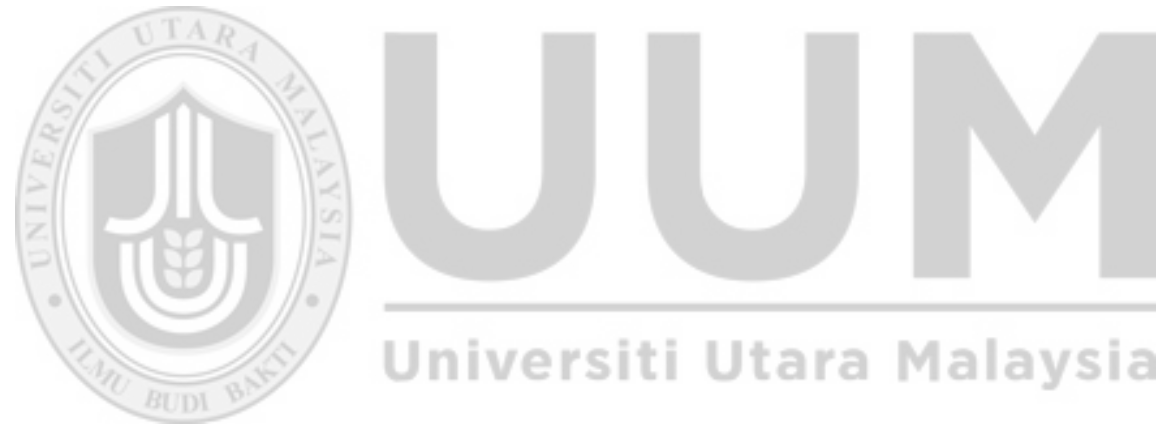




\section{LIST OF TABLES}

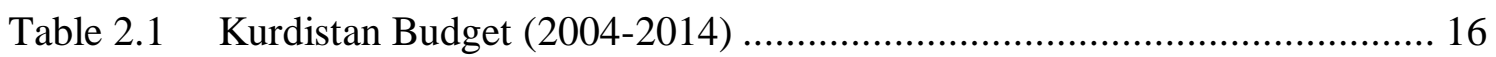

Table 2.2 Details of Consultative Service Delivery Program II .............................. 31

Table 4.1 Citizens Top Priorities in Porto Alegre PB 1992-2005 ……………........ 52

Table 4.2 Reliability Analysis of Pilot Study ……….............................................122

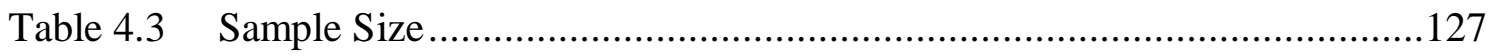

Table 5.1 Summary of the Respondents Profile ……................................................137

Table 5.2 Frequency Distribution of Age ............................................................138

Table 5.3 Frequency Distribution of Gender.........................................................139

Table 5.4 Frequency Distribution of Occupation ……............................................140

Table 5.5 Frequency Distribution of Education ...................................................141

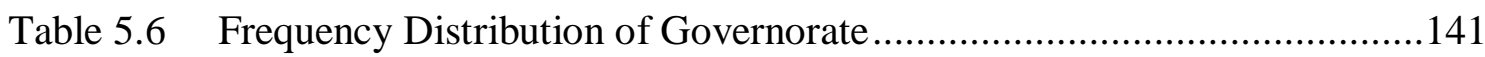

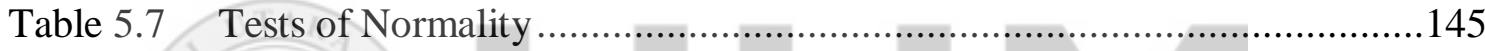

Table 5.8 Tests of Normality: Skewness \& Kurtosis............................................146

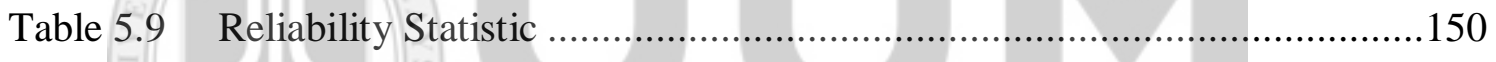

Table 5.10 Correlation between Deliberation and Capital Budgeting Process ............152

Table 5.11 Correlation between Communication and Capital Budgeting Process......153

Table 5.12 Correlation between Communication and Capital Budgeting Process......154

Table 5.14 Model Summary ...............................................................................156

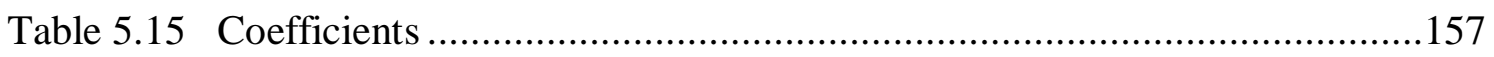

Table 5.16 Standardizes Coefficients: Beta …………..........................................158

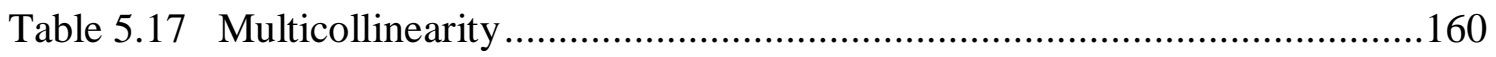

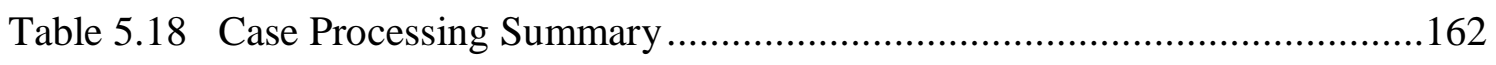

Table 5.19 Dependent Variable Encoding …………….........................................162

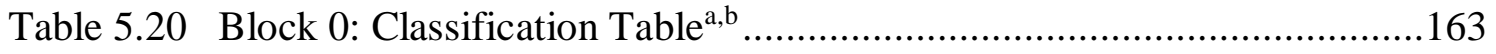

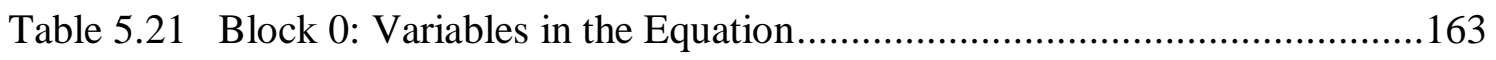

Table 5.22 Omnibus Test of Model Coefficients .......................................................164

Table 5.23 Block 1: Model Summary ……………….............................................165

Table 5.24 Hosmer and Lemeshow Test..............................................................165

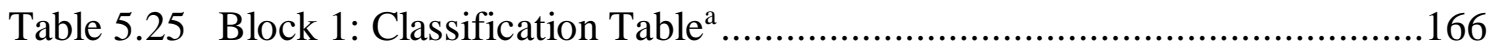


Table 5.26 Block 1: Variables in the Equation........................................................168

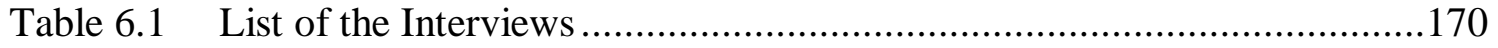

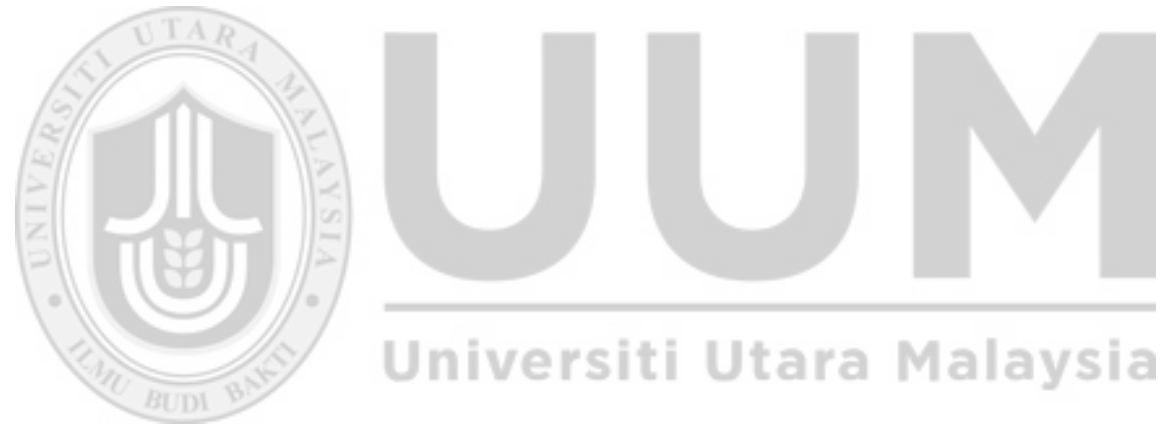




\section{LIST OF FIGURES}

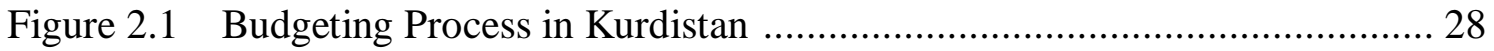

Figure 2.2 Consultative Service Delivery Program ........................................... 35

Figue 3.1 Budgetary Participation through Communication............................... 74

Figure 4.1 Participatory Budgeting Process in Peru ......................................... 88

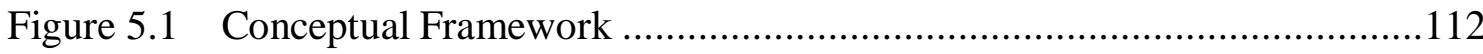

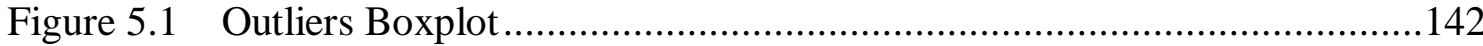

Figure 5.2 Boxplot after Outliers Removed ....................................................143

Figure 5.3 Normal Q-Q Plot of Budget Deliberation .........................................147

Figure 5.4 Normal Q-Q Plot of Budget Communication ......................................148

Figure 5.5 Normal Q-Q Plot of Budget Information ..........................................148

Figure 5.6 Normal Q-Q Plot of Capital Budgeting Process .................................149

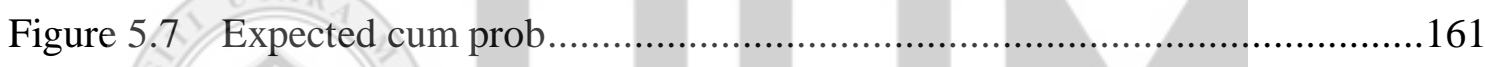




\section{LIST OF APPENDICES}

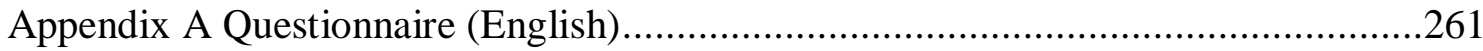

Appendix B Questionnaire (Kurdish) ..........................................................266

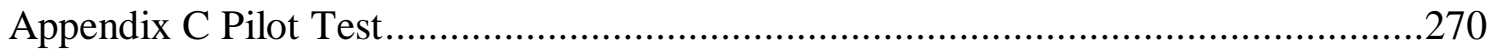

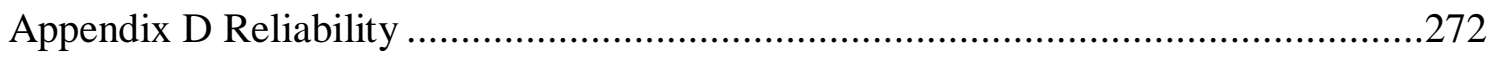

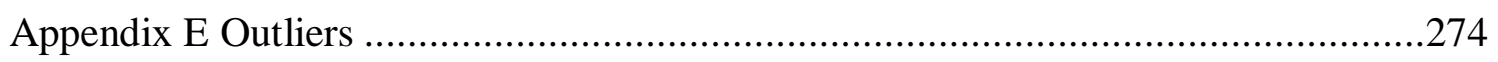

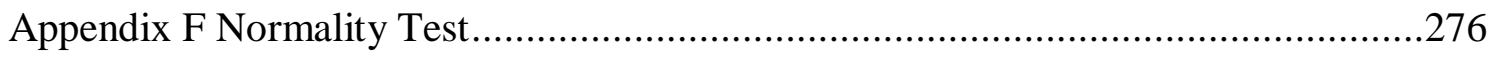

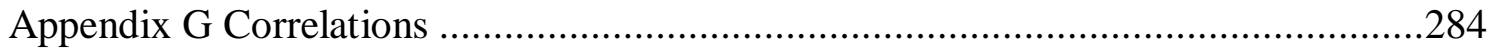

Appendix H Multiple Regression Analysis ....................................................28

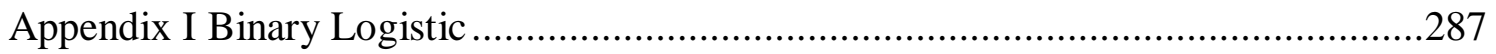

Appendix J Frequencies: Background of the Respondents .................................290

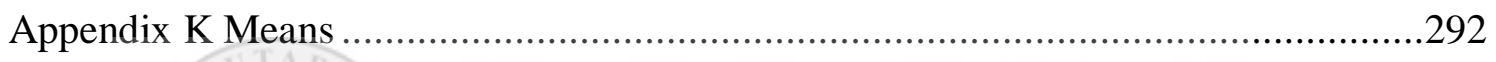

Appendix L Authorization Letter for Data Collection............................................294 


\section{LIST OF ABBREVIATIONS}

ACDI

BOI

CAG

CBD

CSDP

DCC

DQI

FDI

GDP

IMF

ISIS

KRG

MoA

MoE

MoP

$\mathrm{MoF}$

MP

NGO

NPM

NTA

OECD

PB

PBP

PEM

RTI

$\mathrm{UKH}$

UNDP

VOCA

WACP
Agricultural Cooperative Development International

Board of Investment

Community Action Group

Capital Budget Decision

Consultative Service Delivery Program

General Directorate of Coordination and Cooperation

Discourse Quality Index

Foreign Direct Investment

The gross domestic product

International Monetary Fund

Islamic State of Iraq and Levant

Kurdistan Regional Government

Ministry of Agriculture

Ministry of Electricity

Ministry of Planning

Ministry of Finance

Members of Parliament

None-Governmental Organization

New Public Management

National Taxpayers Association

The Organization for Economic Co-operation and Development

Participatory Budgeting

Public Budget Participation

Public Expenditure Management

Right to Information

University of Kurdistan-Hewler

United Nations Development Program

Volunteers in Overseas Cooperative Assistance

World Alliance for Citizen Participation 


\section{CHAPTER I INTRODUCTION}

\subsection{Introduction}

Public participation in countries fiscal policies has recently becomes an important determinant of economic development and sustainability. Public participation is seen to be substantial instrument to promote efficiency, effectiveness, equity, service delivery and enhances the level of public satisfaction. It's also significant to preserve democratic principles of government (Yarnell \& Fogg, 2007, p.12). In this sense, openness towards local communities has becomes a dominant feature of good governance.

The Kurdistan Regional Government (KRG) has faced several budget issues lately. The problems emerged due to the mismanagement of the public financial system. The KRG revenue mainly comes from the country's oil and gas export. The total budget approved by the Parliament in 2013 was US $\$ 14,642$ billion, while the total population is 5.3 million (Kami, 2013). Previously, Kurdistan Region Received 17 percent of the national Iraqi budget, but the government is no longer receives budget from central government in Baghdad. The KRG is now relies on the oil exports and local incomes that received from customs and taxation. Economically, the KRG is independent. Since the oil price fluctuating, it becomes very difficult for the KRG to expect revenue. Since the price of 
oil has declined since the second half of 2014, the government provided less to the investment projects and services.

Since the emergence of Change Movement as the main opposition political party in 2009, discussing budget related issues and quality of services has become a subject of argument among sectors of society. The arguments mostly associate with the lack of transparency, integrity, accountability, and public participation, especially in the investment budget (UNDP, 2009; Zebari, 2013). In Kurdistan there are two primary types of budget which are recurrent budget and investment budget also known as a capital budget. According to the Ministry of Finance $(\mathrm{MoF})$, recurrent budget takes almost 70.48 percent of the total budget, while the investment budget is only 29.52 percent. There is also a secondary type of budget known as "Provincial Development Budget" which is more related to capital budget. This budget is to support local governments from different provinces to implement certain types of projects to improve country's infrastructure.

\subsection{Background of the Study}

Public participation is the form of openness that can be used in public budgeting process as an essential motive of good governance. Citizens' participation in budget preparation assumed to be an important determinant of successful budgeting process. It motivates full budget disclosure and assists people to contribute in public financial activities including the allocation of budget and expenditure. As participatory process generated in budgeting process, good governance might be achieved and authorities could be more transparent 
and accountable towards citizens. Public participation in general term is defined as the practice of communication and engaging community members in the decision making process, including agenda setting, decision and policy formulation by the institution that is responsible for the policy development (Loukis et al, 2012, p. 63; Rowe \& Frewer, 2004). In good public financial management system, the openness and public participation activities are necessary to bring in the stakeholders into the process.

Participation could occur through direct citizen participation or community representation with the help of civil society organizations. Public participation is also significant to pursue government institution to bring in more inputs and take public concerns into consideration. In such situation, the level of transparency and efficiency of projects would be much better. Transparency as intertwined component of participatory budgeting (PB) described by the International Monetary Fund (IMF, 2013) as the openness of the government towards citizens from all financial activities that occurred in the past, present and the future. Thoroughly, the outcomes of the fiscal activities could be assessed. The IMF code describes public participation in four different aspects which are associated with citizens, including public access to government information, clearly defining official roles and responsibilities, integrity and clarity of information, and both internally and externally scrutinizing and evaluating fiscal policy information (Folscher, 2010, p. 7). 


\subsection{Statement of the Problem}

The main problem of this study is the lack of public participation in public budgeting process of Kurdistan. It sought to be the contributing factor of dissatisfaction over service delivery and the misuse of large government budget. The lack of public participation also causes ineffectiveness of the public agencies, lack of public services, illegitimate government decisions and negative perception on government administrators and unlikely outcome of the projects (Wouters, Hardie-Boys \& Wilson, 2011). In Kurdistan Region, the lack of public participation in decision making process has caused the misuse of revenue (UNDP, 2009, p.7). Since the government does not deliberate citizens in planning budget projects, a large budget spent on the projects that people are generally do not appreciate it. Ordinary citizens are not the only sector of community excluded by the policy makers, but professionals and budget expertise are also excluded. Shamal Nuri (2013), a Kurdish economist and managing editor of "Political Economy" to Anatolu Agency, indicates that the KRG does not rely on the budget professionals, academics, economists, economist syndicate, and research institutions. He accuses government for neglecting public and highlights that Kurdistan Economists Syndicate has more than 6,000 members and hundreds of expertise, but the government has so far denied their roles and does not even deliberate a single member $(A A, 2013)$. He further argues that government does not trust their abilities to contribute in decisions.

The issue of trust is specifically one of the major obstacles of public participation in public sector organizations. Citizens usually require transparency and participation in decisions, but public organizations distrust their citizens (Nascimento, 2012, p. 11). Means, the 
community members and professionals are not usually welcomed by the government to exchange their ideas over public budget decision. With this intention, budget planning, especially investment budget in Kurdistan is mainly decides by the Ministry of Planning (MoP) and the line ministries without taking major inputs from local communities and local budget expertise.

Despite the fact that citizens' participation is snubbed, public budget in Kurdistan is more planned on political will rather than priorities and needs of citizens (Tawfiq-Shukor \& Khoshnaw, 2010). The lack of deliberation, and public hearing created ineffective budget and caused low quality public services. Also, the authors highlighted that the KRG budgeting system does not rely on scientific consideration. For instance, the highly advanced urban areas receive 73 percent of the total budget; as a result, the penurious rural areas that destitute more budgets only receive 27 percent of the resources. The KRG has given little consideration to human development services, education, health services, water sanitation, social welfare, infrastructure performance and housing. The root of the problem seems to be related to the lack of budget communication, and public deliberation.

Government becomes more accountable when public engages in the process of decision making. In the developed systems, officials engage community members and pursue good governance practice to enhance public services. Therefore, in Kurdistan public participation and knowledge on government budgets is at the bottommost (Qadir, 2007, pp. 19-26). The author related this issue to the stranglehold of the ruling families over economic and financial sectors. He also illustrates that political parties mainly the PDK 
and the PUK are using tax revenue, customs revenue and treasury for their own benefits and he called "personal slush funds." There are other authors highlighted this issue in their works. Rauf (2015) describes Kurdistan budget as "amusing budget." He explains that through the budget allocated for redundant projects in 2013, the KRG was able to build up 13,000 residential units or 18 typical schools as students are suffering due to the lack of school building and the large size of the classes (Rauf, 2015, p.28-29). However, the budget was allocated to the old projects that was included in the previous budget law. There are evidences explained by Rauf, that government provided budget to the same projects several times. The redundancy of the projects will cause the lack of financial resources. The lack of financial resources again causes another problem which makes government to be unable to finance new project.

The lack of public participation in Kurdistan led to major corruption and disappearance of public revenue. The KRG has allocated budget to some projects that were never exit and some projects has been presented repeatedly, but never materialized (Rauf, 2015, p.33). For instance, in 2011 budget, the KRG has allocated US\$550 million to 1275 projects in different sectors, while the budget was already allocated to these projects previously in the 2010 budget. In another example, he pointed out KRG has allocated more than US $\$ 100,000$ to the Ministry of Interior for the purpose of opening swimming pools for women in two locations, while the Ministry of Interior has nothing to do with such projects. Ministry of Interior is accountable for security and traffic, building swimming pool is relating to the Ministry of Municipalities. The KRG closed budget system, has facilitated the act of corruption especially when it comes to the fake projects. 
The evidence of the fake projects and redundancy of the projects are two major issues that associated to public participation. The lack of public engagement probably facilitates any corruption acts.

In the study by the UNDP (2010) found that there is opacity and minor civic participation in the KRG public financial management decisions. The process is highly relying on political factors rather than public needs and country's development strategy (UNDP, 2009, p. 14). Political factor associates the dominant role of the two main political parties over budget decision. The political parties mainly conclude the KRG decisions based on their interest in order to influence their voters. As a result of that, public participation in the country's public budget is snubbed (Frazer, 2011). Furthermore, the KRG lacks of budget reports, financial statement, and information regarding the integration of the financial management within government agencies and ministries. This is described as the key administration problem which impacts on public budget participation (Gomez Insua \& Alfero, 2015). In Kurdistan Region, the financial system is more to let things flooded afore allocating resources through the use of smart mechanism to target the regions strategic development plans (UNDP, 2009, p.13). The study also highlights that "weak capacity and little experience at local levels to carry out integrated, participatory strategic planning and budgeting, which could enable governors to respond to local communities' most important needs while aligning their development efforts with national priorities and vision" (UNDP, 2009, P.6). 


\subsection{Research Questions}

i. Why is capital budgeting process in Kurdistan lack of public deliberation?

ii. How can budget communication influences on the outcome of capital budgeting process?

iii. How can transparency and access to budget information impels the effectiveness of capital budgeting process?

\subsection{Objectives of the Research}

i. To determine why is capital budgeting process in Kurdistan lack of public deliberation.

ii. To explain how can budget communication influences on the outcome of capital budgeting process.

iii. To explain how can transparency and access to budget information impel the effectiveness of capital budgeting process.

\subsection{Significant of the Study}

This research is very important to be conducted. Firstly, it's important to evaluate the horizon of the KRG transparency and public participation. Obviously, transparency and public participation in Kurdistan has some problems, but there is not adequate scholarly works and researches. Therefore, existing problems should be documented in order to recommend certain recommendation to the government to solve the issues. 
Secondly, in the next few years the KRG budget is expected to be tripled as the drilling will be completed and the government will start to export more oils to the international markets. For that reason, people are concern and questioning the way that KRG plans and spending their revenue. Their concerns are because the natural resources belong to the citizens. That gives them the right to expect delivering more services in return. Conducting this study will help the government to understand and take public concerns into the consideration.

Thirdly, this study will become an important literature for the academicians and the KRG to conduct further research on the remaining gaps. The government is severely affected by corruption and large budget wasted by the government agencies due to the mismanagement of public finance.

Despite its democratic practices, there are gaps that challenge Kurdistan's democratic consolidation and legitimacy of public policy decisions. Previously, a large budget was distorted for unnecessary projects and citizen inputs somehow denied by officials. So, this study could be helpful in explaining several budget issues that associates to the lack of budgetary participation. Public budget participation in Kurdistan is really a new topic, and few studies have been conducted in this area. However, this study could be a very significant literature for practitioners and researchers. Apart from that, this study analyses the importance of PB in enabling government agencies to consider the needs of the communities. The other significance of this study could be intensified in terms of recommendations and findings (See chapter 5, 6, 7). 


\subsection{Scope of the Study}

The study was conducted in the Southern Part of Kurdistan which is officially known as Kurdistan Region. Besides, the study did not include the governorates of Kurdistan, which are administered in cooperation between Kurdistan and Iraqi government, such as Kirkuk, but it focuses on the three provinces that are fully under the control of the KRG. Kirkuk is not included in this study, because the city budget is still coming from the central government of Baghdad. The KRG does not have any legal authority over the budget of the city. For that, it has been excluded from the study. Therefore, the three provinces Erbil, the capital of Kurdistan Region, Duhok and Sulaimaniyah included. Each administrative provinces covers several town and villages. So, all the cities, towns and villages within the administration of the three KRG provinces are included such as Erbil, Sulaimaniyah, Duhok, Zakho, Koya, Soran, Raniya, TaqTaq, Chamchamal, Halabja, and etc. The study concentrates on the process of public participation in the first stage of budget which is "budget formulation" or "budget preparation". Also, this study only covered one type of the budget, which is capital budget, also known as investment budget. In public finance, people are more interested to participate in the investment budget rather than recurrent budget which their participation might not have significant influence over the process. Finally, investment budget offers more opportunity for public as it's about agenda setting, defining and selecting budget priorities. 


\subsection{Definitions of the Terms}

Public participation: it's the process by which stakeholders and those who are affected by decisions are consulted and engaged in decisions related to them to maximize the efficiency and effectiveness of the decisions in one hand and satisfying public needs on the other hand. In this study public participation is specifically used as a budgetary participation in which defined as the process of engaging citizens in the capital budgeting process to perform, and encourage government to select projects and services that are best fulfills public needs.

Capital Budget Process: It's a process of making decision over budget that provided for investment projects and services based on the selection of the best priorities to deliver better services to the citizens and satisfy their needs. This process does not relates to the salary of the government employees, rather to physical projects such roads, highway, schools, hospital, water sanitation, sewages, electricity and other related projects.

Deliberation: It's a democratic participatory method that could also happen in nondemocratic systems. Deliberation refers to careful discussion and contemplating policy options prior to the final decision. Deliberation in public budget assist citizens to contribute in collective action for the common goods through rational discussion and arguments generated from individual participants. 
Communication: it's the process of exchanging, consulting and transmitting information among stakeholders through the use of different methods to express and communicate their opinions, needs, and choices in order to collaborate and reach to the collective decision on particular policy such as budget communication between local communities and government to deliver better services and selecting most needed projects.

Information: It's a set of data and evidences, and a key measurement of public participation that helps citizens to utilize in their interaction with other individuals or government in forms of report and publication such as budget reports, service and project details to assist citizens to actively participate in capital budget decisions and determine the right options.

Policy Preference: It's a set of policies and programs to be selected in the public policy decisions on the bases of most relevant choices to satisfy public needs. Example of a policy preference is budget priorities that administrators decide through the use of public participation techniques.

Public Service Delivery: Is the necessary services that citizens receive from government and cannot be provided by the private sector. The government obliged to offer verities of services through the use of public budgets. The type of the services and the level of 
satisfaction rely on the selection of the priorities through the process of public participation in the capital budget process.

\subsection{Chapter Summary}

This chapter explained the background of the study, research objectives and the significance of the study along with operational definitions. The main problem of the study which is lack of public participation in KRG budget explained and then followed by 3 research questions, and 3 research objectives. The objectives of this study were to identify the obstacles of public budget deliberation, explain the significance of budget communication and information in making public budget decisions.

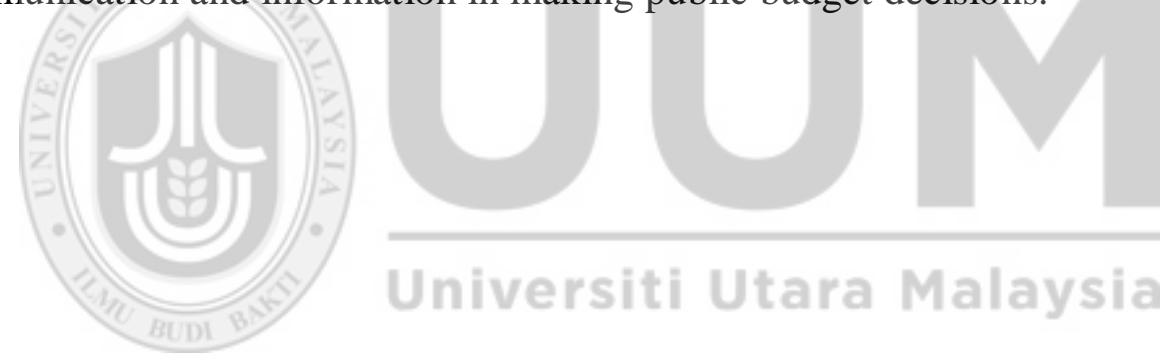




\section{CHAPTER II}

\section{BUDGETING PROCESS}

\subsection{Introduction}

This chapter provides a brief description about Kurdistan in order assist readers to understand the geographical location of Kurdistan, its political and financial system. Then it describes budget and budgeting process in general. It also explains all general phases of budgeting and particularly discusses budgeting process in Kurdistan. This is to help readers to better understand how government prepares its budget from agenda setting into the evaluation. It will also introduce the MoP that decides for the allocation of capital investment budget. The study also obtained some information from the primary sources to explain capital budget. This section described Par Consultative Service Delivery Program (CSDP) which is the first participatory budgeting program officially introduced in Kurdistan. The information discussed in this chapter, partially derived from primary sources.

\subsection{Kurdistan: An Overview}

Kurdistan literally, means the land of the Kurds, covers a large area of the Middle East which is estimated to be 390,000 square kilometers. The country has been divided in the Treaty of Lausanne on July 1923 between Turkey, British Empire and the allies. Despite 
attempts to create their own nation state, Kurds failed to achieve this goal until the popular uprising in March 1991 when Kurds in Iraqi Kurdistan upraised against the former Iraqi regime. They were able to achieve their self-rule region under the protection of the international community. For the first time in the history, Kurds have held parliamentary election. The democratic process did not take so long. The power sharing agreement between the two main political parties Patriotic Union of Kurdistan (PUK) and Kurdistan Democratic Party (PDK) fall apart and country has experienced the bloody civil war for almost four years. In 1998, the PDK and the PUK has signed Washington Agreement to end up the civil war.

The semi-independent Kurdistan is also known as Kurdistan Region or Southern Kurdistan (mostly used by the Kurds) is located in the south of Turkey, north of Iraq, North East of Syria and west of Iran. The area covers 40,643 square kilometers with a population of 5.351, 276. The Kurds have gone through difficult times. Due to unfortunate civil war, economic sanction and lack of revenue, Kurds was unable to successfully rule and develop their country until American intervention to Iraq which opened a new door for the Kurds to develop. After the invasion of Iraq in 2003, due to the exploration of natural resources and opening up to the globe, the Kurds have moved to the new era which helped them to develop their public administration system. The lack of revenue was an obstacle to the Kurds before 2003 to provide adequate services and projects to meet up public needs. This led the government to only provide necessary services with limited budget includes electricity, clean water and security, while no budget or a very small 
budget provided to other sectors. The government that time relied on the customs for the revenue.

However, after the invasion of Iraq and subsequently the collapse of Saddam Hussein, the Kurds were able to get a share of 17 percent of the national budget from Baghdad, and that becomes an important source for the KRG budget. The following Table shows the total budget of Kurdistan in 10 years.

Table 2.1

\begin{tabular}{ll} 
Kurdistan Budget (2004-2014) & \\
\hline Year & US\$ Billions \\
\hline 2004 & 2.230 \\
2005 & 3.560 \\
2006 & 6.539 \\
2007 & 8.258 \\
2008 & 9 \\
2009 & 10.400 \\
2010 & 9.166 \\
2011 & 10.500 \\
2012 & 12 \\
2013 & 15.696 \\
2014 & 90.573 \\
Total &
\end{tabular}

Adopted from Rauf (2015, p. 12) 
Economically, Kurdistan was growing firmly during the last 10 years. However, this growth was disturbed by attacks of Islamic State (IS) and tensions with the Iraqi government over oil revenues. The region is still striving to sustain its economic and political development despite all the hardness. The country's proven oil reserves estimated at 45 billion barrels. According to Ashti Hawrami, the minister of Natural Resources, Kurdistan is able to export 1 million barrels of oil by the end of 2015, and this number is expected to jump to 2 billion by 2019 (Swint, 2013). According to the recent figures, Kurdistan is now producing over 600,000 barrels of crude oil per day (Al-Ansary, 2014). The status of Kurdistan both economically and politically becomes stronger in the region. The large oil reserve of Kurdistan makes people to expect better governing system, and more services.

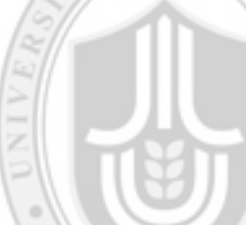

Kurdistan Region is divided into three governorates; Erbil, the administrative capital of Kurdistan Region; Sulaimaniyah, the cultural capital of Kurdistan and Duhok. Recently, the parliament has approved the establishment of another governorate known as Halabja. The governorates alienated into some districts and then to sub-district (Kirmanj, 2014, p.155). The government provides budget to each of these governorates based on their population to guarantee an equal distribution of income between citizens.

The administrative body of Kurdistan is mainly divided into three main institutions, including Kurdistan Presidency, Kurdistan Parliament and Kurdistan Regional Government (KRG). The government is practicing executive power based on the laws and 
regulations issued by Kurdistan parliament. The KRG is also in charge budget allocation, public policy making, security, public services, investment, and managing natural resources (KRG, 2012). The president of Kurdistan has an utmost executive authority and should be elected by majority in the democratic election process every four years. The president is allowed to serve in his position for no more than two terms. The president of Kurdistan Region is accountable for authorizing military promotion, laws enacted by the legislature as well as appointment of the prime minister.

The parliament of Kurdistan Region is another important institution. The parliament consists of 111 seats. The main role of the parliament is discussing budget proposals and enacting new laws. The role of the parliament is more effective after the emergence of opposition Change Movement. In theory, parliament plays a major role in public financial management and seen as the bridge between executive power and the citizens. They audit public policies and discuss the public issues relates to people as well as administration. The parliament founded to issue new laws, promote accountability, pluralism, transparency and representation. To be more representative, the parliament provided 11 seats to minority groups (Turkmens, Assyrians, Chaldeans, and Armenians) and quota for women which should not be less than 30 percent of the total seats (KRG 2012). According to the constitution, no laws should be enacted without the endorsement of the Kurdistan Region's parliament including budget related laws.

Regarding the economy and public financial management, in the last 10 years, the economy of the country has grown by large. The annual real GDP growth rate was 12 percent, while the rate of unemployment, according to officials was 5 percent (Investing 
Group, 2013; Kirmanj, 2014, p. 155). The investment project also increased rapidly and based on the official statistics from 2006 to 2013 over US $\$ 30.5$ billion has been invested in different sectors with high contribution of foreign firms (Investing Group, 2013). For the budget, the government claims that it allocates budget based on the concepts of needs, balance and fairness. However, in practice this concept is subject of argument and does not seem to be like what KRG is claiming.

\subsection{Budgeting}

Describing the process of resource allocation and public expenditure are essential to comprehend fiscal policy. Fiscal policy is defined as the mobilization of the resources needed for financing public goods and services which includes the usage of tax revenue,

public expenditure, debts and government operations to pursue the economic activities of the community in a better way (Premchand, 1989, p. 4). The government budget may have some similarities with private companies' budgets. However, the purpose of public budget is to deliver public services. The government budget is a plan to manage revenue and expenditure for the designated fiscal year. It has to be associated with short term, as well as long term projects. Its also described as the plan to stabilize, distribute and reconstruct country's public needs (Burkhead \& Miner 2009, p. 13). In the proper budgeting system, all levels of the government and all government departments and agencies are involved in the preparation, implementation and assessment process. 


\subsection{Budget Cycles}

Budgeting is one of the government most complicated process (see figure 2.1). It is defined as the management process in which combines planning, controlling, monitoring and reviewing to generate decent budget proposals (Ghosh, 1996, p. 61). Budgeting needs to go through several stages to be finalized. Any government spending relies on the budget proposal. The budgeting process usually consists of four main stages includes budget preparation, legislature approval, budget implementation and the review.

In the first stage, government institutions, agencies and departments should prepare budget proposal. Budget preparation is based on forecasting revenue and expenditure for the fiscal year. Budget preparation is guided by certain instructions and guidelines that help government and people to understand the process (Musell, 2009, p.4). The government should explain why and how to distribute budget, followed by proper budget estimation. After preparing budget and providing all information and details, the institutions send the budget proposals to the related ministry or any other department of the government that is responsible for the preparation of the budget. There, they conduct modification and decide whether to send the proposal to legislature or not. After approving budget proposed by the ministry, they usually send the proposal to the MoP and MoF; then, the budget proposal to be forwarded to the legislature whether its parliament, house of the representative or senate. The legislature enactment is to ensure that revenue and expenditure meets public needs and deliberate budget proposal to explore the existing gaps (Burkhead \& Miner 2009, p. 13). The MPs deliberate budget and either ratify or disapprove the proposal with simple majority votes. If the parliament disapproved 
any part of the budget, it will be forwarded to the ministry of planning with comments and notes. After modification, the proposals will be forwarded again to the parliament for approval. Without legislature ratification, budget can not be implemented by the executive. After approving budget by the legislature, the executive body should sign the budget draft before it becomes a law for implementation. Executive body, mainly MoF has the authority to disapprove budget and send it back to the legislative body for further discussion, or the executive may just veto on some line items or some parts of the budget.

After approving budget by legislation and executive, the implementation stage follows. At this stage, the authorized body of the government takes responsibility to implement planned budget, which encompasses collecting revenue to finance government programs. The process of budget implementation should be incremental and ensure the appropriate use of the budget. Budget implementation has several aspects includes cash management and debt management. Cash Management is the situation where the revenue provided in the budget does not occur based on the designed schedule, but the government may borrow money for the short time to make ends meet (Marseille, 2009, p. 4). However, debt management is borrowing money to meet budget deficit that may happen for many reasons. The government borrows money through written agreement and issuing bonds that indicates the interest rate and the date where the government should return the borrowing (Musell, 2009, p. 4). 
The final stage of the budgeting is budget review, which includes monitoring and auditing. In this stage, an authorized agency review and audit budget spending to ensure that government programs are effectively and efficiently implemented. To audit budgeting, a variance report should be prepared and includes a month by month spending, how and where the money spend so that cash flow projection could be done WACP (2001, p.25). If the monthly breakdown of the budget implemented, then comparison and review would be applicable. In fact, many of the world countries define their budget and spending, according to monthly break down. For instance, how much budget is needed for September and how much spent and where does the budget spent. Then, as the review completed, there should be a report that indicates expenditure met designed objectives.

Budget is an essential part of the government finance and it "reflects the relative power of different individuals and organization to influence outcome" (Musell, 2009, p. 6). The successful budget is the one that inflow is equal to the outflow. It means the revenue and expenditure balanced. However, the budget deficit is one of the problems that many countries are facing now. A balanced budget is the core feature of the financial management and the core responsibility of the leadership to achieve (Shah, 2007, p. 188189). 


\subsection{Public Expenditure and Redistribution of Resources}

Public expenditure is the money that government utilizes to finance public goods and projects. Public expenditure defined as an element of aggregate demand, impacts on the private consumption, and aggregate supply. Any increase in public expenditure probably shifts the composition of the total demands (Chu \& Hemming, 1998). Aggregate demand means the sum of the overall demands on the final goods and services in the given price and time.

The government is accountable towards public; thus, they need to have constructive budget plan. Planning and prediction are two essential elements of public expenditure. Planning comprises of setting goals and policies, but forecasting is an expectation. Forecasting does not generate planning in every circumstance, but it provides a framework for policy maker to consider future implications (Pemchand, 1983). Similarly, government spending should be accurately planned and forecasted. Pemchand (1983) provided three stages of classification to be in the budget. The first step is to identify factors that cause the increase of spending; measurement and forecasting should follow. Second, "an assessment of the standards of service required, or objectives to be met, needs to be undertaken; and third, the costs of providing services and the time profile of those costs for use in budget formulation must be computed" (Premchand, 1983, p. 206).

To enhance public services, government has to spend its budget on services that have potential for public such as education, health, and other infrastructure services which are 
known as a common good. For instance, providing infrastructure to facilitate private investment, operations and maintenance to ensure that public infrastructure remains serviceable, education services to productivity. A general administrative and legal framework should be formulated to support complex economy (Chu \& Hemming, 1998).

One objective of the government expenditure is to maximize and achieve public goods. Public goods are "characterized by no rivalry in consumption" (Chu \& Hemming, 1998). No rivalry means, no competition between individual citizens over specific goods and services that government provides. For instance, when government builds a school or a hospital, every citizen can use it regardless of their differences. Another example is public roads which are used by everyone who lives within the boundary of the given state. The distribution of the budget or the purpose of public expenditure is to provide public goods. The second characteristic of the public goods as described by Anderson is that they are "non-excluded." That means public good is applicable for everyone (Chu \& Hemming, 1998). Hence, the government's intension from funding army is not for protecting some of the citizens and excluding others, but it is for defending the whole society. A similar case could be applied to public services like water, sanitation, sewages, public transportation and so on.

\subsection{Budgeting Process in Kurdistan}

Budget cycle is defined as the process in which government decides on the allocation and distribution of the funds. It encompasses the process of budget formulation, legalizing 
budget through legislative approval and budget execution by the authorized institution (Ehrhart et al., 2006, p.1). Budgeting process in Kurdistan like any other countries goes through several phases until it places for implementation. In theory, the government fiscal year starts in January and ends in December. Public financial management plans in Kurdistan Region begins at the beginning of June (MOF/KRG, 2012). Practically, the KRG budget does not comperhend the exact time frame, but in most cases the process takes longer and more complicated. The budget cycle should comply with "Financial Management Law and Public Debt Law set out in the CPA Order 95" (UNDP, 2009, pp. $13)$.

In the first step of budget, all the KRG agencies and local governments send their proposals to the line ministries. Each ministry prepares own proposals and send them it to the MoP and the MoF. As the collection of the tables completed, MoP and MoF together communicates and discuss proposals with the line ministries regarding investment and recurrent budgets. Therefore, the MoP and MoF separately dealing with recurrent as well as capital budget. The MoP is collects proposals from line ministries and deals with capital investment budgets, but the MoF and Economy deals with recurrent budget. Recurrent budget also known as opperational budget is allocated to salaries, good and service requirement, and other government expenditures that redunds every financial year.

The investment budget is divided into capital budget and provincial development budget. The MoP directly involves in plaing capital budget, but the provincianal counciles are in 
charge of provincial budget. In practice, the MoP deals with both investment and provencional development budget. The capital expenditure is allocated for the investment projects and services provided to the citizens by the MoP in coordination with the line ministries. Each ministry has several departments and institutions. So, the municipalities, ministry departments and directorates propose their projects to their ministries. Then, ministries select projects and prepare a proposal. Later, ministries send a list of the proposed projects with an estimated capital needed to complete the project to the MoP.

The MoP reviews each proposal separately. The MoP has an authority to remove or to suggest new projects in the proposal or in some cases minimize the proposed budget by the line ministries. Not every projects listed by the line ministries subject to approval by the MoP. Therefore, the MoP only funds necessary project and sets priorities and selects the most cost-effective variants. All projects suggested by ministries can not be funded because the budget has a limit and government is incapable of funding every projects. To successfully implement the budget, the MoP promotes operational efficiency and predicts future budget constraints. After the completion of negotiation with line ministries, MoP send a draft of the budget proposal to the parliament to scrutinize.

The parliament of Kurdistan negotiates budget primacies and errors. Ministries and the representative of the ministries stand in front of the parliament and should respond to any concerns and question asked by the MPs. In case of refusal, the parliament sends back the proposal to the MoP and MoF for amendment. However, if the budget approved by the 
Parliament, the council of the ministries recieves the ratified proposal. Subsequently, the projects would be implemented regularly and if there is any added priority or necessary project need to be funded, the funds would be given through the deduction of other projects. In some countries, public administrators, local governments highly rely on the citizens to formulate budget, but in the role of public participation in Kurdista Region's public budget is not clear in any stages. There is also no legal framework to enforce MoP and other ministries to communicate and deliberate with local communities prior to the budget decision.
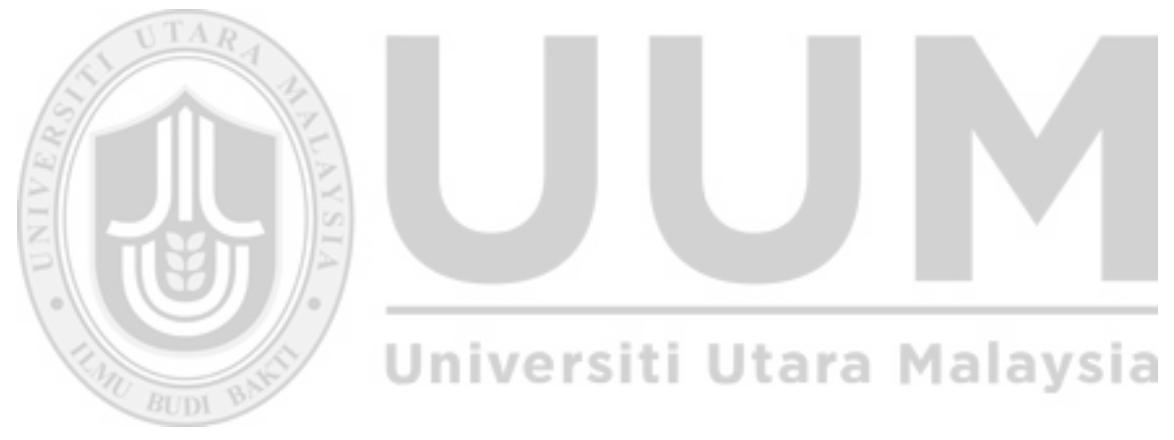


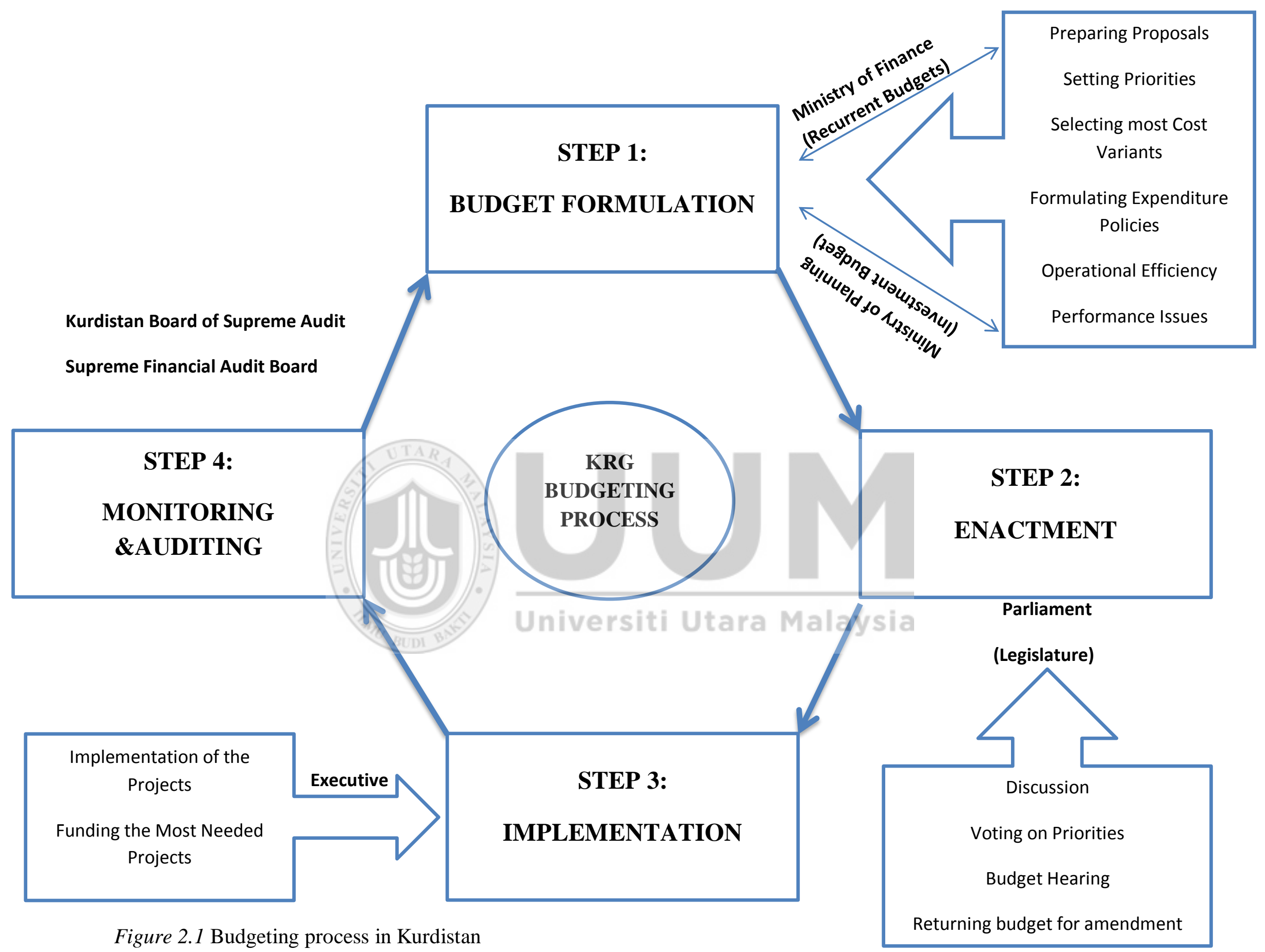




\subsection{Ministry of Planning}

The KRG ministry of planning is one of the key ministries since it plans the future development strategies of Kurdistan. The MoP is seeking to reform in the government structure, improve private sector, and attracts more FDI to ensure sustainable growth in all aspects. The ministry is also authorized to promote human capital and increasing coordination between government departments. The most important function of the ministry is preparing investment budget annually and guaranteeing proper distribution of the resources. The MoP is divided into some divisions and directorates as the following:

1- General Directorate of Investment Budget

2- General Directorate of Strategic Planning

3- General Directorate of Development, Coordination and Cooperation

4- General Directorate of Human Resource Development

5- General Đirectorate of Administration and Finance

6- Kurdistan Quality Control and Standardization

7- Kurdistan Regional Statistic office

There are two major directorates in the MoP that deals with investment budget. The first one is the General Directorate of Investment Budget. This directorate designs investment budget and allocates money for the investment projects in Kurdistan's annual budget. The directorate distributes the projects in three provinces. The directorate funds the investment projects that have more primacy to citizens, especially projects that have direct impacts on public life. Also, more priority will be given to uncompleted projects rather than the new projects proposed by line ministries. 
The MoP only performs planning and provides fund for the physical services, but the implementation of the projects is in coordination with line ministries. The directorate general of investment budget is an umbrella to three other directorates that working together to perform investment budget plan, including "directorate of the priority study of projects, directorate distribution of projects, directorate of project feasibility" (Ministry of Planning/KRG, 2014).

General Directorate of Coordination and Cooperation (DCC) is another directorate in MOP that dealt with the issue of budget transparency, accountability, public participation in public budgeting process. This directorate functions in many different ways. Therefore, one of the best programs established and performed by the DCC was CSDP in coordination with the World Bank.

\subsection{Consultative Service Delivery Program}

The MoP and the World Bank jointly with technical support of Agricultural Cooperative Development International and Volunteers in Overseas Cooperative Assistance (ACDI/VOCA) initiated the Consultative Service Delivery Program (CSDP) to improve the capability of the local communities and the government to promote the delivery of public services. This program has given an opportunity to the local communities to directly engage in the decision making process as well allocation of public resources. Local community also engaged in small scale projects prioritized by their communities. As a community driven program, the CSDP empowered local communities to define their 
needs and priority based on the resources allocated to them. The first phase of the program was initiated in 2007 known as (CSDP) and funded by ACDI/VOCA, which is an American non-profit organization.

This program was used in three governorates (Erbil, Sulaimaniyah, and Duhok) as well as Garmyan administration and covered 16 different locations in aforementioned governorates. The location of the program was not selected randomly, but certain criteria have been used, including poverty rate, public access to basic services such as school, hospital and others, the level of vulnerability, and public access to government support (Muhammed, 2012). As the program flourished, the MoP initiated the second phase of the program (CSDP II) in 2011 with the help of World Bank. The program was entirely funded by the KRG and the World Bank offered technical assistance

Table: 2.2

Details of Consultative Service Delivery Program II

Project Locations

Total No. of CAG members

Voters voted on CAG members

No. of approved proposed projects

No. of the citizens benefited directly from projects

No. of capacity building trainings

No. of community members benefited directly from capacity building training
16 location in three provinces

192 members, 12 members for each location 9163

200

168846

83

1839

Adopted from General Directorate of Projects/Ministry of Planning 
The consultative Service delivery program is not one stage program, but it offered training and certain criteria. Members of the Community Action Group (CAGs) trained in order to handle the complexity of projects and better understand the needs of their community. The program used several participatory methods with the aid of CAGs, NGOs and local governments, including survey, public hearing, focus group, public discussion, comments, collecting and listing new ideas. Every members of the community were given a chance to equally share their ideas and contribute in policy development.

At the beginning of the program, community leaders, community based organizations as well as local government representatives gathered to identify key community members who are capable of facilitating community participation. In the second stage which is known as "participatory community Assessment" meetings were held to identify the needs of the community and the problems they had. They were also prioritized services needed by local communities. In this stage, leaders of the community, known as “Community Action Group (CAG)" were elected to represent citizens and organize meetings (Muhammed, 2012).

The CAGs worked with their community to understand and identify their needs and concerns. Project identification was very important because community members and CAGs were both involved in focus group discussion to identify problems and the projects. The needs of the community were different from one community to another. Some of them required school due to the high rate of illiteracy, while another community asked for 
water sanitation, sewages, or others. However, each community member was given a chance to contribute in solving the problems and propose new ideas. The CAGs asked the community members for choosing two projects. Subsequently, the election process completed, project technical planning followed. The CAGs then prepared proposals. In the planning project, community members also contributed as well as participated in the planning management.

After the completion of project proposals, in project financial planning stage, projects were given to the government to provide funds for implementation. The government had an authority to reject CAGs proposal. The KRG had to re-assess the projects, if they rejected the proposals. In case of project verification by the MoP, CAGs presented project to for feasibility study at the proposal review committee.

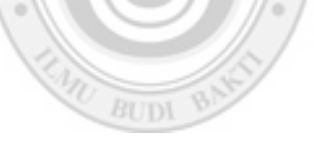

As the proposals approved, the implementation of the projects began. The CAGs monitored the implementation of the projects. After the completion of the projects, CAGs, World Bank and MoP conducted participatory evaluation survey to ensure the project implemented correctly. Finally, the program hand over to the communities. 


\subsection{Chapter Summary}

This chapter introduced Kurdistan to the readers and provided an insight of how the system is working. Then it explained budgeting and budget cycle. Budgeting possesses four main stages, namely preparation, enactment, implementation and evaluation. Then it described how KRG forms budget in details. An overview was given to introduce the MoP which is responsible for preparation of the capital investment budget. This chapter also explained the consultative service delivery program which is a participatory program previously implemented by the MoP in coordination with the World Bank.
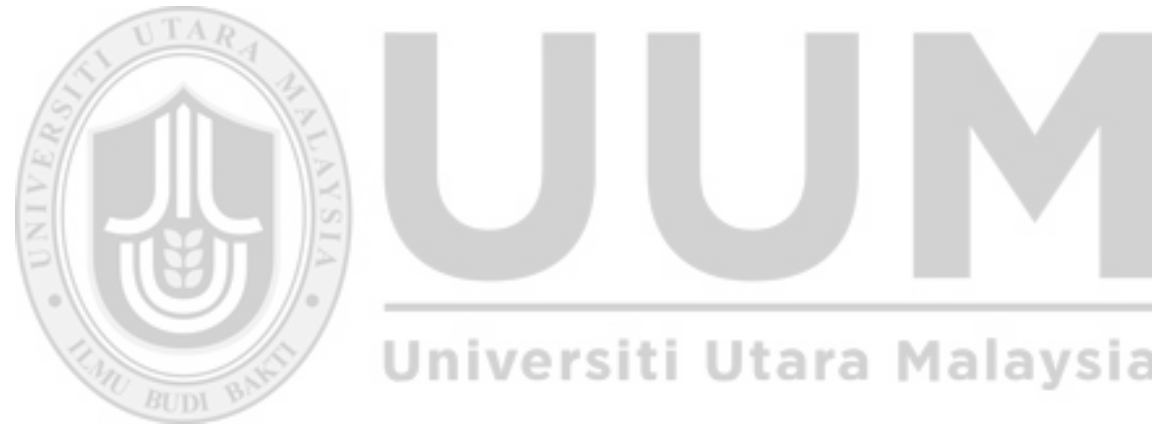


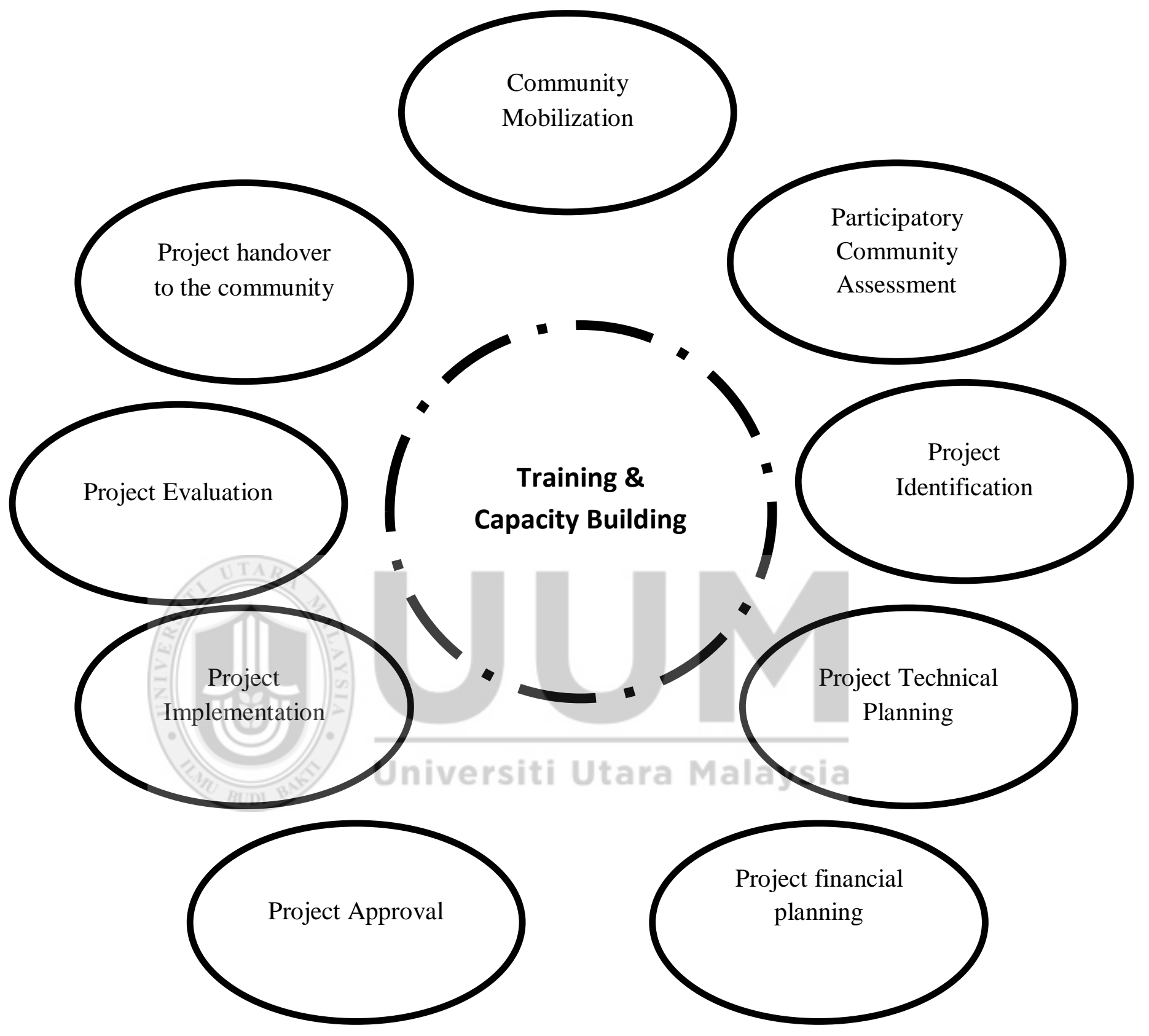

Figure 2.2 Consultative Service Delivery Program Cycles

Adopted from Kurdistan Ministry of Planning (2015) 


\section{CHAPTER III \\ LITERATURE REVIEW}

\subsection{Introduction}

The literature review is a very significant part of the research that helps you to understand the work of other scholars. This literature mainly focuses on the importance of budget participation, and previous studies relates to public budgeting and decision process. It also explains the role of communication, deliberation, information, transparency, legislature, and public scrutiny in government budgets. This chapter overviews the relationship between public participation and public budgeting process and find out the existing gaps in the literature.

\subsection{Public Participation}

Public participation has become a modern mode of governance to legitimize democratic government through the inclusion of community actors for the purpose of resolving public shared problems (Klinke, 2011). Scholars have examined the elements of good governance and consider public participation as one of them. Scholars disagree with the inconsistency of the definitions. Tim Gray (2006, p. 27) argues that many works in this area created confusion and resulted in mismanagement of the entire process. He also acknowledged that different definitions muddled readers understand the true meaning of public participation. The concept is actually needs to be defined based on the study areas. 
It's rational to argue that public participation in election process is different from public participation in public budgeting process.

In this study, the term used to explain public participation in capital budgeting as part of public policy and decision making process. Andrews and Shah (2002) defined public participation as the extent of the influence that citizens might have on the final decision related to public services. Another scholar defined the concept as the inclusion of stakeholders in the process which somehow relates to their life (Theron, 2008, p. 14). James L. Creignton (2005, p. 7) defined the concept of public participation as "the process by which public concerns, needs, and values are incorporated into governmental and corporate decision making." Public participation is a multi-dimensional theory described as an ongoing communication and interaction between policy makers and stakeholders (Creighton, 2005 \& Spiess, 2008, p. 7). The literature also indicates that the aim of this multi-dimensional communication is to make everything clear which allows stakeholders to understand public budgeting process (Spiess, 2008, p. 42). Public participation treated by Creighton (2005) as "continuum" and that continuum classified into four categories. The first category is "inform the public." Means public should be aware of the government decisions. To some extend this one is relates to transparency and public access to government information. Therefore, not just ordinary citizens, but employees from ministries have not been informed previously on the KRG budget intention and plans (UNDP, 2009). The first Creighton category of public participation is breached and not considered by the Kurdistan Regional Government. Creighton argues that information does not establish participation, but it's an integral part of public participation that allows 
people to obtain complete information. It also assists them to target plans to formulate their judgment under the reflection of available information. The second category is "Listen to the Public." Informing public is not enough to obtain a favorable outcome from government policies. When government listens to the concerns of people and acts accordingly, cooperation and trust between policy makers and citizens increase. In Kurdistan government does not listen to public, but some policy makers in coordination with political parties formulating budget proposal. Instead of listening to public, the government listens to political parties. For that the decisions more reflects the will of political parties rather than citizens since the KRG does not listen and not ready to hearing public concern. The author relates public hearing and availability of access to the information as intertwined elements to peruse public participations which none of them fulfilled by the KRG. He maintains that access to information would profoundly refer to "checklist" or "procedural" public participation. In the absence of such procedures, the decisions will have unfavorable impact on policies. The third category is "engage in problem solving." Public participation in the problem solving is important for the fact that government is an agent to serve citizens. Professionals and expertise may even play a larger role if they are given a chance to engage in order to utilize their knowledge and skills to overcome common problems. It has been explained by Nuri that out the government of Kurdistan does not engage expertise and citizens in the process. The last category is "develop agreements." As the information accessed to people, government listens to public concerns and people engaged in the policy decision, both sides can develop agreements to pursue common goals and team up to overcome malfunctions. As 
discussed, none of these categories met by the KRG. According to Creighton budgeting in Kurdistan is not participatory because none of these categories approached by the KRG.

\subsubsection{Public Participation and Delivery of Public Services}

A literature shows the relationship between public participation and public service delivery as a key measurement of capital budgeting process. Some results show positive significant relationship between public participation and public service delivery, while some others find no relationship or negative relationship. Heller (2001) found budget participation in Brazil and India have induced public expenditure for public services provided to poor communities. Other scholars like Wambler \& Boulding (2010); Schneider and Goldfrank (2002) studied such relationship based on sectors. Their finding shows that public participation increases the allocation of public funds to sectors that best works for citizens includes health, education and sanitation services. Similarly, the evidences from previous studies demonstrate that public participation influences the outcome of public services. In the study of 390 municipalities in South America, it has been identified that public participation in decision making increases the effectiveness of agricultural services. It might associate to the ability of ordinary citizens to determine their service (Aragones \& Sanchez-Pages, 2009). Speer (2012) cites from the World Bank that PB increased pro-poor orientation services. Their findings also indicate that a project that goes through public participation is more complicated compare to the project that decided by the government. This relates to the time and resources allocated for the processes. For instance, the KRG government spend millions of dollars for the training and empowerment during communicative service delivery program. 
This money could be utilized in other projects. Also, the time they spend for the training and empowerment has caused the delays of the projects. However, the government should provide a mechanism to use less funds for the training process, instead empower citizens through volunteer works. Usually, public participation takes time, and it has a very complicated setting compare to the centralized process. Therefore, the services that citizens receiving in the participatory budgeting program is more satisfactory for citizens. Goldfrank (2002) in the study of Montevideo, Paraguay, highlighted a significant relationship between public participation and public service delivery. Thus, participatory process facilitates the flow of information between citizens and officials, which consequently could be used to improve services. The success of such process depends on the situation and varies from one location to another. For instance, the same program used in Uruguay, was already failed in Venezuela (Goldfrank, 2011) and some other municipalities in Brazil (Boulding \& Wampler, 2010).

Despite the importance of public participation in public service, but there are studies that show no significant relationship between public participation, government responsiveness and service quality (Brautingam, 2003; Francis \& James, 2003). Brautingam (2003) found public participation does not change the direction of decisions. This issue is associated with the fact that citizens are not sure whether their communication taken or not. Besides, he found that public participation does not necessarily changes the directions of decisions towards poor communities. That produces an unjust distribution of public budgets. Instead policy makers have to preserve balances between social classes. If the government more concentrates on poor, then other classes become poorer and dissatisfy with the 
services they receive. The government in such cases assesses communities based on their needs and provides services based on the needs. Priority must be given to the most needed projects. This inequality is very obvious in Kurdistan Region, where the government provides more services to the neighborhoods that upper class and officials are concentrated. The same differences also explained between the rural and urban areas. The fact citizens from urban areas receive more services compare to the rural areas. In Kurdistan Region, more than third of the total budget utilized for the projects in the cities, the remaining budget is allocated to the urban areas (Tawfiq-Shukor \& Khoshnaw, 2010). However, the gap should be small and villagers should also receive certain kinds of projects that associates to their daily lives. In fact, rural services might be less costly, and easier to provide due to the scale, type, and the size of the projects. Therefore, due to the lack of understanding and lack of attention to the poor and marginalized communities, a huge gap is seen between rural communities and urban residents.

More studies conducted elsewhere to define the relationship between public participation and service delivery. Francis and James (2003) studied public participation in public financial management of Uganda. They found no significant relationship between public service delivery and participatory budgeting. Therefore, the results of such relationship could be different elsewhere. Baiocchi, (2001) and Shah (2007) found that public participation increases services and well-being of the poor communities and they get access to better quality services. Similarly, public participation in the capital budgeting process improves human capital, quality of the services, and efficiently delivering public services (Evans, $2004 \&$ Peers, 2012). 


\subsubsection{Issues and Solutions of Public Participation}

The level and effectiveness of public participation relies on the environment and conditions that provided for citizens and policy makers to interact. There are many challenges that limit the scope of citizen participation, such as inequality, education, and superiority of elites. One issue of public participation is inequality and gaps between social classes. This issue undercuts motivations and impacts of public participation (Faguet, 2009). Equality is a pre-condition for the success of the participatory budgeting process. Inequality has a negative impact on citizens to participate in collective decisions, participatory discussions, and cooperation between community members and policy makers (Bardhan, Ghatak \& Karaivanov, 2007). Other issues such as lack of education, financial resources, capacity building, and information discourage participatory budgeting process (Krishna, 2006; Fung \& Wright, 2001). Little details have given to understand how these limitations discourage participatory budgeting. Also, it's not clear whether these limitations could be applied to the countries that are new in using participatory budgeting. It might be argued that each country has a particular environment, and that supposed to be considered when studying public participation in public budgeting process. In Kurdistan, public participation might require several pre condition that has not been investigated yet. This study in the following chapters will see if the conditions and environment is different in Kurdistan.

Corruption is another burden of public participation, especially in the budgeting process and it happens when elites bribe organizers of the PB to preserve their interest. This is another kind of manipulation by elites to utilize public budget to enrich themselves and enforce their agenda on the entire process (Sheely, 2015; Acemoglu \& Robinson, 2008). 
In Kurdistan both bribes and corruption is commonly practiced by the KRG public administrators and the government is well aware of that (Smail, 2013). This limitation associates to the lack of public participation in KRG public budget. However, elites control over participatory institutions could be eliminated if citizens mobilized and actively participate in the process (Sheely, 2015).

The success of overall participatory programs depends on several other conditions that related to the capacity and willingness of officials and civil society organizations (Speer, 2012). The officials in some countries are more responsive towards citizens and willing to listen to their concerns. In developing countries including Kurdistan Region, officials usually apply rigid policies where citizens are not seen as an active participator in public policy decisions. Similarly, civic society organization in those countries is inactive and fails to mobilize citizens. So, the gaps to implement participatory mechanism in public financial management of Kurdistan could be examined here as no bridge established between government and ordinary citizens. In the absence of that relationship, decision quality and public services will be different. Scholars have identified that the influence and the size of civil society organization changes the effectiveness of the decisions (Abom, 2004; Eugren, 2008).

To overcome issues, the government must activate the role of civic society organizations and empower citizens (Speer, 2012). To underscore the issue of manipulation and elites, the "ladder of participation" was used by Arnstein (1969). The author believes that 
manipulation of decision process is to expand elites' self-interest on behalf of the wider community. Elites and interest groups in many occasions, undermine participatory decision process to maintain their interest particularly when their interest clashes with the interest of wider community over budget preferences (Sheely, 2015, p.251; Fung \& Wright, 2003). In such participatory programs, decisions reflect the interest of elites and interest groups rather than citizens (Shah, 2007). To overcome manipulation, information should be disseminated (Arnstein, 1969; Durose \& Rummery, 2006). To strengthen the relationships between government and citizens, they recommended information dissemination, citizen's partnership, and consultation.

Hickey (2002) proposed possible solutions to several participatory issues. He recommends the replacement of social aspects of participation into political aspects of participation. Such practice shifts social activities into self-governing practices. This approach promotes public participation, especially to the marginalized groups and guarantees civil society engagement in decision related activities, particularly budget decision (Fung \& Wright 2003). Hickey also proposed citizen's empowerment by authorities to understand the purpose of their participation and methods to ensure constructive outcome of their participation. He also added that policy makers should interact with citizens to promote their status. After all, participation should be treated as a natural right to be exercises by anybody who wants to participate in public policy making process. 


\subsubsection{Arguments against Public Participation}

Public participation is not always positive, but there are studies that found negative influence of public participation on decision making process. Some scholars described public participation as the new tyranny (Cooke \& Kathari, 2001). Through the review of the literatures and previous studies, five arguments provided against public participation.

Public participation is criticized to have no effects on vulnerable population and little evidence found to support conclusive outcome of participation. Walti, Kubler and Papadopoulos (2004) identified that vulnerable groups can not make their voice heard in deliberation process due to the lack of knowledge and cultural resources. It's also argued that citizen empowerment is more symbolic. Vulnerable citizens usually lack of knowledge and the training activities. This makes them to be unable to survive in the competitive environment where elites have upper hand. It's also logical to argue that intellectuals and high class citizens might have a dominant hand in the process due to the education they possess and their influence on the final decision.

The second argument is public participation is usually lead by the elites. Elites sometimes are using donation and bribing officials to misrepresent community members (Craig \& Porter, 2001). The outcome of this will be unlikely for citizens and their voices will not be heard if decisions contradicts with their interest. Thus, undermines the value of citizen's participation and citizens will have no impact on the final decision. 
Third, the heterogeneity of the participants further expands conflict between stakeholders. The interest of different participants may raise disagreement and surpass public goods. The interests may not be revealed in all cases, but it may remain confidential. Therefore, it makes the decision to be made on behalf of others interest (Sihlongonyane, 2001). The concept of public participation is not about homogeneity of the interest, but to combine heterogenic interests for the purpose of common goods. The outcome of this process leads to the establishment of homogeneous interest.

Another issue of public participation is the degree of influence that participants might have on the final decision (Leduka, 2009). Public participation may be ineffective when participants' choices ignored in the final decision. Apart from that, Leduka (2009) found another problem which is again related to the vulnerable groups. He believes that vulnerable groups are lack of time and money. Accordingly, they may not have enough resources to devote for the participatory activities. In the absence of their participation, the decision may not represent community members and it expands gaps between social groups (Leduka, 2009, p. 46).

Lastly, public participation may fail to have advantages over public services and needs without considering the significance of incentives. Some researchers are aware of the issue and arguing that political parties and representatives might use participatory mechanisms to enforce their political agenda (Bland, 2011). For instance, Wampler (2008) analyzed political aspects of PB in Brazil and found that politicians and political 
parties are using PB to increase their popularity and obtain electoral votes. For that reason, he argues that public participation in the budgeting process is more seen as a move by workers party. When politicians and even ordinary citizens find their interest in the process, they become passionate on their participations. However, when citizens find their interest is not considered or they find no interest to participate, they will be grieved to do so. In this case, the government should encourage citizens through the creation of citizen's interest in public policy making process and that's what Bland (2011) meant by the incentives.

\subsubsection{Civil Society Participation}

The role of civil society organizations is essential in public budgeting process. Wampler (2007) studied PB in Brazil and highlights their positive role. He critically analyzed the role of institutions that direct people to iwork hand in hand with policy makers and facilitate them with effective problem solving frameworks. The framework can be used to resolve service problems. It paves the way and creates communication channel, and links people to the government. That might help poor marginalized communities to raise their voices. Civil society involvement in public expenditure management ensures positive social and economic outcomes and initiates the maximization of confidence towards public institutions (Heimans, 2002). The World Bank recommends all countries to strengthen the role of the civil society organizations and citizens in the PEM process and "government decisions about how public money is budgeted and utilized" (World Bank, 2011). Apart from that, civil society organizations sometimes focus on the efficiency of spending, whether it causes poverty reduction and problem solving or not 
and may sometimes campaign against government spending to pressure officials to be open. However, in Kurdistan region there is no civic society organization working on budgeting issues and public participation. There are hundreds of civic society organization that even created burden to the KRG budget because they receive money from government. In exchange, they provide little or no support to improve KRG administration system particularly the financial system.

Moll and Ficher (2000) produced scholarly argument in accordance to their research findings. They believe that individual participants in budgeting process publicize their individual needs and give up some of their rights to the public. This could be done through supports of civil society organizations. Solidaries-Dade (2003, p. 105) quoted from one of his participants named "Roselain" to explore the significance of civil society organization in PB process. Roselaine claimed that in the first stage, she was only thinking of her personal needs to pave her road. As she participated in the PB and coordinated with her fellow citizens under the supervision of civil society organizations, she turned to reconsider her stands. Subsequently, she devoted her personal wants to public. She stressed that she is no longer concerns about the road in her neighborhood to be paved or not, but public needs and common goods becomes her essential. This outcome is really important because citizens will learn to love their community more than themselves and that eradicates the individual selfishness and greedy. The process also prevents "clienteles and corruption" and promotes administration performance of budget formulation. In the absence of civil society organization, the bridge between social groups and government might not be created. 


\subsection{Participatory Budgeting}

PB is a democratic process of deliberation in which people contributes in the formulation of budget decisions. This method was first used in Porto Alegre, Brazil in 1989 and then widely applied elsewhere. Since then, more than 1000 municipalities have applied certain forms of participatory programs all around the world including Kurdistan Region (Gomez, Insua \& Alfaro, 2015; Patman, 2012; Sheely, 2015, p. 252). The PB allows participants to identify priorities, developing budget proposals and identifying projects needed for the community. Also, people are voting over the best proposals and projects to be funded in the budget. However, PB goes beyond that. It gives participants an opportunity to transcend common problems with argumentative rationality. In PB citizens are discussing and negotiating government spending and setting budget priorities. Citizens to participate in the budgeting process must have comprehensive knowledge on the process and control over government finance activities. Knowledge understanding the process minimizes the scope of corruption and maximizes public satisfaction over government spending (Timmons \& Gorfias, 2014).

The PB was first emerged to overcome authoritarianism and manipulation of the budget decisions by elites. It was a transformation in the democratic governance practice. PB has been articulated as the turning point in promoting citizen relationship to the government agencies (Leduka, 2009). At the begging of its emergence, only small numbers of citizen that estimated to be less than 1000, engaged in PB program. In three years, the number largely increased to 8000 . In Kurdistan Region, 168846 citizens engaged in the participatory budgeting program CSDP. In this process citizens collaborating with 
officials to allocate budget for the projects and develop policy choices (HABITAT, 2008). It's a sustainable process encourages citizens to contribute in the allocation of the resources for the purpose of enhancing citizen's livelihood and establishment of the deliberative framework. PB does not only cover one phase of budgeting, but it covers the whole process including the implementation, monitory and evaluation. Therefore, more priority is given to the first step wherein citizens can put their agenda into decision setting.

The outcome of citizens' engagement in PB of Porto Alegre was supportive to be accepted by mass population and then globally recognized. Prior to the implementation of PB, only 49 percent of Porto Alegre was covered by basic sanitation, but this percentage has increased to 85 percent in 1996 (Aragones \& Sanchez-Pages, 2009). Simultaneously, 5 times more housing units were built and students' admission in elementary school increased to 190 percent; as well as more than 95 percent of the households now receiving water supply. These improvements were due to the influence of PB where citizens defined their preferences and basic needs in the budget proposal. The outcomes of the process resulted in transforming citizen's life into the new age and citizens delivered better education, social and health services especially the middle class citizens. This might be associated to the participatory budgeting programs in Kurdistan region where government concentrated on the poor and marginalized rural communities. The CSDP programs covered 16 locations outside of the cities. The citizens of these areas suffered due to the lack of basic services, therefore, the consultative service delivery program offered them with tremendous services in which they never received before. The most essential services selected by citizens in these areas were water sanitation, sewages, roads, and education. 
However, if the government implements similar program in the cities, citizens might require different services especially those relates to the housing, transportation, health and education services. Also, it might be varying from one city to another. For instance, citizens of Sulaimaniyah complaining on the lack of water sanitation services; but, in Erbil people might require housing and environmental protection services. Elsewhere might prefer pavement and transportation services as in Garmyan province. Previously, the KRG has given little consideration to human development capacity programs, health and other related projects. By offering such services, citizens will be delighted and budget decisions will be more effective. These issues also occurred in Porto Alegre prior to the implementation of PB which has given more priority to capacity building, basic health and education services.
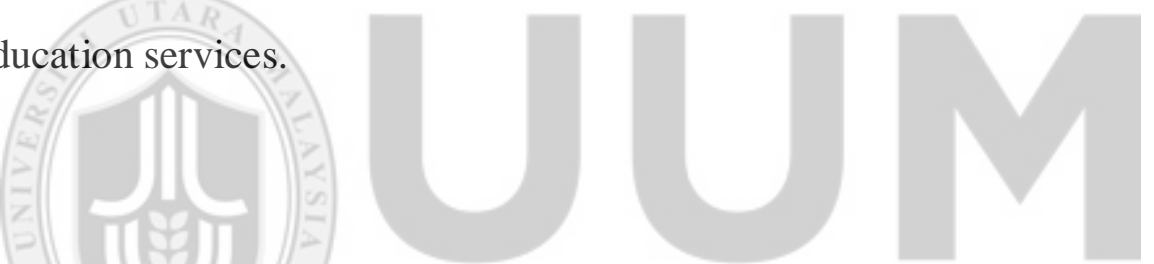

The following Table indicates that Porto Alegre's infrastructure was not developed in the first place and citizens were more concerned on land use regulations and paving. Thus, they conveyed more priority to the basic infrastructure services. As these sectors developed, their priorities have changed to housing, education and health services. This gives an insight to the policy makers to coordinate citizens on their needs. Otherwise, the resources might be utilized in the wrong place for the wrong services. 
Table: 3.1

Citizens Top Priorities in Porto Alegre PB 1994-2005

\begin{tabular}{|c|c|c|c|}
\hline Year & $1^{\text {st }}$ Priority & $2^{\text {nd }}$ priority & $3^{\text {rd }}$ priority \\
\hline 2005 & Housing & Education & Social services \\
\hline 2004 & Housing & Social services & Education \\
\hline 2003 & Housing & Education & Paving \\
\hline 2002 & Housing & Education & Paving \\
\hline 2001 & Paving & Housing & Basic sanitation \\
\hline 2000 & Housing policy & Paving & Health \\
\hline 1999 & Basic sanitation & Paving & Housing policy \\
\hline 1998 & Paving & Housing policy & Basic sanitation \\
\hline 1997 & Housing policy & Paving & Basic sanitation \\
\hline 1996 & Paving & Basic sanitation & Land use regulation \\
\hline 1995 & Paving & Land use regula & Basic sanitation \\
\hline 1994 & Land use regulation & Paving & Basic sanitation \\
\hline
\end{tabular}

Adopted from Aragones \& Sanchez-Pages (2009)

\subsubsection{Outcomes of Participatory Budgeting}

The outcomes of PB is different depending on the location and the success of the process. PB has political implications. Citizens in PB are considered as the legitimate components policy decision. They are more likely to vote for the political party or the person that listens to their demands and satisfies their needs. In contrast, they vote against politicians 
that are not pleasing their will during election (Aragones \& Sanchez-Pages, 2009). Besides, Timmons and Gorfias (2014) found that PB surges public satisfaction and citizens' commitment as well as restores government credibility. In this sense, legitimacy and commitment are two important determinants of good budget performance. Furthermore, PB improves public policies and good governance practices. It's widely used as a form of democratic governance to better allocate resources and promote public services, especially in agriculture, health, and education sectors. Jaramillo and Wright (2015) found a significant and positive relationship between voluntary public participation and agriculture services. They also found, public participation positively associates with the effectiveness of services provided by the government It was also highlighted that public participation significantly impacts on service problems. It means participation in budgeting process generates better quality, quantity, and distribution of the services. The authors have made comparison between municipalities that conducts PA and those that do not. They found municipalities with public participation in agricultural services perform better with a better service and less problems.

The PB was also studied in terms of human development. Boulding and Wampler, (2010, p. 129-130) found a significant positive relationship between PB and human development. Simultaneously, they found little to no impacts of PB on inequality. The author also found a significant relationship between public participation and the reduction of the extreme poverty rate. It means PB eliminates worst poverty rate, but little impacts found on the well-being of the citizens. Unlike the previous finding, the most recent literature by 
Jaramillo and Wright (2015, p. 287) emphasized the average agricultural policies implemented through PB, are less effective.

The PB has potential to maximize profits, reduce poverty and further develop national strategic development. Citizens and civil participation in public budgeting process is crucial because it subsequently promotes "transparency and accountability with regard to public finances, building safeguards against corruption; and ensuring that public money are allocated equitably so that the interests and needs of poor and marginalized groups are adequately addressed" (WACP, 2012). Al-Kodmany (2000) emphasized on the importance of public participation in three points. He claims that higher citizen's participation supports more policy expectation and better impacts on the government plans. Also, the greater participation increases the sense of ownership. Participation persuades government to implement planned projects. One of the gaps in Kurdistan public budget is the redundancy of the projects as government fails to instigate planned projects. This issue could be resolved through public participation. Accordingly, the KRG can save a large budget and utilized to other capital projects. For years, millions of dollars wasted by the KRG officials to the redundant projects. Millions also disappeared by the corrupted officials under this excuse. Public participation here might cure this serious disease in Kurdistan budget as recommended by Al-Kodmany (2000). The author also highlighted that public participation coaxes officials to take public concerns into account. Thus, drives better policy implementation and good governance practices. 


\subsubsection{Conditions of Participatory Budgeting}

Bland (2011, p.864) classified the most important conditions of effective PB into two categories. The first category entails primary conditions and divided into four main conditions including:

1- The commitment of mayor's willingness to take citizens participation into consideration;

2- Availability of financial resources;

3- Decentralized political system;

4- Finally, decisions on policies should be made by participants without intervention or restriction from government authorities.

The citizens' engagement in budgeting process might not ensure the process goes well and everyone satisfied. There is possibility that clashed over citizen's and policy makers' preferences occur. In this case, the outcome of the participatory process could be less effective (Aragones \& Sanchez-Pages, 2009). Subsequently, if the second surpasses first, the process will be ineffective and more possibly to fail. When citizens participating in the policy making process, they are looking forward to see their views and preferences taken into consideration. It impacts on the level of participation in the future. If citizens treated with courtesy and consideration during deliberation process, they will be happy to participate in the future programs. Participants might calculate the cost and outcome of their participation (Aragones \& Sanchez-Pages, 2009, p. 59). 
The second category entails secondary conditions that believe to be supportive including the active role of civic organization in tracking public attention to participate in the capital budgeting process. The willingness of government officials to communicate public choices. Also, qualified and educated personals support the PB process to be adopted smoothly. The parliament should issue some rules and regulations to ensure the enforcement of PB (Bland, 2011, p.864). For instance, in Peru budget participation has become a law since 2003 and it's mandatory to all Peruvian municipalities to perform public participation (Jaramillo \& Wright, 2015, p.238). These rules have major impact on the policy changes where citizens are included to deliberate their shared concerns. In Kurdistan, there is no such laws that enforce policy makers to make budget participatory. The government does not even have the intention for such laws. The parliament and the government is more concentrating on the power and domination rather than issuing laws that can improve public services in the country. In the presence of participatory budgeting law, the KRG can overcome several issues and transform power from corrupted officials to the citizens themselves. Also, the budget might be utilized for the public good and that avoids the domination of political parties and elites over financial institutions. The absence of such laws explains the gaps between Kurdistan public budget and Peru public budget.

Another study by Jaramillo \& Wright (2015) suggests three major strands to peruse effective budget participation. The first strand is "participatory democracy" which helps citizens from wider community to involve and promote accountability. The second strand is "associative democracy" which improves the functions of civil society organization to 
facilitate collective action. The last strand is "deliberative democracy" which makes participation more effective through discussions between citizens and authorities regarding budget preference, cost of the projects, and other details prior to the decision making (Van Cott, 2008; Jaramillo \& Wright, 2015). The KRG provided democratic ground for citizens to express themselves, but the democracy is lack of accountability. Also, the kind of democracy exist in Kurdistan is neither participatory, associative, nor deliberative when investigated in relation to public financial management. The PB could not be a self-reliant civic process, but it is a joint process that requires the government agents to coordinate with citizens (Great \& Sintomer, 2005). So, in PB citizens and government agents are complementary. In the absence of either side, the process will be incomplete an ineffective.

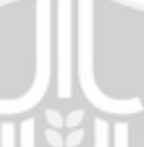

In the study of PB in South African, Leduka (2009) comes up with four main factors that seems to be necessary for the implementations of PB. The first factor is the availability of positive political environment, wherein citizens can freely participate with adequacy of knowledge and information. The second factor is process design which denotes to the availability of the resources in order citizens to be allowed to realize the extent of their demands. Thirdly, different approaches should be applied in order citizens to be able to participate such as focus group meeting, committee members meeting, and civic meetings (Gret and Sintomerm, 2005). Finally, the outcomes of the PB should be clear for everyone and citizens should realize the extent of their influence in the final decisions. 


\subsubsection{When Participatory Budgeting is more influential?}

The PB desperately impacts on all steps of budgeting. However, PA is more effective in the initial stages and the outcome will be more effective (Franklin \& Ebdon, 2005; Theron, 2008; Chambers, 1997). The authors believe that if citizens participating in the budgeting process from the first stage, they can better influence on the decision. It also empowers citizens through the experiences and knowledge they obtain as a result of interactions with other participants. It binds participants together and increases trust and understanding. Other scholars have argued that PB does not solely need to happen in the initial phases, but it also needs to be two way communications between principal and agent or citizens and authorities in order to have major constructive impact (King, Feltey \& Susel, 1998; Ebdon, 2002). This argument clarifies that effectiveness of the process depends on the nature of interaction between government and citizens.

It has been articulated that assessment of public participation in the budgeting process varies based on the stages of budgeting (Speer, 2012; Leduka, 2009). Public participation in the first stage of budgeting looks like a gateway where citizens enter into the process and setting up new policy agenda. Accordingly, citizens can feed their alternatives in the proposal. Actually, citizens have less control in the implementation and evaluation stages. Participation in the initial stage is more important to induce public service delivery because this is where citizens voice out their concerns and choices. 


\subsubsection{Methods of Participatory Budgeting}

The PB can happen in different forms. It may be direct in the sense that citizens are physically engaging in the process of decision making, identifying their problems and setting priorities. The indirect $\mathrm{PB}$ happens when citizens represented by their representatives (Gret \& Sintomer, 2005). It also happens in the form of town meeting where citizens or the representation of citizens invited to discuss budget proposals. It could be formal when participants comply with certain rules and procedure, or it could be informal where people can participate without invitation (Jaramillo \& Wright, 2015, p. 283). There are several methods for citizens to involve in PB includes participants sampling, election of representatives, use of questionnaires, preparation of documents, distribution of information, preference modeling, debate, negotiation, arbitration and voting (Gomez et al, 2013).

\subsection{Deliberation}

Many scholars studied public deliberation, especially political philosophers, but little consideration has given to public deliberation in public policy making process (Stie, 2008). Scholars mainly treated public deliberation as a form of political democracy, and neglected the prominence of public deliberation in administration and decision making process. The fact is deliberation can even occur in other forms of government, such as authoritarian regimes; but not as effective as democratic governments (Parkinson \& Mansbridge, 2012). It is very significant to determine how public deliberation influences policy decisions related to real life situation. 
Public deliberation in general form is a multi-dimensional theory. It has studied in various types of research, including political philosophy (Cohen, 1997; Gutmann \& Thampson, 1996), communication (Carcasson, Black, Sink, 2010; Pearce \& Littlejohn, 1997; Gastil, 1993), public opinion (Gastil, 2008; Page, 1996), citizens' juries (Crosby, 1995) and several others. It is an important motive of democratic governance in which urges stakeholders to involve in the governing process. Public deliberation is a citizen centric process that maintains the interest of the public and treats them as a nub of government decisions.

If in the past, voting was the only way to pursue democracy, recently deliberation is more important to evaluate democracy and public participation. It has been emphasized in the work of Chang (2012) that to promote public goods, deliberation should be used to connect the process of policy decision making along with reasoned based discussion where members of society come together to make certain decisions. For him, it's a transformational process of democracy in the modern age were indirect democracy replaced by the reasoned based discussion. Indeed, democracy is not merely talk-centric rather than vote centric.

Public deliberation in public policy refers to the discussion between citizens and government officials for the purpose of making collective decision. Deliberation is described as the capacity of community members to get into the meaningful dialogue and 
come out with judgments to resolve public issues (Roberts, 2004, p. 340). In the citizen's perspective, public deliberation is the process of making difficult choices among variety of alternatives that can best serve community needs and preferences. It's also described as the method of discussion and binding individual groups together in order to operationalize their agenda (Gentry, 2012).

\subsubsection{Definitions of Public Deliberation}

There is no standardized definition of public deliberation. Therefore, most definitions focusing on reasoned based discussion among people over policy issues (Burkhalter, Gastil, \& Kelshaw; 2002; Gastil, Gastil, Black, \& Lawra, 2008). Burkhalter, Gastil, and Kelshaw (2002) defined public deliberation as the combination of democratic process known as egalitarian, where citizens are given an equal chance to speak up their concern and demands through dialogue and tentative discussion with delicate analyses of the problems. Another definition is given by Gastil, Black, and Lawra (2008). They defined public deliberation as getting people together to examine problems carefully and find out solutions for the existed problem. By combining the aforementioned definitions, public deliberation could be defined as the form of democratic decision making in which assists people to propose relevant alternatives and carefully discuss issues afore reaching to the final decision. 


\subsubsection{The Value of Deliberate on Public Policy Process}

Mill and Rousseau emphasized on the significance of deliberation in the public policy process. They portrayed deliberation is a method to create collective decision which for Mill known as the common good and the general will for Rousseau (Patmen, 1970). Both theorists agreed that deliberation maximizes the sense of belonging among citizens and ensures more commitment. The citizens of Kurdistan are not widely committed towards their government and services they receive. They believe that government is a financial institution to enrich some top officials and politicians. Because they are not taken into the governing process, they always questioning government accountability. In addition to that, they do not usually care for public services. For instance, they waste public services like clean water and electricity, not because they are lack of it, but to revenge on government exclusions. Also, the lack of deliberation is seeming to have a drastic impact on the concord of community members. The citizens of Kurdistan are clearly divided and fragmented. The sense of belonging is very low and it could be perceived in the sense of deliberation. Deliberation can directly underpin individual skills and knowledge or indirectly motivates individual identities and strengthen the sense of political efficiency for the purpose of common goods (Burkhalter, Gastil, and Kelshaw, 2002). Deliberation empowers citizens and cultivates them with knowledge on the complexity of the process (Munno \& Nabatchi, 2014).

According to the National Consumer Council (2008) deliberation helps policy makers to offer better policy, provide better services, enhance social bindings, and promote democracy. It was previously applied in several countries including UK, Paraguay, Brazil, 
Argentina, and many others. The research has found that public participation through deliberation promotes the quality of decisions (Munno \& Nabatchi, 2014) and enriches policy makers with problem solving skills.

Several other advantages could be generated from deliberation. According to the Game theory, deliberative democracy facilitates free and fair participation and creates opportunity for discussion and information sharing between participants prior to the voting process. In deliberative democracy there are three main stages which participants given an opportunity to share their views (Linda \& Meirowitz, 2009). The first stage is offering a set of policy choices. Participants can deliberate their preferred choices. They also realize to what extent officials take their concerns into consideration. The second stage is supportive to evaluate available information in the way they interact with each other. Lastly, participants realize the essence of their participation in the decision process and the output of their participation on selecting priorities. Consequently, along public needs, an inclusive decision could be produced (Parkinson \& Mansbridge, 2012).

\subsubsection{Methods of Deliberation}

Deliberation could be conducted through the use of different methods, includes public discussion, public debate (de la Porte \& Nanz, 2004). These methods are significant to form public choices based on reason-centric analysis, public meeting, citizens' panel, citizens' conference. These methods sometimes organized by civil society organizations or private foundation to assist citizens to engage in the decision making process 
(Chambers, 2003, p.316). The primary objective of these methods of deliberation is to generate legitimate decision, urging citizens' commitment, cooperation, mutual understanding, avoidance of all exclusion, and promoting the outcome of the decisions (Chambers, 2003, p. 317).

Deliberative venue and forum could be used to encourage citizen's participation. In deliberation venue, citizens bring up common issues and discuss policy choices with other community members. In several occasions, deliberation persuades participants to accept majority decisions in the voting process. It is also an essential instrument to encourage people to carefully express their views and adopt possible solutions to existing problems. Lastly, Goodin (2000) emphasized that participants can also deliberate with themselves and it is known as internal deliberation. Internal deliberation helps individuals to come up with a new idea through interpersonal communication. It could be shared with other participants during deliberative forum and becomes a common decision.

\subsubsection{The Preliminary Elements of Effective Deliberation}

Deliberative democracy theory functions under a special environment that equality, transparency, integrity, communication and decision participation are rationally bounded (Jonga, 2012, p. 130). Some of the following elements are also described in the discourse quality index (DQI) which used as measurement of deliberation. The following elements also identify the success and implementation of public deliberation 


\subsubsection{Equal Opportunity}

Equality is a pre-condition to successful deliberation (Jonga, 2012; Druckman \& Nelson, 2003; Nabatchi, 2010; Gastil, 1993; Burkhalter, Gastil \& Kelshaw, 2002; Gastil, Black, \& Lawra, 2008). Jonga (2012) highlights the most important determinant of wellfunctioned deliberation which is the avoidance of individual domination and giving participants an equal chance to share their preferences. Deliberation protects ordinary citizens from the domination of elites which they normally have major impact on the decisions (Druckman \& Nelson, 2003). Deliberation process is a clear cut of democracy and elite's power of manipulation.

Stakeholders in public policy deliberation should be given an equal chance to express their concern and propose their alternatives (Gastil, 1993). It might be argued that it is difficult for everyone to speak up in a kind of deliberation where many participants engaging. This may lead to discriminatory behaviors among participants. The discriminatory behaviors or dominating discussion by a particular group, raises moral conflicts (Evans \& Kotchetkova, 2009; Davies et al, 2006). It also illegitimate decisions because not everyone had an opportunity to discuss their views. To overcome this issue, additional time could be given to participants to speak or the principles of "equal speaking time" to be practiced (Burkhalter, Gastil \& Kelshaw, 2002). This method assists organizers of the meeting to determine each individual's speaking time. Equal chance here does not mean everybody obliged to speak their mind, but they should be left free to speak or not. Therefore, when they decide to speak, they should not be interrupted, but they have to be heard and respected. 


\subsubsection{Respect to Participants}

Deliberative democracy considers ethical problems and respects the diversity of interests and views. Otherwise, it could be very difficult for individual participants to find themselves in the discussions where conflict arises due to ethical issues. Participants should be treated sincerely with honor and pride. They should not be interrupted when they want to deliver their views (Gastil, Black, \& Lawra, 2008). In this manner, equal opportunities must be given to participants and their voices to be heard.

\subsubsection{Availability of Information to Participants}

In democratic deliberation, information should be available for each participant and it is morally justified for stakeholders to request such information. It's a moral obligation for individuals holding the information to handover to the participants (Gastil, 1993). It is difficult to expect people to govern themselves without proper knowledge of the process and data that needed to engage in decisions. In this respect, transparency and the flow of information should be in place. Stakeholders must have access to the relevant information (de la Porte \& Nanz, 2004). Therefore, availability of information is not solely empowering participants to deliberate policy decisions, but they need to be educated (Gawthrop, 1998; Nabatchi, 2010, p.381). The more effective deliberative discussion is the one that integrates with the adequacy, reliability of information (Gouran \& Hirokawa, 1996). Information as Hebermas (1984) emphasized could be statistics, surveys, or objective measurements that goes beyond individual biases. 


\subsubsection{Diversity of Views}

The other precondition of deliberation is the availability of diverse views, interest, alternatives, and solutions (Fishkin, 1991; Dahl, 1989). Deliberation should promote evaluation criteria to consider ethics of the discussions. In the absence of evaluation criteria and issues relating to the moral values, it becomes difficult for individual participants to propose constructive policies. Participants also need to prioritize their needs and offer a set of alternative to operationalize. Without offering alternatives and considering participant's views, deliberation may not occur. A range of possible solution should be used to deal with problems if it emerges.

\subsubsection{Preserving Participants Interest}

In deliberation, it is always expected that participants pursuing their interests, but it should be treated as a way to understand stakeholder's concerns. To deal with that, their interests should be considered (Nabatchi, 2010) and to be allowed to preserve their interests. This will also encourage them to further participate in deliberation process. Therefore, when a participant feels his interests deserted, he will be disappointed to participate in the future activities. It is imperative to carefully listen to every participant, especially when it is about the wider population (de la Porte \& Nanz, 2004). However, the inclusion of stakeholders and considering their views is not the only way to peruse healthy deliberation. Individual participants should come out with innovative solutions to target the interest of wider community rather than alternatives that only elites or certain people can benefit. 


\subsubsection{Participate in Coordination with Policy Makers}

Budget decision could be incredibly effective if it's shaped in coordination with government officials. Officials can better understand the issues when they are facing their citizens and heeding their concerns other than attainment of information in the secondary sources (Gastil, Black, \& Lawra, 2008). However, deliberation is not always relying on alternatives and solutions, but also the nature of deliberation between parties. The significances of deliberation could be extended through coordination. As a duty of policy makers, citizens need to be empowered to manage themselves in developing policy alternatives and furnishing policy gaps (Wildavsky, 1979). This produces a healthy tie between government and the wider community to better understand each other and strive to obtain mutual interests. Besides, officials may benefit from citizen's experience (Gastil, Black, \& Lawra, 2008). Government officials should engage in analyzing information to mobilize public support to the policy decision (Bessette, 1994).

\subsubsection{Public Deliberation Predicament}

The theorists of deliberative democracy, raises one important question which is egotism of the individual participants. An ego and selfishness effect on individual preferences and judgments, but it's not always negative. Mansbridge et al (2010) argue that self-interest should be included in deliberation process as defined by the aggregative models. Their justification for that is motivating individuals to participate and creates the sense of belonging. Those who engage in decision making, knows the impacts of policy on their livelihood and establishing best mechanism to obtain better policy upshots (Mansbridge 
et al, 2010). Budget decisions have more impacts on citizens. For that, participants establish proper method to produce positive outcome.

Public deliberation could be used as a method to overcome issues of representation. Citizens may not be well represented when representatives have interest in the process and somehow directed by elites. However, public deliberation can possibly resolve this issue by encouraging stakeholders to directly participate in the process (Choi, 2014). For instance, if only representative of communities engaging in the budget discussions, the decision may not reflect the entire citizens. Sometimes representatives are biased toward stakeholders, but deliberation somehow eliminated this issue by engaging all citizens in the process of decision making.

In public deliberation process, participants usually propose variation of alternatives and set of solutions. Its possible when conflicts over policy alternatives and solution arise among participants. Accordingly, evaluation criteria should be applied to determine the effects of each solution as well as alternatives that proposed during the deliberation process. Obviously, the interests and objectives of the participants are varied and different agenda could be proposed. Thus, value trade-offs between proposed solutions and alternatives needs to be carefully analyzed (Mathews, 1994). This process is about making difficult choices among inconsistent options. 


\subsubsection{Learning and Responsiveness}

Learning and responsiveness are two normative determinants of effective deliberation (Nabatchi, 2010). Learning refers to the experiences and empowering citizens' skills, which promotes the quality of regulatory alternatives. More preciously, it means that policy makers and participants learn from their past mistakes. The preceding knowledge cultivate them with better understanding of the process and abandon misleading agenda. Consequently, it guarantees high quality decisions (de la Porte \& Nanz, 2004).

Responsiveness means that policy makers from government departments respond to the concern of local communities and act accordingly. Responsiveness is the extent of voices heard by policy makers. Citizens are expecting their voices to be heard rather than

symbolically participate to justify and legitimize decisions. It's expected from government to carefully respond citizen's concerns and views (de la Porte \& Nanz, 2004).

\subsection{Communication and Budgeting}

Communication is one of the elements of public participation where individual participants exchanging their views over budget alternatives. Budgetary participation provides a setting for managers to exchange information and ideas with stakeholders for planning budget and effectively controlling the process (Poon, Pike \& Tjosvold, 2001). Accordingly, budget communication is defined as the process of consultation and coordination between subordinates and superiors in formal and informal forms in the budgeting process (Abd Rahim, 2004). Communication has been used as a method in 
budget participation in order subordinates negotiate with superiors (Shields \& Shields, 1998) and thoroughly explain budget plans and objectives (Chenhall \& Brownel, 1998). It facilitates information sharing between subordinate and superior during budget discussions. This will provide a framework where stakeholders can exchange their views over budgetary plans.

Only few studies available on the use of communication in public budgeting process. Most of the studies conducted in this area found a positive significant relationship between the two. For instance, in the study of Poon, Pike and Tjosvold (2001) budget communication positively increases the effectiveness and control of public budgeting plans. Scholars found that public participation through communication brings a positive outcome to the budget decision over capital assets (Sheilds \& Sheilds, 1998; Nouri \& Parker, 1998). They also concluded a positive significant relationship between budgetary communication and performance. It has been emphasized that budget communication increases the sense of belonging, control, trust, commitment, cooperation, and public acceptance of budgetary plans. In another research, it has been found that communication plays an important role in directing public officials to introduce major policy decision (Ebdon, 2002). In the same study, around 77 percent of the respondents addressed that their input influenced on the final budget decision. Controversy, 9 percent indicated that their input did not have any influence on the budget decision, but 14 believed that their views somehow influenced on the decision. 
Another study was conducted by the city of San Diago Municipality. They used communication in 2005 fiscal year and found a proper communication helps policy makers and citizens to exchange information over the policy choices. Budget communication avoided rumors and emboldens commitment. The study explored that a clear budget communication helps community members to enrich government with better policy proposal and selecting relevant priorities (City of San Diego, 2005, p. 36). The selection of relevant priorities has been an issue in Kurdistan public budget and discussed in the problem statement. Since the government is lack of communication with citizens, they wrongly decide for the allocation of the budget. They used to provide budget for the projects that does not have prospective returns to the citizens. However, communicating citizens as shown in this literature, enhances the level of satisfaction and assists policy makers to select the right project.

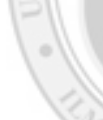

There are different methods to apply communication and organize dialogue between affected parties in the budgeting process. Budget communication could be direct face to face communication, or it can be through information technology and online methods. Jensen (2008, p. 9) found that face to face meeting and direct contacts are the most influential mediums of communication where citizens can influence on decisions (Jensen, 2008, p.19). This method seems to be more effective as citizens can be in direct contact with policy makers to send their messages, explain their issues, and preferences with confidence. However, online methods could be ineffective in the way that citizens are limited and it is not easy to communicate with a larger group online. Jensen (2008, p. 20) realized no significant relationship between online communication and citizens influence 
on policy decisions. In contrast, Ebdon (2002, p. 286) in the study of Kensas city realized 89.3 percent of the participants rely on the media coverage as one of the most effective methods of communication. There are hundreds of local TV channels in Kurdistan Region along with more than 50 satellite channels, 587 registered magazines and 231 newspapers (Kurdistan Journalists Syndicate, 2016). However, the government failed to use these channels to broadcast its budget activities to people. They also failed to share public awareness to encourage people to participate in budget planning activities. These channels could be very effective if government intends to communicate budget with citizens. The online and internet media is also ignored by the government. Even the official website of KRG ministries is bare of the financial reports and activities. They are either outdated information or irrelevant to be used in the participatory budgeting process.

Budgetary participation through communication may happens through upward and downward dialogue between subordinate and superior (Qi, 2010; Rahim, 2004). The method of principal agency used to define the relationship between key actors. In public budget, principal is officials and policy makers. Agents are citizens or stakeholders that receive services. In upward communication subordinates proposing new information to the government officials. Stakeholders better know what they need and what they are expecting to receive from public budget. Their information may lead to better budget decision. The information that agents possess can shift stakeholders' preferences and its a way to transform decision power from principal to agents. This process results in better allocation of resources and more satisfaction. In downward communication, subordinates delivering information from superiors to realize their goals, duties, and the nature of the 
budgeting process. The sole player in Kurdistan public budget is the superiors. Thus, decisions conceived based on their mindset along the interest of their political parties. The following diagram explains this relationship.

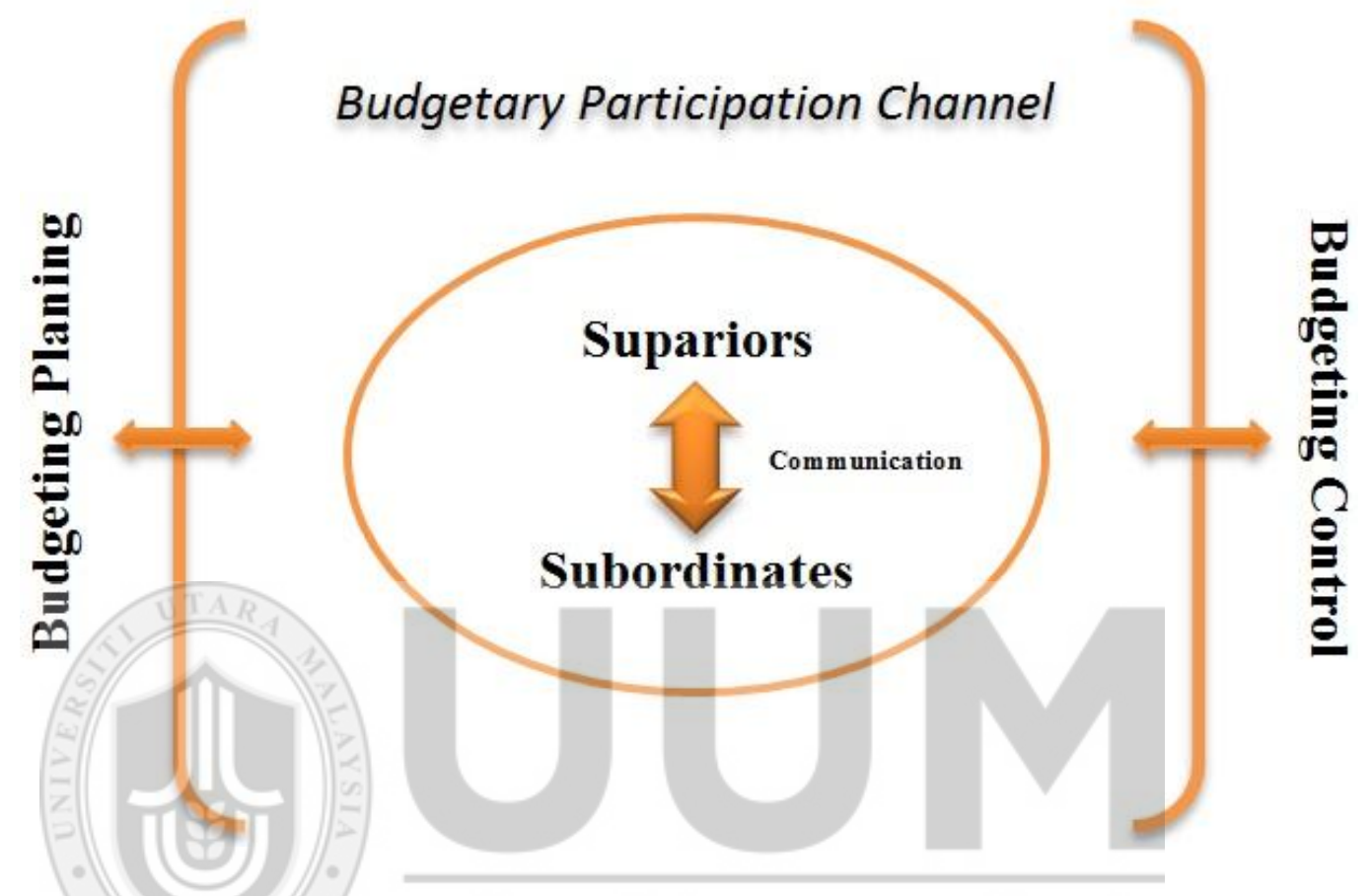

Figure 3.1 Budgetary participation through communication

Adopted from Qi (2011, p.30)

\subsection{Information}

Information becomes a valuable instrument to improve public policy and enhance citizen participation in political, social and financial activities. Access to public information bears financial benefits, political reform and way to establish good governance (Yannoukakou \& Araka 2014). Government information increases public confidence in government operations and the way decision making originated. In the absence of information, 
decision makers unable to guarantee public trust. This degrades legitimacy of the decision and causes ineffectiveness and inefficient policy choices (Napoli \& Karaganis, 2010). Thus, policy makers should be open towards their citizens in order to scrutinize and evaluate public budget decisions. In the global level, demands for government information increased. Officials are now under public pressure to deliver adequate information to citizens (Relly \& Sabharwal, 2009). The pressure ascended due to the advancement of technology and global interconnectedness which has increased the expectation of citizens towards government. To be truly transparent, the government should allow citizens to access all sorts of information (Jaeger \& Bertot, 2010). More clearly, citizens need to have a physical, intellectual, and social access to public information (API). Budget information could be a kind of information that assists citizens to set as well as evaluate decisions.

\subsubsection{Approaches to Access Public Information}

Circulating information is very different compare to the traditional methods used in the past, such as Television, Newspapers, and Magazine. If in the past, somebody needed to access government documents, reports and other sorts of information, the person had to physically show up, but recently hundreds of available online (Cuillier \& Piotrowski, 2009).

Collier and Piotrowski (2009) laid down four major methods to access public information. The first method is proactive dissemination of information. The government agencies are 
voluntarily disseminating information to citizens through press, online methods (ex. searchable databases), a library and depository. The KRG ministries does not disseminate proactive information. They are also not willing to voluntarily release budget related information. Secondly, unlike proactive information, requests should yield to government to obtain particular information from government. In this approach, citizens physically seeking for the intended information and there is high possibility to obtain. Sometimes the laws enforce government institution to provide any type of information for public (ex. the KRG Right to Information Law). However, most people are not aware of such laws in Kurdistan. The KR citizens are not willing to voluntarily seek for the budget information in order to participate unless for research. This culture should be created in order to in order to allow anybody to obtain required information for budgetary participation. Lastly, leaking information is another method which helps citizens to obtain information, especially confidential information that somehow relates to national security (e.g. WikiLeaks and whistleblowers), military and diplomacy or sometimes corruption reports. These kinds of information are very sensitive and could not be obtained easily. Therefore, leaking sources would help to reveal confidential and sensitive information. This type of information is very common in Kurdistan Region. Even though the KRG does not provide proactive information, but budget related information always released from leaking sources. The opposition MPs leading this trend to release more government information regarding budget activities. However, this kind of information politicized and usually associated to corruption in financial institution such as fake budget projects, misallocation of the budget and KRG deceptive budget plans. In the recent days, even information about Kurdistan budget is leaking from international journalistic organizations such as 
WikiLeaks. However, the government must disclose budget related information to citizens as it impacts on their daily lives. Ehrhart et al (2006, p. 22-23) provide experimental evidence on budgeting processes and clinched that budget efficiency depends on three key policy implications. The first implication is stressed by the voting power. The second implication concerns on the top-down budgeting that depends on the preference of the individuals engaged in the budget planning to obtain major financial management disciplines. The third policy implication relates to the budgeting process relies on public disclosure and detailed budget information; otherwise, it shrinks the accuracy and quality of the budget plans.

\subsubsection{Open Government Data}

Open government data refers to the collection, generating, managing, gathering, recording, and documenting information that performed or discussed by public administrators (Allen, 1992; Birkinshaw, 1997; Meijer \& Thaens, 2009). The notion is defined as data that owns by the government and can be used, distributed and disseminated by citizens without censorship (Yannoukakou \& Araka, 2014). Open government relies on transparency, accessibility and the reclaiming available information in all types and means. Open government might not function without data; To be considered as open, data must meet 8 principles, namely "complete, primary, timely, accessible, machine process able, non-discriminatory, nonproprietary, and license free" (Harvey, 2014, p. 219; Garvin 2012, p. 179). 
Recently, the demands for open government have frequently increased. This relates to the growth of demands on transparency, integrity, creativity, and public participation in in public policy making process (Janssen, 2012). Open government disseminates information in all levels and entities of the government concerning public financial management, budget report, taxation, education, health programs and etc. The government administrations should not keep any information confidential that does not detriment national security and government vision. In the other word, the government should be accountable to disclose any sorts of information that required by citizens.

\subsubsection{Transparency \\ Transparency is an essential tool of budgeting which implied by the democratic} governments. It reyeals adequate information on how the government policies formulated, how resources allocated, to what extend government fulfilled its accountability towards public in delivering public services to citizens. It inspires policy makers with data and information to improve the creativity and effectiveness of the policies (Lukensmeyer, Goldman \& Stern, 2011). Transparency refers to information disclosure or clarity of the activities. According to Richard W. Oliver (2004, pp.3) with reference to dictionary of Oxford, the terms is derived from the combination of "trans" which means movement and "parent" which means visibility or clarity. Based on this compound word transparent budget could be defined as a movement of information between government agencies and community members. The original meaning of transparency as emphasized by Oliver (2004) described as "having the prosperity of transmitting light, so as to render bodies 
lying beyond completely visible or an active disclosure, the public right to know." Transparency in budgeting process means the disclosure of public information where everybody has access to reports and data on expenditure.

\subsubsection{Transparency Culture}

The government looks like organization in which stakeholders expect their needs to be fulfilled. Motivation from top officials, influences budget practices to be more efficient. Managers, who provide information on organization's activities, can accelerate better policy decisions. Thus, when stakeholders obtain information on the organizational activities, they will provide comments and suggestion to further improve the decisions especially in public finance. Controversy, keeping all the information in the secret files complicates and undermines participatory budgeting process. Consequently, it increases the level of dissatisfaction.

Djurović-Todorović and Djordjević (2009, p.288) correlated transparency to the implications of the organization. They quoted "budgetary outcome profoundly influenced by the institution, which comprises both formal and informal rules" (2009, p.288). Here, organizations are able to create transparency culture. To prevent the violations of budget outcomes by politicians, transparency and accountability culture must be applied as an important instrument to prevent their unfavorable will. 
Oliver (2004) identified four major principles related to the transparency culture, includes leadership commitment, formalized process, training programs, and communication with stakeholders. Leaders must be committed to the organization culture of transparency and maintain their communication with stakeholders. They also need to reveal their agenda to the public. The second principle is accessibility of reliable and accurate information in the timely manner. Furthermore, adequate training must be given to stakeholders to analyses and utilize information they receive. Skill building and human capital development are significant to maintain organizational transparency. It aids employees to know how to prepare reports and analyze documents.

\subsubsection{Information and Public Policy Participation}

Governments should encourage active participation of citizens in all sectors, especially on the issues relating to them such as capital budgeting. Disseminating information makes people to realize their rights and duties as well as fulfill their civic obligations. In the absence of accurate information, it's impossible for public to involve effectively in the decision making process. It could be argued that public participation and availability of information or openness are two intertwined terms that influences the quality of decisions as well as the efficiency and effectiveness of the government.

The access to public information is well esteemed by people in participatory government. Although, policy makers are ambivalent toward public participation, but it's a legitimate right for every citizen to acquire knowledge and information from government on the 
policy formulation, implementation as well as evaluation (Ho \& Ni, 2004; Jaeger \& Matteson, 2009; Tsai, Choi, \& Perry, 2009). Citizen's pressures and requests for information can be analyzed as determinant of oneness and integrity of the government. It could be interpreted as instrument to perform government policy more precisely and influence on decisions quality (McGregor, 2006; Page \& Shapiro, 1983).

Scholars identified access to information or an informed citizenry prevents the misuse of public budgets, corruption, nepotism, the inaccuracy of the government (Bertot et al., 2009; Cullier \& Piotrowski, 2009; Mulgan, 2007; Relyea, 2009a; Shuler et al., 2010). Obviously, when provision of government information is accessible, public administrators may not conduct corruption acts as others auditing the system. For that, public information is an essential component that facilitates the functions of the society. Transparency also takes citizens towards creating new ideas, designing new projects and developing new services to stimulate economic growth and social well-beings (Yannoukakou \& Araka, 2014). Therefore, to express their views, citizens have to be wellinformed. In that regard, government information can be used to benefit community members rather than agency itself.

\subsubsection{Information on Policy Intentions}

The provision of information is profoundly influencing the quality of decisions. Citizens need to know about the policy intention before its enactment by the legislature. This method helps government to know whether decision supported by population or not. 
When citizens prior to the policy decisions know about the intention of the government for conducting certain policies, especially in planning capital budget, citizens will be willing to contribute with local authorities. For that, policy proposals should not be secretive, but to be disclosed to public in order to provide a room for citizens to give their comments, views, and suggestion. Abdullah and Abdul Rahman (2015) in the study of Kurdistan Region found that nearly 70 percent of the respondents prefer initial information, while only 30 percent of the respondents prefer information after making the decision. Demanding information in the initial stages of decisions making relates to the importance of these information in generating new policy agenda and formulating new policy choices accordingly. Information provisions have two valuable effects, including democracy fulfillment and efficiency of the policy. In a democratic system, citizens should be informed about the ongoing policy making process, also to understand the intention of the government to stimulate participation. Informing citizens prior to the decision is also valuable for the performance tof /good/governance and smoothly implementing decisions.

The significant of information prior to the decisions making explained in two perspectives (Napoli \& Karaganis, 2010). The first perspective is utilizing such information by politicians and interest groups to prove themselves on the ground and attract their supporters. When politicians know about the intention of government, they can use lobbies to change decision based on their interest. Such information could be utilized by political parties to attract voters during election. 
To prevent personalization or politicizing information, the government has to comply with standards of quality information as "complete, timely, and factual information provisions" (James, 2004). If government fails to abide by aforementioned standards, the democracy and legitimacy of the government will be endangered. Therefore, citizen has the right to know the content of the government intentions. It's perfectly reasonable for the government to utilize all information channels to conceptualize policy choices.

\subsubsection{Public Access to Government Information Law}

The right to information law (RTI) was a great move in some countries like Sweden to oblige public administrators to provide adequate information to their people. Sweden was the first country in the history adopted RTI law nearly two centuries ago (Ackerman \& Sandoval-Ballesteros, 2006). The access to information law provides a legal framework for citizens to obtain relevant information (Piotrowski \&/Rosenbloom, 2002; North, 1999). The main objectives of ATI Law were to produce good governance, achieving more trust, and enhancing the extent of public participation (Mendel, 2008). ATI was seen to prevent the misuse of public budgets and develop budget variances (Roberts, 2002). Information could not be obtained easily in the absence of legal procedures, ATI, freedom of expression, free media, and telecom infrastructure. With the lack of these components, information could not adequately disseminate to citizens. The KRG owns RTI law and its dynamic, but not widely recognized by the citizens. In the other words, people do not know their rights in the law and what are the information that allowed to be given to them upon their request. This caused misunderstanding between citizens and government. 
Citizens generally believing that government rejects their requests if they demand for budget information. However, the KRG is legally enforced to provide information when requested by citizens.

\subsubsection{Citizens' Access to Government Information in Kurdistan}

In terms of good governance and openness Kurdistan is still an infant, but citizens are struggling to pressure on governments to be more liable towards citizens. The KRG Prime Minister Nechirvn Barzani in the launch of the government strategy on good governance and transparency promised that the government works to allow public access to government information to institutionalize government, preserve public interest and ensuring accountability and democratic representation (KRG, 2009). Recently, the government has achieved some improvement in terms of transparency.

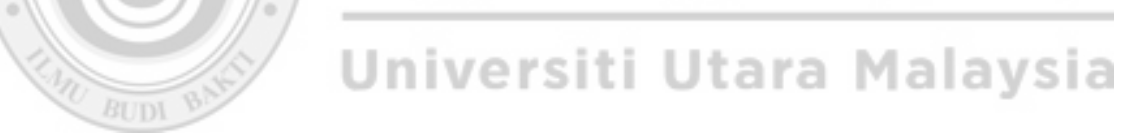

For the first time, Kurdistan parliament adopted Right to Information Law No. (11) for 2013. The law provides a legal framework for government administrators and departments to provide necessary information to all citizens except some information that relates to national security. Accordingly, citizens all guaranteed legal support to access and demand information of all types and forms held by a government institution without any burdens excluding the exceptions defined by law. Previously, citizens, government employees, and ministries were not aware of what is happening inside government departments especially in terms of public financial management (UNDP, 2009). The law was a move to ensure transparency in public organizations and assist people to receive information 
that they are looking for. The law ranked 28 out of 95 countries in the world by (www.rtirating.org) with 98 points out of 150 (IFJ, 2014; Mendel, 2014). Enacting RTI was a great achievement, but the question is to what extend government departments and authorities abide by this law or do citizens have adequate information about the RTI law? Surprisingly, in a survey conducted Smail (2014) to evaluate the RTI law, 44 percent of the participants, mostly government employees and the journalists, do not even know there is such a law. In this respect, the researcher puts criticism on citizens, especially government employees for not having information on the law that widely covered by the media. In another survey, 65.63 percent believed they can not obtain the kind of information they are looking for (Abdullah \& Abdul Rahman, 2015, p.3453).

\subsection{Chapter Summary}

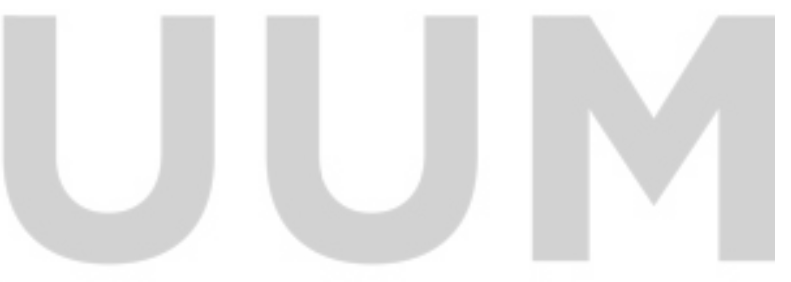

This chapter elaborated the importance of public participation in reference to public financial management. The chapter first defined the concept of public participation and gave an imperative background on PB process which was first introduced in Porto Alegre in Brazil. Then it jumped to the elements of public participation and provided previous literature, findings and arguments on the relationship between those elements and public service delivery, satisfaction and public preference as important determinants of capital budgeting process. Besides, the chapter has given an insight on how to conduct participatory methods in the real world and elaborated different participatory programs all around the world and the outcomes. 


\section{CHAPTER IV METHODOLOGY}

\subsection{Introduction}

This chapter explores the methods used in this study. The first part describes underpinning theories, research model constructs, research framework, hypothesis development. Then it highlights the research design used in this study along with instrument design, pilot study, reliability and validity test, research design, populations, sampling, source of data, and the instrument used to collect data. Lastly, this chapter explains how the qualitative and quantitative data separately analyzed.

\subsection{Underpinning Theories}

The theories used in this study, explained in this section and related to the existing problem. These theories initiated to be the foundation of the research medal. However, the research model was not limited to these theories, but participatory budgeting model, previous literature also become the foundation of this study. Theories are limited to the study of budgeting and they are lack of understanding in terms of public financial management. Therefore, budgeting is part of public policy and decision making. Thus, the study discussed and related the theory of public administration. Under public administration theory, new public management theory, theory $\mathrm{X}$ and $\mathrm{Y}$ discussed. 


\subsubsection{Participatory Budgeting Model}

This model realized to be an effective method of budgeting process that offers opportunity for citizens to negotiate budget allocation and prioritizing investment projects (Alves, 2014). The model emphasizes on participatory elements such as consultation and communication in planning capital budget process. The model developed based on the theoretical foundations described in deliberative democracy. Deliberative democracy becomes a grounded theory of participatory budgeting for practical experiment in the real world democracy.

In this model people are considered as the central part of the decision and the process is sought to deliver services that are best matches citizens preferences. The model allows citizens to list their priorities through participatory mechanisms. It becomes popular due to its importance in developing two key aspects of traditional budgeting includes the promotion of information dissemination between government and stakeholders and urges officials to fulfill the needs of community members in target setting. Secondly, it has improved accountability of public servants (Alves, 2014). Several contributions of PB listed by Alves (2014) including political commitment of public institutions to integrate effective projects derived from participatory process, utilization of time and capital to organize forums to encourage community members to participate in the budget of municipalities. PB has been used to fulfill the most popular demands of citizens, increasing accountability, civic engagement, and aggregating alternatives. Thus, a set of criteria prepared to fairly distribute the resources. In PB, feasibility study will be conducted to the projects. The process also promotes transparency to combat poverty and 
ensures service incentives for the poor communities. In this process, information is treated as a golden tool. Information positively associates to counter corruption, accountability and economic efficiency (Heald, 2006). Garcia, Pinto and Ferraz (2004) identified that PB relies on the availability of information in order to be successfully implemented. (For details on participatory budgeting, see 3.2).

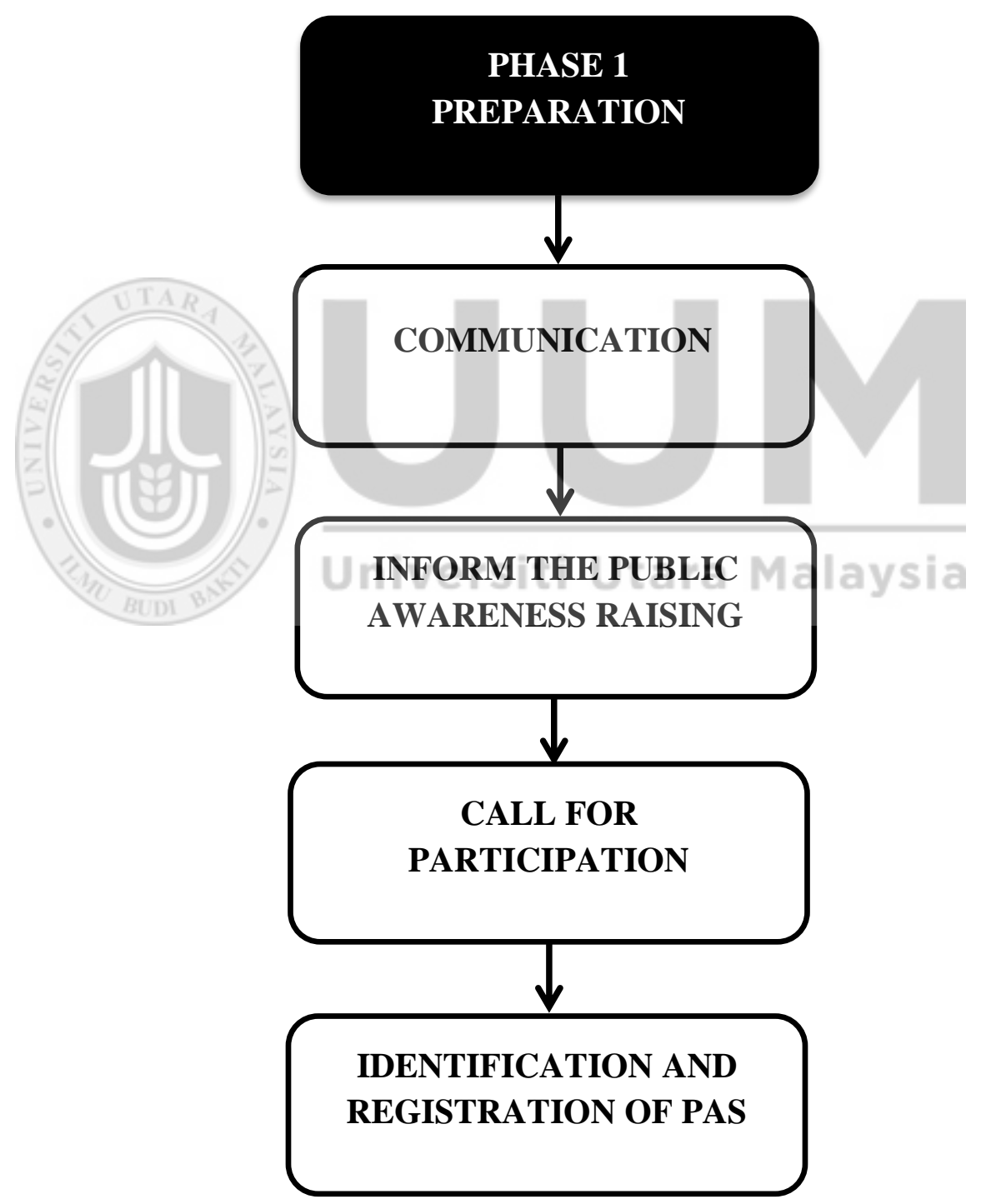

Figure 4.1 Participatory budgeting processes in Peru

Adopted from Dias (2012, p. 206) 


\subsubsection{Public Administration Theory}

The theory of PA has emerged at the end of the 19th century in the USA, then widespread around world. The most important figures contributed in developing this theory as a separate academic discipline was Max Weber the father of Bureaucracy, Fredrick Winslow Taylor pioneer of "Principles of Scientific Management," Gulick and Urwick (1937) wrote "Public Administration and Classical Theory," Mary Follett founder of "Organizational Theory and Organizational Behavior," Chester Bernard the pioneer of "Management Theory and Organizational Studies," Herbert Simon pioneer of "Decision Making Science and Organizational Theory."

Public administration is the combination of "public" which means governmental and administrative which means management. The combination of two words as explained by Naidu (1996) refers to the management of public affairs by public institution to achieve public interest. Public administration is a broaden theory, it's applicable in a variety of sciences. It deals with politics, sociology, laws, and economics. Public policy as a subfield of PA is an action-oriented. In the economic perspective, PA interacts with individuals as well as their choices. Decisions made in the public sphere should consider public choices. Even though, the theory is lack of explanation about budgeting, but its still possible to form the relationship. Public administration theory deals with the management of public affairs. Budgeting is public concern and the most important document of government. So, public budget can not be separated from public administration. More importantly, the theory of public administration explains that the quality of financial management decision relies on the techniques used by public administrators. In this study, 
public participation is examined as essential technique to make capital budgeting decision for the purpose of maximizing public services. In this sense, both public participation and public budget could be explicated in relation to public administration theory.

The classical theory of PA, which was pioneered by Gulick, Urwick, Follet at the end of nineteenth century represents the emergence of management science. The classical theory of PA is based on two approaches includes efficiency and economy. For Henery Foyol, administration theory is the study of overall human activity that could be influenced by others. For him, PA relies upon "planning, organizing, commanding, coordinating, and controlling." He has given 14 principles of organization in his book "General and Industrial Administration." What relates to public financial management, decision making, and public participation is "unity of command and direction, subordination of individual interest to general interest, and equity". The main objective of public participation is convenient with this explanation, because participations aims to make collective decision to achieve public interest. The classical public administration theory might offer little to citizen's participation in budgeting process. Therefore, the new public management (NPM) provides a greater opportunity for public engagement. The NPM is an evolution of PA that was first used by Margret Thatcher and known in the work of Hoods (1989). The NPM has challenged the traditional PA theory and questioned the efficiency and effectiveness of the bureaucracy in providing public services. In NPM, bureaucracy ought to be transparent, liable, and receptive to meet stakeholders' demands, needs and choices. Stakeholders in public sector are community members who have their stakes in the decisions. In the other words, they are effected by the decisions. Therefore, 
NPM believes that their needs should be fulfilled based on their choices. Public participation has the paralleled notion for public policy decisions that requires openness, inclusiveness, receptiveness, and accountability of bureaucracy. Hoods (1989) also designated that bureaucracy is responsible to manage public expenditure in the way that public preference and voices to be heard as well as government offers quality programs. The key objective of capital budgeting process is also to ensure public needs satisfaction. Citizens can be satisfied when they find the quality and the quantity of the services fulfills their needs. However, to ensure that quality and quantity of the services are in a good condition, citizens should be part of the decision. The NPM also gives a chance to community members to involve in economic, financial and commercial activities.

In contrast to the traditional approach of PA which is output oriented, NPM is process oriented. Process oriented in NPM could be evaluated in terms of quality services provided by administrators. Moreover, in NPM citizens are not seen as passive recipients of government services, but active participants which their roles are important in the success of PA (Basu, 2004). This feature also correlates to theory Y which is supportive towards public engagement in governance. The second feature of NPM is the presence of actual managerial leadership. Leaders should be able to influence their subordinates to perform their tasks through the use of human capital and behavioral relationship. Reward policies should be used to encourage stakeholders in administration. The NPM also assists administration to revive the outlook of "bureaucracy from a machinelike, rigid, impersonal, inefficient, wasteful, and ultimately ineffective custodian of the public interest in a dynamic, result oriented, efficient, responsive, and responsible public servant 
who is sensitive and aware of public needs, wishes and preferences" (Basu, 2004, p.48). So, productive managerial leadership, fulfillments of public needs and quality services are main features of NPM (Basu, 2004, p. 46-48).

There are other theories under public administration that supports the research model. McGregor in his books entitled "The Human Studies of Enterprise" in 1960 established theory $\mathrm{X}$ and $\mathrm{Y}$ in PA. He has also identified the significance of leadership. According to theory X, human beings are unable to decide for themselves, but they need someone or good leadership to be directed and controlled. According to theory X, people are lazy. They are usually impartial to work or to bear responsibility. Thus, they need a rigorous supervision by administrators. The theory also requires the use of force to influence people. Controversy, McGregor theory of $\mathrm{Y}$ which is more applicable in modern democratic systems and budgetary participation, treats individual as cooperative and hardworking. It also enlightens that Individuals are able to support public administrators in making particular decisions. In contrast to theory $\mathrm{X}$, theory $\mathrm{Y}$ emphasizes that individuals are smart, intelligent and active. They know how to take responsibilities and perform their tasks. For that, they must be included in the decision process and their contributions must be appreciated (Arslan \& Staub, 2013, p. 104). Bobic and Davis (2003) supported Theory $\mathrm{X}$ and they believed that public participation in decision making can significantly influence on the decision quality and organizational performance. 
Herbert Simon (1916-2011) pioneered the theory of "Bounded Rationality" and decision making theory in PA. He emphasizes that decision making is a method to choose the best alternative among different choices. The core idea of PA is about decision making to satisfy public needs. Simon maintains that public satisfaction relies on the quality of decisions by administrators. He has correlated human behavior to the decision process. Simon has classified decisions in four main stages. The first stage is problem identification to realize the issues that persuaded public administrators to make a particular decision. Simon suggested the inspection of decision making activities to identify problems. The second stage is alternative development. In this stage activities are designed to perform decision plans. After the identification of problems and developing alternatives the third stages follows, which is alternative appraisal. This stage is very important because when there is a project; government administrator must realize the costs and the benefits. The outcome and alternatives should be identified for the evaluation process. The final stage in decision making according to Herbert Simon is the "solution selection." Administrators here, select the most relevant alternatives to accomplish decision objectives in the cost-effective manner. In all stages, human behavior is must be taken seriously because it reflects the success of the plans and activities. Naidu (1996) contends that PA is a form of management system that relies on human relations. Communication rationality relates to this study as it highlights the importance of costeffectiveness. It's an item of capital budgeting process measurement. To identify whether projects are efficient, the advantages should be measured against the cost estimation as in bounded rationality. This measure can also cover a major issue of budgeting in Kurdistan 
which is the misuse of public money for the projects that does not have much impacts on the well-being of the citizens.

As discussed previously, public administration theory relates to the subject area. The theory covers several issues in Kurdistan public administration particularly issues related to public satisfaction, service delivery and behavior of government authorities with citizens. Hence, it has been partially used to construct the framework of this research and also designing the questionnaires. Many scholars, including Laegreid and Christensen (2013) have used this theory in relation to public service delivery. Scholars have studied that public participation in budgeting is way to improve service delivery and quality program. The NPM provides several choices in order stakeholder to choose their best preference that helps to provoke quality of services and enhance delivery of public services. They also stressed that NPM helps vulnerable people to participate in developing new policy models and service design. The NPM sees technological advancement as a major instrument to push further participation in service design through information and communication channels including internet forums, social networking websites and others (Laegreid \& Chritensen, 2013, p.352).

\subsubsection{Communication Rationality}

The theory of communicative rationality helps researchers to explain the importance of rational communication in the decision making process. The major philosophers of communicative rationality are Jürgen Habermas and Karl Otto Apel. In this theory, 
communication is the major generator of rational decision making which provides opportunity for citizens to exchange different interest, values, knowledge, expertise, opinions, skills and resources. This theory discusses two approaches of public participation namely communication and deliberation.

Therefore, communication is more discussed here. Accordingly, policy makers are not the only policy generators, but citizens are involved in the decision making process. The participants in this theory exchange different types of knowledge and information through communication channels and formal procedures in forms of data and reports. It's believed that communication, mutual understanding, public participation, rationality, transparency, action, and reaction incrementally grew (Innes, 1998). Thoroughly, new policy meaning and understanding could be obtained to eventually construct a decision. Communicative rationality in the planning process facilitates the movement of information between stakeholders, government, civil society organizations, and interest groups (Hatley, 2013; p. 44). In the budgetary participation, the information also disseminated between participants, and everyone cooperate to establish common ground. However, Hatley (2013) the author is uncertain about the complexity of the process such as organizing and conducting workshop, open meeting. This is due to the fact that such process entails longer time, and more efforts. However, it is not necessary for communication to take long time if there is efficiency in the process. 
Healey (2006; p. 263-66) proposed five general schemes that policy making should possess in communication. Collaboration is the first proposition which includes power sharing between participants and government. In public sector organizations, policy planning through deliberation and social inclusion can ensure power changing and eliminates constraints of communication that sometimes dominated by elite groups. Giving more attention to participants' knowledge and their experiences is another scheme that citizens feel their participation is valued. Thirdly, it's essential to pay an accurate attention to the nature of communication, the routines and the way of communicating issues. This scheme is more to avoid any sorts of discrimination and exclusion. Fourth, the author sees deliberation as the most essential instrument of social mobilization. Deliberation in communication rationality helps to construct and improve institutional capacity, transforming knowledge from one participant to another. Subsequently, the outcome of the process forms a new cultural community. Lastly, miscommunication and misrepresentation should be criticized. Elites believed to dominate dialogue practices in communication, and it should be constricted. The five schemes including collaboration, communication, power sharing, deliberation, equal participation are important components of the policy formulating process. These schemes are tools of budgetary participation, along with some other instruments completes the process of budgetary participation.

According to the literature provided by Innes and Booher (2010) the collaborative approach of communication rationality should enable to produce cherished social outcome. The authors designed three conditions that offer opportunities to individual 
participants to meritoriously participate. The conditions are "full diversity of interests among the participants," the interdependence of the participants who can not get their interests met independently and "engagement of all in a face to face authentic dialogue meeting of Habermas' basic speech conditions." The outcome of this practice in public budget participation creates a proper policy system which can be adopted in complicated settings. The authors also commended to provide adequate information to the participants otherwise decisions will have a knock-on effect on the legitimacy and viability of decisions. Participants in communication rationality must accommodate interdependency and mutual interests, otherwise collaboration can not be obtained and results will be unconvinced. When there is mutual interest, participants advocate their times, energy, skills, and knowledge to collectively reach to the agreement. They can better motivate each other without disrupting anybody's interest.
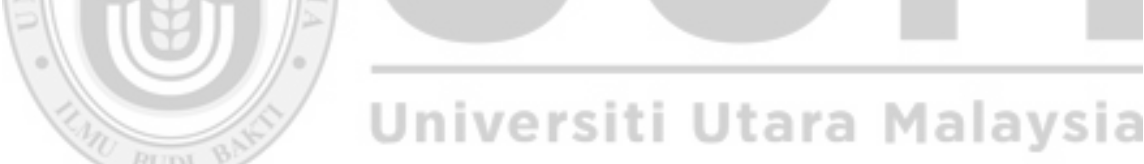

Theory of communication rationality also relates to the negotiation theory in the sense that "interdependence among interests is key to moving past zero-sum games to creative mutual gain agreements" (Innes \& Booher, 2010). This argument consistent with Habermas views on "Ideal Speech" that indicates public deliberation ensures all participants obtain accurate, legitimate, genuine, and transparent outcome. Besides, participants must be given an equal opportunity, equal chances to speak up their concern, and to be heard by the policy makers. The authors have concluded their literature by explaining the outcome of this theory in the planning process that can be adopted in participatory budgeting to achieve objectives of capital budget. Firstly, participants realize their mutual interest. Secondly, the process maximized trust and commitment 
among participants. Lastly, participants overcome common problems and develop new approach to tackle public policy issues.

\subsubsection{Deliberative Democracy Theory}

The history of democracy dates back to the Romans and Athens, but the forms of democracy has changed gradually and new theories derived from the mother democracy such as deliberative democracy. Deliberative democracy is another theory that was first developed by John Rawls, Jürgen Habermas and Cohen; then second generation followed, including Dryzek, Young, Goodin, Thomson, and Gutmann. As explained in the work of Gutmann and Thampson (2004), deliberative democracy is the form of participation that people deliberated over policy choices. The author also indicates that deliberative democracy concentrates more on planning policy than evaluating policy. This theory relies on the reasons given by ordinary citizens or delegates over their preferences, which automatically change the outcome of the policy (Gutmann \& Thampson, 2004). The traditional form of democracy mainly focuses on voting process when it comes to the issue of decision making and citizens' participation. However, the modern theorists of deliberative democracy more emphasize on the significance of deliberation in social aspects (Gastil, Black, \& Lawra, 2008). In this respect, deliberative democracy involves citizens and stakeholders in the decision process in more broaden way.

The notion of deliberative democracy described as the process of making collective decisions through the engagement of all stakeholders by offering them a reason based 
discussion (Elster, 1998). The theory also refers to the relationship between citizen's collective judgment and public policy decision derived from deliberation process (Cohen \& Fung, 2004). In deliberative democracy, citizens engage in policy formulation from all stages of public policy making by offering various methods (Chambers, 2003). Public budget was specifically highlighted in the theory, but as part of policy making, it could be studied under deliberative democracy theory. Budgetary participation can not be separated from deliberative democracy if one well understands the magnitude of deliberation in the capital budgeting process. Deliberation explained by Chamber (2003) helps to overcome weak citizenship and combining each participant views to discover best solution to the issues rather than just giving citizens a chance to vote without meaningful participation.

Deliberation is democracy, but democracy is always deliberative. Habermas (1989) argues that democracy can not be deliberative by transcending individual interests, but it could be deliberative when affected individuals combine their interests to generate common ground. In the other words, those who are affected by decisions and their representatives should directly engage in the process. Accordingly, decisions could only be democratically legitimate when it is from the ground where citizens are submissive to. It ensures that stakeholder options are fed into the process. Therefore, options should be derived from relevant information, rather than randomly placing everyone's agenda in the decision (de la Porte \& Nanz, 2004). 
The theorists offering more argument on deliberative democracy theory that could be adopted in budgetary participation. Cohen (1997) stated that deliberation forms the characteristics of citizens and preserving their interests through their contribution in the process of making the outset of the common good. Rawls (1993) on the other hand, concentrates on the approach of equal citizenship in his literature and correlated to public goods. However, Habermas (1984) concern about entails of public deliberation and argues that there should be no limitation for citizen to participate and public process should be bounded by moral consideration. He also rejects any exclusion and domination. It was also argued that in the absence of equal participation, no agreement could be achieved. A decision made in public through citizen participation promotes justice and equity (Cohen, 1989; Raw1, 1993). However, for Habermas (1984) communicative rationality and legitimacy are core values of deliberation. Elster (1995) supports the Habermas claim and believes deliberative democracy influences on the legitimacy of the policy choices and provides relevant information for citizens to engage in policy setting. He also maintains that the use of deliberation maximizes equity of the policy choices and citizen's commitment. Consequently, better policy outcome could be achieved (Elster, 1995). Deliberation also deals with the stability of public interest by diminishing domination and better assessing people's preference (Dryzek \& Christian, 2003).

\subsection{Research Model}

Based on the problems and the objectives, the research model (see page 112) constructed. The model was based on underpinning theories, models and previous studies. Three main theories were adopted namely public administration, communication rationality and 
deliberative democracy. Therefore, deliberative democracy theory was the main theory and more related to the budgetary participation process and the problem statement. It was the dominant theory for deliberation and sub-theories of public administration (NPM, theory $\mathrm{Y}$, bounded rationality) was conclusive to communication and information. Communication rationality theory was taken as important theory to explain the impacts of communication and deliberation in public policy making process. Along with aforementioned theories, participatory budgeting model was used. The study treated "public participation" as independent variable and "capital budget process" as the dependent variable. Three dimensions used under public participation including deliberation, communication and information. Capital budgeting process on the other hand, was used as dependent variable. The study drew direct relationship between public participation dimensions (deliberation, communication and information) and capital budgeting process.

\subsubsection{Independent Variables}

The construct of three independent variables will be discussed in this section, namely deliberation, communication and information against capital budgeting process. Public participation dimensions are separately used against PB. Deliberation refers to rational discussion; communication refers to dialogue, negotiation, consultation, public hearing, and information refers to transparency and availability of documents, data, and reports related to public budget. 


\subsubsection{Deliberation}

Deliberation is a contemplation and careful argument between stakeholders. Deliberation is defined as a careful weighing of different alternatives to act thoroughly along with other individuals (Mathews, 1994). This term is commonly used in the study of public participation. Deliberation could be conducted through workshop, conference, community meetings, polling, citizen's panel and juries. The most effective technique of deliberation is citizen juries where large number of participants (at least 20 participants) engages in decisions making (Degeling, Carter \& Rychetnik, 2015).

To measure deliberation, researchers are usually using Discourse Quality Index (DQI) which was introduced by Steiner et al. (2004) and Bachtiger et al. (2009). However, they derived the key principle of DQI from Habermas discourse ethics, Goodin (2000) and Sanders (1997). In the discourse ethics, participants discuss issues with natural language and conversation are rationally constructed. Despite the differences and arguments that might arise during the discussion, participants have to reach to the agreement. To do that, every participant should be treated sincerely with respect and consideration (King, 2009). Differences is indeed arising during deliberative process, therefore it does not mean discussions to turn into threat, or using unethical approaches to convince participants to give up their claims. Such action, undermines the merits of the rational deliberative discourse. Also, another role of deliberation discourse proposed by Habermas (2005), Chamber (1996) and Dryzek (1987) is to allow participants equally speak up their concerns. Their claims as they argued should be treated with consideration to achieve common goods. Therefore, it has to be free of internal or external coercion, threats, and 
bribery in order participants freely expressing their demands (King, 2009). However, the decision shall be logical and rationally discoursed. The above argument mainly prescribed by Habermas was a foundation to the discourse quality index model. Therefore, this model was mostly used in the political study; but, this study related to budgeting and public policy making process. The DQI measures deliberation through equality, interactivity, justification rationality, common good orientation, respect, sincerity, truthfulness, and "agreement with demands, and counterarguments, and constructive politics" (Bächtiger et al, 2009). The Steiner et al (2004) prior to Bachtiger et al. (2009) included open participation, common goods consideration, respect to the participants, constructive politics and justification rationality in their discourse quality index. Equal participation and prevention of elite domination is a precondition to the deliberative process. In every deliberative process, citizens are required to offer certain level of participation in which they can give and take (Soo-Hye, William \& Donna, 2015). It improves the interactivity of the participants to understandathes essence of their participation. Besides, in DQI, the common goods orientation should be a cast in the sense that deliberation is not an individualist process, but it's a process to ensure the trade-offs between the most important needs to preserve "greatest good for the greatest many" (SooHye, William \& Donna, 2015). Several claims, projects and recommendations could be made during deliberative discourse. Therefore, the proposals have to be well examined by the participants and the most cost effective and advantageous proposals to be selected to ensure the quality of the decision and common good orientation achieved. This process is known as "consideration of trade-offs" or the value of trade-offs in DQI. 


\subsubsection{Communication}

Communication has been used as important participatory mechanism which refers to the information sharing and opinions over budget alternatives. Good communication recognized as one of the four factors of successful budgeting process (Willoughby, 2002). This variable was constructed in relation to the theory of communication rationality and previous studies. Communication is one of the five major schemes of public policy decisions in communication rationality theory (Healey, 2006). Habermas in theory of communication rationality believes that communication motivates participants to realize their mutual interest. The communication practice maximized trust and commitment among participants and lastly participants might overcome common problems and develop new approach to tackle public policy issues. In the previous literature, communication was mainly used to define the relationship between top management and agents. In the classical public administration systems, downward communication was more common. However, in the modern administration and financial system, upward communication is more conventional. Faith (2013) believes that the acceptance of the budget decision relies on the proper upward communication, regular meetings with subordinates. Also, the applications of the budget priorities and target setting affected by the behaviors of the top management as well as organization culture.

The upward communication well fits budgetary participation in which gives a citizens' opportunity to share their knowledge and opinion on the budget targets. The effective upward communication in the sense of "game spirit" used by Hofstede (1968) to increase budget motivation and reception of the budget targets. The principal or top management 
in private organization becomes a director or policy makers who represents government in public sector, and agents could be either employees or the citizens who are affected by the decisions.

To measure budget communication Yuen (2004) used power of manager (Fisher et al., 2000), budget variances explanations (Bruns and Waterhouse, 1975; Galbraith, 1977); reward system, relationship between superior and subordinates (Harrison, 1994), peer relationship (Hirst, 1981; Nouri, 1994), and budgetary feedback (Lukka, 1988). However, this study is not intending to use reward system as its more related to the private sector organization. Thus, it has been excluded and other measurements. However, the remaining five measurements proposed by Yuen (2004) used in this study to measure budget communication in capital budgeting process of Kurdistan. Peer relationship is described as the extent of the liaison in which the top management close and cooperate with subordinates. It also relates to the sharing information between superiors and agents regarding budget activities and variances in order to solve common problem without making complicated environment for blaming and criticism, but more likely to complement each other and maintain good performances (Yuen, 2004). The peers' relationship was also used to measure budgetary communication by Nouri (1994). He showed that a strong peer relationship contributes in minimizing the inclination to generate budgetary slack. However, a poor relationship will have a reverse impacts on the budgeting process. Hirst (1981) has found that a hostile relationship causes uncertainty and tensions in the budgeting process. The extent of the relationship between superior and subordinates is very essential to create a harmonious environment to obtain common 
goals. To practice this relationship, its suggested by Yuen (2004) to use "consultationlike" approach. The policy makers in public budgeting process needs to consult their citizens and expertise regarding their needs, preferences and the budget related issues. If there is a good relationship, all together may attain common goals and consider reasonable mistakes. The power of managers on the other hand is important as it can change the direction of the budget plans. Policy makers can play a positive role if they involve in the budgeting process. They can influence on the budget setting decisions through the use of negotiation with others. So, if the policy makers negotiate budget alternatives among themselves, it might improve budget decision. When a problem arises during budgeting process, it's very important for the top management to communicate and explain unfavorable variances in order to overcome the issues and perform a better budget. The other measurement used was budgetary feedback. Participants in the budgeting process are more likely to participate in the process where they receive feedbacks. It has been argued by Yuen (2004) that superiors and subordinates should be clear toward each other and offering feedbacks concerning the extent in which their efforts utilized to achieve budget goals. Participants are looking forward to be treated with courtesy and consideration and providing feedbacks will be a need to consider their future participation. This method was also used by Francis-Gladney et al. (2004) who measured budgetary communication in terms of "budgetary participation, budgetary explanations and budgetary feedback.” 


\subsubsection{Information}

Information is a necessary element of public participation where completes other participatory mechanisms. The National Taxpayers Association (2013) defined information as the key principle of public participation in public financial management. In that sense, it could be argued that budget participation without information may have no influence over the capital budgeting process. Also, citizens need to know why they are participating, and what would be their influence? Do they have adequate information over policy alternatives? Or they just participate without knowledge. This independent variable was derived from previous literature about participatory budgeting and new public management theory. In new public management theory, transparency is seen as important component of decision making process. Also, without adequate information it might be very difficult to maintain budgetary participation. To measure information, this study has used a framework that was developed by the International Monetary Fund (IMF). The measurements concentrated on four aspects of information disclosure including "clarity of roles and responsibility, public availability of information, open budget preparation, execution, reporting, and assurance of integrity" (Oliver, 2004, p. 5). In order to understand if the system is open for people or not, its required to establish understanding whether the roles and responsibilities are clearly defined or not. To do that necessary information should be provided by the government to public regarding budget activities

and progress. It's also essential to measure the extent of openness in the preparation of capital budget. Lastly, to decide on the openness of the system, the government made up to provide budget reports on the entire process to fulfill IMF measures that was used. 


\subsubsection{Dependent Variable}

This section discusses the construct of the dependent variable along with the measurements used.

\subsubsection{Capital Budgeting process}

Capital budgeting process also known as capital budgeting decision is the allocation of capital into physical assets and projects. The capital budgeting process associated to everyone's daily lives without exclusion of any social groups. Accordingly, citizens have rights to engage in capital expenditure related decisions. This study examines the relationship between public participation as independent variable and capital budgeting process as dependent variable. The relationship between the two variables has been subject of research, especially in Latin America. According to the World Bank (2015b), PB is usually about the capital investment budget where community members embracing deliberation, setting budget plans and influence the performance of the overall process. Martian (2013, p. 2) operationalized Capital budget process as an action to plan and decided on the government physical assets and financing investment projects in accordance to the selected priorities. Capital budgeting decisions identifies the method of financing physical projects and service. It also indicates how funds to be committed to the projects in order to deliver better services to citizens. The key objective of capital budgeting process is to assist policy makers to be informed on the methods of priority setting and public needs through the engagement of citizens (Institute for Local Government, 2014). 
To measure capital budgeting process, Putra (2009) identified two fundamental categories includes "preference decision" and "screening decisions." Preference decision relates to the selection of projects and policies defined in the budget proposal after evaluating the expected costs, quality, and time. A screening decision on the other hand relates to the level of public satisfaction or determining whether services are delivered by stakeholders as its planned or not. The two categories are significant to understand the outcome of capital budgeting process.

In this study, capital budgeting process has been used as dependent variable. Under capital budgeting process, there are three key elements that all together determine and measure the performance of capital budgeting process. The first element is public preferences studied by Dryzek and Christian, (2003); Novy and Leubolt (2005); Aragones \& SanchezPages (2009); Qi, (2010); Bland (2011). Secondly, public satisfaction studied by Yankelovic (1991); Nicholas and Rest (1999); Sale, Stafford and Davis (2007, p. 14); Wouters, Hardie-Boys \& Wilson (2011); Timmons and Gorfias (2014). Thirdly, public service delivery studied by Heller (2001); Schneider and Goldfrank (2002); Francis and James (2003); Brautigam (2003); Evans (2004); Wambler and Anderson et al (2009); Aragones and Sanchez-Pages (2009); Boulding and Wampler (2010); Boulding (2010); Goldfrank (2011); Speer (2012); Abom (2004); and Peers (2012). These elements have been used by the aforementioned scholars to determine how capital budgeting process influenced by participatory mechanisms. 
Heisinger and Hoyle (2012) provided comprehensive understanding of the capital budgeting decisions. They maintained capital budgeting decisions is a range of techniques that helps policy makers to decide on the best kind of project and services for the purpose of fulfilling stakeholders wants. Since the budget has a limit, projects and services must compete to be prioritized. Competing here means projects should be listed and policy makers in collaboration with citizens determine the most cost variant projects. The most cost variant projects should be funded (Heisinger \& Hoyle, 2012). This technique helps to deliver sufficient public services as stakeholders mutually understand the essence of their contribution and collectively prioritize the most needed projects. Citizens are giving their preferences of the best policy choices that expected to deliver best services to the citizens.
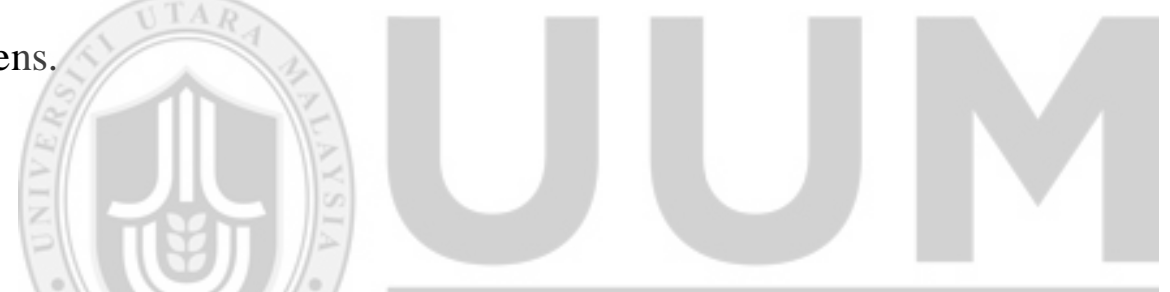

The previous studies have shown PB shift citizens' preference from one service turnover to another. For instance, a study conducted by Aves (2014) to explore the influence of PB on the expenditure of Brazilian municipalities. He found that citizens selected services that represent their needs such as health care and sanitation. Since 1990, sanitation and health care services has increased by 20 percent as citizens realized what is good for them and what services they need to deliver. The shift in the patterns of services was resulted from public meetings and discussions. Consequently, the rate of infant mortality in Brazil has decreased by almost 40 percent. 
Other major technique commonly used to measure capital budget process is public satisfaction. Satisfaction and performance was used as dependent variable under budgeting process in relations to public participation as independent variable. It was also noted that the more participation, creates better conditions for the success of budget activities; consequently, more satisfaction could be attained (Kock, 2007, p. 155). However, this is not always the case, because there are previous studies that addressed negative relationship of public participation on public satisfaction under certain circumstances. For instance, Kweit and Kweit (2007) highlighted that citizen participation is not directly maximizes trust in government. Also, active participation does not mean support to government decisions. Nevertheless, their findings indicate that active citizen participation negatively impacts on the government. This relationship associates to the responsiveness of the officials and feedbacks they receive (Kweit \& Kweit, 2004).

Public satisfaction also demonstrates two important measurements of capital budgeting process including efficiency and return on investment. For instance, Kerr (2008) emphasized that satisfaction brings efficiency and return on investment. In capital budgeting process, the return on investment should be measured. If the cost of citizen's participation is higher than the expected benefits, they will not compromise their future participation. Indeed, if citizens find more benefits than times and efforts they spent, they will be more active in the future programs. 


\subsubsection{Conceptual Framework}

\section{Public Participation}

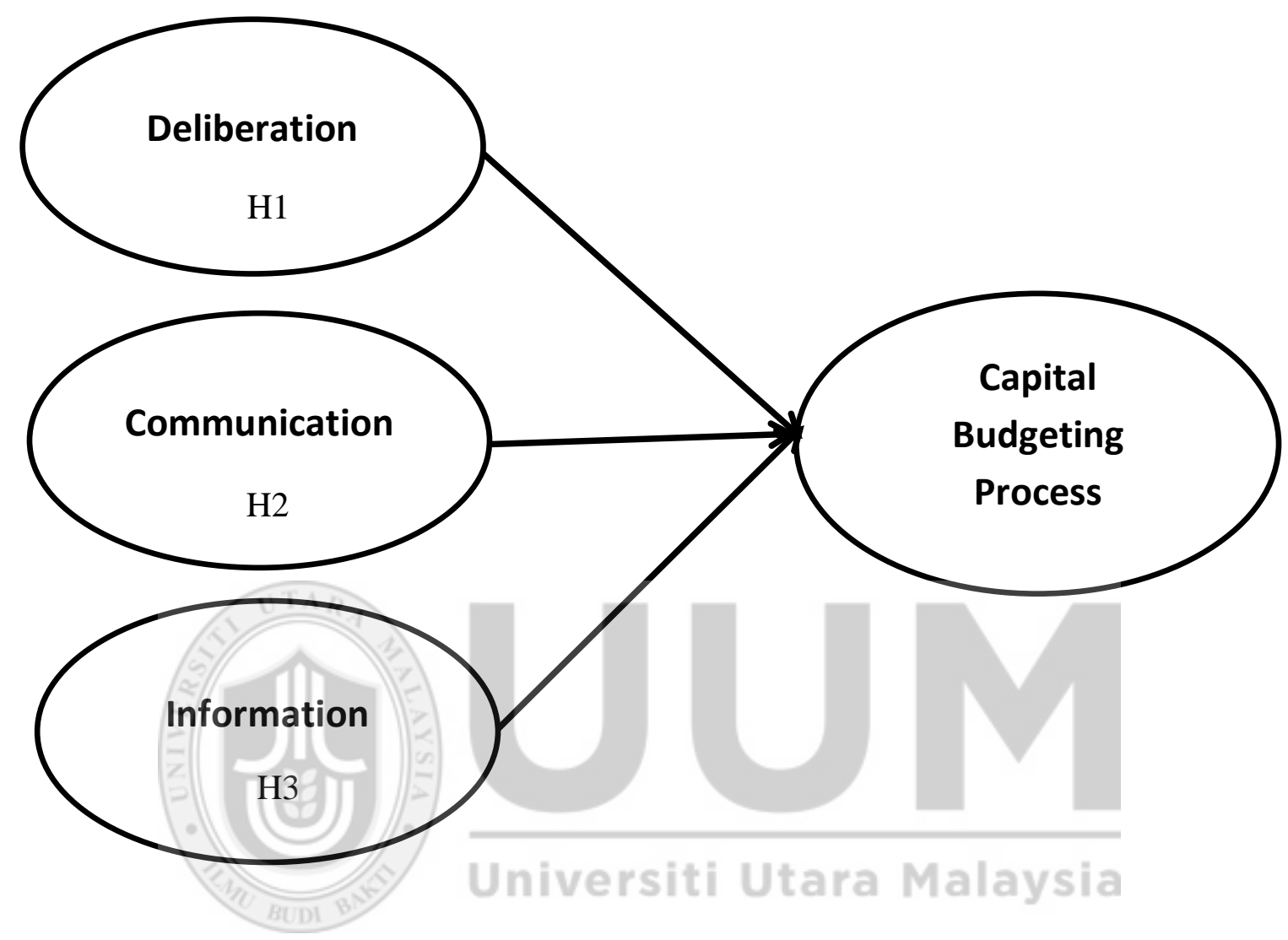

Figure 4.2 Conceptual Framework

\subsection{Hypothesis Development}

In this section, the formulation of the hypothesis has been explained. Also, a direct relationship between independent variables and dependent variable has been designed based on the research model. This relationship hypothesized into three different hypotheses to fulfill research objectives. 


\subsubsection{Deliberation}

Deliberation is the form of participation that people becomes a center of decision making process. Gutmann and Thampson (2004) indicated that deliberative democracy concentrates more on planning policy than evaluating policy. This theory relies on the reasons given by ordinary citizens or delegates over their preferences, which automatically change the outcome of the policy (Gutmann \& Thampson, 2004). To elaborate this statement, the example of "Oregon Health Services Commission" was given where several alternatives ranked by participants to be funded in the commission budget. Consequently, the commission achieved better outcomes compare to previous budgets. The commission also received less complainant and critics as citizens directly participated in the process of priority setting. The essence of deliberative democracy was previously examined by Dryzek (200), Gastil and Levine (2005). They found that deliberation enlightens citizens towards more democratic citizenry which ultimately increases governance by the people. This process also eliminates elite rules inside government if individual participants are autonomous and well informed about the details of the decisions (Jacobs, Cook \& Carpini, 2009).

There are some other studies identified the outcome of deliberation in public policy making process. However, the studies about deliberation were mostly associated to politics and democracy. Most of these studies came out with positive outcome of public deliberation on public policy decision as Patmen (1970); Habermas (1989); Burkhalter, Gastil, and Kelshaw (2002); Munno and Nabatchi (2014); Karpowitz and Mendelberg, (2011, p.3). Controversy, not all results are positive, but some authors has found no 
relationship or negative relationship between deliberation and decision making process. For instance, Morrell (1999) concluded that deliberation has no relationship with collective decisions. He also found deliberation does not have any influence over satisfaction. Unlike aforementioned findings, Karpowitz (2006) emphasized that conditional deliberation has a positive significant relationship to the decisions. Conditional deliberation is the level of knowledge possessed by each participant over deliberation process. Here, deliberation has positive influences on the participants' preferences. Thus, participants can lobby city councils at ease. Additionally, the deliberation process shifts participants' mindset, expand their interests, helps to manage conflicts and increases the effectiveness of the decisions. The Effectiveness of deliberative participatory model depends on the dialogue orientated and horizontal relationship between government and community members. This study hypnotized the relationship between deliberation and capital budgeting process as following:

H1: There is a positive relationship between deliberation and capital budgeting process.

\subsubsection{Communication}

Communication is not a prevalent topic in the study of budgeting. Therefore, it's an important technique to be used in decision making process. There are lack of understanding of the essence of budgetary communication in public budgeting process, but there are still some works available in this field. Previously, communication was used as independent, dependent, and intervening variable, mostly in private organizations (Kock, 2007). Abd Rahim (2004) tested the relationship between budget communication as independent variable and budget spending as dependent variable. $\mathrm{He}$ has 
operationalized the definition of budget spending as the type of budget that allocated for non-salary components. Budget spending refers to the capital investment budget that used for physical activities and services (Abd Rahim, 2004). He found a positive relationship between the two variables. He tested the relationship between communication and budget goals; and commitment as intervening variable and he came up with positive significant relationship. In another study by Kock (2007) the level of public participation has been used as independent variable, communication, satisfaction and performance as the dependent variables. Communication also treated as intervening variable and participation as independent. The study concluded that communication increases interaction between principal and agent (Kock, 2007).

In the study about Kenya, Faith (2013) used communication as an item in his survey questionnaire. He asked a question about the influence of budgetary communication and found budget communication between parties that are involved in budget planning, will helps to reduce the waste of financial resources with mean value of 4.21 . The parties that involving in participatory budgeting process, is usually policy makers, civic society organizations, budget expertise and citizens. So, the relationship between communication and public budgeting process could be designed. In another rare study, Yuen (2004) examined the relationship between communication and budget slack. She used communication and reward system as her independent variables in relation to budget slack. She administered a survey to 108 hotel managers in Macau. Her finding obviously identified a positive relationship between communication and budgetary slack. In the other word, she found that when the budget is communicated between those who are 
affected by the decisions, is increasing efficiency of the budget and leads to the clarity of the goals. Also, it deteriorates the complexity of budget targets and shrinks budget slacks. Pemela Reid (2002) in her study about impacts of budget target setting participation on motivation argued that meaningful participation through improved communication should have indirect impact on the budget performance. Habermas also focused on communication and believes that it establishes the rules of participation. He also explained in the theory of communication rationality that the process leads to efficiency, rational choice, and achievement of the goals. The three outcomes are the consequence of instrumental, strategic and communicative action identified by Habermas ( $\mathrm{O}$ 'brien, 2009). In this sense, the second hypothesis formulated and a direct relationship designed between communication and capital budgeting process as following:

H2: There is a positive relationship between communication and capital budgeting process.

4.3.3 Information

The relationship of information to public policy decision was previously tested by several scholars, but the findings are different. Transparency and access to information has been described by Gomez, Insu, and Alfro (2015) as the focal obstacle that still facing public administrators in formulating public policy decision particularly in the budgeting process. According to the World Bank (2015) access to public spending information in PB is necessary to combat corruption, eliminating eliteisism and clintalism, promoting government credibility, enhancing trust on public sector organization (World Bank, 2015). 
Several studies have come out with likely result regarding the relationship between information and decision making process. It has been concluded in the study of Searing et al, (2007) and Michels (2011) that access to public information significantly increases the legitimacy of the policy decision. Transparency maximizes the sense of control by the authorities and it will expand understanding by public as well as decision makers over the decision (NTA, 2013). Simultaneously, there are arguments against disclosure of public information. Sometimes decision makers need to close and limit access to public information to maintain their works without interruption (Licht, 2013). However, the relationship between information disclosure and policy making process could be different based on sectors.

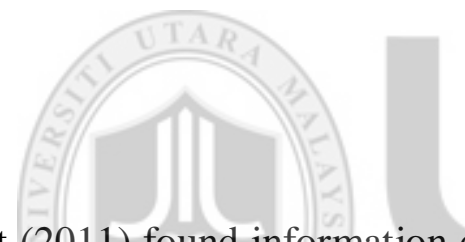

Licht (2011) found information disclosure negatively relates to the decision making and trust over health care programs. He argued that when citizens access to information; they prioritize services in particular sector which are costly for the government to fund. The health programs could be very costly; sometimes, the government incapable to what citizens prefer in this sector. Therefore, in participatory budgeting programs, health sector is one of the popular sectors that citizens choose as budget priority. If government accepts what public prefers, the remained budget will not be adequate to provide services in other sectors. However, if government avoids sectors that citizens really do not appreciate, results in mistrust on the government and the illegitimacy of decisions (Licht, 2013, p. 4). Additionally, Grimmelikhuijsen (2010) believes that access to information disappoints citizens toward authorities and the way decision is made. Controversy, the same author tested information in other policy areas and found positive relationship between 
transparency, culture and leisure policy (Licht, 2013, p. 11). The result also shows that citizens in open information system are more likely to accept decisions compare to the closed systems. Lastly, Meijer (2009b) found neither positive nor negative relationship between information disclosure and decision making process. Accordingly, the third hypothesis formulated as following:

H3: Accesses to budget information can positively impacts on the capital budgeting process.

\subsubsection{Research Hypothesis}

Hypothesis 1: There is a positive relationship between deliberation and capital budgeting process.

Hypothesis 2: There is a positive relationship between communication and capital budgeting process.

Hypothesis 3: Accesses to budget information can positively impacts on the capital budgeting process.

\subsection{Research Design}

Research design is the plan of the study. It discusses techniques used in conducting this study. This research employs exploratory research design to define the problems that are unveiled clearly. This type of research is important to be employed in order to identify the reasons behind the lack of public participation in the Kurdistan's budgeting process 
and its impacts on the overall development of the governing system. Moreover, this study generates data through the use of mixed method research design.

\subsubsection{Mixed Method}

Mixed method research design used in this study which described as the combination of qualitative and quantitative approaches. This method is widely used by researchers to study different aspects of the research. Mixed methods defined as the combination of qualitative and quantitative methods to "legitimate the use of multiple approaches in answering research questions, rather than restricting or constraining researchers' choices

(Johnson \& Onwuegbuzie, 2004, p. 17-18). It's an expansive and creative form of research, not a limiting form of research.

This method is more reliable and does not limit the researcher to include any parties and methods to provide proper answer to the research questions. As explained by Creswell (2006, p. 9-10) mixed method helps researcher to use any kinds of data that relevant to the field without any restriction of the kind of methods. More clearly, using this method in this research will help to address the research question that can not be answered by either model. In this study, adequate answer could not be achieved without the use of mixed method. Obviously, policy makers and MPs are more interested in the interview than any qualitative methods. Officials in Kurdistan may prefer to answer research questions through interview not questionnaires. If this research only focused on the citizens, the results could be biased and would not represent the whole citizens. This 
model is more relevant to address research problems. By combining inductive and deductive thinking; a better solution could be addressed. For the reasons discussed above, both qualitative and quantitative methods used to obtain relevant data.

\subsection{Pilot Study}

Pilot study is defined as the small scale study conducted prior to the collection of the main data which aims to identify the consistency, randomization, and any issues to be corrected prior to the conduction of the full scale of the research (Whitehead, Benjamin \& Campbell, 2014). Pilot study helps to test research procedure, reliability and validity, and

sample size calculation (Arain et al. 2010). To test validity and reliability of this study and curtail the future challenges and errors, a pilot study was conducted to confirm if the items and instruments are on the right track. The aim of this study was to take 10 percent of population as pilot sample size. Accordingly, 40 questionnaires were distributed in the first stage, and 31 returned. For that, 7 more questionnaires distributed in the second stage to target 10 percent of the total population. Overall, 38 questionnaires returned. The pilot study was conducted in Erbil, the capital of Kurdistan Region.

\subsubsection{Reliability and Validity}

Reliability and validity are major elements of research that assist researcher to measure and weigh instruments. Reliability and validity of the study gives a credit to the findings. It assists researchers to unbiased and designs questions that are clear and comprehensive for the respondents (Foddy, 1994). 
Validity concerns with the measurement of the instrument, but reliability is more concern with consistency of the measures. In this study, content validity has been used to perform reliability test before distributing questionnaires for the pilot study. Babbie (2004) defined content validity as the degree of embracing instrument to the particular concept. It also helps to ensure that items are adequately and well represented (Sekaran \& Bougie, 2013).

Validity test certifies that the concepts and dimensions have been explained adequately. For the purpose of this study, the questionnaire reviewed by three senior lecturers. After revision and correcting the errors, the questionnaires translated from English to Kurdish. The Kurdish version of the questionnaire reviewed by assistant lecturer and a Kurdish language instructor to ensure the clarity of the language and easy to understand. In the pilot study, respondents were asked to provide any comments and suggestions to improve the questionnaire; or to provide any concerns, confusion, and misunderstanding.

Reliability on the other hand is defined as the level of measurement consistency in different period of times for various items (Sekaran \& Bougie, 2013, p.228). It also explained as the extent of the measurement without errors or biases. To measure internal consistency and ensure that instruments are free of errors, internal reliability test performed which is also known as "internal consistency" (Sekaran \& Bougie, 2013). The reliability analysis was performed through IBM SPSS Statistics 20, by using Cronbach's Alpha. 
Cronbach's alpha is the most popular instrument to measure reliability (Tavkol et al, 2011). It was first developed in 1951 by Lee Cronbach's Alpha and then widely used to measure "internal consistency of a test or scale." Internal consistency determines the homogeneity of the items (Sekaran \& Bougie, 2013, p.229; Tavkol et al. 2014, p.54). In Cronbach's Alpha, there are different numerical values. However, in most studies, the accepted value is ranged from 0.70 to 0.95 (Tavakol \& Dennick, 2011; Hair et al, 1998). This value indicates consistency and stability of the instruments and indicating that items are "hang together as a set." The value of Cronbach's Alpha for all variables in the pilot study higher than 0.7. Separately, Cronbach's Alpha for Deliberation was 0.836, communication 0.808 , information 0.884 , and lastly for capital budgeting process was 0.889. Based on this result, the items are consistent and approved (See Table 4.1).

Table 4.1

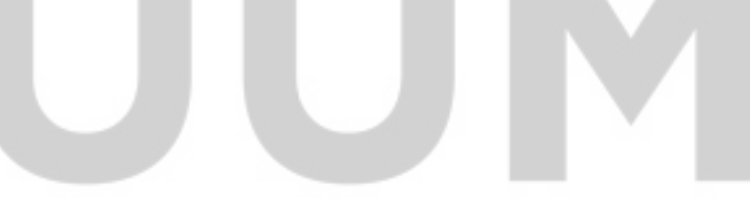

Reliability Analysis of Pilot Study

\begin{tabular}{lll}
\hline Construct & N. of Items & Cronbach's Alpha \\
\hline Deliberation & 10 & .836 \\
Communication & 9 & .808 \\
Information & 8 & .884 \\
Capital budgeting Process & 16 & .889 \\
\hline
\end{tabular}




\subsection{Population and Sampling}

Population and sampling is the process in which a group of people is selected to represent the wider population in forms of statistical analysis. In this study, systematic sampling was used and participants selected randomly within the wider population. Systematic sampling is defined as the method in which the first unit is selected randomly and the rest of the population follows based on predetermined pattern (Singh \& Mangat, 1996). Its equivalent to the simple random sampling if the units are numbered randomly (Barreiro \& Albandoz, 2001). This type of sampling is commonly applied in research and considered to be convenient alternate to simple random sampling. This sampling method is very resourceful to attain favorable stratification effects and it's not subjected to any restriction of the number of supporting variables and presents a greater balance into the sample (Zhang, 2008). This sampling method can be used easily and conclude the sample units to the entire population (Barreiro \& Albandoz, 2001). This method is more inclusive to hand out survey questionnaires to the ordinary-citizens of Kurdistan Region without restriction to the unit of analysis.

The target population in this study divided into categories. The first category was ordinary citizens. Citizens selected from all sectors of society and representative of different social groups included. The term of ordinary citizens applicable to the people who understand the questionnaire. Means, not everybody on the street understand the process of budgeting. The questions were mainly distributed in the universities, government departments, hospitals, schools, municipalities, banks, Economists Syndicate, Sulaimaniyah court, youth centers, coffees and many other places. 
The second category was different from the first category which was questionnaires respondents due to their position understanding of the issues of the second category. The semi-structured face to face interview was implied in the qualitative part of this study. Harrell and Bradley (2009) distinguished between unstructured interview, semi structured interviews and structured interviews. In unstructured interview, the conversation is free flowing and the researcher has a least control on the course of the discussion and answers provided by the respondent. Also, the discussion might go to different direction. However, semi-structured interview mainly applied when the researcher tries to investigate the topic deeply and tries to further understand the issues through answers provided by the interviewees. This method helps the research to achieve a consistent and complete information from different interviewees. Therefore, the questions of the structured interviews are designed before the interview starts with the same order. The same questions might be asked to the different respondents to obtain different answers on the matching topic. However, this research found the second method more applicable to this study.

Semi- structured interviews as explained by Harrell and Bradley (2009) are frequently used in policy research. This study is more relates to public policy and that makes this method well fit the research. Also, several questions are prepared but not limited further questions. Through the conversation, more questions generated. The interview participants were mainly elites such as parliament members, policy makers and professionals. Applying this method was to ensure accuracy, balance and inclusion of the targeted population. Usually, elites are more interested to be interviewed rather than just 
simply answer the survey questions. Also, through conversation the scope of understanding and knowledge on the topic expanded. Apart from that, the study was unable to generate a complete answer to the research questions and problems through survey. This method helped to provide adequate answers to the research questions especially the first questions that tries to identify the limitation of public deliberation in public budgeting process of Kurdistan.

Finally, the size of the sampling is different for survey questionnaires and the interviews. For the survey, the study intended to reach the number of the respondent into 384 . To do so, 465 questionnaires distributed and 402 were returned. In this number, 387 questionnaires treated valid in the final analysis. The threshold of 384 was not randomly decided, but it was in accordance to the previous studies by Payne and McMorris (1967). The authors categorized the sample size based on the number of population in each particular study as shown in Table 4.2.

This study has used systematic sampling and questionnaires distributed on ordinary citizens. Ordinary citizens could be the majority of the country population who are affected by the budget decisions. Also, this study did not count individuals who are under 18 years old age as part of the study. According to the Kurdistan Government Official statistics, the total population of Kurdistan Region is 5.2 million. Majority of Kurdistan population are aged below 20 years with almost 50 percent (KRG, 2016). In total 35 percent of the population are aged below 14 years and only 4 percent aged over 60 years. 
Accordingly, if the total population is 5.2 million and half of the population is under 20 years old, then the remaining citizens will be 2.6 million. In this number, it's possible that part of them do not have certificate and any information about budget. According to the KRG official data, almost 26 percent of the population are illiterate (KRG BOI, 2016). The 26 percent of the remaining 2.6 million population becomes 1850,000 . If 60 percent of the population understand budgeting process, then the number of valid population becomes 1.11 million. According to Payne and McMorris (1067), if the number of population $(\mathrm{N})$ is between 1-10 million, the sample size becomes 384. Accordingly, my sample size $(\mathrm{S})$ becomes 384 since population $(\mathrm{N})$ is 1.11 million.
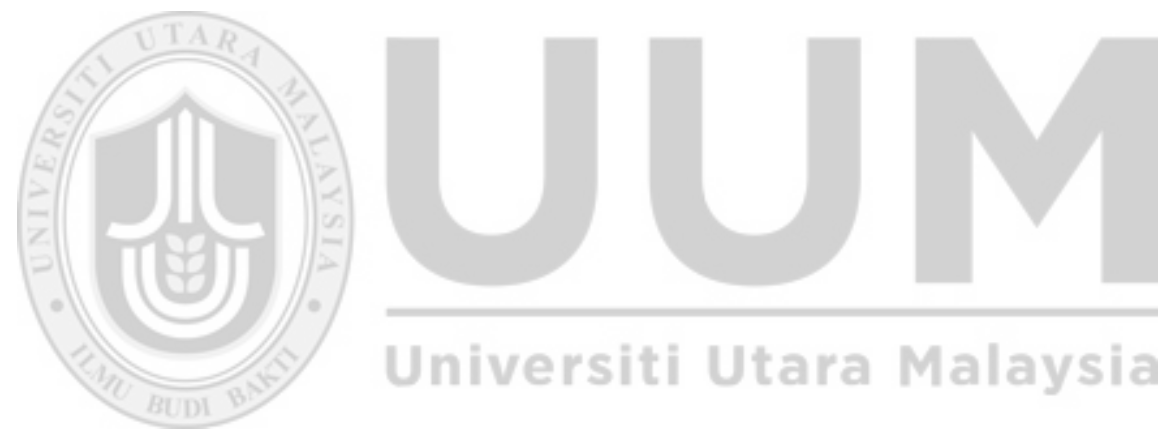
Table: 4.2

Sample Size

(Confidence level 95\%; Margin of error + or $-5 \%$ )

$\mathrm{N}=$ Population $\quad \mathrm{S}=$ Sample

\begin{tabular}{|c|c|c|c|c|c|}
\hline $\mathbf{N}$ & $\mathbf{S}$ & $\mathbf{N}$ & $\mathbf{S}$ & $\mathbf{N}$ & $\mathbf{S}$ \\
\hline 10 & 10 & 220 & 140 & 1,200 & 291 \\
\hline 15 & 14 & 230 & 144 & 1,300 & 297 \\
\hline 20 & 19 & 240 & 148 & 1,400 & 302 \\
\hline 25 & 24 & 250 & 152 & 1,500 & 308 \\
\hline 30 & 28 & 260 & 155 & 1,600 & 310 \\
\hline 35 & 32 & 270 & 159 & 1,700 & 313 \\
\hline 40 & 36 & 280 & 162 & 1,800 & 317 \\
\hline 45 & 40 & 290 & 165 & 1,900 & 320 \\
\hline 50 & 44 & 300 & 169 & 2,000 & 322 \\
\hline 55 & 48 & 320 & 175 & 2,200 & 327 \\
\hline 60 & 52 & 340 & 181 & 2,400 & 331 \\
\hline 65 & 56 & 360 & 186 & 2,600 & 335 \\
\hline 70 & 59 & 380 & 191 & 2,800 & 338 \\
\hline 75 & 63 & 400 & 196 & 3,000 & 341 \\
\hline 80 & 66 & 420 & 201 & 3,500 & 346 \\
\hline 85 & 70 & 440 & 205 & 4,000 & 351 \\
\hline 90 & 73 & 460 & 210 & 4,500 & 354 \\
\hline 95 & 76 & 480 & 214 & 5,000 & 357 \\
\hline 100 & 80 & 500 & 217 & 6,000 & 361 \\
\hline 110 & 86 & 550 & 226 & 7,000 & 364 \\
\hline 120 & 92 & 600 & 234 & 8,000 & 367 \\
\hline 130 & 97 & 650 & 242 & 9,000 & 368 \\
\hline 140 & 103 & 700 & 248 & 10,000 & 370 \\
\hline 150 & 108 & 750 & 254 & 15,000 & 375 \\
\hline 160 & 113 & 800 & 260 & 20,000 & 377 \\
\hline 170 & 118 & 850 & 265 & 30,000 & 379 \\
\hline 180 & 123 & 900 & 269 & 40,000 & 380 \\
\hline 190 & 127 & 950 & 274 & 50,000 & 381 \\
\hline 200 & 132 & 1,000 & 278 & 75,000 & 382 \\
\hline \multirow[t]{3}{*}{210} & 136 & 1,100 & 285 & 100,000 & 384 \\
\hline & & & & $1,000,000$ & 384 \\
\hline & & & & $10,000,000$ & 384 \\
\hline
\end{tabular}

Adopted from Payne \& McMorris (1967)

The second category was interview, which is smaller than questioners. According to

Bertaux (1981, p. 35) minimum of 15 participants needed for interview. However, Atran, 
Medin, and Ross (2005) suggested minimum 10 respondents. This study used mix method research design and that allows the smaller sample size as discussed by Bertaux (1981). Similarly, the minimum 10 respondents recommended by other scholars. Accordingly, the study has chosen 11 interview respondents. It does not violate the recommended number suggested by Atran, Medin, and Ross (2005).

\subsection{Data Collection Procedures}

The mixed method used as an explanatory research design to explain the implication of the role and impacts of public participation in the public budgeting process of Kurdistan. Through questionnaire and interviews, the study addressed research problems and tested the all the hypothesis.

\subsubsection{Interview}

The interview is defined as the systematic way of talking to collect data for the purpose of obtaining knowledge and information. Kvale (1996) defined interview as "interchange of views between two or more people on topics of mutual interest, sees the centrality of human interaction for knowledge production, and emphasizes the social status of research data." Interviews could be different and methods that are used depend upon the type of interview which classified into four type structured interviews, semi-structured interviews, unstructured interviews, non-directive interview. Interview could be telephone interview, social media networks interview, email interview, face-to-face interview and etc. The questions could be open-ended questions with no restrictions on 
the respondent's answer or closed ended with the respondent having a limited range of responds.

Total of 11 interviews conducted and 10 of them recorded through the use of modern voice recorder. However, ten out of eleven participants interviewed personally in forms of face to face interview. One interview was conducted by email as a participant was not ready his voice to be recorded. Regarding the techniques and ethical concerns, the purpose of the interview was explained before starting the interview. The term of confidentiality was also addressed at the beginning of each interview. They were also asked and informed about the length of the interview. This method was supportive because they knew how long they have to sit and answer interview questions. The interviews were conducted in Kurdish. Interviewees were given a chance to use the language which they were able to answer the questions and express themselves properly. Almost all participants used to speak in Kurdish.

\subsubsection{Questionnaires}

A questionnaire is a common method of data collection mainly in quantitative and mixed method research. In this method, a set of written questions prepared for the respondents. Questionnaires could be distributed personally, mailed or to be distributed electronically through email or other electronic tools (Sekaran, 2003, p.236). The survey questions administered personally and respondents were given an adequate time to answer. Some of them were given almost a week to answer especially those who stayed in Erbil. The confidentiality of the respondents was measured. 


\subsubsection{Survey Design}

The survey questions adopted from the Literature and theories that were previously discussed. The questions are designed in the logical way to identify and confirm the problems that discussed in the statement of the problems. Then, it related to the process of public participation and determine the outcome of the budgeting process in the absence or lack of public participation. Also, the outcome of participatory process and implications of deliberation, communication and information on the overall process of capital budgeting process asked. In the other words, the questions are designed to identify the problem, to identify the cause of the problems, to explain the consequences of the problems and provide solutions mainly through participatory budgeting mechanism to better perform capital budget and improving KRG budgeting system. For deliberation, the study linked but not limited to the Discourse Quality Index (DQI), type one measurement which mainly focuses on the rational discourse in deliberation. This measurement was introduced by Steiner et al. (2004) and Bachtiger et al. (2009). These are also discussed in the preliminary elements of public deliberation in Literature Review and research construct. The questions of the second variable which is communication, linked to the theory of communication rationality. Some other authors also used good communication in their study against successful budgeting decision. Therefore, good communication could be different based on the conditions and environments. Additionally, some measurements of Yuen (2004) explained in research construct used to form some of the questions. The information on the other hand was measured and designed based on four key principles that was provided by the International Monetary Fund (IMF) to measure information disclosure and transparency in public budgeting process includes "clarity of 
roles and responsibility, public availability of information, open budget preparation, execution, reporting, and assurance of integrity" (Oliver, 2004, p. 5).

Apart from the IMF four principles, the questions also used previous literature for creating a list of questions to better understand information disclosure situation in Kurdistan public budget. Lastly, the questions of the dependent variable (capital budgeting process) was designed based on Putra (2009) who has identified two fundamental categories of capital budgeting process includes "preference decision" and "screening decisions." The two categories are significant to understand the outcome of capital budgeting process. Also, other measurements which is again consistent with Putra (2009) categories used to measure capital budgeting including the return on investment, public service delivery and public needs satisfaction. So, based on the theories, measurements, previous studies and the nature of the problems, the instrumentations has been designed. In some cases, direct questions asked in order to simply identify whether there is deliberation, communication and information in capital budgeting process of Kurdistan or not. Also, some direct questions were asked to find out whether citizens are satisfied with the level and quality of services they receive in order to measure the effectiveness of public expenditure and relate it to public participation. This method was also used by Jaramillo and Wright (2009) to measure the extent of participatory fora in Peru budgeting process. They asserted that they used a direct questions and simply asked municipal officials whether there is public participation or not. Same questions were asked civil society organization to understand and measure participation in Peruvian public budget. As questionnaire first designed and the five point Likert scale ranged from "strongly disagree" to "strongly agree" employed. 
The pilot test conducted to measure the reliability of the instruments. Also, the questions were reviewed by the Kurdish language instructors and a lecturer in order to be clear and comprehensible for the respondents and avoid any misunderstanding.

\subsubsection{Explanatory Sequential Design}

This study employed mixed method explanatory sequential design. This method encompasses of two different stages in which quantitative method followed by qualitative (Creswell et al. 2003). In the other words, the quantitative data which is mostly in a numerical form is collected and analyzed, then the qualitative data which is in the form of text follows (Ivankova, Creswell, and Stick, 2006). In this approach quantitative data were collected and analyzed in the first stage. As the goal of the first stage targeted, the second stage followed, which was qualitative data collection and analysis. This method is sought to be supportive in interpreting initial survey results (Creswell \& Clark, 2011, p.72). The study implied questionnaire initially and followed up by the interviews. Conducting survey prior to interview is because survey is considered more confidential and participants may answer questionnaires without any hesitation. The result of the survey was an important tool to structure interview questions. Creswell and Clark (2011, p.67) indicated that explanatory sequential design helps to shape data collection procedures in the second stage as questions and participants will be specified and instruments of data collection established. They believe that explanatory sequential design preserves consistency of the study and reliability of the responses. This method also provides an in depth understanding of the research problem (Ivankova, Creswell, and Stick, 2006). One of the other key advantages of this method as explained by Morse 
(1991) is to deal with unexpected results ascends from the qualitative study. Interview respondents are sometime hide information and provide a tricky answer to the questions, other than providing an honest and straightforward answers. It might be related to the positions of the interviewees especially when they are holding a high government positions. However, with the availability of data collected through survey, they will be more likely to provide true answers.

\subsection{Data Analysis}

The data obtained in this research analyzed and examined through the use of Tables, charts, figures. This study utilized statistical software named "Statistical Package for the Social Sciences" (SPSS), version 20 and 22, Nvivo, as well as Microsoft Office Excel to analyze data collected. The quantitative data were first keyed into the excel sheet and then transferred to SPSS for analysis. The instruments have been coded and given deliberation (D), communication (C), information (I), and capital budgeting process (CB) to be analyzed through Statistical Package for Social Sciences (SPSS). Then, the data was analyzed. The first step of analysis started with data screening and detection of the possible outliers. After outliers removed, the frequency distribution of the respondents was analyzed and followed by then normality and reliability of the instrument. The Person's Correlation Coefficient used to measure the strength of the relationship between public participation approaches and capital budgeting process. Also, the hypothesis tested through Person's Correlation Coefficient. The Linear Regression Analysis used to predict the capital budgeting process through independent variable. 
The qualitative data was first transcript and translated into English. The transcription is the transformation of spoken language into text. Interview transcription could be done in several different ways including selective protocol, comprehensive protocol, clean read or smooth verbatim transcript, pure verbatim protocol, protocol with special characters, protocol with comment column (Philipp, 2014). In this study, the pure verbatim protocol used for 10 interviews. This method is described as the word by word transcription without even excluding the utterances and too close to the natural language used in the interview. For a single interview, the selective protocol used. In the selective protocol the researcher takes the relevant part of the interview which relates to the research questions and covers the important parts of the research (Philipp, 2014). However, the entire parts of the interyiews will not be transcript. Thus, only the relevant content has been transcript, translated, nodded, coded and then analyzed. The translated transcripts were first nodded and then coded through Nvivo. Nvivo is a commonly used computer application for qualitative data analysis. After the completion of the coding, the important words and contents of the interviews have been analyzed manually. The qualitative content analysis applied in this study which is the most commonly used method of qualitative data analyses to interpret the meaning of the interviews (Schreier, 2012). The qualitative content analysis consists of three main approaches: directed content analysis, conventional content analysis, and summative content analysis. The study used summative content analysis which starts with identifying important contents and words in order to comprehend the contextual use of the text and it goes beyond that to latent content analysis. Latent content analysis allows the research to interpret the data to the content (Hsieh \& Shannon, 2006; Holsti, 1969). However, despite the different uses of the 
approaches of content analysis, this method of analysis requires to fulfill seven steps including the formulation of the research question so as to be responded, sample selection for analysis, categorical definition to be used in the study, the codes to be processed and the coder training to be outlined, the implementation of the coding process, trustworthy determination, and finally analyzing the outcome of the coding process (Hsieh \& Shannon, 2006; Emmert \& Barker, 1990).

The most significant step of the content analysis is coding process which organize the large amount of the text into much fewer content categories (Hsieh \& Shannon, 2006; Weber, 1990). Through content analysis the researcher is also organizes data that has been coded into categories which is known as coding scheme (Hsieh \& Shannon, 2006; Poole \& Folger, 1981). That has facilitated the qualitative data analysis process of this study and the large quantity of the transcripts has been lessen into fewer content categories.

\subsection{Chapter Summary}

This chapter discussed the theories that were used in this research. The chapter also conceptualized how the research model constructed. The study explained mixed method research design that was used in this study as inclusive and accurate method. The sample size of 465 selected for the survey and 11 respondents participated in the interview. The obtained quantitative data analyzed through SPSS, and qualitative data analyzed through Nvivo and manual analysis. 


\section{CHAPTER V}

\section{QUANTITATIVE FINDINGS}

\subsection{Introduction}

This chapter shows the result of quantitative data analysis. The data has been collected in Erbil, Sulaimaniyah and Duhok. Systematic sampling method was used. The target population was citizens with minimum high school certificate in order to ensure that respondents qualified and capable of understanding questions.

\subsection{Primary Data Collection}

The total questionnaires distributed were 465 to target recommended sample size of 384 (see figure 4.3). Almost 402 out of 465 questionnaires returned and 63 questionnaires were not returned. As a result, the response rate becomes 86.45 percent. There were 4 other questionnaires that were not filled up properly and removed from the data set along with 11 outlier cases in the first stage as shown in figure 5.1. The overall response rate was 81 percent and 377 questionnaires remained as part of the analysis. The questionnaires distributed and then collected from public servants and officials in the MoP, Sulaimaniyah Municipality, University of Sulaimaniyah, University of Duhok, University of Kurdistan-Hewler, American University in Sulaimaniyah, University of Soran, University of Koya, Kurdistan Board for Medical Specialty, Kurdistan Hospital in Erbil, Raniya Municipality, Kurdistan 
Economist Syndicate, Branches of Kurdistan Democratic Party, Change Movement Headquarter in Erbil, three high schools in Erbil, Sulaimaniyah Court. Some questionnaires were individually distributed in the youth centers, cafes, libraries and public places.

\subsection{Demographic Distribution}

Demographic distribution statistic used to determine the background of the respondents. The survey embraces five items (see appendix A) represents the "Background of the Respondents" including age, gender, occupation, education and governorate. 2 items including gender and governorate have 100 percent validity; however, 6 cases were missing for occupation, 2 cases for education and only 1 respondent didn't reveal his age. The following Table shows the descriptive statistic for the overall population. Respondents were asked to provide their background information including age, gender, occupation, level of education, and the governorate.

Table 5.1

Summary of the Respondents Profile

\begin{tabular}{lccccc}
\hline & Age & Gender & Occupation & Education & Governorate \\
\hline Valid & 376 & 377 & 371 & 375 & 387 \\
No Respond & 1 & 0 & 6 & 2 & 0 \\
\hline
\end{tabular}




\subsubsection{Frequency Distribution of Age}

The frequency distribution of respondents for age has been classified into three categories. In the first category respondents ranged in age from 18 to 25 years. The frequency distribution for this category was 108 with percentage of 28.6 percent. Most of the participants were aged between 26 to 46 years old. This category (shown in Table 5.2) has a frequency distribution of 223 with percentage of 59.2 percent. That means the majority of the respondents' age falls into the 26 to 45 years' age range. The reason for high frequency rate in this category of age relates to the fact that young people in Kurdistan make up a majority of the population. However, only 44 were aged above 45 years with 11.7 percent. Overall, there was a missing data with 0.6 percent, the rest of the cases were valid.

Table 5.2

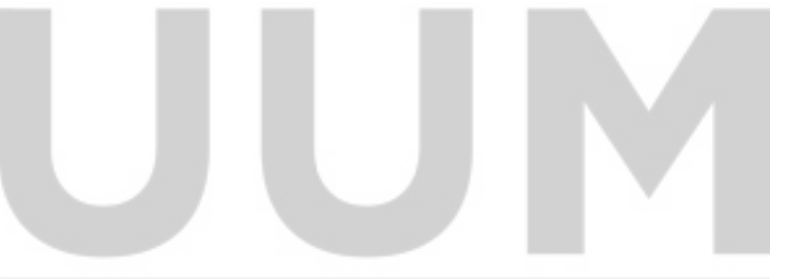

Frequency Distribution of Age

\begin{tabular}{lcr}
\hline Age & Number & Percent \\
\hline Between $18-25$ years & 108 & 28.6 \\
Between 26 - 45 years & 223 & 59.2 \\
Above 45 years & 44 & 11.7 \\
No Respond & 1 & .6 \\
Total & 377 & 100.0 \\
\hline
\end{tabular}

\subsubsection{Frequency distribution of Gender}

To obtain a better result, the research tried to be more inclusive in terms of gender distribution. The frequency distribution of male respondents was 237 with percentage of 62.9 percent. However, the frequency distribution of female respondents was 140 with 
percentage of 37.1 percent. All cases for this item were valid and there were no missing data.

Table 5.3

Frequency Distribution of Gender

\begin{tabular}{lcr}
\hline Genders & Number & Percent \\
\hline Male & 237 & 62.9 \\
Female & 140 & 37.1 \\
Total & 377 & 100.0 \\
\hline
\end{tabular}

\subsubsection{Frequency Distribution of Occupation}

In the background section of the questionnaire, respondents were asked to choose their occupation category. They were given five choices, namely government employee, private sector employee, students, not employed and other. For others, they were asked to specify. In the total of 377 respondents, 249 of them fall around government employee category with percentage of 66 percent. The high rate of frequency distribution of government employees was expected. Almost 69 percent of the budget goes to the government employees, and out of 5 people 1.4 of them receive salary from government. The frequency distribution for private sector employees and students somehow equally rated with 11.4 percent for private sector employees and 11.7 for students. The frequency distribution for unemployed was 23 with the percentage of 6.1. Lastly, only 12 respondents ticked "other" with percentage of 3.1 percent. Overall, there were 6 missing values, 98.2 percent of the cases were valid. 
Table 5.4

Frequency Distribution of Occupation

\begin{tabular}{lcr}
\hline Occupations & Number & Percent \\
\hline Government Employee & 249 & 66.0 \\
Private Sector Employee & 43 & 11.4 \\
Student & 44 & 11.7 \\
Not Employed & 23 & 6.1 \\
Other & 12 & 3.2 \\
No Respond & 6 & 1.6 \\
Total & 377 & 100.0 \\
\hline
\end{tabular}

\subsubsection{Frequency Distribution of Education}

To understand the level of education, respondents were given five choices namely high school certificate, diploma, degree, postgraduate, and other. Obviously, people with degree could understand the budgeting process better than people with no education. In a total of 377 participants, 177 of them hold a bachelor degree with percentage of 46.9 . Therefore, the holders of diploma certificate have the frequency distribution of 88 with percentage of 23.3 percent. The frequency distribution for high school certificate was 55 with percentage of 14.6 percent. The number of respondents holding postgraduate certificate were 49 with 13 percent. For other, the frequency distribution was only 1.6 percent. Overall, there were only 2 missing data with 0.5 percent, the rest of the cases were valid (see Table 5.5). 
Table 5.5

Frequency Distribution of Education

\begin{tabular}{lcr}
\hline Level of Education & Number & Percent \\
\hline High School Certificate & 55 & 14.6 \\
Diploma & 88 & 23.3 \\
Degree & 177 & 46.9 \\
Post Graduate & 49 & 13.0 \\
Other & 6 & 1.6 \\
No Respond & 2 & .5 \\
Total & 377 & 100.0 \\
\hline
\end{tabular}

\subsubsection{Frequency Distribution of Governorate}

The survey questionnaires were administered in Erbil, Sulaimaniyah and Duhok. More than half of the respondents located in Erbil governorate which is the capital of Kurdistan Region. The frequency distribution was 194. The frequency distribution for Sulaimaniyah governorate was 117 with percentage of 31 percent. Therefore, the frequency distribution for Duhok governorate was 63 with percentage of 16.7 percent. In terms of population, Duhok is the smallest governorate in Kurdistan and Sulaimaniyah is the largest. These percentages do not only reflect the true population of the cities, but questionnaires were also distributed in a small towns and rural areas. Overall, all 377 cases were valid.

Table 5.6

Frequency Distribution of Education

\begin{tabular}{lcr}
\hline Governorates & Number & Percent \\
\hline Erbil & 194 & 51.5 \\
Sulaimaniyah & 117 & 31.0 \\
Duhok & 63 & 16.7 \\
No Respond & 3 & .8 \\
Total & 377 & 100.0 \\
\hline
\end{tabular}




\subsection{Detection of Outliers}

Detecting outliers is very important to achieve the accurate result and cleaning data set from the values that are far different from the rest of the data (Byrne, 2010). Outlier is portrayed as detector to identify the value of numerical data that are very high or very low. Outliers and the extreme values may change empirical analysis, especially normality, regression and correlations. To identify outliers in this study, boxplot analysis used to identify all outlier cases.

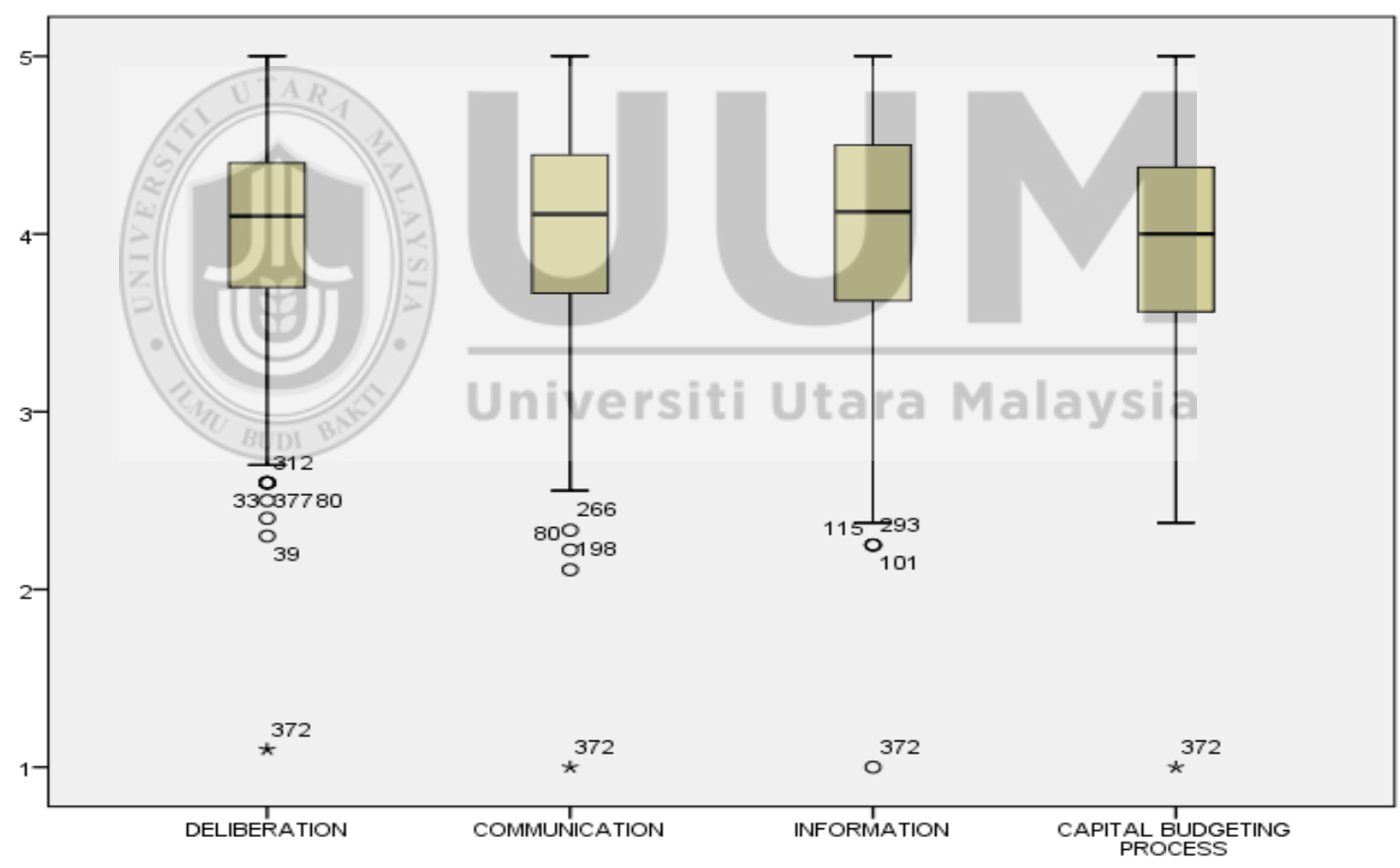

Figure 5.1 Outliers boxplot

As illustrated in figure 5.1. Several outlier cases have been detected in all variables. One of the cases (case number 372) was an extreme case. The rest of outlier cases $(115,293$, 101, 266, 80, 198, 312, 33, 377, 80, 39 and 372) were normal cases but they might still 
influence on the result of regression analysis. To provide more accurate results and conduct better analysis, perceived outlier cases were removed. Also, some cases violated the result of logistic regression including case number 3,66,78,79,133,200,204, 218, 221, 270. They were removed in the last stage. The boxplot presented in graph 5.2 shows the normal boxplot as outliers removed. Subsequently, the number of the cases decreased from 398 to 387 then to 377; overall, eleven (21) cases were removed from the data set.

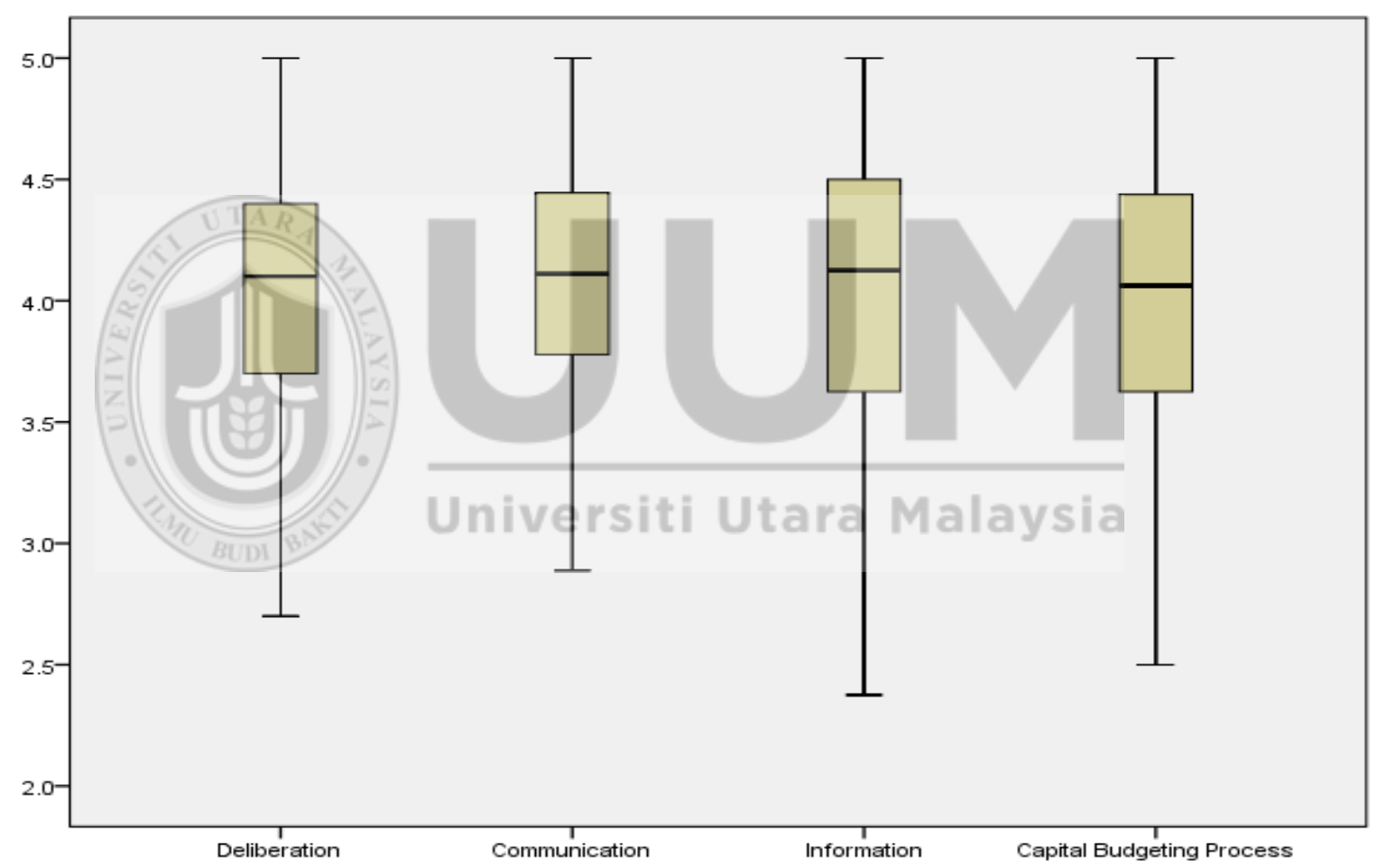

Figure 5.2 Boxplot after outliers removed 


\subsection{Normality Tests}

Normality test is usually used to designate bell shaped and symmetrical curve with greater frequency scores in the center. There are several statistical as well as graphical assumptions to explore normality including Kolmogorov-Smirnov, Skewness, Kurtosis, Histogram, Normal Q-Q Plot, and Boxplot. In this study, empirical measures such as a Kolmogorov-Smirnov Statistic and Shapiro-Wilk, Skewness and Kurtosis used to assess shape characteristics of the data set, presented in Table 5.7 and Table 5.8.

\subsubsection{Kolmogorov-Smirnov and Shapiro-Wilk}

This test was very common to examine the normal probability. However, it could be inaccurate when the sample size is large. To assess normality, Ghasemi and Zahediasl advised not use this test. Yet, the study still looked at the value of this test to find out normal assumption. To achieve the result of analysis, the study looks at the level significant as shown in the following Table. To assume normal distribution of the scores, the significance value should be greater than .05 (Pallant, 2007, p. 62; Coakes, 2013, p. 43). However, as shown in "Sig." column, the significant value of all variables, including deliberation, communication, and information is equal to 0.000 , and the value of capital budgeting process is equal to 0.001 That means the significance value is lower than 0.05 . That explains the data for all variables significantly deviated from normal distribution as $.000<0.05$. 
This result is expected and very common when the sample size is large. The large sample size in this study which is 377 ("df" =377), caused the rejection of normality assumption in the data set.

Table 5.7

Tests of Normality

\begin{tabular}{lcccccc}
\hline & \multicolumn{3}{c}{ Kolmogorov-Smirnov $^{\mathrm{a}}$} & \multicolumn{3}{c}{ Shapiro-Wilk } \\
\cline { 2 - 7 } Variables & Statistic & $\mathrm{df}$ & Sig. & Statistic & df & Sig. \\
\hline Deliberation & .105 & 377 & .000 & .960 & 377 & .000 \\
Communication & .087 & 377 & .000 & .974 & 377 & .000 \\
Information & .099 & 377 & .000 & .971 & 377 & .000 \\
Capital Budgeting Process & .067 & 377 & .000 & .985 & 377 & .001 \\
\hline
\end{tabular}

a. Lilliefors Significance Correction

\subsubsection{Skewness and Kurtosis}

Skewness and Kurtosis measure the shape of data distribution. Skewness characterizes

the extent of symmetry in the distribution of the variable. Kurtosis measures the level of flatness or peakedness of the variables. The perfect value for both skewness and kurtosis is zero. The positive skewness refers to the positive skew as symmetric tails ranging mostly towards the positive values, but negative skewness indicates the extension of the tails towards negative values. The positive value of Kurtosis characterizes the peaked distribution of the values also recognized as leptokurtic, but the flatter distribution of values, that designates negative kurtosis also recognized as platykurtic. The tolerated value of the skewness and kurtosis ranged between \pm 1.96 . If the test value is higher than -1.96 and lower than 1.96 at $p<0.05$, the normality assumption will be assumed. However, this range is changes based on the sample size. The sample size of this study is greater 
than 200 ("df"=377). Thus, the accepted value of skewness and kurtosis is \pm 2.56 at $P<0.001$ (Rose, Spinks \& Canhoto, 2015; Ghasemi \& Zahediasl, 2012). Table 5.8 reveals that normality assumption is assumed since the distribution values of the variables are lower than 1 . The obtained value of skewness is -0.549 for deliberation, -0.318 for communication, -0.482 for information, and -0.210 capital budgeting process. The obtained value of kurtosis is -0.372 for deliberation, -0.478 for communication, $-0,171$ for information, and -0.500 for capital budgeting process. The obtained values do not violate the threshold \pm 2.56 . Subsequently, it could be concluded that normality is assumed at $P<0.001$.

Table 5.8

Tests of Normality: Skewness \& Kurtosis

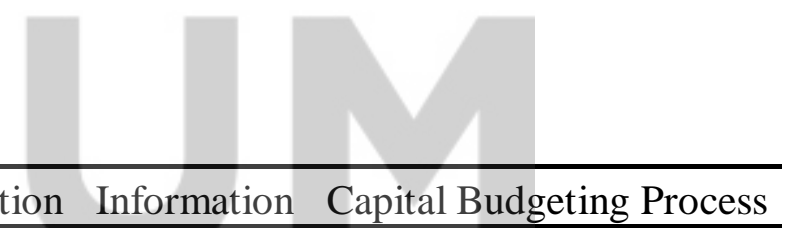

\begin{tabular}{lrrrr}
\hline Skewness & -.549 & -.318 & -.482 & -.210 \\
\cline { 3 - 5 } Std. Error of & .126 & Univ.126siti Ut.126 & Malaysi .126 \\
Skewness & & -.478 & -.171 & -.500 \\
Kurtosis & -.372 & -.478 & .251 & .251 \\
Std. Error of & .251 & .251 & .251 \\
Kurtosis & .251 & &
\end{tabular}

Alternately to Kolmogorov-Smirnov, Shapiro-Wilk, Skewness and Kurtosis test, it's suggested by Pallant (2007) and Coakes (2013) to run histogram, normal Q-Q Plot, and Boxplot to visually inspect the normal distribution of the data set. Visual inspection could be more effective in study with large sample size and the graph could better represent a normal distribution of the data set. 


\subsubsection{Normal Probability Plot}

Normal Q-Q Plot is an important technique to check for normal distribution of scores through visual inspection. In Q-Q plot, when the sample is normally distributed, the cases mainly fall around the straight line (Tabachnick \& Fidell, 2007; Pallant, 2013). Accordingly, the normal probability plot as illustrated in the following graphs demonstrates that the data is normally distributed for all variables. The normal probability plot is reasonably normal as it's linear. For further inspection, the study also conducted a visual inspection by using boxplot. The inspection result for Box Plot shows a normal distribution of the data set. However, it's not perfectly normal, but reasonably acceptable.

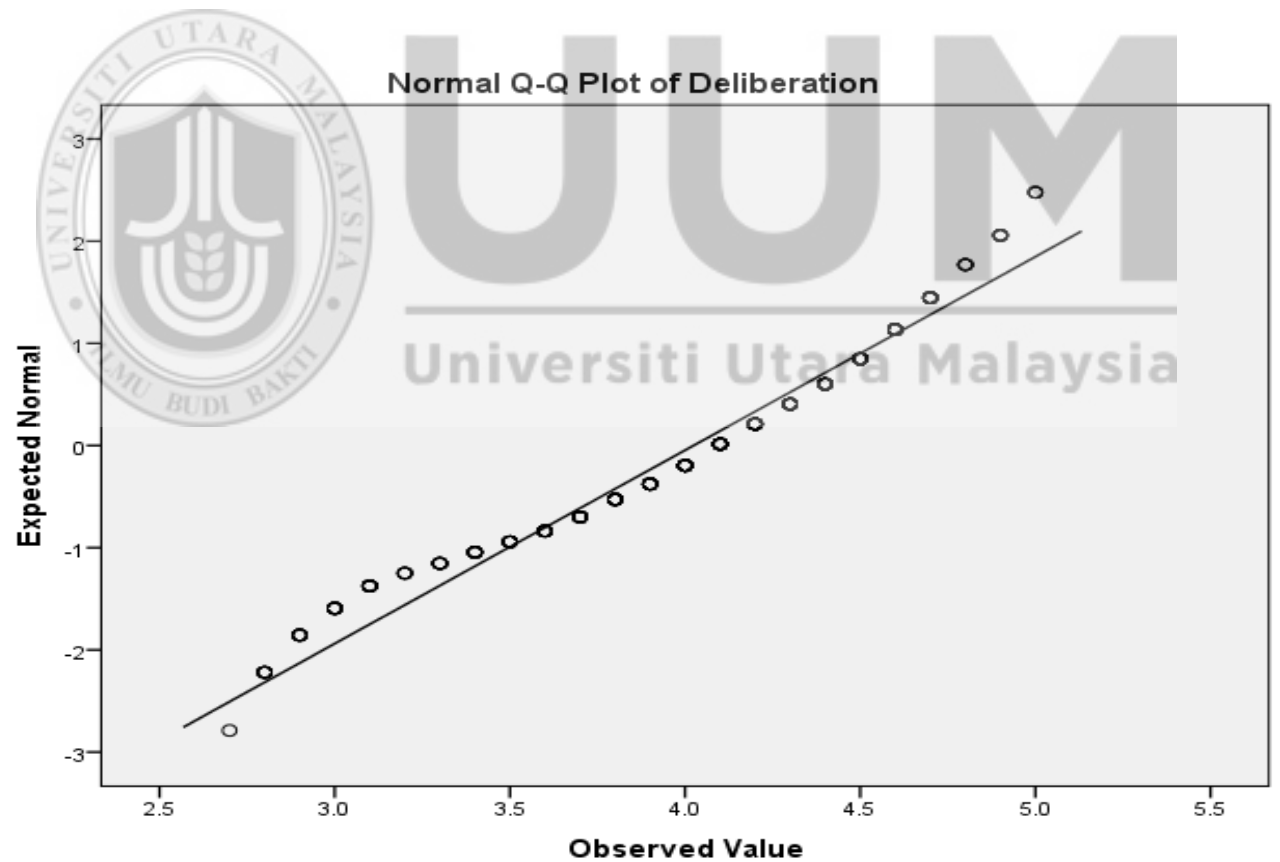

Figure 5.3 Normal Q-Q plot of budget deliberation 


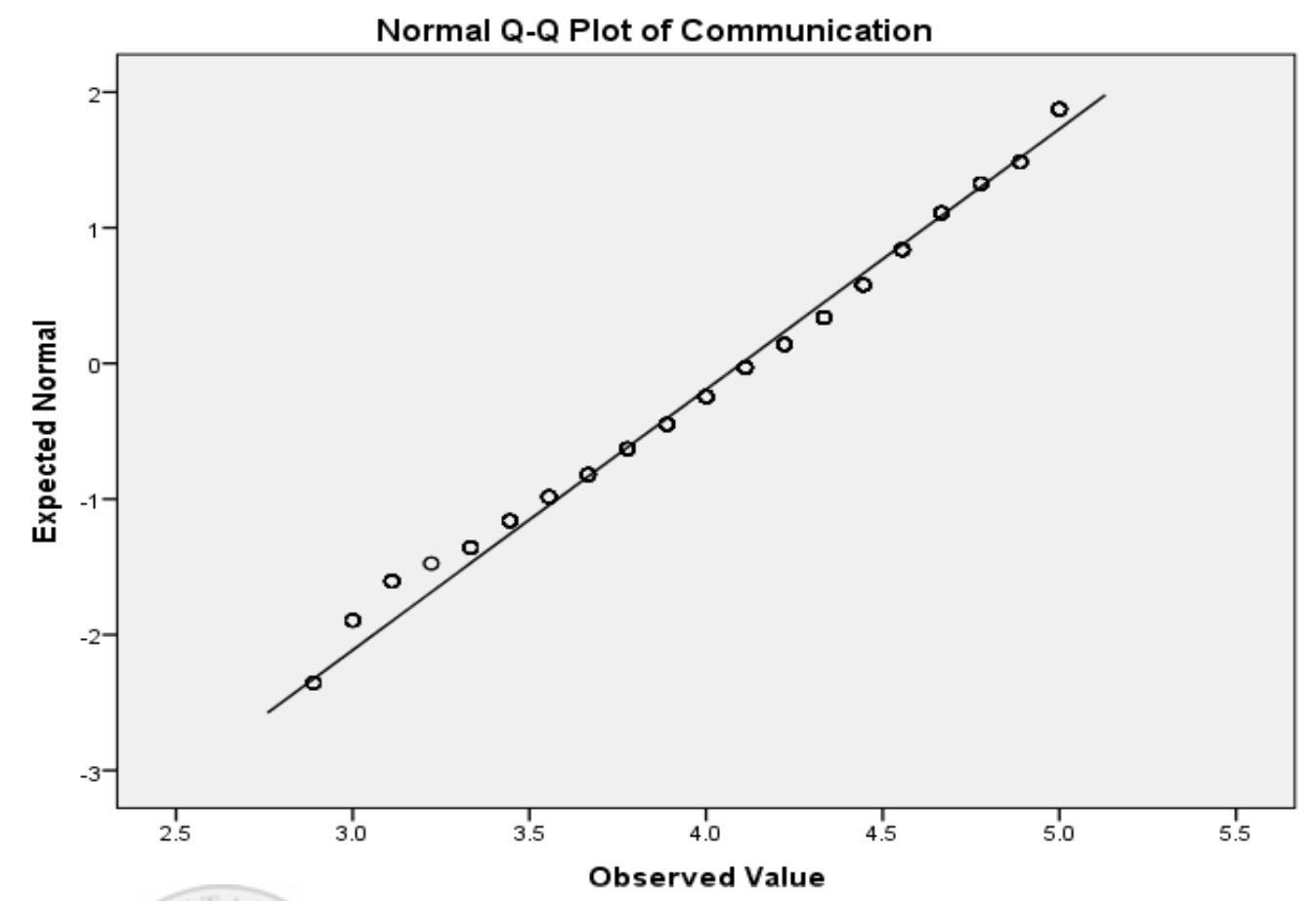

Figure 5.4 Normal Q-Q plot of budget communication

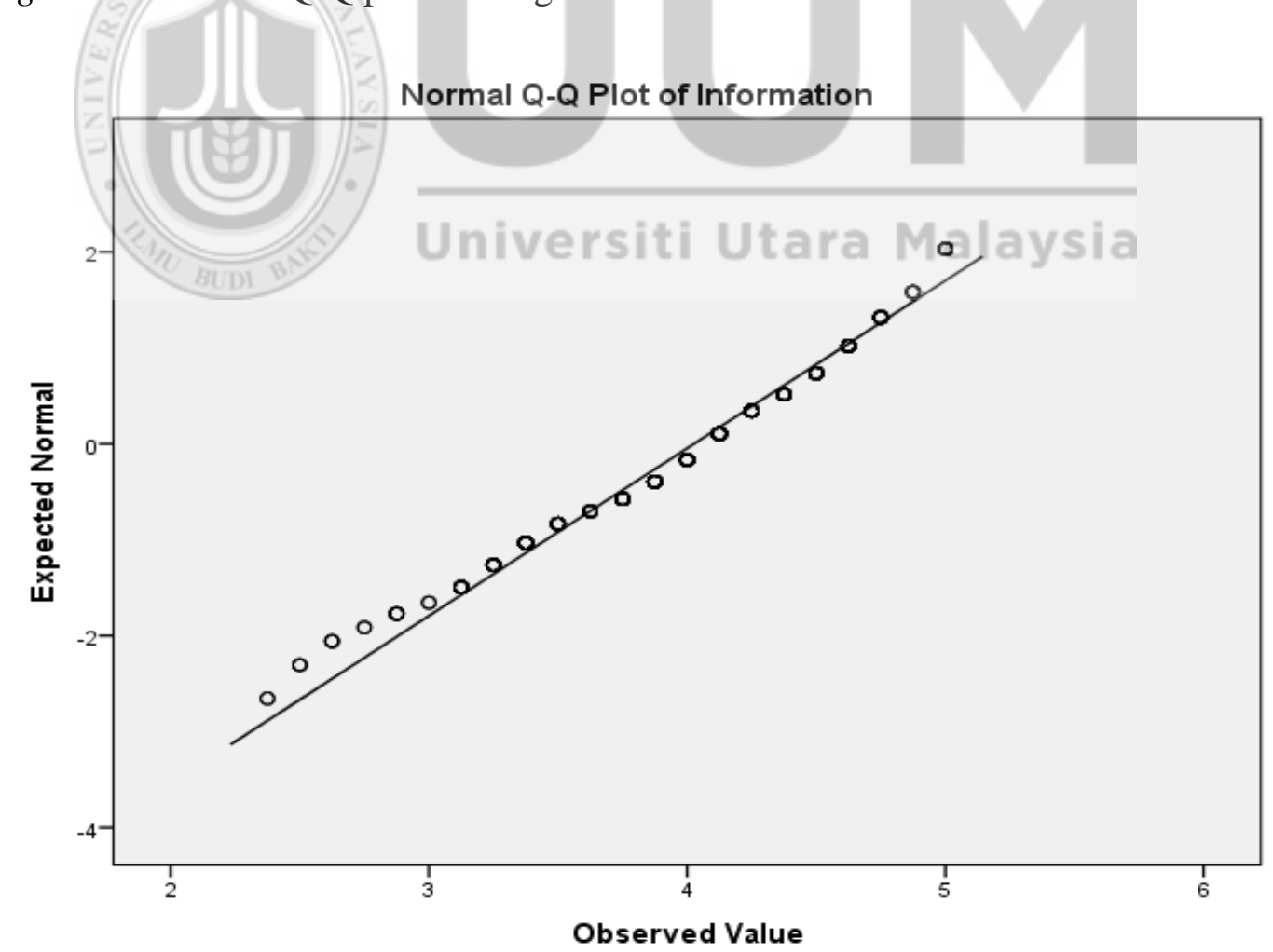

Figure 5.5 Normal Q-Q plot of budget information 


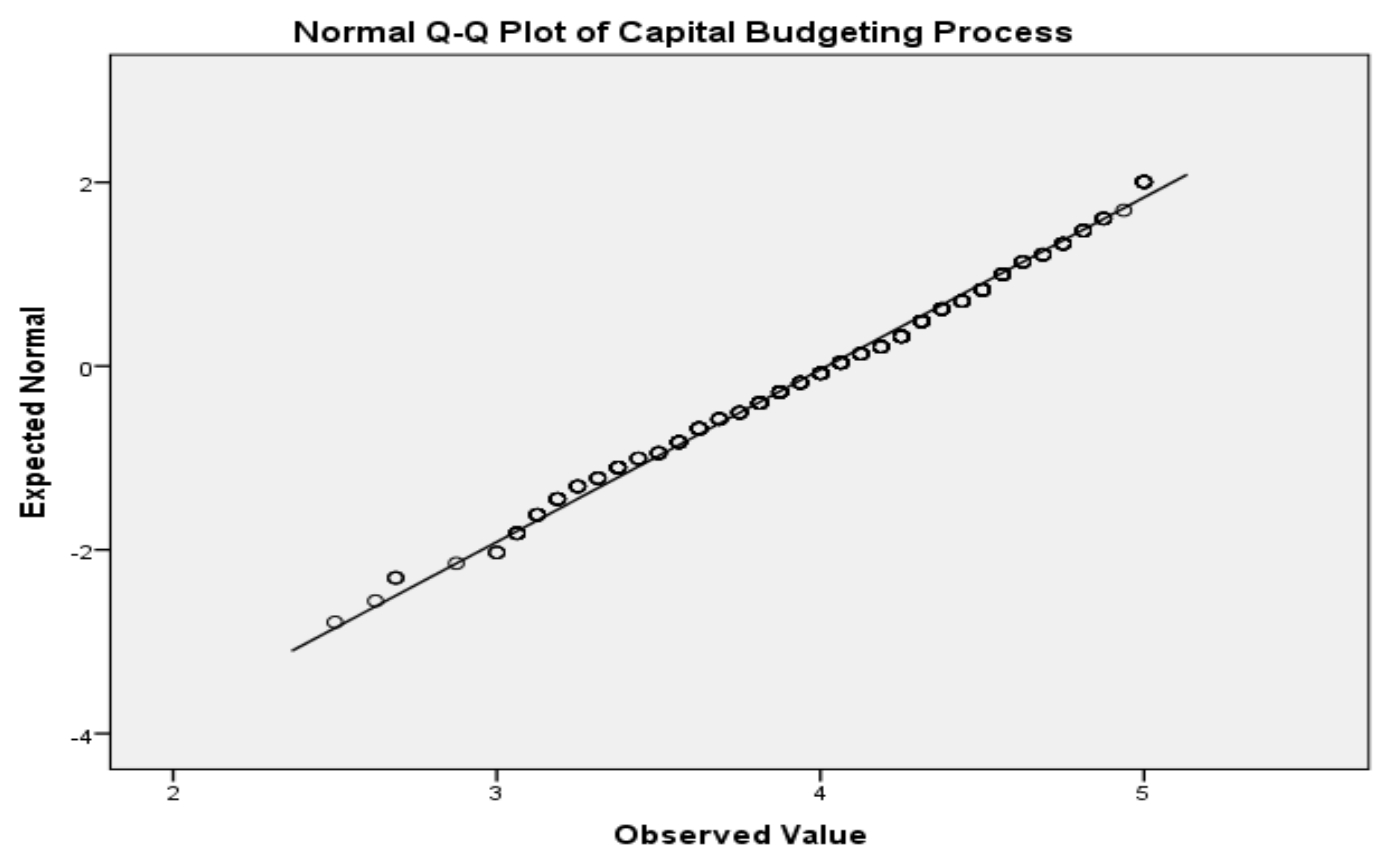

Figure 5.6 Normal Q-Q plot of capital budgeting process

\subsection{Instrument Reliability}

The reliability of the instrument is essential to measure internal consistency of the instrument. Reliability study is to ensure that items hang together. To test for instrument reliability, Cronbach's Alpha has been used which relies on the item correlations within the test. The value of Cronbach's Alpha ranged between 0 to 1 . The accepted value of Cronbach's Alpha is 0.7 and above (Devellis, 2003; Pallant, 2007). Three independent variables (deliberation, communication and information) were tested and followed by the dependent variable (capital budgeting process) which was also tested for internal consistency through Cronbach's Alpha. 
All 10 items of deliberation were tested with 100 percent validity and without excluding any cases. The result given for deliberation was .716 which is acceptable. The second variable tested for reliability statistics is communication. Out of 377 cases, none of them excluded. Under communication, 9 items have been tested. The result is given as .757 . For information, all cases were valid and the overall value of .706 was given. Under capital budgeting process, there were 16 items and the analysis shows that all 377 cases are valid. The Cronbach's Alpha coefficient value given to capital budgeting process was .849 which is higher than all other variables and considered very good (see Table 5.9). The overall result for Cronbach's Alpha, indicates the reliability of all items.

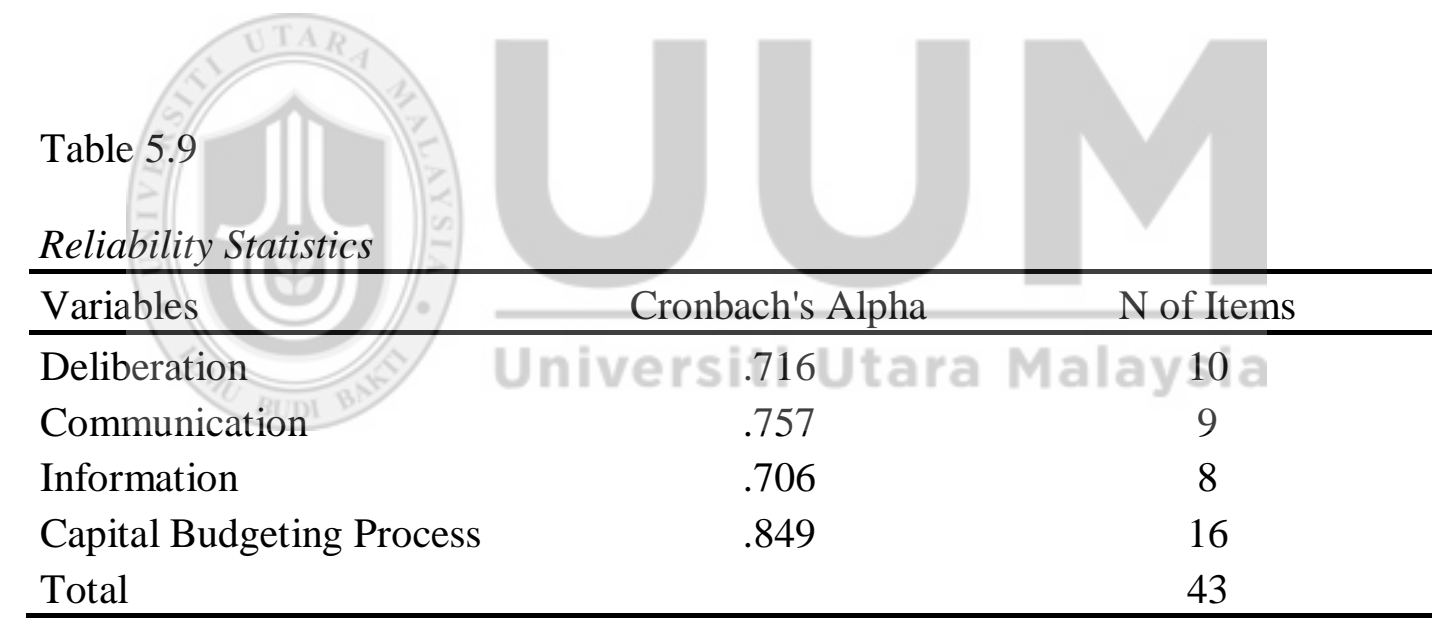




\subsection{Person's Correlation coefficient}

Person's correlation analysis used to measure and describe the direction and strength of the relationship between two different numerical variables in which changes in one particular variable associated with the changes in other variable (Ahmed \& Mamat, 2003, p.27; Chuan et al. 2011). This study measures the degree of linear relationship between independent variables (deliberation, communication and information) and dependent variable (capital budgeting process). The strength of the relationship ranged into relative, average ad strong correlation (John, 2008; Pallant, 2007).

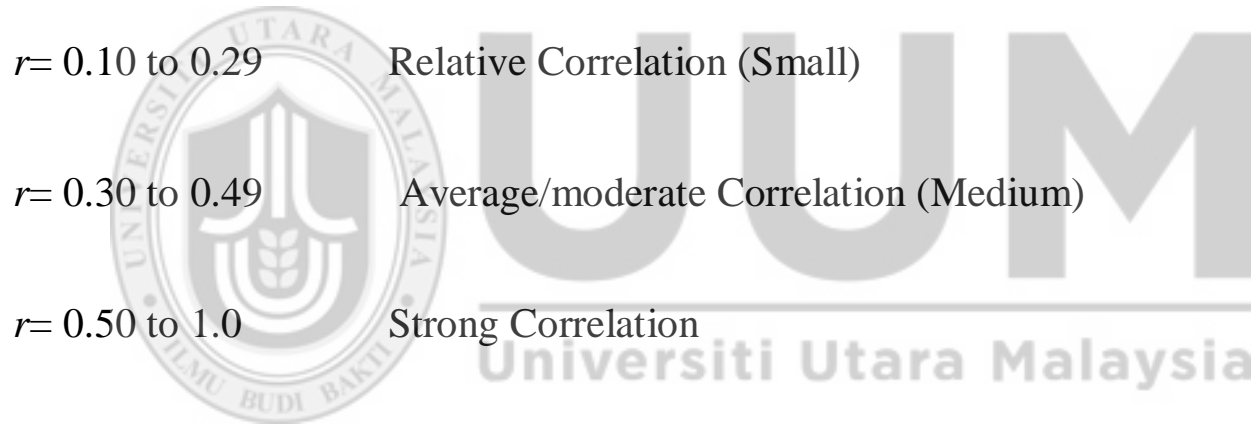

Positive correlation happens when the increase in the score of one variable causes the increase of the score in other variable. However, negative correlation happens when the score of one variable increases, the scores in other variable decreases. Apart from negative and positive correlation, there is also zero correlation which happens when the value " $r$ " is equal. The " $r$ " value referred to "correlation coefficient." The value of $r$ shows the strength of the relationship between variables and the closer " $r$ " value to 1.0, the stronger correlations will be. 


\subsubsection{Correlation: Deliberation and Capital Budgeting Process}

As presented in Table 5.10, the correlation between budget deliberation and capital budgeting process was explored by using Pearson's moment correlations. The result of the analysis shows positive correlation $(r=.518, n=377, p<.01)$ between deliberation and capital budgeting process at 0.01 level (2-tiled). Similarly, the strength of the relationship was measured based on the ranges and criteria provided by John (2008) and Pallant (2007). Accordingly, there is a strong positive correlation between the use of budget deliberation and capital budgeting process. The star over perceived value is an obvious indicator of a significant relationship between the two variables. Overall, budget deliberation contributes $r=518$ to the success of capital budgeting process. This indicates the acceptance of $H 1$.

Hypothesis 1: There is a positive relationship between deliberation and capital budgeting process (accepted), $r=.518, n=377, p<.01$.

Table 5.10

Correlation between Deliberation and Capital Budgeting Process

\begin{tabular}{llcr}
\hline & & Deliberation & Capital Budgeting Process \\
\hline Deliberation & Pearson Correlation & 1 & $.518^{* * *}$ \\
& Sig. (2-tailed) & & .000 \\
& $\mathrm{~N}$ & 377 & 377 \\
Capital & Pearson Correlation & $.518^{* *}$ & 1 \\
Budgeting & Sig. (2-tailed) & .000 & \\
Process & $\mathrm{N}$ & 377 & 377 \\
\hline$* *$ Correlation & is significant at the 0.01 level (2-tailed).
\end{tabular}




\subsubsection{Correlation: Communication and Capital Budgeting Process}

As presented in Table 5.11, the correlation between budget communication and capital budgeting process was explored by using Pearson's moment correlations. The result of the analysis shows positive correlation $(r=.610, n=377, p<.01)$ between communication and capital budgeting process at 0.01 level (2-tiled). Similarly, the strength of the relationship was measured based on the ranges and criteria provided by John (2008) and Pallant (2007). Accordingly, there is a significant positive correlation between the use of budget communication and capital budgeting process. The star over perceived value is an obvious indicator of significance relationship between the two variables.

Overall, budget communication contributes $r=610$ to the success of capital budgeting process. This indicates the acceptance of $H 2$.

Hypothesis 2: There is a positive relationship between communication and capital budgeting process (accepted), $r=.610, n=377, p<.01$.

Table 5.11

\section{Correlation between Communication and Capital Budgeting Process}

\begin{tabular}{llcr}
\hline & & Communication & Capital Budgeting Process \\
\hline Communication & Pearson & 1 & $.610^{* *}$ \\
& Correlation & & .000 \\
& Sig. (2-tailed) & & 377 \\
& $\mathrm{~N}$ & 377 & 1 \\
Capital Budgeting & Pearson & $.610^{* *}$ & \\
Process & Correlation & & 377 \\
& Sig. (2-tailed) & .000 & \\
& $\mathrm{~N}$ & 377 & \\
\hline
\end{tabular}

**. Correlation is significant at the 0.01 level (2-tailed). 


\subsubsection{Correlation: Information and Capital Budgeting Process}

As presented in Table 5.12, the correlation between budget information and capital budgeting process was explored by using Pearson's moment correlations. The result of analysis shows access to government information positively $(r=.656, n=377, p<.01)$ increases the effectiveness of capital budgeting process at 0.01 level (2-tiled). Similarly, the strength of the relationship was measured based on the ranges and criteria provided by John (2008) and Pallant (2007). Accordingly, there is a significant positive correlation between the use of information and capital budgeting process. The star over perceived value is an obvious indicator of significance relationship between the two variables. Overall, budget information contributes $r=656$ to the effectiveness of capital budgeting process. This indicates the acceptance of $H 3$.

Hypothesis 3: Accesses to government information can positively impacts on the capital budgeting process (accepted), $r=.656, n=377, p<.01$.

Table 5.12

Correlation between Information and Capital Budgeting Process

\begin{tabular}{llcr}
\hline & & Information & Capital Budgeting Process \\
\hline Information & Pearson & 1 & $.656^{* *}$ \\
& Correlation & & \\
& Sig. (2-tailed) & & .000 \\
& $\mathrm{~N}$ & 377 & 377 \\
Capital & Pearson & $.656^{* *}$ & 1 \\
Budgeting & Correlation & & \\
Process & Sig. (2-tailed) & .000 & 377 \\
& $\mathrm{~N}$ & 377 & \\
\end{tabular}

**. Correlation is significant at the 0.01 level (2-tailed). 


\subsection{Regression}

Multiple regression analysis is to identify the extent in which the variance in dependent variable explained by independent variables. Multiple Regressions also helps to elaborate the relative contribution of independent variables. The predictor variable or independent variables are assigned as $\mathrm{X}$, and the dependent variable assigned as $\mathrm{Y}$. Before testing regression analysis, Xs and $\mathrm{Y}$ has been converted to dummy variable. The five level Xs and Y has been changed into two level dummies. The value greater than 3 converted to 1 , else to 0 . The regression analysis then conducted.

\subsubsection{Evaluating the Model}

To determine how well the model fits and how well the model explained the variance in the dependent variable, the model has been evaluated. In the " $R$ " column (see Table 5.13) represents the value of " $R$ " and its to measure the quality and the level of prediction for variables. In the other words, it represents multiple correlation coefficients. The value of " $R$ " in this case is .516 which shows good level of prediction. Therefore, the value of $R$ Square as shown in the Table indicates the extent that variance in the dependent variable (capital budgeting process) explained by independent variables (deliberation, communication and information). The result of this analysis shows that the value of $R$ Square is 0.266 which means deliberation, communication and information explain 26.6 percent of the variability of capital budgeting process. This result is acceptable. In addition to $R$ Square, in the model summery, the Adjusted $R$ Square estimates the true value of the population. The Adjusted $R$ Square value is 0.260 which represents 26 percent. 
Table 5.13

Model Summary

\begin{tabular}{llccc}
\hline Model & $\mathrm{R}$ & R Square & Adjusted R Square & Std. Error of the Estimate \\
\hline 1 & .516 & .266 & .260 & .10778 \\
\hline
\end{tabular}

a. Predictors: (Constant), Information, Deliberation, Communication

\subsubsection{Statistical Significance}

To measure statistical significance in multiple regression analysis, we look for ANOVA as shown in Table 5.14 bellow. The main objective of ANOVA test is to find out if the model well fits the data or not. The result of Anova test indicates that deliberation, communication and information significantly predicted capital budgeting process, $F(373)$ $=45.092, p<.0005$ and that indicates the model is well fits the data. Also, when "sig." = $.000 ; p<.0005$, it reaches to the level of statistical significance. Table 5.14 provided the summary of the ANOVA test in multiple regression analysis.

Table 5.14

ANOVA

\begin{tabular}{lccccr}
\hline Model & Sum of Squares & df & Mean Square & F & Sig. \\
\hline Regression & 1.571 & 3 & .524 & 45.092 & $.000^{\mathrm{b}}$ \\
Residual & 4.333 & 373 & .012 & & \\
Total & 5.905 & 376 & & & \\
\hline
\end{tabular}

a. Dependent Variable: Capital Budgeting Process

b. Predictors: (Constant), Information, Deliberation, Communication

\subsubsection{Estimated Models Coefficients}

Estimating model coefficients is to realize statistical significance by examining the value of " $t$ " and "Sig." Conducting this test helps to realize whether or not independent variables (deliberation, communication and information) make a statistically significant unique 
contribution to the dependent variable (capital budgeting process). According to Pallant (2013) if "sig" value is less than 0.05 that verifies independent variables makes significant unique contribution to explain dependent variable. The value of all Xs are lower than 0.05. The "Sig" value for budget deliberation is $0.022<.05$, and the value for both communication and information is equal to zero, $p=0.000 ; 0.000<0.05$. Hence, it could be concluded that coefficient has statistically significant contribution in explaining capital budgeting process. Table 5.15 explains Coefficients.

Table 5.15

Coefficients

\begin{tabular}{|c|c|c|c|c|c|}
\hline \multirow[b]{2}{*}{ Model } & \multicolumn{2}{|c|}{$\begin{array}{c}\text { Unstandardized } \\
\text { Coefficients }\end{array}$} & \multirow{2}{*}{$\begin{array}{c}\text { Standardized } \\
\text { Coefficients } \\
\text { Beta }\end{array}$} & \multirow[b]{2}{*}{$\mathrm{t}$} & \multirow[b]{2}{*}{ Sig. } \\
\hline & $\mathrm{B}$ & Std. Error & & & \\
\hline (Constant) & .621 & .048 & & 12.888 & .000 \\
\hline Deliberation & .070 & .030 & .109 & 2.292 & .022 \\
\hline Communication & .169 & .048 & .169 & 3.525 & .000 \\
\hline Information & .275 & .030 & $11+.456$ & 9.064 & .000 \\
\hline
\end{tabular}

a. Dependent Variable: Capital Budgeting Process

\subsubsection{Comparison between Predictors}

This study compared independent variables separately in their relationship to capital budgeting process. The study used multiple regression analysis to find out which variable contributes more to explain independent variables The standardized coefficients "Beta" used to identify the most important predictors. The column "Standardized Coefficients Beta" shows that given value of information is larger than communication and deliberation. The obtained $\mathrm{R}$ value or Beta illustrates in the table is 0.456 indicates a moderate to strong correlation between access to government information and 
effectiveness of capital budgeting process. In the other words, the Beta value explains the extent in which variance in the outcome variable explained by information. This means information explains 45.6 percent of the variability of capital budgeting process. Budget information has the strongest correlation to capital budgeting process comparing to deliberation and communication. This explains that information is more essential in planning capital budget. The second important variable was communication with beta value of 0.169 . However, the relationship is weak and does not contribute much in explaining capital budgeting process comparing to information. The given value also explains the relationship between communication and outcome variable. Therefore, it only explains 16.9 percent of the variability of capital budgeting process. Comparing to information its less important; however, this value is much better than the given value to deliberation. Deliberation as shown in the following table, has a least contribution in explaining capital budgeting process. The given beta value to deliberation is 0.109 which is the lowest contribution and only explains 11 percent of the variability of capital budgeting process.

Table 5.16

Standardizes Coefficients: Beta

\begin{tabular}{|c|c|c|}
\hline & Standardized Coefficients & \\
\hline Model & Beta & Sig. \\
\hline (Constant) & & .000 \\
\hline Deliberation & .109 & .022 \\
\hline Communication & .169 & .000 \\
\hline Information & .456 & .000 \\
\hline
\end{tabular}

a. Dependent Variable: Capital Budgeting Process 
The above tables in this section portrayed that $\mathrm{X}$ information has the largest and strongest unique contribution in capital budgeting process. The beta value given to communication indicates that budget communication contributes less to explain capital budgeting process, but it's higher than budget deliberation. Though, budget deliberation has a least contribution to explain capital budgeting process with beta coefficient 0.109 and it's the lowest. Thus, budget information could be the most preferred approach of public participation in capital budgeting process. Actually, it's a pre-condition and a complementary tool to other participatory approaches. Budget information eases PB and encourages people to utilize knowledge and information they receive in planning capital budget. However, it does not mean the remaining two variables does not have any contribution in the capital budgeting process. However, communication is found to be more significant comparing to deliberation. Deliberation is the least important predictor because its more complicated than communication and information. Information dissemination is very easy in the modern age. There are hundreds of tools that government can disseminate bulks of documents and information to public. Therefore, communication requires times, efforts and resources to take place. Deliberation on the other hand is more complicated and time consuming process comparing to communication. Deliberation sometimes causes disagreement and conflicts between participants. Deliberation also requires more arrangement in order to organize the panels and meeting. For that, it's less likely by the participants. 


\subsubsection{Multi Collinearity}

Multicollinearity is one of the issues that effectively impacts on the output of Multiple Regression analysis. It happens due to the redundancy and correlation matrix of predictor variables when they are highly correlated. To detect collinearity, the given value of tolerance and Variance Inflation Factor (VIF) was analyzed. When the value of tolerance is smaller than 0.10 , multicollinearity becomes primary concern. In contrary, the VIF value of greater than 10 indicates the presence of high correlation between predictors and the output variable. That indicates the presence of multicollinearity. The output of multicollinearity presented in Table 5.17 shows value of tolerance given as 0.875 (deliberation), 0.851 (communication), and 0.776 (information). Here, tolerance value of predictor variables are greater than $0.10(p>0.10)$, multicollinearity is not concern. The VIF value also indicates no violation of collinearity assumption since VIF value is smaller than 10. The finding confirmed that there is no highly correlated predictor variables exceeded recommended value of multicollinearity.

Table 5.17

Multicollinearity

\begin{tabular}{lcr}
\hline & \multicolumn{2}{c}{ Collinearity Statistics } \\
\cline { 2 - 3 } Model & Tolerance & VIF \\
\hline (Constant) & & \\
Deliberation & .875 & 1.143 \\
Communication & .851 & 1.175 \\
Information & .776 & 1.288 \\
\hline
\end{tabular}

a. Dependent Variable: Capital Budgeting Process 


\subsubsection{Normal P-P Plot of Regression}

Although, the study diagnosed normality of the data set in previous sections, but to ensure that multiple regression analysis goes smoothly, the study provided normal P-P Plot to visually inspect normality distribution and detect extreme outlier cases. Figure 5.7 demonstrates that points fall on the straight lines from the bottom left to the top right and found no major deviation from normality (Also see Histogram, page 286).

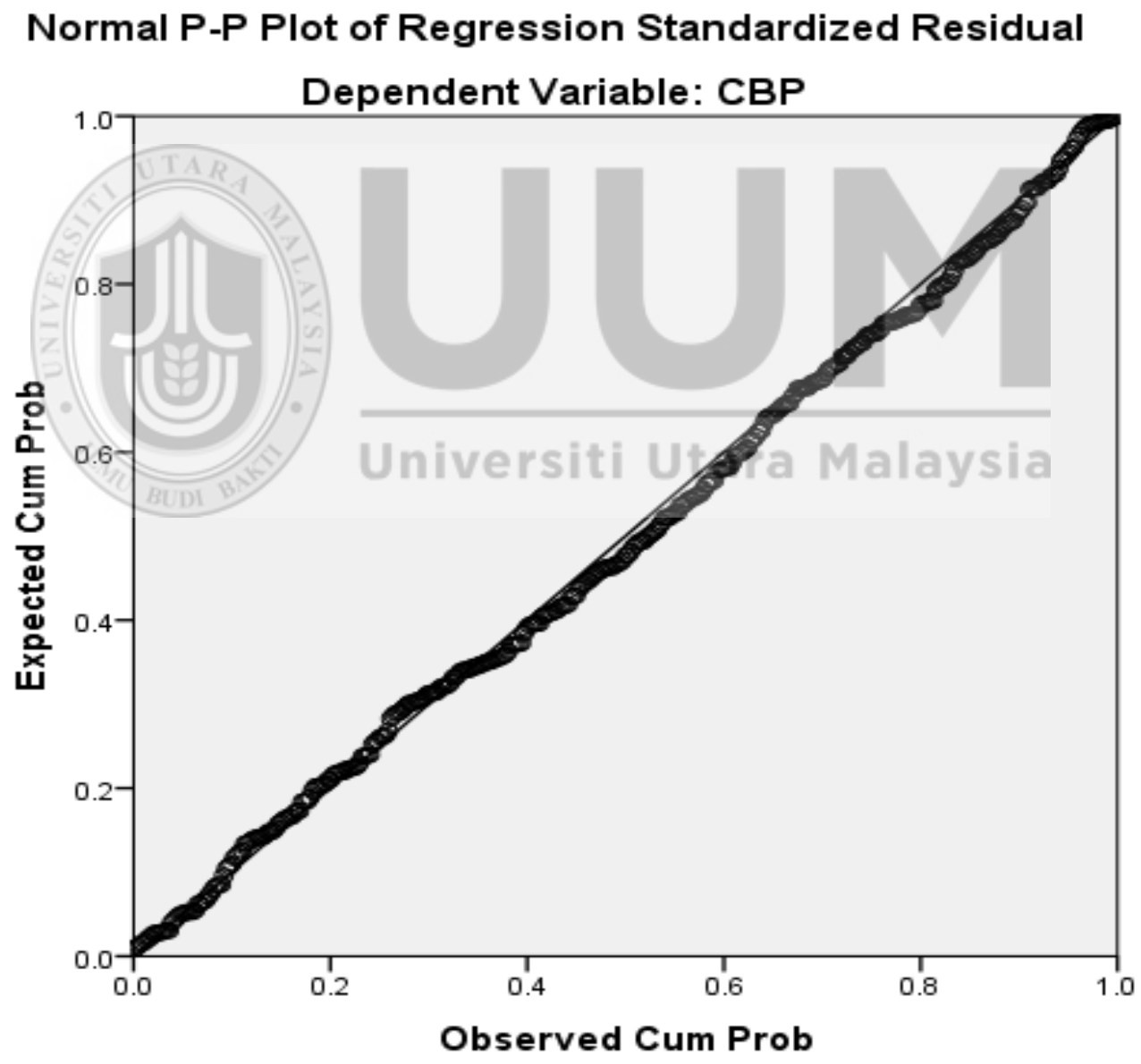

Figure: 5.7 Expected cum prob 


\subsubsection{Logistic Regression}

The logistic regression is to test the model in order to predict the categorical dependent variable with two or more levels. It also helps to understand how well independent variables explain the categorical variable. In order to perform this test, dummy variable has been created. The existing variables recoded into dichotomous (one categorical) variable. The value of 0 and 1 used to code dichotomous variable. The case processing summary (Table 5.18) explains the number of the cases included in this analysis which is 377 without excluding or missing any cases.

Table 5.18

\begin{tabular}{llcr}
\multicolumn{2}{l}{ Case Processing Summary } & & \\
\hline Unweighted Cases & & $\mathrm{N}$ & Percent \\
\hline Selected Cases & Included in Analysis & 377 & 100.0 \\
& Missing Cases & 0 & .0 \\
& Total & 377 & 100.0 \\
Unselected Cases & Universiti Utara & 0 \\
Total & & 377 & .0 \\
\hline
\end{tabular}

a. If weight is in effect, see classification table for the total number of cases.

The dependent variable encoding (Table 5.19) illuminates how SPSS dealt with the outcome variable coding. In the case of this study, the dependent variable encoding shows that original values of capital budgeting process are recoded as "Disagree" and "Agree" with internal value " 0 " and " 1 ".

Table 5.19

Dependent Variable Encoding

\begin{tabular}{lr}
\hline Original Value & Internal Value \\
\hline Disagree & 0 \\
Agree & 1 \\
\hline
\end{tabular}




\subsubsection{Block 0: Beginning Block}

The following tables (5.20) shows the result of the data analysis without the use of any predictors in the model. It also describes the baseline model. The prediction of the baseline model is usually made on the categories that occurred more often in the dataset. The classification Table illustrates that the model guessed "Agree" as in first Colum is "6" compared to the second column which is "371." This indicates more respondents agreed with the existing statements. The overall percentage of correctly classified cases is 96 percent.

Table 5.20

$\begin{array}{llll}\text { Block 0: Classification Table } & & & \\ \\ \end{array}$

a. Constant is included in the model.

b. The cut value is .500

The "Variables in the Equation" demonstrates the coefficient for the constant. Accordingly, the model with just the constant is statistically significant predictor of the dependent variable as $\mathrm{p}<.000$ along with accuracy of 98 percent of the time.

Table 5.21

Block 0: Variables in the Equation

\begin{tabular}{llcccccr}
\hline & & B & S.E. & Wald & df & Sig. & Exp(B) \\
\hline Step 0 & Constant & 3.211 & .263 & 148.649 & 1 & .000 & 24.800 \\
\hline
\end{tabular}




\subsubsection{Block 1}

The following tables shows the result of our model in which a set of independent variables tested. The first table Omnibus test of Model Coefficients indicates how the model performs. The result shows that model is well performed as the given values to Block is significant at .000; $<<.005$. According to Pallant (2013) the highly significant value is below 0.05 . Thus, the model is well performed. The Chi-square value given in Table (5.22) is 33.607 with 3 degree of freedom.

Table 5.22

\begin{tabular}{l|lccc}
\multicolumn{6}{l}{ Omnibus Tests of Model Coefficients } & & \\
\hline & & Chi-square & df & Sig. \\
\hline \multirow{2}{*}{ Step 1 } & Step & 33.607 & 3 & .000 \\
& Block & 33.607 & 3 & .000 \\
& Model & 33.607 & 3 & .000 \\
\hline
\end{tabular}

Table (5.23) "Model Summary" demonstrates the usefulness of the model. The -2 Log Likelihood explains how well the model predicts capital budgeting process. Actually, the smaller the result, the better the model will be. If the statistic result is smaller than 425.666 that means, the model well predicts capital budgeting process (Wuensch, 2015). In this case the statistic is 27.983 which is a likely result. The next row shown in Table (5.23) is Cox \& Snell R Square and Nagelkerke R Square which offers an indication of the outcome variable explained by the model that's ranged between 0 and 1 . The obtained value is not true value of R Square statistics that provided in the multiple regression analysis, but they 
are more described as pseudo R Square. The given value here are 0.085 and 0.566 which indicates the dependent variable is explained 8.5 percent to 56.6 percent.

Table 5.23

Block 1: Model Summary

\begin{tabular}{lccc}
\hline Step & -2 Log likelihood & Cox \& Snell R Square & Nagelkerke R Square \\
1 & $27.983^{\mathrm{a}}$ & .085 & .566 \\
\hline
\end{tabular}

a. Estimation terminated at iteration number 8 because parameter estimates changed by less than .001 .

The statistic result for Hosmer and Lemeshow Test explains whether the model well fits the data or not. If the value of Hosmer and Lemeshow is less than 0.05 , that means the model is poorly fits the data. However, the value given in this study is 1.000 which is greater than 0.05. The obtained value supports the model used. The Chi-square value given in the following table is 0.422 with significance level of 1.000 . The value is larger than .05 which concludes support for the model.

Table 5.24

Hosmer and Lemeshow Test

\begin{tabular}{lccr}
\hline Step & Chi-square & df & Sig. \\
1 & .422 & 8 & 1.000 \\
\hline
\end{tabular}

The following "Classification Table" measures the degree in which the model is predicting the correct category (Disagree, Agree) for each cases. This could be compared with other "Classification Table" in Block 0. The second classification table defines the improvement achieved by way of including the independent variables in the model. Table 3.39 specifies that the level of accuracy is lower if predictors are included in the model by 0.3 percent. The previous result indicated that overall percentage of accuracy is 98.4 , 
but the overall percentage of the correctly classified model with predictor variables included is 98.1 percent.

Table 5.25

Block 1: Classification Table ${ }^{a}$

\begin{tabular}{lllccr}
\hline & & \multicolumn{3}{c}{ Predicted } \\
\cline { 3 - 4 } & & & Capital Budgeting Process & Percentage \\
\cline { 3 - 4 } & Observed & & Disagree & Agree & Correct \\
\hline Step 1 & Capital Budgeting & Disagree & 1 & 5 & 16.7 \\
& Process & Agree & 0 & 369 & 99.5 \\
& Overall Percentage & & & & 98.1 \\
\hline
\end{tabular}

a. The cut value is .500

The Variable in the Equation shown in Table (5.26) provides an explanation of regression coefficient (B), Wald statistics and Expo (B) for all categories. It describes the contribution of each independent variable. The B value in the second column explains the direction of the relationship. The negative value indicates the increase in the score of one independent variable decreases probability of dependent variable. In the B column, there is one negative value (-1.294) for deliberation. Thus indicates budget deliberation does not effectively impact on the outcome of capital budgeting process. The B value for communication was (2.379) and significant. Also, the B value for information was (4.758) which indicates any increase in transparency and budget information positively impacts on capital budgeting process. The positive B value indicates that people who are agreed on performance of communication and information in the budgeting process of KRG, are passionate to support the implementation of budgetary participation in capital budgeting process. 
The Exp (B) on the other hands, explains the odds ratios for deliberation, communication and information. This explains the degree in which the increase of the corresponding measure by one unit changes the Odd Ratio (OR). More clearly, if the increasing value is smaller than 1, any increase occurring in the independent variables causes the drop in the OR of the outcome variable; therefore, if the value added is larger than 1 , the increase in the OR of the outcome occurring. Further, Pallant (2013) highlighted that the accuracy of the confident relies on the sample size used. If the sample size is large, a very smaller interval occurs. Based on the obtained result shown in $\operatorname{Exp}(\mathrm{B})$ column indicates the value associates with deliberation is .416 . Thus, the OR of the people agreed that budget deliberation more positively impacts on the outcomes of the capital budgeting process is .416 times or 2.40 percent lower than the people who were disagree on the same issue. More clearly, when deliberation increases by one unit, the odd ratio for capital budgeting process drops by .274 . However, the obtained $\operatorname{Exp}(\mathrm{B})$ value for communication and information exceeded 1 . The OR for the people who agreed that budget communication effectively impacts on the capital budgeting process is 10.796 times higher than the people who were disagree on the same manner. Similarly, the OR of the people who agreed to that budget information increases the effectiveness of capital budgeting process is 116.479 higher than the people who were disagree that transparency and budget information increases the effectiveness of the capital budgeting process. Lastly, the confident interval for deliberation is ranged between .012 to 6.325 . This result can assure that 95 percent of the actual value of OR in the population placed between 0.299 to 6.325 . The confident interval for communication is lied between .299 to 389.439 ; for information is 5.169 to 2624.883 . 
Table 5.26

Block 1: Variables in the Equation

95\% C.I.for $\operatorname{EXP}(\mathrm{B})$

\begin{tabular}{|c|c|c|c|c|c|c|c|c|}
\hline & Predictors & $\mathrm{B}$ & S.E. & Wald & Sig. & $\operatorname{Exp}(B)$ & Lower & Upper \\
\hline \multirow[t]{4}{*}{ Step $1^{\mathrm{a}}$} & Deliberation & -1.294 & 1.601 & .653 & .419 & .274 & .012 & 6.325 \\
\hline & Communication & 2.379 & 1.829 & 1.691 & .193 & 10.796 & .299 & 389.439 \\
\hline & Information & 4.758 & 1.589 & 8.961 & .003 & 116.479 & 5.169 & 2624.883 \\
\hline & Constant & -15.158 & 5.162 & 8.623 & .003 & .000 & & \\
\hline
\end{tabular}

a. Variable(s) entered on step 1: Deliberation, Communication, Information.

\subsection{Chapter Summary}

This chapter analyzed and demonstrated the result of quantitative studies. The finding showed that the data are normally distributed and all variables are reliable. All three variables, namely deliberation, communication and information have a strong and positive relationship with capital budgeting process. Thus, all hypotheses were accepted. The study also found that independent variable $(\mathrm{X})$ have a good level of prediction of the dependent variable. Also, the independent variable makes a statistically significant unique contribution to the dependent variable. 


\section{CHAPTER VI}

\section{QUALITATIVE FINDINGS}

\subsection{Introduction}

This chapter analyses the results of a qualitative method to address the objective of the study. The main purpose of qualitative study is to obtain a better result in answering research questions and acknowledge the views of other parties including the government, parliament and expertise. For qualitative study, semi-structured face-to-face interview deployed. The total numbers of people interviewed were 11. Although, attempts have been made to conduct more interviews, but failed to materialize. Several attempts have been made to interview a director from the Ministry of Municipalities, but the designated person was not available. Instead, a director from Harir Municipality was interviewed. Overall, two MPs were interviewed. One of them (Ali Hamasalih) is a well-known MP and economist who writes and works on budget. Apart from him, the minister of industry, and four government officials, including the director of capital investment budget in the MoP interviewed. Lastly, an interview was conducted with Shamal Nuri, a contemporary economist, and journalist. A committee member of the Kurdistan economist syndicate was interviewed. Voice recorder was used to record 10 interviews, including the Skype interview. The advisor to the minister of electricity provided written answers through email. 
Table 6.1

List of the Interviews

\begin{tabular}{|c|c|c|c|c|c|}
\hline $\begin{array}{l}\mathbf{N} \\
\mathbf{0}\end{array}$ & Name & Position & Contact Address & $\begin{array}{l}\text { Date of } \\
\text { Interview }\end{array}$ & $\begin{array}{l}\text { Place of } \\
\text { Interview }\end{array}$ \\
\hline 1 & Aland Mahwi & $\begin{array}{l}\text { Member of } \\
\text { the chamber } \\
\text { of economic } \\
\text { studies: } \\
\text { Change } \\
\text { Movement }\end{array}$ & $\begin{array}{l}\text { +964(0) } 7701945850 \\
\text { alandmahwy@gmail.com }\end{array}$ & $18 / 10 / 2014$ & Sulaimaniyah \\
\hline 2 & $\begin{array}{l}\text { Ali } \\
\text { Hamasalih }\end{array}$ & MP & $\begin{array}{l}\text { +964(0) } 7704796002 \\
\text { alihawlati@gmail.com }\end{array}$ & $02 / 10 / 2014$ & Erbil \\
\hline 3 & $\begin{array}{l}\text { Ayub Anwar } \\
\text { Smaqayii }\end{array}$ & $\begin{array}{l}\text { Economist \& } \\
\text { University }\end{array}$ & Ayubanwar74@gmail.com & $14 / 10 / 2014$ & $\overline{\text { Erbil }}$ \\
\hline 4 & $\begin{array}{l}\text { Dr. Anwer } \\
\text { Omar Qader }\end{array}$ & $\begin{array}{c}\text { General } \\
\text { Director of } \\
\text { Planning \& } \\
\text { following } \\
\text { MoA i v }\end{array}$ & $\begin{array}{l}\text { +964(0) } 7504660879 \\
\text { dgplan@krg-moawr.org }\end{array}$ & $27 / 9 / 2014$ & Erbil \\
\hline 5 & $\begin{array}{l}\text { Hamadamin } \\
\text { Hawrami }\end{array}$ & Advisor MoE & Hawramany59@gmail.com & $25 / 9 / 2014$ & $\overline{\text { Erbil }}$ \\
\hline 6 & $\begin{array}{l}\text { Mohamad } \\
\text { Haji }\end{array}$ & $\begin{array}{c}\text { Director, } \\
\text { Harir } \\
\text { Municipality }\end{array}$ & $\begin{array}{l}+964(0) 7504539427 \\
\text { Muhamadhaji08@gmail.com }\end{array}$ & $5 / 11 / 2015$ & Harir \\
\hline 7 & Samal Sardar & $\begin{array}{l}\text { Minister of } \\
\text { Trade and } \\
\text { Industry }\end{array}$ & & $05 / 10 / 2014$ & Sulaimaniyah \\
\hline 8 & $\begin{array}{l}\text { Sarbast } \\
\text { Khidir Mantik }\end{array}$ & $\begin{array}{c}\text { Director of } \\
\text { statistic dep: } \\
\text { Kurdistan } \\
\text { Board of } \\
\text { Investment }\end{array}$ & $\begin{array}{l}+964(0) 7504551059 \\
\text { Sarbast ali@yahoo.com }\end{array}$ & $09 / 10 / 2014$ & Erbil \\
\hline
\end{tabular}




\begin{tabular}{|c|c|c|c|c|c|}
\hline 9 & Shamal Nuri & $\begin{array}{l}\text { Economist } \\
\text { and Editor in } \\
\text { chief: } \\
\text { Political } \\
\text { Economic }\end{array}$ & $\begin{array}{l}+964(0) 662518402 \\
+964(0) 7504512761 \\
\text { Shamalnori2001@yahoo.co } \\
\underline{\mathrm{m}}\end{array}$ & $15 / 10 / 2014$ & Erbil \\
\hline 10 & Soran Omar & MP & $\begin{array}{l}\text { +964(0) 7501126064 } \\
\text { soranomar8@ @ahoo.com }\end{array}$ & $18 / 10 / 2014$ & Erbil \\
\hline 11 & Zagros Fattah & $\begin{array}{l}\text { Director } \\
\text { General for } \\
\text { Capital } \\
\text { Investment } \\
\text { Budget }\end{array}$ & $\begin{array}{l}+964(0) 662224558 \\
+964(0) 7504923604 \\
\text { Zagros25@hotmail.com }\end{array}$ & $06 / 10 / 2015$ & Erbil \\
\hline
\end{tabular}

As the nature of semi-structured interview, some of the questions prepared prior to the interview. The questions were different from one person to another but related due to the background of the respondents in terms of their position and works. The questions were asked to provide relevant answer to address problem statement and research questions. The follow up questions were used to generate new answer and enrich the qualitative findings. Through the answers provided by the interview participants, the research was successful in obtaining relevant answer to the following questions:

i. Why is capital budgeting process in Kurdistan lack of public deliberation?

ii. How can budget communication influences on the outcome of capital budgeting process?

iii. How can transparency and access to budget information impels the effectiveness of capital budgeting process? 
All the recorded interviews were transcripted and translated to English. Through the use of Nvivo, the transcripts have been nodded and classified in order to facilitate analysis. Subsequently, the summary of the nodes exported through Nvivo and manual analysis followed to complete the report.

\subsection{The Extent of Public Participation in Kurdistan.}

The degree of public participation has been analyzed in order to better understand the influence of citizens in public budgeting process of Kurdistan. The respondents provided different views on the extent of public participation. Some of them reported that there is no public participation. They have given different description to the existing economy and financial system in the region. One respondent addressed:

"The economy is just like a horse and the card, in which the horse is the economy and the card is politics. In our country, politics is the horse that pulls the card which is economy. That means politic pulls economy. Those who are planning economy are more influenced by the external as well as individual factors than economists" (Shamal Nuri, 2014).

Soran Omar, stressed that citizens do not have any participation unless in an occasion which is the day of election. Else, the government does not like to engage neither citizens, nor expertise. Likewise, Ali Hamasalih believes that participation in budgeting process does not exist, and when it happens, it's more symbolic and their voices are not heard by the government. In the other words, if there are cases of participation, it's just to legitimize government actions; otherwise their contribution does not have any impact on the final decision. Similarly, Mohamad Haji described the extent of public participation in Kurdistan, and claimed that relationship between government and citizens over 
government capital budget is not good enough. He believes that government does not deliberate citizens in budgeting process. He found no workshop, public meeting and citizen juries to be held by the municipalities to deliberate citizens. However, he still believes that the projects are somehow suggested by the citizens and community members because citizens asking government what they need to be delivered. Therefore, they are voluntarily giving recommendation and suggestion to the government of what they need to be offered in terms of public services and projects, otherwise government as he said will never consult their needs in capital budget.

Another evaluation was made by Aland Mahwi. He believes in the first stage of the budgeting, which is known as budget preparation in Kurdistan, citizens have no roles and do not participate in the process. This is true for other stages unless the legislature. $\mathrm{He}$ believes that there are some sorts of coordination between citizens and the parliament over budget proposals. Apart from that, Aland Mahwi has expounded another type of budget, known as the "Provincial Development Budget". In this type of budget, citizens participating and their views are taken into account. The officials responsible for distributing this budget are elected representatives of the citizens. He maintained that citizens are somehow involved in prioritizing projects and the overall budget decisions. Notwithstanding, this budget is still under capital investment budget.

Other respondents have addressed the lack of public participation in the budgeting process, but they didn't deny the fact that there pseudo participation. Ayub Smaqayii and Hamadamin Hawrami assumed that there is actually a proportional participation. 
Hamadamin Hawrami added, citizens were engaged to the preparation of budget in the ministry of electricity and conducted some projects in coordination between, Japan International Cooperation Agency, the World Bank and community members. Yet, he has admitted that "the participation is not enough." Controversy, ordinary citizens are not aware of the budgeting process at all, added by Ayub Smaqayii. To participate, he said he needs to use personal connection with policy makers. Thus, indicates the selectiveness of the government in deliberating citizens in the budgeting process which is not open for ordinary citizens. Ayub Smaqayii stated:

There are some sorts of participation; but, thus are proportional. When it happens, it's through personal connection not formal procedures. For instance, you may know someone in the parliament, government, or ministries to invite you; otherwise, the government does not invite us. Also, it might ensue through political parties. (Ayub Smaqayii, 2015).

In like manner, Zagros Fatah, the director of capital budget in the MoP underscored the issue of connection to participate in the budgeting. He admitted that there is not much participation and ministries submit their proposals to the MoP; then, MoP decides to approve their proposal. Although this may be correct, but, participation is still there which differ from one person to another and added, "If the mayor knows me, he might accept my requested project; but if he doesn't like the person, he does not listen."

Lastly, Anwer Qader, a director of planning projects in the Ministry of Agriculture (MoA) narrated that there is public participation in his ministry. He identified that in the 
MoA, they have coordinated with citizens to approve and select projects. He explained his statement by giving an example of participating 1000 farmers as representative of 160,000 farmers in their strategic plan. Those representatives were selected from different communities based on merits. Later they were communicated in consultative process.

\subsection{Setting Budget Priorities in Kurdistan's Public Budget}

This section elaborates how government sets budget priorities in Kurdistan. It gives an insight to understand whether citizens are deliberated and centered in defining budget priority g or not. The respondents were asked about the method of setting priority in public budgeting process.

Some respondents reported that decisions over budget priorities centralized by government and citizens have no role in prioritizing and selecting their demanded projects. Shamal Nuri identified that government performs centralized budget decision. Because of the existing classical system, the government has failed to deliberate citizen's needs. Unlike modern bottom up systems, KRG centralized budget decision. He stated:

"The budget is prepared inside ministries by some budget experts without having accurate and adequate data and without deliberating public needs" (Shamal Nuri, 2015).

Due to the complexity of the system and lack of transparency, Shamal Nuri was unable to answer whether prioritized projects reflects public need or not. However, he guessed that budget decision does not go along with public needs and conceded: 
"People sometimes requesting a new road, but the government renovates the old one or builds a new road in different locations which is not really requested by them. This happens because the KRG doesn't have priority. For instance, the residents of one village may need water, but the government builds a stadium" (Shamal Nuri, 2015).

In reference to his ministry, Hamadamin Hawrami agrees that KRG does not prioritize services through consultation, but the decision is made by the General Directorate of Planning in the Ministry of Electricity in coordination with other departments. However, they conduct feasibility study for their projects to evaluate the expected side effects.

Albeit, Anwer Qader sees people as the center of the decision in the MoA and their key objective of budgeting as he added, is to satisfy citizens rather than fulfilling their own interests. Though, has articulated:

"When we have a project to offer, we first communicate with scitizens, villages, municipalities, and their representatives. We take their views and sometimes we even want them to sign up agreement. We used to halt our operations in some projects that were under construction including dams, as we know citizens are not appreciating the project. If they do not want the project, we do not do it" (Anwer Qader, 2014).

In the same fashion, Zagros Fatah, Ali Hamasalih, and Soran Omar consistently addressed that ministries solely prioritizes projects and services which means people are outside of the process. At the end, the MoP makes the final decision over the projects proposed by the line ministries. For instance, if the ministry of health decides on the project, that project will be proposed by the Ministry of health rather than citizens. Although, citizens are excluded, but ministries do not randomly decide on the project. Each ministry has their own criteria and plans. Budget priority enumerated follows: 
"The governor decides. In the towns, the mayor decides what project to be priorities. How does mayor decide? They decide based on the fact that someone goes to them and asks for a project, another person asks for another project" (Zagros Fatah, 2014).

Correspondingly, Sarbast Mantik emphasized that ministries have their short term and long term strategy in which they design services in coordination with citizens and professionals. Although, Aland Mahwi is from the opposition political party, but he admitted that budget priorities are not selected by policy makers, but people have their role in proposing. However, its not always true. He has elaborated:

"...the government allocates budget, according to their (citizens) necessities and implement the project for the next budget year. When there is a demand for a project, the government puts strategy on how to fund that project in the budget .... Such demands constitute around 15 percent of the government budget. The government decides for the rest of the projects... They (KRG) feel, they study, or they know what people needs, or maybe they want to listen to attract voters and obtain their politically ambitious..." (Aland Mahwi, 2014). 


\subsection{Factors that Caused the Lack of Public Budget Deliberation}

As discussed above, most respondents either addressed no participation or lack of public participation in public budgeting process. The respondents also provided some factors that burden citizen's deliberation in the budgeting process. This section provides answers to the first research question "why is capital budgeting process in Kurdistan lack of public deliberation?" The factors classified into the following:

1- The absence of good financial system

2- Political parties' interference

3- Corruption and nepotism

4- Budget limitations

5- The lack of trust between government and locals

6- The weakness of civil society organizations

\subsubsection{The Absence of Good Financial System}

The financial system is usually a key contributing factor of good governance in public financial management. Obviously, a better financial system could provide an opportunity for citizens to participate in public policy planning including public budget. Mohamad Haji has demonstrated that public budget is lack of public deliberation as government never used deliberative methods such as community meeting, gathering people and discussing budget priorities, survey and workshop. Without giving further details, he found government as a burden to the lack of public deliberation. 
Some of the respondents have related the lack or absence of public deliberation in Kurdistan's public budget to the absence of a good financial system. Some of the respondents agreed that financial systems in Kurdistan region are very complicated and left no room for citizens and expertise to contribute in the budget decision. One of the respondents added:

"There is no budget in this world without a problem. However, what's important is to pass budget with minor deficiencies, to facilitate the implementation of public demands" (Shamal Nuri, 2014).

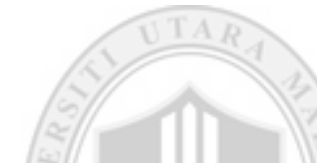

Surprisingly, Shamal Nuri stated that, citizens do not even know there is a financial system. They are also uncertain of the type of financial system and how it functions. He complained on the system that it's the end of the year and the budget not yet approved.

Soran Omar, revealed that in Kurdistan Region, investment budget becomes a tool to misuse public money and justify corruption acts. For him the allocation of public budget is not efficient, but as he stated officials allocating public budget disorderly. Thus, the KRG can not decide on how to allocate budget priorities and how to allocate a budget that allows citizens to fulfill their needs. Shamal Nuri relates the KRG failure to the lack of expectation and complexity of the system that degrades budget deliberation with citizens. For instance, the government has paid millions of dollars to consultant companies, but 
without expectation, they were unable to overcome budget deficiencies. He elaborated his point by giving an example of MoA. He said that MoA admitted their failure and only implemented 13 percent of their strategic master plan designed in coordination with foreign consultation companies. Then again, Ayub Smaqayii correlated this issue into the complexity of the system. He also conveyed that the lack of budget deliberation is because "we perform classical model of budgeting in Kurdistan....we only add and deduct some numbers...”

For Ali Hamasalih the KRG does perform budget deliberation because “...they can not set budget priorities; besides, the government can not allocate budgets for all projects." Thus, relates to the weakness of the system. He maintained that government is lack of planning and financial institution. The lack of planning has restricted the scope of participation, noting that:

"They (KRG) proposed several projects to be funded in the budget, and they didn't have enough money for all; subsequently, the projects remained until the next financial year which becomes a recurring project" (Ali Hamasalih, 2014).

\subsubsection{Political Parties Interference}

The political parties, mainly the PUK and the KDP have major influence on capital budget decisions. The government budget decisions somehow shaped by the political parties. The 
director of capital investment budget in the MoP does not deny the fact that political parties have their role in discouraging people from participation. He stated that political parties have their influence on budget decisions. It has become a burden that budget is not participatory prepared. By the same token, Ayub Smaqayii and Soran Omar both agreed on the similar factor that associates to political parties. Ayub Smaqayii tried to explain the factors that explain the lack of public deliberation and highlighted that the projects will be implemented in accordance to the interest of political parties. Otherwise, as he asked "many demonstrations happening and people asking for projects and services, but the KRG does not provide a budget for these projects, or when they allocate budget, it's too little to complete them or they postponed the project." Likewise, for Soran Omar, political parties have dominated public administration system and capable to change KRG decision. He reported:

"The two main political parties that ruled this country for decades (the PUK and the $P D K)$ allocated budget to hundreds of projects to their organs, to their members. For example.....the government rents houses, while there are luxury hotels and apartments.... funded by the KRG, and have been used by the political parties" (Soran Omar, 2014).

As political parties controlled budget decision, the government is incapable of contributing ordinary citizens in preparing budget. The impacts of political parties are stronger than the impacts of ordinary citizens. Political parties can even define the location of the project with no consideration to public as highlighted by Soran Omar. By the same token, Mohamad Haji identified that some areas do not receive even basic services such as school and roads because they are affiliated to different political parties. 
Aland Mahwi articulated that political parties endeavoring to utilize large amounts of money from public budget to fulfill the demands of their members. For instance, as he explained they put thousands of their members on retirement list and provide their monthly pensions through public money. Subsequently, that has posed an intense pressure on government budget, especially on a capital investment budget in which caused less money to be allocated to the projects. The smaller budget caused minor participation (for details, see section 6.3.6).

The impacts that political parties have on the budget decisions is not direct for Ali Hamasalih, but they can indirectly influence on the budget decisions. For instance, the head of the political bureau of one of the political parties may find a project important and asks particular ministry or the MoP to be funded in the budget. Although, Ali Hamasalih finds doesn't find their direct impacts, but raised another issue which is fake projects. He has accused political parties for making large profits on behalf of citizens through the use of fake company names that resulted in several low quality projects. As the result of their interference in the budgeting process, as he initiated, their profit increases and people are suffering. The other side of this, you can not investigate and evaluate the projects implemented by their companies because they are more powerful than anybody even ministers and directors. 


\subsubsection{Corruption and Nepotism}

Corruption is normally one of the factors that disrupt good governance. Corruption could contribute in several administration issues, including public financial management. Corrupted officials may take an opportunity to conduct their corruption acts in the absence of citizens in budgeting process. In the presence of people and transparent process, policy makers may not see any direction to use public resources to their personal needs. Thus, officials are trying to put citizens outside of the process. In relation to that, interview respondents zealously addressed the issue of corruption as an obstacle to public budget deliberation in Kurdistan Region. Fake projects might be one of the factors that policy makers are not willing to deliberate citizens. Soran Omer addressed:

"There are fake projects listed in the budget and government also provided budget to them, but they do not exist in real. I can say public budget becomes a source to corrupting and the misuse of public funds; otherwise, funds should have been allocated to strategic projects, to rebuild the country's infrastructure especially in agriculture and industry sector......"

These projects are used by the political parties and the corrupted high ranking officials to hide their corruption acts. Also, political parties trying to mandate their activities by using public resources. This could be a very obvious example of corruption by the political parties in public budget that makes government to exclude wider community in public budget deliberation. In Kurdistan Region, political parties dominated all sectors of government and if they allow government to deliberate citizens, they will be insecure to conduct any acts of corruption especially stealing public money in the name of projects. On the same issue, Aland Mahwi maintained: 
"Public budget was used by political parties, especially ...... the PUK and KDP......They used different names to justify their usage of public money. For instance, when their political party needs a building, they don't use their own money, but they use public budget.... false names like cultural building or restaurant. ......... sometimes the budget also used for private sector projects such as a Choueifat International School in Erbil and Duhok."

Nepotism which is another type of corruption contributes to the lack of deliberation in the budgeting process. Aland Mahwi deliberated the issue with examples. He said, the KRG provided projects and services to the location where officials are living. He elaborated his claim through the example of a small village in Qaradakh (an area near Sulaimaniyah) which he believes to be well known by people:

"Since the brother of ..... the minister of Peshmarga lives in that village, no one allowed to implement any kind of projects in that area if they don't implement the same project in his village. The government has provided all their necessities, even more than they need. However, if you take a look of $10 \mathrm{~km}$ further, there are villages with higher population, but the government didn't provide even half of the services provided to the aforementioned village" (Aland Mahwi, 2015).

The above claim was also confirmed by a local person from the area, but he does not want his name to be revealed. He even said, just few hundred meters from that village, villagers does not even have basic needs.

\subsubsection{Trusting Locals}

The government does not trust local citizens and their experiences. Some respondents found trust as an obstacle to the lack of public deliberation in the KRG budgeting process. Ayub Smaqayii addressed that government does not trust local people; instead they hire foreign consultation companies to prepare budget proposals. He also maintained that has 
not reached to the level to deliberate local experts in preparing budget proposal. Likewise, Shamal Nuri emphasized that government pays millions to the foreign consultation companies other than deliberating budget with local experts and citizens. The government relationship with local economists is very weak and they put trust on the foreigners. Priority is more given to foreign expertise who might have no understanding on the KRG budget. Shamal Nuri revealed that those companies has failed to support government in preparing good budget and added:

“.... They (foreign expertise) copied their countries own system and trying to apply here ...... their psychology and budget are very different from ours ...... when they propose a project for farmers, they don't conduct a feasibility study... In our country ...... we have financial instability, we may have achieved development in some sectors, but we do not have strategic plans. For instance, only 13 percent of the agricultural development plan was implemented while it's a very well structured program, but not applicable to Kurdistan because its copied from other countries" (Shamal Nuri, 2015)

Shamal Nuri believes that if government gives them an opportunity, they can do a better job. Locals can better understand the psychology of people and the kind of services are needed; but, he said "we are so attracted by foreigners." He provided an example of a British consultation company signed $\$ 60$ million contract with the KRG, but he said the company had a messed up master plan and they admitted. He was voluntarily showed his willingness to help government along with other academicians and budget expertise, but the government has refused to deliberate with them. Simply, this issue is because KRG does not trust local expertise.

Ayub Smaqayii equally criticized civil society organization as they don't show their supports to the government. He believes within Kurdistan Economist Syndicate, not 
everyone eligible to participate in the budgeting process. Since economists are politically affiliated, the KRG does not trust their ability to have an effective role in the process. Though, Shamal Nuri argues that in any case, local expertise can have better impacts.

\subsubsection{The Weakness of Civil Society Organizations}

Civic society organizations in public budgeting process usually become a bridge between citizens and government. However, when discussing the role of Civic society organizations in Kurdistan, things are different. There are over 2000 NGOs working in Kurdistan. There are less than 10 NGOs working in economic sector and none of them specifically working in public finance. However, the key player in Brazilian PB and other countries is Civic society organizations. Ayub Smaqayii describes the role of civil society organizations and added:

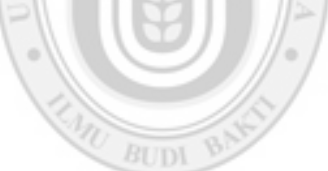

"We are weak because we don't participate, we are not active, we don't have enough budgets, our relationship is not good and this is because of our weakness and also officials are not deliberating with us" (Ayub Smaqayii, 2015).

Shamal Nuri rebutted this argument and believes that NGOs are performing their jobs very well, but the KRG does not appreciate their views. He challenged KRG that he wanted to participate previously, but they didn't appreciate his willingness: He also stated: 
"The KRG suffers from terrible financial crises, but the government..... do not deliberate budget with civil society organizations ....... if we take Economist Syndicate, we have over 6000 members; many of them are experts, professionals, holding master and doctorate degree, but we have not been deliberated" (Shamal Nuri, 2015).

\subsubsection{Budget Limitation}

Every budget has limit and not every project that citizens demanding could be placed in the final proposal. One of the issues of public participation arises when government deliberating budget with citizens because their demands increasing. When government fails to fund all deliberated projects, disagreement and conflicts arises. For that, the government sometimes is not willing to deliberate budget with citizens. If comparing

budget and population size, Kurdistan may have a big budget compare to other developing countries. However, as addressed by Aland Mahwi, budgeting in Kurdistan has several limitations mainly the imbalance between capital investment budget and recurrent budget. The KRG prime minister on January 22, 2016 highlighted this issue. He said, there are almost 1.4 million employees in public sector. Thus, the larger part of the budget goes to the salary of employees and the capital investment budget did not exceed 31 percent of the total budget in the last 10 years. For the salary of employees, the KRG needs at least US\$800-850 million monthly, Aland Mahwi said. This has become a key limitation on public deliberation.

Ali Hamasalih also concern on the limitation of financial resources in order to maintain deliberative process in the KRG public budget. He said, the budget is not even enough for 
the salary and basic services and in such circumstances public participation might not be possible and claimed:

"we can carry out public participation when there is money, in the absence of money that can not happen. Again, I give you Raniya as an example. If you ask people to list their needs, they list 300 schools, each neighborhood ask for school, asks for road, and the budget is not adequate for that" (Ali Hamasalih, 2014).

He found inadequacy of the financial resources burdens overall participatory process. He has elaborated, if the KRG deliberates citizens in preparing budgets, citizens may become more critical and dissatisfied for not including all their proposed services in the proposal. The issue is very serious and should be solved if government intends to perform participatory budgeting process. He addressed:

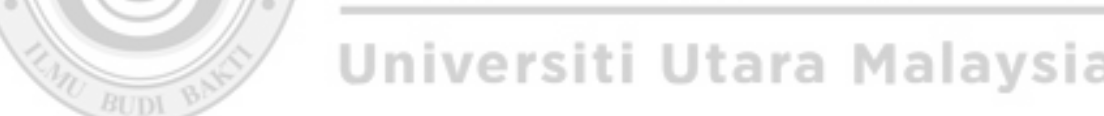

“...........they (citizens) may ask for the projects that all together needs 100 billion (Dinars: US\$1=1120 Dinars), while the government only provided 2 billion to Ranya projects ..... This 2 billion again will be divided on sectors .......... with this amount of money, they can only build a school or a road......"

Although, Ali Hamasalih is known to critical towards government, but he tries to justify that government is right for not deliberating budget with citizens. Instead he criticized private sector companies. He said private sector was unable to fill up the existing gaps in services provided to citizens. The government capacity is limited and they can not provide every service, but private investment should fill up the existing gaps. In some countries, private sector building schools, hospital, highways, and develop infrastructure, but in 
Kurdistan, they have no contribution. Also, people are not ready to pay for the highway, if they show their willingness to help government.

All government officials interviewed in this study addresses that budget provided to their projects is scantiness and they need more money to fulfill their plans. For instance, one respondent highlighted the exact budget, they need for their projects, but the government failed to provide, that might discourage farmers to continue farming:

"Comparing to other countries, the funds that we have is only 9 percent. For that, we can only provide 9 percent of their (Farmers) necessities ....... As the MoA, we need 720 billion dinars for our projects to support farmers. However, they $(K R G)$ only provide $\$ 50$ million, which is 9 percent. In the total budget, it's about 1.91 percent. We (MoA) usually ask for at least 10 percent of the (total KRG) budget, because we need more budget" (Anwer Qader, 2014).
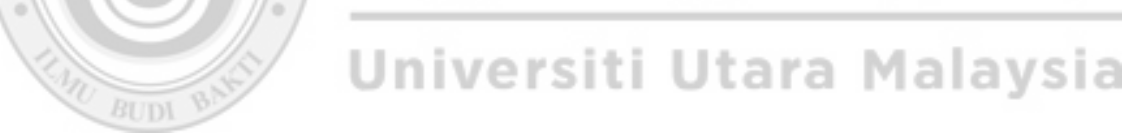

However, this issue is explained in details by Ali Hamasalih and Aland Mahwi. They agreed that KRG ministries does not have strategic plan to allocate balance budget. The KRG is randomly planning budget that caused the lack of resources. Zagros Fatah criticized the way that ministries preparing their budget. He said they don't consider how much budget is available. They usually send a list of projects that exceeds the amount provided to them. The MoP in this case cut of part of their budget and takes out several projects in the proposal forwarded to them. This is cheating for Aland Mahwi by the ministries that negatively influenced on the budgeting process. The KRG ministries usually proposing more than $25-30$ percent of the budget allocated to them, while 
according to the global standard, this amount should not exceed 5 percent. The same issue also happens in the reverse way. There were cases pointed out by Aland Mahwi that MoP allocated budget for ministries that never asked for. On the same token, Ali Hamasalih highlighted that there was cases that a particular ministry asked for 2 trillion dinars to complete a project, but MoP allocated 500 million. This issue pushes KRG ministries not to deliberate citizens, because they are certain their budget will not be enough for what people asking for. Also, they will find unlikely outcome if they just symbolically deliberate citizens.

Although, the ministry of planning excludes some proposed projects, but that does not solve the issue of budget limitation. The proposed projects remain to the next financial year, whereas the government can only provide budget to uncompleted projects approved in the previous financial year. This is because the MoP removed the project or shortlisted to the next financial year. Ali Hamasalih described this as an obstacle to deliberation. Subsequently, the KRG may not be able to deliver sufficient services as well as satisfying their needs. He was certain that 90 percent of the money allocated to capital investment projects goes to uncompleted or recurrent projects, and around 10-15 percent allocated for new projects. In the best case scenario, this number does not reach to 20 percent. He reported:

"You have 5 trillion and you have 100 old projects. These old projects are not completed and you can not skip them. So, you need to allocate money for the completion of these projects. According to the MoP, to complete uncompleted projects, the KRG needs 16 trillion......... If we take 2013 or 2012 as criteria as an example, to complete the projects delayed in these financial years, we need almost 8 years without even conducting a new project during that period" (Ali Hamasalih, 2014). 


\subsection{The Positive Outcomes of Budget Communication}

The process of public participation could have several positive influences on the overall process of budgeting. This study intends to explore how can budget communication influences on the outcome of capital budgeting process. This section examines the importance of budget communication in relation to Kurdistan Region.

There are many likely outcomes of budget communication that changes the direction and the influence of the decision towards public needs satisfaction and public services. Respondents have provided adequate resources to answer this research question. Mohamad Haji has explained that people are partially satisfied with services provided by the government except the quality of the projects that citizens are not satisfied with. For him the quality of projects is not good enough and some projects are delayed for several years without any progress. However, he believes that in the presence of community participation, this may not happen, the quality will be better as well as the implementation will be faster as they collaborate in the process. Moreover, one of the respondents has explained the way that sharing views in the budgeting process can make decisions more effective and acknowledged:

"If people truly engage in the process, the sense of citizenship will be twisted. They become patriotic, they love the country, the people and the environment. An individual participating in policy making process becomes a productive citizens and vice versa" (Smqayy). 
Accordingly, when citizens have a sense of citizenship, they become more concern and mind on how to use the budget in the right projects and services that citizens really need. In the absence of budget communication, public budget will be misused. By the same token, Hamadamin Hawrami addressed that communication and participating citizens in the budgeting process is very significant. He agreed that if citizens communicated in selecting projects, the advantages will be higher in terms of quality and outcomes. Another respondent provided a coherent response. Ayub Smaqayii maintained that when citizens have the sense of citizenship, they become responsible in using public services which probably induces the quality and quantity of services as exhibited:

"You know if citizens have the sense of citizenship, they will become a servant of all sectors. They would be more conscious in using electricity, in using water, in using roads, in respecting security, they would be more patriotic and sacrifice for the country and the people, and they don't simply throw rubbish on the streets. The government can gain millions from each citizen annually if they participate ..... (Ayub Smaqayii, 2014).

Zagros Fatah who has experience with PB and worked in some PB programs provides an important insight on how collaboration and consulting citizens in some PB induced the effectiveness of budget decisions. The first outcome of budget communication as he discussed is democratization and empowering citizens to make the right choice. He argues that as he witnessed the impacts of participation in budget decision. More importantly, he addressed a practical contribution of public participation in budget decision that brings better outcome for both sides. He enlightened that if I make a budget decision in the absence of proper communication with stakeholders, I make it right on my table and I have no idea what citizens really need and added: 
“... Because you are making a decision not on my table of what people in Said Sadiq needs, or what this village wants.... Maybe if I go to the aforementioned village, my expectation will be: oh this village needs a school, no actually they need a water network, a sewage network. When we visited the village, people all together asked for the sewage network. Maybe if not this program, we couldn't bring them sewage network, even after 10 years. So, this is decentralization, the decision is made like that. It includes community participation. Means, the community participated. It's very important. Do you know what the key importance of participating is? They feel ownership!" (Zagros Fatah, 2014).

The other key importance of this process is increasing the sense of belonging and cooperation with parties accountable for the implementation of the projects. He said people are willing to take care of the projects, helping each other, helping contractors and respecting government officials. Through participation as he said, you are empowering your citizens and this is how government can create inclusive institution that benefits community members and society as a whole. The last thing he addressed is consultation reduces the misuse of public budget because as he said people will become a safeguard and know the amount of budget needs to complete the project, how much has been expended. The result will be less chance of stealing or misusing budget and it will automatically induce public service delivery. 


\subsection{The Influence of Information over Budget Decision}

Information associated to the capital budgeting process and used as a condition to continuing participatory process. This section provides an answer to the third research question which aims to examine how access to information increases the effectiveness of capital budgeting decisions.

Zagros Fatah has realized the significant of information in the capital budgeting process. He proclaimed that in the $\mathrm{PB}$, people will be given informed on how the process is functions. He has postulated:

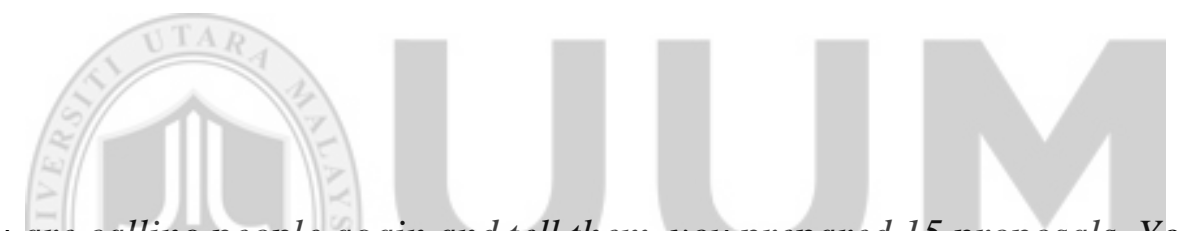

"You are calling people again and tell them, you prepared 15 proposals. You tell them we have only 500,000 dollars. So can you please vote for two of them because we can only implement two of them? So, they vote for the top priorities. The two projects that get the most votes will be approved. Participants can also participate in the tendering process to see how this is done" (Zagros Fatah, 2015)

This process is more described as transparency because you let your citizens know how much budget is available, how to tender, select, implement and evaluate projects. Information is not only significant for people to participate, but also for government to understand what different communities in different locations need. He maintained that "the representatives of the towns and cities collect information on what people really need, whether they need water sanitation or other projects." This is to understand and carefully making capital budget decision, without access to information, neither citizens, nor government capable of understanding each other and pursue participatory programs. 
Though, Mohamad Haji claimed that citizens in Kurdistan Region do not have information over the process and they do not know how much money is allocated to their projects, what kind of projects to be implemented and other budget details. He maintained that they know about government plan when government starts to implemented proposed project.

However, some of the respondents found it challenging to obtain data on the government financial activities. One respondent explained transparency condition in Kurdistan's public budget and he found it very difficult to get the data that he was looking for. He even could not obtain data for his study on the budgeting, but as he said to get data on government finance, citizens need to use connection. In the participatory budgeting programs, government is required to deliver latest data to the citizens. The director of statistic department in BOI identified that citizens have no information on the projects and the KRG in general, is not supportive. However, he claimed with confident that his board gives any kind of information on their activities and plans if citizens asking for; but government is not willing to voluntarily give data without request from the second party.

In contrary, Shamal Nuri complained about the lack of information and data in capital budgeting process. Through his observation, he concluded that Kurdistan budget is not transparent and it's a complicated process. He stated that "since we don't have accurate data and statistics on the budgeting, it's not easy to have a well-planned budget." He 
further attested the issue of accessing information in Kurdistan and listed several budget problems that somehow associate with information:

“... Another problem is the budget deficit, lack of transparency in the budgeting, the lack of transparency in expenditure, and lack of transparency in oil revenue. For instance, in my research I didn't cover oil revenue and the expenditure in this sector, because I was sure that I won't get any data for that......" (Shamal Nuri, 2015).
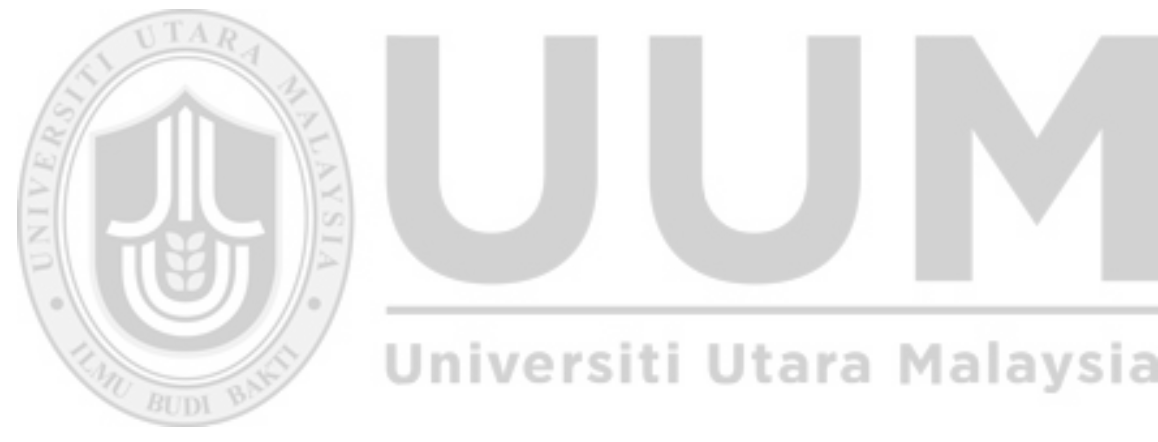


\subsection{Budget Decision in the Absence of Citizens' Participation}

This section explains the situation in which citizens are excluded from budgeting. It also provides a good interpretation of the problem statement, the first and second research questions. Actually, the condition of the budgeting process in the absence of community members or their representatives is very critical. One of the major issues that arise in the absence of public participation is opening doors for corruption. Officials will have a better chance to steal or to misuse public money. Aland Mahwi tried to give a clear vision in which excluding citizens in Kurdistan budgeting have caused political parties to include their projects in the budget proposal. He claims with confidence that hundreds of projects found in the budget, which has nothing to do with citizens, rather than fulfilling the needs of political parties, such as building their political headquarter, building their institutions for their political parties use. These projects mainly funded in KRG budget in that supposed to be used for public services. However, in the lack of public participation, they find better chance to utilize budget for their interest. This situation impacts on public services since the money supposed to be used for public service, misused by political parties.

Apart from using for political parties, the KRG budget was also used for private projects. Aland Mahwi gave the example of the Choueifat International School, which is a private project, but funded by the KRG. He indicates that, only the school nearby rich families may capable of sending their family to that school; otherwise, ordinary citizens can not afford to study there. He believes almost 90 percent of Choueifat students are from high ranking public officials, and 10 percent belongs to rich families. However, his concern is 
mainly because such projects should not be funded through public budget that supposed to be used for public services not to private sector and establishing private business. Thus, Soran Omar asserted that public budget becomes a source to misuse public funds rather than satisfying public needs.

Other issues related to such conditions raised by Shamal Nuri and Anwer Qader. Shamal Nuri emphasized that citizens will not be committed toward their government if their roles is not taken in the budgeting process. If citizens ignore, they will have the sense of spoiling projects other than supporting. On the same issue, Anwer Qader believes planning projects without deliberating citizens does not make sense and will have no value. He found out this fact during implementation of some projects in his ministry which decided without the acceptance and contribution of citizens. He pointed out that the recipients of the services were not happy for what we offered to them and they didn't appreciate our efforts. Besides, he maintained that people rather make fun of such projects than dealing with. Unlike previous respondents Zagros Fatah cited that when citizens remained outside planning process, “that doesn’t mean the projects are not good, but they are lack of public participation." However, he noted:

"When the government implements a project without the participation of people, people are raising their voices and blaming government for it, what the government is up to, oh don't know, they make a building! For what? Oh I don't know, I don't even know who is staying there tomorrow." 


\subsection{Increasing Public Satisfaction and Better Services through PB}

Budget decision through participation can change the quality of decisions and the perception of citizens of the services they deliver as articulated by Mohamad Haji. Some of the respondents underscored the relationship between public service delivery and PB. Ali Hamasalih believes government can not either fulfills public needs; neither accomplish its budget goals due to the lack of financial resources and complexity of the system.

Other respondent like Shamal Nuri criticizes government finance and maintains that ignoring public views in the budgeting process impacted on the lack of public services and public satisfaction. He sustained that people paying tax for everything, and we live on a sea of oil. Citizens are expecting to deliver better services from KRG. He has asserted, when people paying tax, their voice has to be heard. He compares Kurdistan Region with the USA on how citizens raising their voices and questioning the system because this is their money that the government uses for budget; however, Kurdistan is lack of that. Consequently, as he contended the quality of services is low, projects are not good. Due to that issue, Kurdistan is still lack of electricity especially during the hot and the fall seasons.

Hamadamin Hawrami asserted that citizens are not dissatisfied of their services to that level. He claimed that due to the development that KR obtained in the last 10 years, the demands for electricity increased by 16 percent annually. For that, he claimed "they need consultation and engaging citizens" in their future strategies. He also did not hide his fear 
of public participation because he believes that when they consult citizens, their demands increasing and it happened in their previous budgets.

Soran Omer believes there is no participation in Kurdistan's public budget. For him, the projects are not good enough in terms of quality and they are not equally distributed. Subsequently, service delivery ruined, people are not satisfied of the services, and private projects replaced public projects. He has contemplated:

“..... There are millions allocated to investment projects, but they don't have any advantage for the citizens. On the contrary, the objective of the project provided by the $K R G$ is to enrich investors and some government officials. Sometimes, KRG officials are shareholders with investors."

If comparing the projects that citizens directly or through their representative participated, much difference could be noted. Citizens are more satisfied with the services they receive through deliberation. The quality/ of the projects in which selected through citizen deliberation is better than projects in which citizens are not participated, Anwer Qader said.

Based on the experience he has with a consultative service delivery program, Zagros Fatah emphasized that citizens pleased and satisfied with the services they received. He explained with confident that if you ask any of the participants, they would be very glad to answer on how satisfied they are. For him, those people are even surprised when they found government provides services in consultation with them. Service offered in that program, appreciated by the communities. 


\subsection{Chapter Summary}

This chapter analyzed the result of qualitative data obtained from interviews. The study confirmed that budgeting in Kurdistan lack of public deliberation. This issue associates to the absence of good financial system, budget limitation, political party's interference, the weakness of the Civic society organizations, corruption, and the lack of trust. This chapter also intensified the essence of budget communication in capital budgeting process. Budget communication is seen to increase public services, return on investment, legitimacy of decision, public needs satisfaction, decentralization and transforming decision power to people. This chapter indicated budget information significantly increases the effectiveness of budget decision and it's a pre-condition to maintain participatory budgeting programs. It also helps to combat corruption and poor financial management. 


\section{CHAPTER VII}

\section{DISCUSSION AND CONCLUSION}

\subsection{Introduction}

This chapter discusses the findings in details. The discussion part is divided based on the research questions and hypothesis. The findings will be compared and discussed in relation to the previous literature.

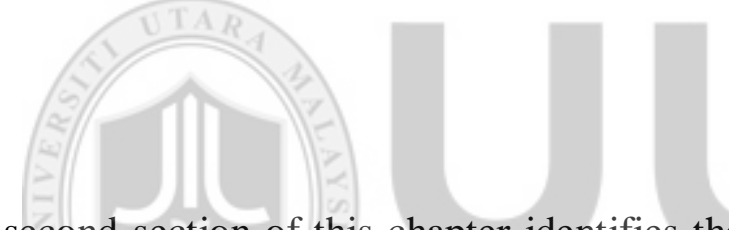

The second section of this chapter identifies the limitations of the study. This research comes up with interesting findings. Part of the findings is new and becomes a major contribution to the existing literature. These contributions highlighted in the theoretical and practical implications. A set of policy recommendations also provided to the government in order to conduct participatory budgeting. Recommendation for future studies followed which identified several research gaps for the future researchers interested to develop this research or conduct further research on the same issue. A conclusive summary of this thesis provided at the end of this chapter. 


\subsection{Public Deliberation and Capital Budgeting Process}

Public deliberation as defined in the previous chapter is a careful weighing or discussion. It's different from public participation in the sense that deliberation refers to discussion in the participatory process, while participation could be deliberation, or consultation. Deliberation does not occur in every participatory process, but it will be very important to become part of the process. The term of deliberation also associated to democracy and it's commonly known as democratic deliberation. Democratic deliberation as discussed by Weeks (2000) offers an extended opportunity for local communities to participate in the decisions and obtain knowledge about policy problems. Deliberation is usually known as part of democracy, but it does not happen only in democratic systems. Deliberation can also happen in authoritarian systems as in China. However, due to the nature of deliberation which includes criticism, discussion, debates, and arguments, it may less likely happen in authoritarian governments.

Public deliberation could have positive impacts on the budgeting process, but it can also bring negative outcomes to the decisions. The finding of the survey questionnaire is consistent with the finding of Patmen (1970); Habermas (1989); Burkhalter, Gastil, and Kelshaw (2002); Munno and Nabatchi (2014). These scholars have come up with a positive correlation between deliberation and decision making process. The positive outcomes of deliberation could be analyzed in the way that deliberation helps policy makers to have better insights on the projects they are instigating. It helps them to tackle service problems. Roberts (2004) found that deliberation assists government institution to expand participatory process and make the right decision. Deliberation impacts on the 
community members and policy makers to congregate through meaningful discussion to accomplish better policy outcome. It significantly influences citizens to take ownership of the process (London, 2004, p.14). When citizens have the feeling of ownership, they will be committed toward the system. This argument is consistent with the survey statement indicating that deliberation can help to form collective action for common goods (mean value 4.11); deliberation drives collaboration and better governance practices (mean value 4.15). Munno and Nabatchi (2014), and Chang (2012) came up with the same result. Their results emphasize that deliberation assists government to solve policy problems as well as promotes the quality of the decisions.

The result of analysis affirms that budgeting in Kurdistan Region lacks of public deliberation. It has become a contributing factor that led the KRG fail to the right choice. The KRG also failed to consolidate different arguments in planning investment projects. Indeed, the KRG is not always deliberate citizens in developing budget alternative. Developing alternatives through deliberation helps policy makers to receive various recommendations to make a genuine choice. It ensures decisions are legitimate, transparent and informed. Eventually, the decision reflects broader community values (Abelson et al, 2007; Bombard et al, 2011; Costa-Font, Forns \& Sato, 2015). Under those circumstances, the KRG will be able to select projects that yield the most return on investment. The study has initiated that deliberation in capital budgeting process will help to select the most cost effective projects (mean value 3.95). The KRG has used to allocate a bulk of money to unessential and unnecessary projects. Consequently, the KRG fails to finance other essential projects due to the lack of financial resources used for unessential 
projects. In the presence of public deliberation, this issue could be resolved since citizens will choose the most cost effective projects. Whereas, the findings of the interviews illustrated that KRG can not conduct meaningful deliberation where there is shortage of financial resources. This argument conflicts with the result of survey questionnaires. Since citizens prefer to be in the center of any government decision, it's expected for them to ask for deliberation in all cases. Therefore, policy makers and budget expertise may observe the capacity of government and obstacles that burden public deliberation to occur. They realize the importance of budget deliberation, but it requires some arrangements and pre-conditions. Citizens find the KRG insincere to put them in the center of decision through deliberation. They believe deliberation assists government to better allocate scare resources and tackle social diprivatization. The better allocation of the resources here could be intensified in terms of redistribution of income and avoiding corruption and the misuse of public funds. Citizens in meaningful deliberative process oversight budget preparation, and oblige officials to avoid delinquencies.

This study also stressed that quality of projects are not satisfactory. Indeed, this issue relates to unconsciousness of the KRG of what people really needs. Obviously, the result of analysis found that projects are not systematically planned based on public preference. Deliberating public preferences is necessary for government to enhance public services and satisfy public needs. Participants supported this argument. Based on that, it could be argued, if the lack of deliberation causes discontent, then deliberation can be essential tool to ensure public satisfaction. Conducting budget deliberation brings better services and enhances communities' bindings. This study has indicated that budget deliberation 
increase collective action for the common good and collaboration between government and citizens. By way of contrast, this finding contradicts Morrell (1999). In his study, the author found no relationship between deliberation and public satisfaction. This study highlighted budget deliberation makes citizens to have positive perception toward government and realizes the essence of their citizenship.

\subsection{Factors of the Lack of Public Deliberation in Kurdistan}

The first objective of this study was to discover factors contributed to the lack of public deliberation. Identifying deliberation constrains are critical to implement participatory mechanisms. Deliberation requires several pre-conditions and particular environment to be conducted. The study explored that factors are different from one place to another especially to the countries that have never experienced budget deliberation. The study has identified several factors limited public deliberation. One of the factors explored in this study is high financial volatility. There is lack of financial resources to implement public deliberation. Major part of the KRG budget allocated to the salary of the employees which is estimated to be 1.4 million employees out of 5 million populations. The KRG has allocated less than 30 percent of its budget to the investment projects since its establishment. That has become a major constrain to participatory budgeting. It might be a bad idea for the government to imply budget deliberation when there is inadequacy of capital. Money is an effective motive to have budget deliberation. The KRG budget is comparatively small for capital investment projects. As a result, the government is unable to discuss public budget with citizens. In deliberative process, people will discuss budget alternatives and their demands increasing comparing to the normal cases. However, the 
government can not allocate budget for every project that citizens deliberating. If government invites citizens to budget deliberation, and ignores their demands, it widens the gaps rather than solution to the existing problems. Individual participants become critical and dissatisfy over services they receive. It's very essential to take citizens demands and proposals into consideration when inviting citizens to PB programs. The PB should not be symbolic, because in the long term, citizens can not trust their government and will be more disappointed. Such process makes them not to participate in the future programs.

Some scholars have assimilated their research on how to conduct deliberation under the condition of financial instability (Gomez, Insuan \& Alfaro, 2015). The study emphasized that its difficult to provide a policy recommendation on how to implement deliberative approaches. They recommended three approaches, namely negotiation, arbitration, and voting. These recommendations are not applicable in Kurdistan. They could be conducted in the country that has decades of participatory budgeting experience, but Kurdistan is new for that, and that also needs financial resources to be implemented. Unlike the previous discussion and the interview findings, Alves (2014) believes that lack of resources is not really an intense factor to prevent public deliberation. For him, the misallocation and distortion of public budget are more serious conditions. Alternatively, to overcome issues of capital limitation, and misallocation of public budget, the author recommended public participation to be a solution. This is also supported by survey respondents who believed, deliberation helps government to manage scare resources more properly (mean value 3.96). Therefore, if the government deliberates citizens in planning 
capital budget and selecting budget priorities, they may be able to fund more projects and services that are really needed. This also lessens the misuse of public budgets and corruption that has already become a burden on Kurdistan public finance. Deliberation and money can affect each other. Money motivates deliberation to happen, and deliberative motivates better allocation of money.

The other limitation of budget deliberation in Kurdistan Region is the weakness of civil society organization. Wampler (2007) discussed that people can better engage in the budgeting process if there is an institution to support them. He also maintained that civil society organizations can provide a framework for policy makers to tackle public issues. This is also seen to be an important motive in the success of the Brazilian PB program. They become a bridge between citizens and government. In many cases, civil society organizations preparing the meetings and forums, then inviting both policy makers and community representatives to deliberate budget. The role of civil society organizations in Kurdistan more concentrates on the democracy, human right and politics. There are nearly 2000 NGOs in Kurdistan, but less that 10 of them working in economic sector, and none of them specifically working on public finance. Part of the civil society organization even becomes a burden to public budget. They receive funds from government budget, but they only exist in names. Unlike local NGOs, some international organization like World Bank, ACDI/VOCA and UNDP have previously played effective role to put up PB on the spot. For the first time, the KRG was able to conduct PB in coordination with ACDI/VOCA and World Bank. Therefore, they inactiveness has caused the lack of budget deliberation. The KRG at this moment needs support from NGOs and Volunteers 
to apply deliberate budget with citizens. Civil society organization and their relationship with local communities and government institutions significantly impacts on the level and effectiveness of public participation (Abom, 2004).

The political parties in Kurdistan are interfering in every aspects of governance. They are directing government decisions to fulfill their agenda. In the budgeting process, the roles of political parties are destructive especially in budget deliberation. They do not allow the KRG to transfer their role into citizens. Deliberating citizens minimizes their influence on the budget decisions. The findings indicate a strong relationship between political party's interference and public deliberation in the capital budgeting process. A least opportunity left for ordinary citizens to deliberate budget with government. Under the influence of political parties, the KRG has funded several projects. These projects did not have impacts on well-being of citizens, but rather used by their members. Political parties have misused millions of dollars. The participants obviously discussed that political parties have limited public budget deliberation and act on behalf of KRG. Political parties are more powerful than policy makers. This issue also described in deliberative democracy theory as implication to deliberation and reasoned based argument. The theory emphasizes that powerful elites and interest groups should not be allowed to dominate decisions. The activities of political parties are funded from public budget. In the presence of citizen's deliberation, they are incapable to use the public budget or conduct corruption acts. That has caused the lack of public deliberation in capital budgeting process. Most respondents in qualitative and quantitative analysis agreed that political parties have effectively influencing on the location of the projects and interrupted budget decisions. They also 
agreed that public budget in Kurdistan is more planned on political will and interests, rather than public deliberation.

Corruption is another contributing factor that contributed to the lack of public deliberation. Corrupted government is not willing to discuss public budget with local communities. Budget deliberation creates difficulties to the corrupted officials to conduct corruption acts. Excluding citizens from rational discussions, facilitates their acts of corruption in public budgeting process. Sheely (2015), Acemoglu and Robinson (2008) highlighted that elites are attempting to manipulate and influence policy makers to prioritize their preferred projects. Thoroughly, imposing their agenda and manipulate wider society. Usually, the position of corrupted officials is strong in the government, and they do everything possible to keep their actions away public eyes. Means, public deliberation makes people to become public finance watchdogs. Hence, it diverts corrupted officials from stealing public money. Since deliberation brings citizens together in the meaningful discussion over policy issues (London, 2004, p.8), it's not interesting choice for corrupted officials.

The KRG is also lack of modern and solid financial system. The KRG still relies on the classical system which for Alves (2014) distorts deliberation and PB process. The modern financial system encourages government to make bottom up decisions. The KRG still applies classical system where decisions made from the top of institutions. Public deliberation is normally applicable to the modern financial system. The KRG depends on 
some classical methods which are not effective in the modern age. Yet, the KRG can not predict its income and expenditure for the next financial year and that deteriorates PB. They usually postpone budget discussion and do not have rigid plan and timeline for the process. The KRG sometimes prepares budget in the second half of the year or at the end of the financial year. Public deliberation requires preparation, time and resources, but when the government decides to prepare budget at the end of the financial year, there will be no time for deliberation. The other problem of the system lies in the number of the projects proposed in the budget. Some ministries are proposing several projects without knowledge on how much budget is available. In such circumstances, the government can not complete all the projects in current financial year. Consequently, the government provides budget for the incomplete projects in the next financial year. This makes the process very complicated, especially for government to deliberate capital projects with citizens. As government lists a bulk of uncompleted projects, policy makers can not invite citizens to deliberate new projects. Instead, they allocate/ existing budget to the old projects. Since the KRG does not have a clear vision on budget policy and expectations, the allocation of the budget becomes very complicated and citizens are not deliberated.

\subsection{Communication and Capital Budgeting Process}

A good communication for Willoughby (2002) is one of the four factors that ensure successful budgeting process. This study concluded a positive significant correlation between the use of budget communication and capital budgeting process. Similar result concluded by Poon, Pike and Tjosvold (2001). They also highlighted that communication improves control and effectiveness of the budgeting process. Communication in the 
budgeting process is the exchange of the information and sharing knowledge between stakeholders and the government over budget priorities and issues. Applying communication in PB is less complicated comparing to deliberation. It does not have to be discussion based, or argumentative.

Communication could be applied through variety of methods. It could be direct face to face communication or through mediating methods. The methods could be consultation, negotiation, dialogue or public hearing that helps community members to deliver their concerns, demands, and suggestions to the policy makers. The outcome of this process as discussed by Abd Rahim (2004); Sheilds and Sheilds (1998); Nouri and Parker (1998) will be positive. Communication is always part of PB process because without communication, the PB might not happen. The policy makers are more interested in communication compare to other participatory approaches. Thus, it has been used as a budgetary participatory tool to assist government to consult citizens in planning budget proposal (Shields and Shields, 1998; Chenhall \& Brownel, 1998).

Communication helps government to understand the perception and suggestions of the people of what they need to be prioritized in the budget. The government collects information of what needs to be done and what needs to be avoided in the budget. Niemeyer and Dryzek (2007) identified that communication ensures public interest, equality, public goods, and agreement on the conflicted preferences. Communication is found to have commitment outcome of public policy. Communicating budget with public 
influences citizens to feel that they are active citizens. It also makes them to sincerely participate and provide feedbacks and solutions to the budget related issues. This approach is very effective to sustain the process of PB. Gomez, Insua and Alfero (2015) highlighted that communication tackles any confusion happening during PB. Accordingly, satisfaction and performance will be achieved (Kock, 2007). Citizens become satisficed because they select priorities and consulted prior to the prioritization of the budget. Citizen's satisfaction enhances commitment towards government decisions over capital services. In accordance to the obtained mean values (see appendix K), it could be discussed that budget communication maximizes cohesion, trust (Searing, 2007; Michels, 2011) and commitment between citizens and the government on one hand; members of the society on the other hand. It encourages people to utilize their skills and knowledge for the preparation of proper budget proposal that its benefits override the costs. Indeed, preserve the principles of equity in the distribution of the projects. Citizens are ready to collaborate with government if they are consulted. Consequently, they follow up the implementation stage that reduces possibility of corruption or misleading decisions. In this case, the government will be able to implement better project with less money.

Despite the significance of budget communication, the KRG was unable to make budget decisions in consultation with citizens. This study has showed that KRG seldom consult citizens about their needs. The government does not support citizens to voluntarily share their knowledge, demands and opinions on the budget. This factor also relates to the low quality of projects, public dissatisfaction of the service delivery. In the absence of budget 
communication, little value will be given to the human capacity development project which prepares individuals sustain and develop Kurdistan in all sectors. If the KRG keeps on citizens' exclusion in budgeting process, the level of dissatisfaction and the misuse of public funds will be higher. Also, projects and services that delivered to citizens in terms of quality and outcome will not be valued. It deteriorates citizen's perception toward government institutions.

\subsection{Information and Capital Budgeting Process}

Information as an element of public participation becomes a significant factor in the successful PB process. A rational based discussion happens when there is reliable and adequate information (Gouran \& Hirokawa, 1996). More precisely, discussions should be knowledge based to create effective budget decision. London (2004) indicated that the key method to engage citizens in the forums and participatory program is access to information especially to the significant issues. Information and communication assists policy makers to draw and structure their decisions and the projection of the revenues.

The World Bank (2015) and the NTA have discussed that access to information in public budgeting process expands accountability and the response of public officials toward public needs. Thus, decision makers through the use of this information in the deliberation process, identifying the projects that required to be given more weight (Schneidar \& Shanteau, 2003, p.523). This is consistent with the findings which states that access to 
budget information contributes in the selection of best policy choices and cost-effective projects.

Some scholars disvalued information and believing that government needs to keep some sorts of information confidential (Licht, 2013). This argument is partially true. The government should keep some information that might have negative impacts on the country development. Previously, the KRG received 17 percent of the Iraqi budget, and the government had to send oil income to Baghdad. However, the KRG engaged in oil business through tankers transported to Turkey, and Iran. The revenue received from this business kept by the government. If the data revealed by the government, the Iraqi government would ask the KRG to send back the budget to Baghdad. Such information needs to be confidential. However, this argument is not always true, because the government can not keep budget information in all cases. Since the revenue comes from people and natural resources, people have an absolute right to access budget information with exception to what has been discussed above. People have the rights to know government revenue and expenditure plan in order to design services accordingly in the meaningful participatory process. Revealing this information helps individual participants to propose relevant priorities. Information in public budgeting process improves the quality of services (Dryzek, 2010). However, different argument contradicts that statement. Grimmelikhuijsen (2010) argues that access to public information drives citizens into confusion and disappointment. This may happen when government does not consider their views and comments or when governments make decisions without deliberating or consulting citizens. In such cases, information may raise disagreement and 
critics. For that reason, Abdullah and Abdul Rahman (2015) argued citizens should be provided with pre-decision information. Also, if the government does not intend to engage citizens in the process, they are better not to reveal every type of information and data on the proposed budget to public. Citizens want to participate when they know the government is planning. Avoiding their willingness results in confusions, critics and complains against government plan. Sometimes, the government even fails to conduct designed as disagreement raises. However, it's suggested for government to inform citizens and then deliberate them over budget alternatives.

Access to public information in PB process prevents corrupted officials to misuse public money. The respondents agreed that corruption and the misuse of public budget in Kurdistan is due to the lack of information in capital budgeting process (mean value 4.17). When there is lack of information, there will be the issue of corruption. Corrupted leaders in the closed systems are more likely to steal public money. When there is transparency of data in budgeting process, they will be incapable or less likely to conduct corruptions acts.

Information is a key pre-condition in every participatory process especially budgeting. Otherwise, public participation can not target its objectives. To be effective in the PB process, citizens are required to have some level of knowledge and details. If citizens have accurate budget information, they propose projects that can be funded without asking more or less than allocated budget. This method also helps to combat corruption and the 
misuse of public budget. This is in line with findings of Bertot et al. (2009); Cullier and Piotrowski (2009); Mulgan (2007) Relyea (2009a) Shuler et al. (2010). These scholars have indicated that when people have adequate and reliable information about the process, corruption, nepotism, and the misuse of public budget could be avoided. This method is important to be used by the KRG to reduce the existing level of corruption. The KRG also suffers due to the shortage of money and people do not believe government for that. Revealing budget information helps government to rebuild trust and also save a large amount of money taken by the corrupted officials. Citizens want to know how their revenues distributed and its their rights to ask for data. In the study by Abdullah and Fitri (2015), it has been revealed that citizens in Kurdistan interested in budget information more than any other type of information. They also want to access information prior to the decisions. This finding encourages governments to provide adequate information on the budget during the budget preparation phase where citizens can utilize them to improve public services.

Citizens, through deliberation provide rational arguments with a kind of information that might be used to make better decision. As discussed by Yannoukakou and Araka (2003) such process stimulates well-being, extracts new ideas, and develops new services. The survey respondents also agreed with the statement that information in the capital budgeting process increases the return on investment. In the other words, when there is available information for government during the selection of budget priority, they will not allocate budget to the projects that are not necessary or appreciated by citizens, but for the projects that citizens really need. 


\subsection{Influence of Public Participation in Capital Budgeting Process}

Good governance highly relies on the involvement of stakeholders in policy decisions. Lukensmeyer, Goldman, and Stern (2011) demonstrate the essence of public participation in their research. They clarified that citizens in PB process might significantly influence on the quality of the government programs and more likely to target the objectives of the policies. Public participation in the government activities enhances policy knowledge of the citizens and persuades people to share their opinions and ideas with the government agencies to plan for better services and improve the accountability and responsiveness of the government (Peers, 2012; Blair, 2000). It also accelerates collaboration that links citizens and policy makers together in order to reach a legitimate decision. Collaborative decision making described by Margerum (2000) could be applied in two stages. The first stage is to build consensus between government and people. Here, both parties should identify key problems, and set a platform to maintain the process. The second stage relates to the implementation and the outcome of the first stage. The direct output of this process will be trust building, mutual understanding, and mutual agreement. The indirect impacts of collaboration may come incrementally such as the institutional changes. To successfully applying participatory program, citizens have to equally participate in the debates; freedom should be given to all participants to share their views and concerns. Also, there should be an honest discussion without keeping anything confidential (North. 2000). Therefore, this study might disagree to reveal almost everything between participants. Certain information should be kept confidential or maybe unnecessary to share. Transparency in an absolute term could have negative impacts. Honesty in the discussion also raises disagreement and conflict between participants. Hence, it's very 
essential for participants to preserve check and balance in their discussions. If the process maintains the balance between participants, it will be helpful for the government to employ solution to the problems that was unclear to the policy makers. It creates an opportunity for the community members to voice out their concerns and proposes their plans.

Public participation improves the flow of information from community members to the government and the other way around. The engagement of citizens in public policy decreases the discretion of government officials in choosing best policy choices. The government can take necessary action to correct shortcoming and policy deficiencies. Citizen participation consolidates democracy, improves citizen's deliberation, breakdown centralized decision making (Alves, 2014) through the empowerment of citizens and engaging them in the decisions through deliberation. Participation also ensures better policy outcome and improves equity and transparency in public expenditure decisions (Weeks, 2000).

Participatory governance is also known as the "the second generation" reforms that are used in the institutional reform in developing world which surpass elite domination in the policy making process (Crook, 2003). Thoroughly, public participation preserves social equality and justice in receiving public services. Lastly, the concept is seen as a "promising design" when communities are collectively making their decisions. It allows public administrators and citizens to find solutions for local issues and decide accordingly (Ostrom, 2005). 


\subsection{Theoretical Implications}

This study has theoretical implication in developing PB process in public administration and governance. The model of this study is a major theoretical contribution. Developing a framework and combining the three independent variables (Deliberation, communication and information) together against capital budgeting process is an emerging contribution to the literature. This framework used in this study was adopted. It was not previously used by other researchers especially in relation to Kurdistan Region's budgeting process. This study was able to bring up three main elements of public participation and creates a model to explore the correlation between public participation and public budgeting process. This implication also adds more value and better understanding of PB and the model could become a proper foundation for future studies in this field.
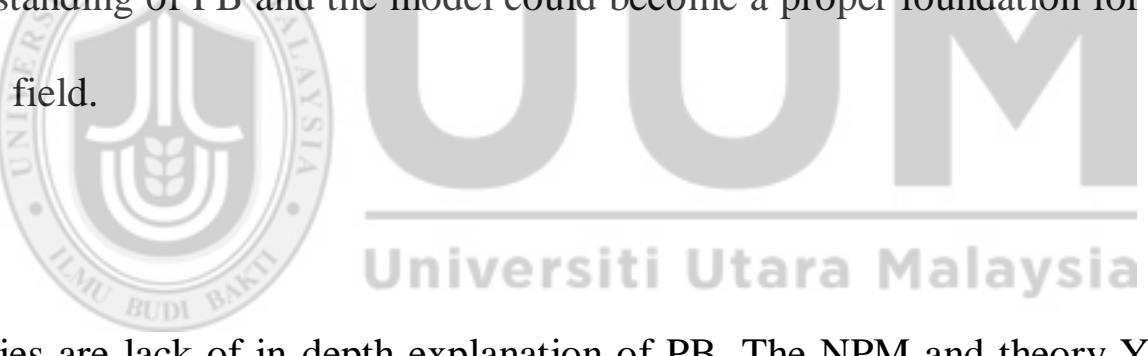

Theories are lack of in-depth explanation of PB. The NPM and theory Y have already covered the importance of a bottom up decision. They find public engagement as a transformational method in decision making process. Therefore, they are lack of discussion in terms of public financial management. They gave least explanation on how public participation impacts on the budget decisions and service delivery. This study has elaborated this correlation in the detailed way and correlated NPM theory to public participation in public financial management. This study will contribute to knowledge and conceptualizing the model to the current literature which is seen to be the main function of the research. Public participation could be important in all aspects of the decision making process, but it could be more important in public financial management. This 
study imparted an insight on how PB can develop the theoretical understanding of public administration. In addition to NPM, the study also developed more understanding on the theory deliberative democracy. The theory was mainly used to understand political issues and democratization. However, little explanation given on how deliberative democracy can be used in public financial management and budget decision making. This study has brought up the issue in a particular location, and correlated to the theory of deliberative democracy which can be used in promoting public financial management systems. This is an imperative contribution in academic disciplines particularly in the fields of public policy, public administration and public finance.

Public participation consists of several elements. These elements have diverse impact on capital budgeting process. This study has maintained that deliberation is different from communication. Deliberation in budgeting process materializes when stakeholders discussing, debating, and arguing budget proposal. It happens in more argumentative way in which citizens enforce their agenda thru rational argument. However, communication happens between stakeholders in dialogue form where citizens negotiating budget alternative without interruption. This can also happen in forms of consultation when a policy makers taking participants views over certain proposals. Every participant is giving opinion without rebutting others. Communication is a participatory method relying on consultation, dialogue, and public hearing. 
There is a gap and confusion in the literature regarding the conditions of participatory budgeting and the elements of public participation. Public participation is proportional. It happens in particular field, but all systems. To conduct participatory budgeting, democracy is not an issue. It might even happen in authoritarian systems; as participatory budgeting not political participation. Budget is designed to deliver services for citizens. Services are part of the government activities in all systems. It's rational to argue that public participation happens in all system, but not in politics.

The presence of democracy could be helpful, but its not a pre-condition. China is a communist country, and they are very strict towards political participation, but they used to have participatory budgeting in some provinces. The PB is also known to works effectively under dictatorship. However, participation in forms of communication could be easier in authoritarian regimes comparing to deliberation. To convince policy makers in public deliberation, citizens arguing and rebutting officials and that might be very challenging to be consolidated in authoritarian regimes. Typically, officials are not in favor of argument in authoritarian systems. Yet, hey accept suggestions and thoughts. It's also possible for them to share knowledge and views on the projects. Citizens are consulted in authoritarian systems and their views are taken into account. For that, deliberation and communication should be treated separately. It does not mean deliberation is impossible in non-democratic system, but communication is more likely to happen. Participations on the hands happen almost everywhere. Therefore, the level, the type, the methods, the actors, and the extent of participation are different and very significant to be examined. 
This study has raised some issues relating to the burdens of public deliberation. The findings of this study are somehow different from previous literature. The result of qualitative analysis came up with the fact that budget shortages can significantly restrain the scope of public deliberation. In the other words, the literature has listed a set of factors that contributing in the lack of public deliberation. However, they did not refer to the lack of capital resources. In the case of Kurdistan Region, budget limitation becomes a central issue. In the literature, significant roles of civil society organization illustrated, but their weakness and absence has not been identified as lumber to deliberation. This study has shown inactive roles of civil society organizations has restrained the scope of public deliberation in Kurdistan Region.

\subsection{Practical Implications}

This research provides a managerial contribution to public administrators and policy makers to improve public financing system. This study may have more practical contributions than theoretical because it's related to the governance and public administration system. The government of Kurdistan is in a serious condition concerning budgeting and financial management. In the last 6 years, Kurdistan had a large budget and services could become more effective and even higher if they used the mechanisms of public participation. This research offers an insight for the policy makers in the KRG to furnish further opportunity to community members and budget professionals to participate in capital budgeting process. 
Public participation is recently introduced to the KRG and officials do not have enough knowledge about the important of public participation in decision that even helps them to become successful in their positions. However, due to the lack of experience and research, little is known on this topic. This study is the first and the foremost in Kurdistan. Even though, there are some works on budgeting, but none of them specifically studied public participation. There is actually a huge gap in the literature when it comes to Kurdistan public financial management system. Therefore, this study raised the issue and defined new policy paradigm for the KRG. In general, the research on public budget in Kurdistan is very limited. If the government carries out such research, it might be costly. For instance, a research was conducted by the UNDP in coordination with KRG-MoP that costs nearly one million dollars on government.

This study defined several budget problems that affected on public life and country's development paradigm such as mismanagement of public money, inadequacy of the projects due to the absence of proper deliberation and communication, high rate of corruption, opacity and inaccuracy of budget related data, random selections of budget priorities. The findings are important implication that provided a framework for government to deal with capital budget in the modern way that citizens become a center of decision making process. If the findings taken into consideration, the government will be able to improve public service delivery, public needs satisfaction, return on investment, transforming decision power to citizens, equal distribution of services, better allocation of the resources, counter corruption, and minimizing the misuse of public budgets. 
Millions of dollars allocated to unnecessary projects annually; but, there is a still gap in the services and citizens are not appreciating those projects. The main reason to be explained in relation to these issues could be the absence of PB. Citizens want to decide by themselves for themselves. In this sense, the findings help KRG to consider the application of PB mechanisms in selecting budget priorities.

This study described the values of PB and several ways to assist KRG policy makers to feed their citizens with quality services. Also, it recommended several strategies to inform citizens about their intention and conduct a site survey in order to identify the kinds of information citizens need. This study encourages government to increase rational based discussion and public hearing to encounter budget problems and justify the legitimacy of the decision that could make sense to ordinary citizens.

\subsection{Limitations of the Study}

In conducting this research, several limitations were found. However, these limitations did not have major impacts. The first limitation relates to the qualitative data collection. In Kurdistan, meeting officials is somehow easy and it's even possible to meet ministers. However, its not easy to convince them to talk to you and record their voices. Some officials that I wanted to interview, were not ready their voices to be recorded or their names to be revealed. They prefer informal discussion and not to mention their names, neither records their voices. Revealing the name of the respondents is significant. If the researcher fails to provide details on the respondent, it may undermine the reliability and 
credibility of the data. For that, the meetings sometimes come up with informal discussion rather than formal interview. Additionally, several attempts have been made to meet particular government officials, but they were on leave. For instance, five attempts have been made to meet the director of planning in the Ministry of Municipality, but he was on leave. The other employees were not interested to be interviewed.

The other limitation relates to inadequacy of data on public finance in Kurdistan. A very few works have been done on KRG budgeting. The information exists in the form of press conference, television programs, and newspaper articles. A few scholarly and academic works published on the KRG public budget. Most recently, there are several gaps in budget that concerned citizens. Thus, citizens and policy makers are talking about budgeting more than anything else in Kurdistan, but when they are not in forms of research or journal articles. Therefore, this limitation shows the importance of this study, which will become a gateway for other researchers to conduct further research.

Civil society organizations have become a limitation to this study. There are nearly 2000 civic society organizations in Kurdistan, but most of them working in other sectors and less than 10 of them working on the economic sector. I tried to reach some of them to understand their roles and contributions. I called them, emailed to them, and tried to use connection to reach them. However, most of them did not even answer me and others honestly told me that they don't have any idea about participatory budgeting. Usually, civil society organizations playing a key role in arranging participatory budgeting forums, 
debates, discussions and meetings, but they could not even understand the term when I tried to convince them for the interview.

Lastly, during my data collection, the Islamic State of Iraq and Syria (ISIS) attacked Kurdistan. I was in Erbil, the capital city of Kurdistan Region which was only 30km from ISIS borders. Citizens were very concerned that time and the government officials were distracted with that issue. The KRG utilized public budget for military purposes to put away ISIS threats. This war has burden public budget in Kurdistan and government was unable to offer new projects. They had to cut a budget for several projects in order to finance military forces to combat ISIS. The Iraqi government was also cut off the KRG budget few months before the emergence of ISIS. That has created a serious financial crisis that KRG was not even able to pay for salaries. Later, the KRG exported oil to the global market and received an amount of budget to pay for government employees and basic services. The projects mainly financed by from local revenues. Previously, Kurdistan had a share in the Iraqi government budget; but now, the KRG independently deals with budgeting without receiving or giving the revenue to the Iraqi government. In better and more stable financial situation, it becomes easier to collect data and deal with capital investment budgeting.

\subsection{Policy Recommendations}

The objective of this study was not only to theoretically explain the impacts of public participation in public budgeting process. It aims to offer policy recommendations to 
improve government financial management system. To conduct participatory budgeting, the KRG has to create an apt environment. To do so, citizens must be empowered through educational programs. Citizens are not cognizant about their rights and duties in Kurdistan Region. The government is liable to increase public awareness especially about capital budgeting process which is part of community activity. In coordination with civil society organizations, the government has to provide particular training courses.

In the training, citizens must be taught and prepared to engage in the budgeting and decision making process. Civil society organizations must be encouraged to play their true roles and help government institution in implementing such process. Previously, the government has allocated millions of dollars to the training and empowerment process to engage small number of citizens in the budgeting process. The KRG should not spend a lot of money on training; instead professionals and NGOs should be encouraged to voluntarily support government. Citizens should be taught to voluntarily help government. It will be another wasting if government does not know how to deal with available capital. Civil society organization can help if government encourage them and asking them to play their roles in educating and empowering citizens. As citizens trained, the KRG can provide supports and programs to help citizens to understand the details of participatory budgeting process. This could be done in several ways, including workshop, public meeting, citizens panel, forum, and many others. 
The KRG must provide some ground elements to enforce PB programs such as introducing the process to the community members and local governments. The government must discuss the initial phases of the budgeting with citizens and listens to their concerns. Citizens should be asked to provide evidence to their discussion in order to reach some conclusions over PB process. It could be vary based on the location and characteristics of different communities and locations. Deliberative forums will be better if the government provides ground elements. Therefore, communicating citizens about their needs and requirements also helps to get insight for the budget plan. For communication, the governments can simply ask people for their opinions about their needs without giving in-depth details or explanation. In fact, the process of communication is easier and less costly comparing to deliberation. In communication the government through Mosques, Churches, sport centers and schools can inform citizens about budget plans. Citizens can be asked to send their preferred projects through emails, website or written letter to their representatives. The government can also list a set of projects and asking citizens to tick their preferred projects through survey questionnaires. Not every citizen had to participate in the survey, but to preserve the equity of the process and excluding domination, the survey must be distributed randomly in designed locations. Then, the most weighted projects should be selected for the implementation. However, to conduct budget deliberation, the government is required to invite community members for a meeting. Then, provides an introduction about government plans and instruction on how citizens can help to make the right choice. Citizens will be asked to provide reasons for their discussions when they propose a project. During deliberative meetings, communication can also happen. The conclusion of the budget discussion with citizens 
must be recapitulated. A list of priority project must be generated through the summary to be distributed as a survey questionnaire. Policy makers should give participants a chance to select budget priority and list the most important choices. The most weighted project will be chosen as a budget priority. In this way, the government can make the right and legitimate decision to satisfy public needs. This brings citizens to the center of decision making, especially in the selection of budget priorities.

Apart from citizens, more power should be given to local governments in preparing budget proposal as they can better represent the citizens. Decentralizing decision will be a good choice to bring everyone into the process. The government should be a government of people in the sense that everyone should be given a chance to participate in the decision making process. Local government should have a chance to lead participatory budgeting process. It will also facilitate the responsibility of government. In addition to this, the KRG should establish a directorate of PB at the MoP to work in coordination with the directorate of budgeting and DCC. The main objective of this directorate should be preparing citizens to the process of public participation. Accordingly, citizens should be provided with adequate information before they participate in the budgeting process. Likewise, all financial reports and the budget amount must be disclosed to people and government should tell citizens of what they are planning to do and how much money is available for these plans. In this way citizens may select a program that both fulfills their demands as well as the budget limits. 
In the modern age, social media networks are the most effective way that can easily influence citizens, especially in providing them with quality information and asking for their feedback. Through local governments, the KRG must provide some pages or websites to encourage citizens to write and share their concerns for services they received and suggestion for the new projects. It does not cost a single penny on the government, but it will a power sharing which binds citizens and the government.

There is a high level of corruption and the KRG has admitted in several occasions. There is one type of corruption which is very serious and caused the misuse of public budget known as fake projects. Several projects funded through public budget, but do not exist in real. Corrupted officials through these fake names added millions of dollars to their accounts. This issue could be resolved through participatory budgeting. PB process ensures high level of transparency and accountability. In the transparent and open system, corrupted officials will be in capable to steal or misuse public money. Besides, citizens will know the kind of projects they deliberated with the cost estimation. They will easily spot any suspicious acts. For that reason, its very necessary for government apply PB.

\subsection{Suggestions for Future Studies}

There are several gaps in Kurdistan public budget that has not been studied by the researchers. One of the best fields to be studied is disparity between capital investment budget and recurrent budget. The KRG pays almost 70 percent of the total budget to the recurrent expenditures. This imbalance dwindled government budget to public services 
and infrastructure projects to sustain country's development paradigm. The government in the best case provided 31 percent of the total budget to investment projects and capital services. However, that does not fulfill the global standard that requires more budgets for the capital projects. This issue will be very important to be studied. Unlike public participation, data is available in this area and the issue is very obvious that seriously troubled government. The KRG has employed thousands in the last 5 years. There are almost 1.4 million employees in public sector, and the government has to provide salary to that number which is nearly $1 / 3$ of the total population. This imbalance is the main factor to the current financial crises along with the decline in oil prices.

The second suggestion for future studies is to study the influence of political parties on the budgeting process in Kurdistan. This study indicated that political parties become a burden towards budget deliberation. In the light of that, it will be motivating to further examine the influence of political parties on capital budgeting process and distribution of public services.

The third suggestion is to study the informal participation in Kurdistan's public budgeting process. This study has initiated some level of informal budget participation especially by the community leaders and through connections. Investigating the role of informal participation in the capital budgeting process is important. It will help to apprehend the needs of formal participation while people have different channels to informally impacts on budget decisions. 
Public participation is a broad topic; it can be conducted in different stages of budgeting. This study examined a segment of public participation which is the preparation of capital investment budget. Nonetheless, public participation could be effective in other stages of budgeting. Studying budget participation in the implementation and assessment phases will be very significant and readers will get the hints on how their engagement plays a constructive role in the entire process of budgeting.

For many people, participation is something new and never expected that governments have engaged citizens in the process of capital budgeting. The KRG has used to engage citizens in some occasion and even introduced some programs which are fully conducted through community members and true process of PB. Evaluating and comparing budget under PB program known as Consultative Service Delivery Program and budgeting in the absence of citizens will be very important to understand how important participatory budgeting is. In view of that, major outcomes of participation will be comprehended for citizens to compel policy makers to communicate budget priorities with them. Besides, the government will be more sympathetic to implement PB. Hitherto, no works has been done to compare the two methods of budgeting.

Through the literature as well as this finding, I realized that the misuse of public budgets, corruption and fake projects are partially due to the lack of public deliberation, consultation and transparency. Conducting a research on the use of public participation to eradicate the misuse of public budgets and corruption will be a very interesting topic. It 
will be a good contribution to create good governance system and better management of public finance in Kurdistan.

\subsection{Conclusion}

In Kurdistan Region, budget becomes a prevalent topic among citizens. The revenue is largely coming from oil and other natural resources. The Kurdistan proven oil reserve estimated to be 45 billion barrels, which is more than the reserve of a country like Nigeria with almost 170 million populations. Due to its geographical location, the customs also become an essential source of income. Although, the country possesses the aforesaid sources of revenue, the budget mishandling has caused the KRG to undergo a very serious financial crisis, corruption and privation of public services. A number of gaps allied with the budgeting found in this study and were left intact neither by the government, nor by the researchers. The good and modern participatory financial system might help to distributed budget more efficiently and better services could be endowed to citizens. Also, the KRG can develop the infrastructure of the region. Therefore, there are many gaps in the system without being determined.

There are two main types of budget in Kurdistan namely recurrent budget and capital budget. Previously, 69 percent of the budget was allocated to the recurrent expenditure including the salary of the KRG employees. This number has recently ascended to 90 percent of the total budget due to the financial crises and the decline of oil price that hardly hit government budget. Due to the large number of government employees, the 
government allocated only 31 percent of the total budget for projects and services. This imbalance in the budget allocation has left several issues and increased services gaps. This issue should have been compelled government to reform its financial system and finds alternative to overcome service issues. Instead the government has employed hundreds and thousands new employees. Unlike recurrent budget, capital budget is the budget that the government allocates to the physical projects such as schools, roads, electricity, water sanitation, government buildings, sewages, airport, and many others. These services can be used by any individual citizens. This study focused on this type of budget where citizens can participate more than other type of budget. This study has verified that services delivered to the KRG citizens are not perfectly designed. Citizens are not satisfied for services they receive. Also, a large amount of money has been misused and inadequate information provided to citizens. Since, capital investment budget is for people, citizens are eager to be engaged in making capital budget decisions. Citizens expecting best services from government, and no one might understand their necessities more than themselves. In this sense, their participation is decisive sought to be a turning point towards good governance system whereas all sectors of society together, striving to make a collective decision for the purpose of the common goods.

Public participation in the budgeting process is portrayed as the inclusion of citizens in the process of preparing budgets and giving them an opportunity to make their choices and prioritize their needs. Public participation in capital budgeting process does not require democracy to function. Democracy may help to better apply some approaches of public participation such as deliberation, but its still tolerable in authoritarian systems. 
There are some provinces in China, and larger part of Latin America where budget participation consolidated. Budget participation is different from political participation. The first one can even justify the second by promoting public services to legitimize the political system. For that, budget participation is treated as a model to improve public administration system and satisfying public needs.

Political participation is not as important as budget participation for ordinary citizens. Everyone needs water, electricity, sanitation, sewages, roads, and other services, but not everyone needs to engage in politics. Hence, budget participation is more striking and needs to be applied to promote public services. Though, public participation in Kurdistan is more deliberated in political spheres. In economic policies and the public financial system, it's unparalleled. Citizens are not empowered to participate in administrative and public financial policy making process. In the democratic systems, public participation in budgeting process becomes a crucial point to get citizens into the governing process.

Public Participation in the budgeting process is commonly known as participatory budgeting. It's a new approach of decision making and emerged in the last two decades in Brazil. Capital services in many countries and regions around the world have convalesced and citizens are enjoying their engagement in PB process. In the last 5 years, the KRG in coordination with some international organization has introduced some budget participatory programs. The outcomes of these programs were interesting and highly welcomed by citizens. Although, this study has identified some degree of public 
participation in the capital budgeting process, but it has to be improved to the larger extent. The study discovered that KRG failed to encourage and prepare citizens to this significant practice. In most occasions, the KRG selects budget priorities without paying attention to public needs. Subsequently, public service delivery is not satisfactory and insufficient. However, the experience of other countries and previous literature has confirmed how important is public participation to deliver better services to citizens and fulfilling their demands. To consolidate democracy and good governance, the KRG needs to empower citizens and provide a scope of participation to everyone interested to intensify their roles in decision making process. It has been known that government can not properly distribute the available budget to the investment projects, if they avoid public inputs in the preparation of budget priorities. The KRG has to reconsider its stands with citizens and creates an open system where citizens become the center of decision making particularly in the capital budgeting.

Even though, there is a lack of budget participation, but budgeting in Kurdistan is discussed more than any other topics on television channels and newspapers. However, only few academic works available and none of them studied public participation in the capital budgeting process. This study becomes a gateway and important resource to academician and leads to further researches. The essence of public participation was unknown in Kurdistan. In the other words, there is inadequate research to show the magnitude of public participation in Kurdistan's public budget and how the issue of budgeting could be tackled through participatory methods. 
Three approaches of public participation used as independent variables namely deliberation, communication and information. These approaches impact on capital budgeting process. Information is required for any participatory process, but not every participatory process could include deliberation and to some extent communication. Deliberation is a form of participation that requires reason based discussion. Its more complicated process compare to communication because it requires a particular setting and a more formal procedure. However, communication is simple and easier for government to implement. It usually happens in forms of consultation and the exchange of information between participants and the government.

This study embraced of three main objectives, three research questions and three hypotheses. To achieve the objectives of this study, primary data were generated from survey questionnaire and face to face interview. The study was conclusive and different parties have taken as sample population. Almost 465 survey questionnaires distributed to ordinary citizens including students, lecturers, public sector employees, intellectuals, members of political parties and some other sectors of society. The semi-structured interview was more specific, attentive to the official sides and professionals, including members of parliament, government directors, university lecturers, budget experts, and ministers. From the result obtained, it has been concluded that public participation exists in Kurdistan, but its not regular. The participation mainly comes from citizens who have connection in the government or through written proposals. Additionally, the government has used to implement consultative service delivery program. That program more focused on communication between participants, community representatives and government 
officials. The outcome of the program was very likely and people satisfied for what they have been offered. It was also a turning point in the government finance towards more participatory budgeting process. However, the program was not deliberative. Although, there is certain level of participation in KRG budget, but the region is lack of public deliberation more than budget communication. In that sense, the study investigated the factors that resulted to the lack of public deliberation as the first objective of this study.

Several contributing factors has been listed that caused the lack of public deliberation, including budget limitation, political parties' interference, corruption, nepotism, the weakness of civil society organizations, the complexity of the public financing system, and the lack of trust between government and local experts. The study also found that government seldom deliberate citizens in the budgeting process and that left negative influence in the capital budgeting process. The factors are mainly paralyzed government finance and made people to find themselves outside of the process. Consequently, it weakened state-community relationships. The study has found positive significant relationship between deliberation and capital budgeting process. The interview participants described the side effects of budget deliberation. Public deliberation as an important method of public participation has been adopted elsewhere and citizens enjoyed discussing budget variances and plans with policy makers. Deliberation is more towards the discussion and argument that occurs during participatory process and forums. There is limitation in officials understanding towards public needs. Deliberation enlarges the scope of their understanding to public issues. Citizens establish an outline for government officials to promote common goods and overcome obstacles. Also, a different argument 
will be generated from discussions. A critical discussion paves the way to assist government to select best projects and make the right decision. It also consolidates the democratic process and incites citizens to exercise their rights in public policy making process.

The second objective of this study was to investigate impacts of communication on the capital budgeting process. The study stressed that budget communication is significantly stimulating capital budgeting process. The significant impacts of budget communication were elaborated both in qualitative analysis, as well as quantitative findings. Communication refers to consultation, exchange of information, and sharing views and knowledge over budget alternatives and prioritizing projects. Communication happens when government consulting citizens about the selection, the type and the location of the projects. Precisely, the government listens encourage citizens to express their opinions and views of what projects to be selected, why that project should be funded, how to conduct selected projects, when to implement that project, who will be benefited, how much budget is needed and how long that project takes. At the end of communication, the government collects a list of comments, views, suggestions, and proposals to decide accordingly.

Communication has been used in most participatory programs, even in Kurdistan communication was focused by the government in the participatory processes that was implemented during CSDP. The KRG mostly uses consultation as a method of budget 
communication. The consultation is found to be effective, especially in terms of service delivery. Citizens can receive better services if government communicates with them during preparation of the capital budgeting process. The officials can not understand better than citizens when they select a kind of project. If policy makers decide on the selection of the projects, they make mistakes. For instance, citizens may need a school, but policy makers might not understand. Instead, they build a road. However, citizens do not appreciate such project and might not even get the benefit. This is a big issue in Kurdistan and large amount of money misused for services that are not appreciated by citizens. Insufficient budget communication increased suspicion on the government. Under any circumstances, citizens are expecting government to communicate their needs.

Consultation and paying attention to public opinions enhances the sense of citizenship and coordination between members of society. It cultivates public awareness on governance and getting citizens closer to the government. In budget communication process, citizens and government mirror each other and accomplish common goods. Instead of criticizing government and creating obstacles to the implementation of the projects, citizens are collaborating government. They also find themselves as part of the system and legitimize decisions. Public projects are planned for people, and when the government decides for people without understanding and examining their needs, people have an absolute right to complain. Though, the projects that are selected through people will have a better outcome, a more gratification and more legitimacy. 
Budget communication educates people to oversee the implementation of projects and empowers citizens to govern themselves. It also helps citizens to expose themselves and essentials in the right way. It urges people to voluntarily rally round each other as well as their government to promote services and improve the system. Notably, budget communication eradicates corruption to certain amounts because people watch over government expenditure activities. Informed citizens in communication process are collecting some kind of information to determine the cost of the projects and services. In such cases, the government can not cheat on the projects. For instance, it happened in Kurdistan when the government allocated one million dollars for a project, but the project expense was less than US\$50 thousand. When government communicates citizens in the budgeting process, this issue could be determined and citizens will not allow any exaggeration in costs. The government officials can not simply steal public money in the presence of budget communication. By conducting budget communication, millions of dollars will be returned to the government treasury and more services could be delivered. It will also lessen the role of political parties in public finance. Budget decision power will be transferred to citizens.

The third objective of this study was to examine how access to budget information associated to capital budgeting process. The positive significant relationship was explored between the access to public information and capital budgeting process. Information was used in the sense of transparency which plays a major role in the PB program. It's a key element and a pre-condition of PB. Without adequate information, public participation may not be materialized, and even if it occurs, it will not unproductive. Citizens can not 
actively participate without having adequate, accurate, and reliable information. Information is a motive, an instrument and a power that shoves people to participate even in the absence of participatory programs. When government plans disclosed to public, they will have certain level of participation. They may possibly oblige the authorities to deliberate and communicate budget plans with public. However, despite the presence of freedom of expression and several channels, but the public financial system in Kurdistan is not transparent. Generally, citizens are not acknowledged on how the government distributes budget and they do not have financial reports, expenditure plans, data and statements.

The government might not be the only party to be blamed for the lack of transparency and reports, but citizens are also responsible. Yet, citizens don't know their rights to access government information. According to the Access to Information Law, the KRG is obliged to provide any kind of information requested by citizens. This law is very helpful to demand for budget information. However, most citizens even realized there RTI law. However, government is also responsible to empower and educate citizens to understand their rights and duties. Public participation is a dual process. The KRG has to inform public and voluntarily educate citizens about their rights that are protected by law. However, the KRG was failed to do that and also unable to disclose financial reports. The government does not have weekly, monthly or annual reports about budget activities. If officials have intention to disclose public information to citizens, they can simply do it through the use of modern technology and internet. However, the KRG failed to do that. Budget information on their official websites is outdated and can not be used in the PB 
program which requires recent and accurate information. In most cases, citizens do not have any information regarding the preparation of capital budget until the draft discussed in the parliament for legislature ratification. The outdated information will be irrelevant to the citizens to influence public budget decisions. Nevertheless, if the KRG discloses budget information in all phases of budgeting, citizens will increase their impact on the process, especially prioritizing projects. It also helps to combat corruption and the misuse of public funds. In Kurdistan there is an issue of fake projects. The KRG under influence of political parties has provided large amount of money to the fake projects, while the projects were deceptive. The informed citizens will not allow that to come about simply. A large amount of budget embezzled by the corruption officials and the details are unknown for citizens. If there is adequate information, people might protest and act to break such delinquencies. Information disclosure will be an important motive to eradicate corruption and the misuse of public funds. It will also inspire public participation and obliges government to input citizens into the process.

Lastly, public participation is not always positive in capital budgeting process. There are some situations where public participation creates a conflict and confusion among citizens. If the government does not have enough money to finance public projects, PB might not be necessary. For instance, when government is shortage of money, its not wise to invite citizens to discuss budget plans. Public demands increasing during participatory budgeting and more projects will be proposed to be financed. Since, the government incapable of financing these projects, the process might have a reverse impact. Citizens might consolidate their voices to be abandoned, but they assume to be treated with 
courtesy and consideration. Overlooking their suggestions increases dissatisfaction, disagreement, and uncertainty. However, the government should overcome obstacles in order to perform a relevant approach of participation. As in case of KRG, the shortage of money along with other five factors that cause lack of public participation should be eliminated and more power to be given to citizens. Likewise, it's dispensable to deliberate strategic and mega projects with ordinary citizens. Ordinary citizens understand their concerns and demands in their areas, but they do not often understand the strategic projects that are beyond their thinking such as highways, national stadiums and some other projects. Alternatively, the government has to consult and deliberate expertise and provide all details. Their participation will be supportive to improve the outcome of the projects.
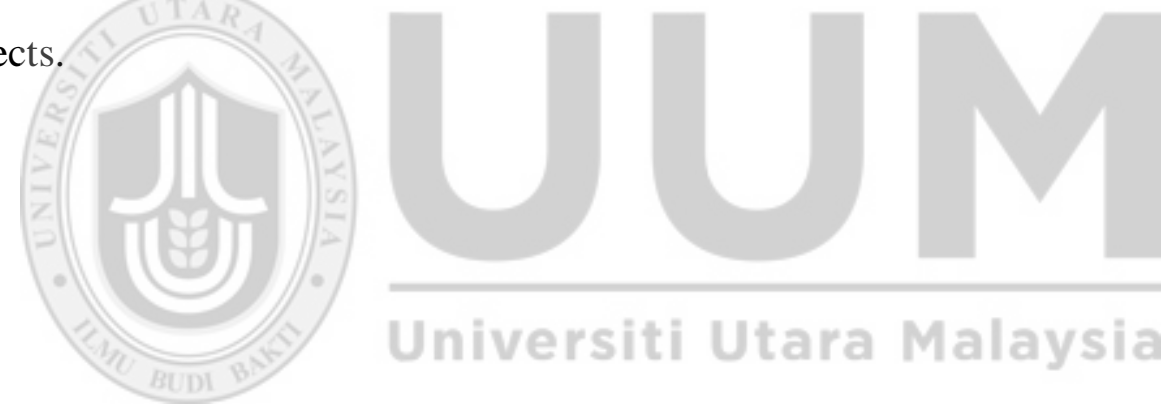


\section{REFERENCES}

AA. (2013, September 30). Analyzing Kurdistan's Economy. Anadolu Agency. Retrieved October 3, 2013, from http://www.aa.com.tr/ks/news/234708.

Abd Rahim, R. (2004). A study of budget characteristics in the annual budgeting process: the case of Universiti Sains Malaysia (Master Thesis, Universiti Sains Malaysia). Universiti Sains Malaysia, Penang

Abdullah, N. N. \& Abdul Rahman, M. F. (2015). Access to Government Information in Public Policy Making Process: A Case Study of Kurdistan. Information. 18 (8), 3447-3458.

Abelson, J., Giacomini, M., Lehoux, P., \& Gauvin, F.P. (2007). Bringing 'the public' into health technology assessment and coverage policy decisions: from principles to practice. Health Policy 82 (1), 37-50. DOI: http://dx.doi.org/10.1016/j.healthpol.2006.07.009

Abom, B. (2004). Social capital, NGOs, and development: A Guatemalan case study. Development in Practice, 14(3), 342-353.

Acemoglu, D., \& Robinson, J. (2008). Persistence of power, elites, and institutions. American Economic Review, 98(1), 267-293. http://dx.doi.org/10.1257/aer.98.1.267

Ackerman, J. M., \& Sandoval-Ballesteros, I. E. (2006). The global explosion of freedom of information laws. Administrative Law Review, 58(85), 85-130.

Ahmed, W. M. A. \& Mamat, M. (2003). Simple Data Analysis Using SPSS: A technical Approach. Terengganu: Cetakan Pertama

Al-Ansary, K. (November 13 ${ }^{\text {th }}$ 2014). Iraqi Kurds Cabinet Approves Plan for Starting Oil Company. Retrieved November 14, 2014, from Bloomberg at http://www.bloomberg.com/news/2014-11-13/iraq-kurds-cabinet-approvesplan-for-starting-oil-company.html

Al-Kodmany, K. (2000). Technology and Democracy. Journal of Architectural Education. 53 (4), 220-228. Retrieved November 5, 2012, from http://www.jstor.org/stable/1425566.

Allen, K. B. (1992). Access to government information. Government Information Quarterly, 9, 67-80.

Alves, S. (2015). Welfare State Changes and Outcomes: The Cases of Portugal and Denmark from a Comparative Perspective. Social Policy \& Administration, 49 (1), 1-23. Doi: 10.1111/spol.12075

Andrews, M. \& Shah, A. (2002). Voice and local governance in the developing world: what is done, to what effect and why? Retrieved February 26, 2015 from http://www1.worldbank.org/publicsector/learningprogram/Decentralization/ Andrews.doc 
Aragones, E. \& Sanchez-Pages (2009). A theory of participatory democracy based on the real case of Porto Alegre. European Economic Review, 52, 56-72. Doi: 10.1016/j.euroecorev.2008.09.006

Arain,M., Campbell, M. J., Cooper, C.L. \& Lancaster, G. A. (2010). What is a pilot or feasibility study? A Review of Current Practice and Editorial Policy. BMC Medical Research Methodology, 10-67. http://www.biomedcentral.com/1471-2288/10/67 .

Arnstein, S. (1969). A ladder of community participation. American Institute of Planner Journal, 35 (4), 216-224.

Arslan, A. \& Staub, S. (2013). Impact on Organizational Performance: Small Business Owners in the Sishane Lighting and Chandelier District. Procedia - Social and Behavioral Sciences, 75, $102-111$.

Atran, S., Medin, D. L. \& Ross, N. O. (2005). The cultural mind: Environmental decision making and cultural modeling within and across populations. Psychological Review, 112(4), 744-776.

Babbie, E. (2004). The Practice of Social Research. 10 ${ }^{\text {th }}$ edition. The US: Wadsworth, Thomson Learning, Inc.

Baiocchi, G. (2001). Participation, activism, and politics: The Porto Alegre experiment and deliberative democracy theory. Politics \& Society, 29(1), 43-72.

Bardhan, P., \& Mookherjee, D. (2007). Decentralization and accountability in infrastructure delivery in developing countries. The Economic Journal, 116, 101-127.

Basu, R. (2004). Public Administration: Concepts and Theories. New Delhi: Sterling Publishers Pvt.Ltd.

Barreiro, P. L. \& Albandoz, J. P. (2001). Population and sample. Sampling techniques (Project Number. 94342). Seville: University of Seville

Bertaux, D. (1981). From the life-history approach to the transformation of sociological practice. In Daniel Bertaux (Ed.), Biography and society: The life history approach in the social sciences (pp.29-45). London: Sage.

Bertot, J. C., Jaeger, P. T. Shuler, J. A. Simmons, S. N. \& Grimes J. M. (2009). Reconciling government documents and e-government: Government information in policy, librarianship, and education. Government Information Quarterly, 26, 433-436.

Bessette, J. (1994). The Mild Voice of Reason: Deliberative Democracy and American National Government. Chicago IL: University of Chicago Press.

Birkinshaw, P. (1997). Freedom of information and Open Government. Government Information Quarterly, 14, 27-49.

Blair, H. (2000). Participation and accountability at the periphery: Democratic local governance in six countries. World Development, 28(1), 21-39.

Bland, G. (2011). Supporting post-conflict democratic development? External promotion of participatory budgeting in El Salvador. World Development, 39(5), 863873. Doi: 10.1016/j.worlddev.2010.09.010

Bobic, M. P. and Davis, W. E. (2003). A Kind of Word for Theory X: or Why so many Nrwfangled Management Techniques Quickly Fail. Journal of Public Administration Research and Theory, 13, 239-264. 
Bombard, Y., Abelson, J., Simeonov, D., \& Gauvin, F.P. (2011). Eliciting ethical and social values in health technology assessment: a participatory approach. Social Science \& Medicine, 73 (1), 135-144. DOI: doi:10.1016/j.socscimed.2011.04.017

Boulding, C., \& Wampler, B. (2010). Voice, votes, and resources: Evaluating the effect of participatory democracy on well-being. World Development, 38(1), 125135. Doi: 10.1016/j.worlddev.2009.05.002

Brautigam, D. (2003). The people's budget? Politics, participation and pro-poor policy. Development Policy Review, 22(6), 653-668.

Burkhalter, S., Gastil, J. \& Kelshaw, T. (2002). Conceptual definition and theoretical model of public deliberation in small face to face groups. Communication Theory, 12 (4), 398-422.

Burkhead, J. and Miner, J. (2009). Public Expenditure. New Jersey: Transaction Publishers.

Byrne, B. M. (2010). Structural Equation Modelling with AMOS: Basic Concepts, Applications, and Programming. London: Rutledge.

Carcasson, M., Black, L. W., \& Sink, E. S. (2010). Communication Studies and Deliberative Democracy: Current Contributions and Future Possibilities. Journal of Public Deliberation, 6 (1), 1-42.

Chambers, R. (1997). Whose Reality counts? Putting the first last. London: ITP.

Chambers, S. (2003). Deliberative Democratic Theory. Annual Review of Political Science, No. (6): 307-326.

Chang, D. (2012). Deliberative democracy: public reason and the common good. Seoul: Parkyoungsa.

Chenhall, R., \& Brownell, P. (1988). The Effect of Participative Budgeting on Job Satisfaction and Performance: Role Ambiguity as an Intervening Variable. Accounting, Organizations \& Society, 13 (3), 225-234.

Choi, I. (2014). What explains the success of participatory budgeting? Evidence from Seoul autonomous districts. Journal of Public Deliberation, 10 (2).

Chu, K. and Hemming, R. (1998). Public Expenditure Handbook: A guide to Public Policy Issues in Developing Countries. Washington, D. C: International Monetary Fund.

Chuan, T. C., Muhamad, M. R., Lian, T. C. Wee, S. Y., Asmai, S. A. (2011). Statistics with SPSS for Research. Melaka: Universiti Teknikal Malaysia Melaka.

City of San Diago (2005). Annual fiscal year 2005 budget. Retrieved March 26, 2015, from http://www.sandiego.gov/fm/annual/pdf/fy05/03v1goals.pdf

Coakes, S. J. (2013). SPSS: Analysis without Anguish: Version 20.0 for Windows. Milton: John Woley Sons Australia.

Cohen, J. (1989). Deliberative democracy and democratic legitimacy. (Hamlin, A. and Pettit, P. eds.), the Good Polity. Oxford: Blackwell.

Cohen, J. (1997). Deliberation and Democratic Legitimacy in Bohman and Rehg (1997). 67-91.

Cohen, J., \& Fung, A. (2004). Radical democracy. Swiss Journal of Political Science, 10, 23-34. 
Cooke, B. \& Kothari, U. (2001). Participation: The New Tyranny? New York: Zed Books.

Costa-Font, J., Forns, J, R., \& Sato, A. (2015). Participatory health system priority setting: Evidence from a budget experiment. Social Science \& Medicine, 146, 182190. Doi: http://dx.doi.org/10.1016/j.socscimed.2015.10.042

Craig, D. and Porter, D. (2001). Poverty and reduction strategy: A new convergence. World Development, 22 (10): 1437-1454.

Creighton, J. L. (2005). The Public Participation Handbook: Making Better Decisions Through Citizen Involvement. San Francisco: Jossey-Bass.

Creswell (2006). Understanding Mixed Methods Research. Chapter One. California: Sage Publication.

Creswell, J. W. \& Clark, V. (2011). Designing and Conducting Mixed Methods Research. Second Edition. London: Sage Publication.

Crook, R. C. (2003). Decentralization and poverty reduction in Africa: The politics of local-central relations. Public Administration and Development, 23, 77-88.

Crosby, N. (1995). Citizen juries: One solution for difficult environmental questions. In O. Renn, T. Webler, P. Wiedemann (Eds.), Fairness and competence in citizen participation: Evaluating models for environmental discourse (pp.157-174). Boston: Kluwer

Cuillier, D. \& Piotrowski, S. J. (2009). Internet information-seeking and its relation to support for access to government records. Government Information Quarterly, 26, 441-449. Retrieved from Science Direct.

Dahl, R. A. (1989). Democracy and its critics. New Haven, CT: Yale University Press.

Davies, C., Wetherell, M., \& Barnett, E. (2006). Citizens at the Centre: Deliberative Participation in Healthcare Decisions. Bristol: Policy Press.

de la Porte, C. \& Nanz, P. (2004). The OMC- a deliberative-democratic mode of governance? The cases of employment and pensions. Journal of European Public Policy, 11 (2), 267-288. DOI: 10.1080/1350176042000194430.

de Sousa Santos, B. (2005). Participatory Budgeting in Porto Alegre: Toward a Redistributive Democracy. London: Verso.

Degeling, C., Carter, S. M., \& Rychetnik, L. (2015). Which public and why deliberate? A scoping review of public deliberation in public health and health policy research. Social Science \& Medicine 131, 114-121. Doi: http://dx.doi.org/10.1016/j.socscimed.2015.03.009

DeVellis, R. F. (2003). Scale Development: Theory and Applications. Chapel Hill: Sage

Dias, N. (2012). Hope for democracy: 25 years of participatory budgeting worldwide. Portugal: InLoco.

Djurović-Todorović, J. \& Djordjević, M. (2009). The Importance of Public Expenditure Management in Modern Budget Systems. Economics and Organization, 6 (3), 281-294.

Druckman J.N. \& Nelson K. R. (2003). Framing and deliberation: how citizens' conversations limit elite influence. American Journal of Political Science, 47, 729-45.

Dryzek, J. (2010) Foundations and Frontiers of Deliberative Governance. Oxford: OUP.

Dryzek, J. S., \& Christian L. (2003). Social choice theory and deliberative democracy: A Reconciliation. British Journal of Political Science, 33 (1), 1-28. 
Durose, C. \& Rummery, K. (2006). Governance and collaboration: Review Article: Social Policy and Society, 5 (2): 315-321.

Ebdon, C. (2002). Beyond the Public Hearing: Citizen Participation in the Local Government Budget Process. Journal of Public Budgeting, Accounting \& Financial Management, 14 (2), 273-294.

Ehrhart, K., Hagen, J. V., Keser, C. \& Gardner, R. (2006). Budget Processes: Theory and Experimental Evidence. Manheim Germany: University of Mannheim.

Elster, J. (1995). Strategic uses of argument in barriers to conflict resolution. New York: W. W. Norton, 236-57.

Elster, J. (1998). Introduction. In J. Elster (Ed.), Deliberative democracy (pp. 1-18). Cambridge, MA: Cambridge University Press.

Emmert, P. \& Barker, L. L. (1990). Measurement of Communication Behavior. New York: Longman.

Evans, E. \& Kotchetkova, I. (2009). Qualitative research and deliberative methods: promise or peril? Qualitative Research, 9, 625-643.

Evans, P. (2004). Development as institutional change: The pitfalls of Monocropping and the Potentials of Deliberation. Studies in Comparative International Development, 38(4), 30-52.

Faguet, J.-P. (2009). Governance from below in Bolivia: A theory of local government with two empirical tests. Latin American Politics \& Society, 51(4), 29-68.

Fishkin, J. S. (1991). Democracy and deliberation: new direction for democratic reform. New Haven, CT: Yale University Press.

Foddy, W. (1994). Constructing Questions for Interviews and Questionnaires: Theory and Practice in Social Research. Cambridge University Press: Cambridge

Folscher, A. (2010). Budget Transparency: New Frontiers in Transparency and Accountability. London: Open Society Foundation.

Francis, P., \& James, R. (2003). Balancing Rural Poverty Reduction and Citizen Participation: The Contradictions of Uganda's Decentralization Program. World Development, 31(2), 325-337.

Franklin, A. L. \& Ebdon, C. (2005). Are we all touching the same camel? Exploring a model of participation in budgeting. The American Review of Public Administration, 35 (2), 168-185.

Frazer, M. (2011). Iraqi Kurdistan Budget Under Scrutiny. Press Tv, Erbil

Fung, A. \& Wright, E. O. (2003). Deepening Democracy. London: Verso.

Fung, A., \& Wright, E. O. (2001). Deepening democracy: Innovations in Empowered Participatory Governance. Politics and Society, 29(1), 5-42. http://dx.doi.org/10.1177/0032329201029001002.

Garcia, A. C., Pinto, F. B. and Ferraz, I. N. (2004). Electronic Participatory Budgeting (E-PPB) Increasing People Participation in the Decision Making Process. Niteroi, RJ: Universidade Federal Fluminense

Garvin, P. (2012). Government Information Management in the 21st Century: International Perspectives. Farnham: Ashgate Publishing.

Gastil, J. (1993). Democracy in Small Groups: Participation, Decision Making, and Communication. Philadelphia: New Society. 
Gastil, J., Black, \& Lawra. W. (2008). Public deliberation as the organizing principle of political communication research. Journal of Public Deliberation, 4 (1). Retrieved from http://www.publicdeliberation.net/jpd/vol4/iss1/art3

Gawthrop, L. C. (1998). The human side of public administration. PS: Political Science and Politics, 31, 763-769.

Gelders, G. (2006). Public information provision about policy intentions: The Dutch and Belgian experience. Government Information Quarterly, 22, 75-95. DOI: $10.1016 /$ j.giq.2004.10.006

Gentry D. B. (2012). Financial fittest: Its priceless public policy deliberation guide. Alexandria, VA: American Association of Family Consumer Sciences.

Ghasemi, A. \& Zahediasl, S. (2012). Normality Tests for Statistical Analysis: A Guide for Non-Statisticians. Int J Endocrinol Metab, $10 \quad$ (2). DOI: $10.5812 /$ ijem.3505

Ghosh, A. K. (1996). India's Defense Budget and Expenditure Management in a Wider Context. Delhi: Lancer Publishers.

Goldfrank, B. (2002). The Fragile Flower of local democracy: A case study of decentralization/participation in Montevideo. Politics \& Society, 30(1), 5183.

Goldfrank, B. (2011). Deepening local democracy in Latin America: Participation, decentralization, and the left. University Park, PA: Pennsylvania State University Press

Gomez, J., Insua, D. R., \& Alfaro, C. (2015). A participatory budget model under uncertainty, European Journal of Operational Research, (Unpublished). DOI: 10.1016/j.ejor.2015.09.024

Gomez, J., Insua, R. D., Lavin, J. M., \& Alfero, C. (2013). On deciding how to decide: designing participatory budgeting process. European Journal of Operational Research, 229, 743-750, http://dx.doi.org/10.1016/j.ejor.2013.03.035

Goodin, R. E. (2000). The constitutional of society. Berkeley: University of California Press.

Gouran, D. S. and Hirokawa, R. Y. (1996). Functional theory and communication in decision making and problem solving groups: An expanded view. In R. Y. Hirokawa and M.S. POOLE (eds.), Communication and group decision making ( $2^{\text {nd }}$ edition, p. 55-80). Thousand Oaks, CA: Sage.

Gray, T. (2006). Participation in Fisheries Governance. Springer: Dordrecht, Netherlands

Gret, M. \& Sintomer, Y. (2005). The Porto Alegre experiment: Learning lessons for better democracy. London: Zed Books.

Grimmelikhuijsen, S. (2010). Transparency of Public Decision-Making: Towards Trust in Local Government? Policy and Internet 2 (1): 5-35.

Gulick, L. \& Urwick, L. (1937). Notes on the Theory of Organization, Papers on the Science of Administration.

Gutmann, A. \&Thompson, D. (1998). Democracy and Disagreement. Ethics, 108 (3), 607-610

Gutmann, A. and Thompson, D. (2004). Why Deliberative Democracy? Princeton: Princeton University Press.

Habermas, J. (1984). Theory of communicative action. Boston: Beacon Press. 
Habermas, J. (1989). The structural transformation of the public sphere. Cambridge: MIT Press

Hair, J. F. Jr., Anderson, R. E., Tatham, R. L. \& Black, W. C. (1998). Multivariate Data Analysis, $5^{\text {th }}$ edition. US: Prentice-Hall PTR.

Harrell, M. C. \& Bradley, M. A. (2009). Data Collection Methods: Semi-Structured Interviews and Focus Groups. California: RAND Corporation.

Harvey, K. (2014). Encyclopedia of Social Media and Politics, Volume 1. California: Sage Publications.

Hatley, P. J. (2013). Preserving Place: A Grounded Theory of Citizen Participation in Community-Based Planning (Doctoral Dissertation). Retrieved April 2, 2014, from

http://scholarcommons.usf.edu/cgi/viewcontent.cgi?article $=5700 \&$ context $=\mathrm{e}$ td .

Heald, D. (2006). Varieties of Transparency. Un Transparency: The Key to Better Governance? Edited by Christopher Hood and David Heald, 25-43. Oxford, UK: Oxford University Press.

Healey, P. (2006). Collaborative Planning: Shaping Places in Fragmented Societies, Second Edition. New York: Palgrave MacMillan.

Heimans, J. (2002). Strengthening Participation in Public Expenditure Management: Policy Recommendations for Key Stakeholders. OECD Development Centre Policy Briefs, No. 22, OECD Publishing.

Heisinger, K. \& Hoyle, B. (2012). Managerial Accounting Paperback - June 1, 2012. Retrieved from http://www.saylor.org/site/textbooks/Managerial\%20Accounting.pdf

Hemon, P. (1991). Government information policy principles. Government Information Quarterly, 8, 393-399. Doi:10.1016/0740-624X (91)90007-U.

Hickey, S. (2002). Transitional/NGOs and Participatorya Forms of Right based Development: Converging with Local Politics of Citizenship in Cameron. Journal of International Development, 14, 841-857.

Ho, A. T. -K., \& Ni, A. Y. (2004). Explaining the adoption of e-government features: A case study of Iowa County Treasurers' offices. American Review of Public Administration, 34, 164-180.

Hsieh, H. \& Shannon, H. E. (2005). Three Approaches to Qualitative Content Analysis. Qualitative Health Research, 15 (9), 1277-1288. DOI: 10.1177/1049732305276687

IFJ (2014). Kurdistan Region of Iraq: Analysis of Right to Information Law. Retrieved from $\quad$ http://www.ifj.org/nc/news-singleview/browse/1/backpid/33/category/reports-publications/article/kurdistanregion-of-iraq-analysis-of-right-to-information-law/

IMF (2013). How Does the IMF Encourage Greater Fiscal Transparency? Washington: International Monetary Fund.

Innes, J. E. (1998). Information in Communicative Planning. Journal of the American Planning Association, 64 (1), 52-63.

Innes, J. E., \& Booher, D. E. (2010). Planning with Complexity: An introduction to collaborative rationality for public policy. New York: Rutledge. 
Institute for Local Governance ILG (2014). Public Engagement in Budgeting. Sacramentoo: California.

Investingroup (2013). The Kurdistan Region 2013: Facts \& Figures. Retrieved May 2, 2014 , from http://www.investingroup.org/files/kurdistan\%20facts\%20\&\%20figures $\% 20$ 2013.pdf .

Jaeger, P. \& Bertot, J. C. (2010). Transparency and technological change: Ensuring equal and sustained public access to government information. Government Information Quarterly, 27, 371-376. Retrieved from Science Direct.

James, P. (2004). Geographic Information Systems in Business. Hershey: Idea Group Inc Janssen, K. (2012). Open government data and the right to information. The Journal of Community Informatics, 8 (2).

Jaramillo, M. \& Wright, G. D. (2015). Participatory democracy and effective policy: is there a link? Evidence from rural Peru. World Development, 66, 280-292. http://dx.doi.org/10.1016/j.worlddev.2014.08.011

Jensen, M. J. (2008). The Internet and Influence: An Analysis of the Impact of Online Communication on Local Government Decision-Making. Center for Research on Information Technology. California: Irvine

John, W. C. (2008). Educational Research Planning, Conducting, and Evaluating Quantitative and Qualitative Research (3rd Edition). USA: Pearson Education International John, W. C. (2008). Educational Research Planning, Conducting, and Evaluating Quantitative and Qualitative Research (3rd Edition). USA: Pearson Education International

Johnson, R. B., \& Onwuegbuzie, A. J. (2004). Mixed methods research: A research paradigm whose time has come. Educational Researcher, 33, 14-26.

Jonga (2012). Prioritizing political banditry than good governance: Rethinking urban governance in Zimbabwe.|International Journal of Humanities and Social Science, 2 (24), 117-135.

Kami, A. (2013, March 7). Iraq parliament passes budget despite Kurdish boycott. Retrieved October 20, 2013, from Reuters: http://www.reuters.com/article/2013/03/07/iraq-budget-parliamentidUSL6N0BZHIW20130307

Karpowitz, C. F. (2006). Having a Say: Public Hearings, Deliberation, and American Democracy. Dissertation. Princeton University.

Karpowitz, C.F. \& Mendelberg (2011). An experimental approach to citizen deliberation. Retrieved April 3, 2015, from http://www.princeton.edu/ talim/An\%20Experimental\%20Approach\%20to \%20Citizen\%20Deliberation\%20-\%20Karpowitz_and_Mendelberg.pdf

Kerr, S. (2008). Satisfactory Snapshot. Press Gany, 7 (1), 1-9.

King, Cheryl Simrell, Kathryn M. Feltey, and Bridget O’Neill Susel. 1998. The Question of Participation: Toward Authentic Public Participation in Public Administration. Public Administration Review 58(4): 317-326.

Kirmanj, S. (2014). Kurdistan Region: A Country Profile. Journal of International Studies, 9, 146-157. 
Klinke, A. (2011). Deliberative democratization across borders: participation and deliberation in regional environmental governance. Procedia Social and Behavioral Sciences 14, 57-60. DOI: 10.1016/j.sbspro.2011.03.022

Kock, N. (2007). Encyclopedia of E-Collaboration. USA: IGI Global.

KRG (2009). Prime Minister's speech at launch of KRG Strategy on Good Governance and Transparency. Retrieved from http://libguides.scu.edu.au/content.php?pid=161580\&sid=1594180

KRG (2012). About the Kurdistan Regional Government. Retrieved May 1, 2014, from http://www.krg.org/uploads/documents/About Kurdistan Regional Govern ment_2012_04_10_h13m19s26.pdf

KRG (2016). The people of the Kurdistan Region. Retrieved July, 2016, from http://cabinet.gov.krd/p/p.aspx?l=12\&p=214

KRG Board of Investment (2016). KURDISTAN FACT SHEET. Retrieved June 2016, from http://www.kurdistaninvestment.org/fact sheet.html

Krishna, A. (2006). Poverty and democratic participation reconsidered: Evidence from the local level in India. Comparative Politics, 38(4), 439-458.

Kurdistan Journalists Syndicate (2016). Reliable Data and Information. Retrieved July 13, 2016 from http://kurdjs.com/index.php/ku/?option=com_content\&view=article\&id=16 4

Kvale, D. (1996). Interviews. London: SAGE Publications.

Kweit, M. G. \& Kweit, R. W. (2004). Citizen participation and citizen evaluation in disaster recovery. American Review of Public Administration 34, (4), 354373. Doi: $10.1177 / 0275074004268573$

Kweit, M. G. \& Kweit. R. W. (2007). Participation, Perception of Participation, and Citizen Support. American Politics Research 35, 3, 407-425.

Laegreid, P. \& Christensen, T. (2013). The Ashgate Research Companion to New Public Management. United Kingdom: Ashgate Publishing.

Leduka, M. (2009). Participatory Budgeting in the South African Local Government context: the case of the Mantsopa local municipality, Free State Province (Master dissertation, Stellenbosch University).

Licht, J. F. (2013). The Effect of Transparency in Decision Making for Public Perceptions of Legitimacy in different Policy-areas. University of Gothenburg: Sweden.

Linda, D. \& Meirowitz, A. (2009). Game Theory, Information, and Deliberative Democracy. American Journal of Political Since Association, 53 (2), $427-$ 444.

London, W. (2004). Creating Citizens through Public Deliberation. New York: Kattering Foundation.

Loukis, E., Charalabidis, Y. \& Diamantopoulou, V. (2012). Different Digital Moderated and None-Moderated Mechanisms for Public Participation. European, Mediterranean \& Middle Eastern Conference on Information Systems 2012 (EMCIS2012). June 7-8, Munich, Germany

Lukensmeyer, C. J., Goldman, J. and Stern, D. (2011). Assessing Public Participation in an Open Government Era: A Review of Federal Agency Plans. Washington, D. C: IBM Center for the Business of Government. 
Mansbridge, J. (2010). Deliberative polling as the gold standard. The Good Society, 19 (1), 55-62.

Margerum, R. (2000). Planning as collaboration. In Abbott, J \& Minnery, J. New Ideas for planning: Linking Theory and practice. Brisbane: Royal Australian Planning Institute.

Mathews, D. (1994). Politics for people: Finding a responsible public voice. Chicago: University of Illinois Press.

McGregor, M. (2006). What Decision-Makers Want and What They Have Been Getting. Value in Health, 9 (3), 181-185. Doi: 10.1111/j.1524-4733.2006.00098.x

Meijer A., \& Thaens, M. (2009). Public information strategies. Information Polity, 14, $31-45$

Meijer, A. (2009b). Understanding modern transparency. International Review of Administrative Sciences 75 (2): 255-269.

Mendel, T. (2003). Freedom of information: an internationally protected human right. Comparative Media Law Journal. Retrieved August 2014, from https://www.article19.org/data/files/pdfs/publications/foi-as-aninternational-right.pdf

Mendel, T. (2014). Kurdistan Region of Iraq: Analysis of right to information law. Center or Law and Democracy. Retrieved from http://www.lawdemocracy.org/live/kurdistan-region-of-iraq-analysis-of-right-toinformation-law/

Michels, A. (2011). Innovations in democratic governance: how does citizen participation contribute to a better democracy? International Review of Administrative Sciences, 77, 275-293.

Ministry of Planning (2014). GD of Investment Budget. Retrieved October 13, 2014 from http://www.mop.gov.krd/index.jsp?sid=1\&id=168\&pid=121

Mitton, C., Smith, N., Peacock, S., Evoy, B., \& Abelson, J., (2009). Public participation in health care priority setting: a scoping review. Health Policy, 91 (3), 219228.

Moll, J. and Fischer, N. B. (2000). Pedagogias nos tempos do Orc amento Participativo em Porto Alegre: Possı'veis implicac,o es educativas na ampliac,a a da esfera pu'blica.

Morrell, M. (1999). Citizens' Evaluations of Participatory Democratic Procedures: Normative Theory Meets Empirical Science. Political Research Quarterly 52: 293-322.

Muhammed, Z. (October 23, 2012). A program helps people participate in decisionmaking. The Kurdish Globe.

Mulgan, R. (2007). Truth in government and the politicization of public service advice. Public Administration, 85, 569-586.

Munno, G \& Nabatchi, T. (2014). Public Deliberation and Co-Production in the Political and Electoral Arena: A Citizens' Jury Approach. Journal of Public Deliberation: $\quad 10 \quad$ (2), $1-31 . \quad$ Retrieved from http://www.publicdeliberation.net/jpd/vol10/iss2/art1

Musell, M. (2009). Understanding Government Budgets: A Practical Guide. New York: Rutledge. 
Nabatchi, T. (2010). Addressing the citizenship and democratic deficits: the potential of deliberative democracy for public administration. The American Review of Public Administration. 40 (4), 376-399, DOI: 10.1177/0275074009356467

Naidu, S. P. (1996). Public Administration: Concepts and Theories. First Edition. New Delhi: New Age International Publishers.

Napoli, P. M. \& Karaganis, J. (2010) On making public policy with publicly available data: The case of U.S. communications policy making. Government Information Quarterly, 27, 384-391. Retrieved from Science Direct

Nascimento, J. L. R. (2012). The contribution of the public participation to avoid the misuse of public funds: a comparison of Brazil and the United States Cases. Washington: George Washington University.

National Consumer Council (2008). Deliberative public engagement: Nine principles. Retrieved from http://www.involve.org.uk/wpcontent/uploads/2011/03/Deliberative-public-engagement-nineprinciples.pdf.

National Taxpayers Association (2013). Budgetary transparency and citizen participation in counties in Kenya. Nairobi: NTA.

Nicholas, A. A. \& Rest, K. M. (1999). Public Participation in Contaminated Communities. Center for Technology, Policy and Industrial Development, MIT, Cambridge, pp. III-1 to III-12). Retrieved from http://web.mit.edu/ctpid/www/tljTL-pubPPCc.htm

Niemeyer, S. and Dryzek, J. (2007). The ends of deliberation: Meta-consensus and inter subjective rationality as ideal outcomes. Swiss Political Science Review, 13 (4), pp. 497-526

North,-D. C. (1999). Institutions, institutional change and economic performance. Cambridge, UK: Cambridge University Press.

North, P. (2000). Is there space for Organization from below within the UK government's action zones? A test of collaborative planning. Urban Studies, 37 (8): 12611278.

Nouri, H. (1998). Job Performance: The Roles of Budget Adequacy and Organizational Commitment. Accounting, Organization \& Society, 23(5), 467-483.

Nouri, H., \& Parker, R.J. (1998). The Relationship Between Budget Participation and job performance: the roles of budget adequacy and organizational commitment. Accounting, organization and society, 23 (5-6), 467-483. DOI: http://dx.doi.org/10.1016/S0361-3682(97)00036-6

Novy, A. and Leubolt, B. (2005). Participatory Budgeting in Porto Alegre: Social Innovation and the Dialectical Relationship of State and Civil Society. Urban Studies, 42, (11), 2023-2036.

Oliver, O. R. (2004). What is Transparency? New York City: The McGraw-Hill Companies.

Ostrom, E. (2005). Understanding Institutional Diversity. Princeton and Oxford: Princeton University Press.

Page, B. I. \& Shapiro, R. Y. (1983). Effects of Public Opinion on Policy. The American Political Science Review, 77(1), 175-190.

Page, B. I. (1996). Who deliberate? Mass media in modern democracy. Chicago: University of Chicago Press. 
Pallant, J. (2007). SPSS: Survival Manual. $3^{\text {rd }}$ edition. New York: Open University Press. Pallant, J. (2013). SPSS: Survival Manual. $5^{\text {th }}$ edition. New York: Open University Press. Parkinson, J., \& Mansbridge, J. (2012). Deliberative System: Deliberative democracy at the large scale. Second edition. UK: Cambridge University Press.

Pateman, C. (1970). Participation and Democratic Theory. Cambridge, MA: Cambridge University Press.

Pateman, C. (2012). Participatory democracy revisited. Perspectives on Politics, 10(01), 7-19. http://dx.doi.org/10.1017/S1537592711004877.

Payne, D. \& McMorris, R. (1967). Educational and Psychological Measurement: Contribution to Theory and Practice. Waltham, MA: Blaisdell Publishing.

Pearce, W. B., \& Littlejohn, S. (1997). Moral Conflict: When social worlds collide. Thousand Oaks, CA: Sage.

Philipp, M. (2014). Qualitative Content Analysis: Theoretical Foundation, Basic Procedures and Software Solution. Klagenfurt: The GESIS - LeibnizInstitute.

Piotrowski, S. J., \& Rosenbloom, D. H. (2002). Non mission-based values in results oriented public management: The case of freedom-of-information. Public Administration Review, 62 (6), 643-656.

Poole, M. S., \& Folger, J. P. (1981). Modes of Observation and the Validation of Interaction Analysis Schemes. Small Group Behavior, 12, 477-493.

Poon, M., Pike, R., \& Tjosvold, D. (2001). Budgetary Participation, Goal Interdependence and Controversy: A Study of a Chinese Public Utility. Management Accounting Research, 12 (1), 101-118.

Premchand, A. (1989). Government budgeting and Expenditure Controls: Theory and Practice. Washington, D.C., International Monitory Fund.

Qadir, K. S. (2007). Iraqi Kurdistan's Downward Spiral. The Middle East Quarterly, XIV: (3), 19-26.

Qi, Y. (2010). The Impact of the budgeting process on performance in small and medium sized firms in China (Doctoral Thesis, Univrsity of Twente, China. Retrieved April 4, 2015, from http://doc.utwente.nl/69978/1/thesis Y Qi.pdf

Rauf, M. (2015). Budget and its motives. Sulaimaniyah: Karo

Rawls, J. (1993). Political Liberalism. New York: Columbia University Press

Relly, J. E. \& Sabharwal, M. (2009). Perceptions of transparency of government policy making: A cross-national study. Government Information Quarterly, 26, 148157. Retrieved from Science Direct.

Relyea, H. C. (2009a). Federal freedom of information policy: Highlights of recent developments. Government Information Quarterly, 26, 314-320.

Roberts, A. (2002). Administrative discretion and the Access-to-information Act: An "internal law" on open government. Canadian Public Administration, 45(2), $175-194$.

Roberts, N. (2004). Public deliberation in an age of direct citizen participation. American Review of Public Administration, 34, (4), 315-353, DOI: 10.1177/0275074004269288.

Rodriguez-Bolivar, M. P. (2014). Measuring E-government efficiency: The opinion of public administrators and other stakeholders. Springer Science: Berlin 
Rose, S., Spinks, N. \& Canhoto, A. I. (2015). Management Research: Applying the Principles. London: Routledge.

Rowe, J. \& Frewer, L. (2004). Evaluating Public Participation Exercises: A Research Agenda. Science, Technology, \& Human Values, 29 (4), 512-556. DOI: DOI: $10.1177 / 0162243903259197$

Sale, D., Safford, S. and Davis, S. (2007). Measuring the Success of Public Involvement. Retrieved January 10, 2014, from http://www.ecoresourcegroup.com/pdf/Measuring\%20the\%20Success\%20of \%20Public\%20Involvement\%20IAP2\%20PQ\%2010-07.pdf

Schneidar, S. L. \& Shanteau, J. (2003). Emerging Perspectives on Judgment and Decision Research. New York: Cambridge University Press.

Schneider, A. \& Goldfrank, B. (2002). Budgets and Ballots in Brazil: Participatory Budgeting from The City to The State (Institute of Development Studies, No. 49). Brighton: University of Sussex

Schreier M. (2012). Qualitative content analysis in practice. Thousand Oaks, CA: Sage.

Searing, D., Solt, F., Conover, P. \& Crewe, I. (2007). Public discussion in the deliberative system: does it make better citizens? British Journal of Political Science, 37, 587-618.

Sekaran, U. \& Bougie, R. (2013). Research Method for Budiness: A skill building Approach. $6^{\text {th }}$ edition. Chennai: Wiley

Sekaran, U. (2003). Research Methods for Business a Skill Building Approach (4th end). New York: John Wiley, 292-297.

Shah, A. (2007). Participatory budgeting. Washington, DC: World Bank.

Sheely, R. (2015). Mobilization, Participatory Planning Institutions, and Elite Capture: Evidence from a Field Experiment in Rural Kenya. World Development, 67. 251-266. http://dx.doi.org/10.1016/j.worlddev.2014.10.024

Shields, J.F., \& Shields, M.D. (1998). Antecedents of Participative Budgeting. Accounting Organization \& Society, 23(1), 49-76.

Shuler, J. A., Jaeger, P. T., \& Bertot, J. C. (2010). Implications of harmonizing egovernment principles and the Federal Depository Library Program (FDLP). Government Information Quarterly, 27, 9-16.

Sihlongonyane, M. F. (2001). The rhetoric of community in project management: the case of Mahlakeng Township. Development in Practice, 11 (1): 34-44.

Singh, R. \& Mangat, N. S. (1996). Title Elements of Survey Sampling. Berlin: Springer Science \& Business Media.

Sintomer, Y., Herzberg, C. \& Röcke, A. (2008). Participatory Budgeting in Europe: Potentials and Challenges. International Journal of Urban and Regional Research, 32 (1), 164-178. Doi: 10.1111/J.1468-2427.2008. 00777.X

Smail, R. A. (2013). Planning Counter-Corruption Strategies in the Developing Countries: Case Study of Kurdistan Region (Published Master Thesis). Universiti Utara Malaysia: Sintok

Smail, R. A. (2014). The Evaluation Right to Information Law No. (11) for 2013. Erbil: Commission of Integrity in Kurdistan Region

Solidarie-Dade (2003) Caminhando para um Mundo Novo: Orc amento Participativo de Porto Alegre visto pela comunidade. Petrópolis/ RJ: Vozes. 
Speer, J. (2012). Participatory Governance Reform: A Good Strategy for Increasing Government Responsiveness and Improving Public Services? World Development,40(12),2379-2398.Doi: http://dx.doi.org/10.1016/j.worlddev.2012.05.034

Spiess, D. (2008). Public Participation in Brownfields Cleanup and Redevelopment: The Role of Community Organizations. Michigan: The University of Michigan.

States of Jersey State Assembly (2010). Corporate Services Scrutiny Panel: Forecasting of Expenditure. New Jersey: SJSA

Stie, A. E. (2008). Assessing democratic legitimacy from a deliberative perspective. (No. 6). Oslo: Centre for European Studies

Swint, B. (November 14, 2013). Kurdistan's Oil Ambitions. Retrieved April 30, 2014, from Business Week at http://www.businessweek.com/articles/2013-1114/2014-outlook-kurdistans-oil-ambitions

Tabachnick, B. G., Fidell, L. S., \& Osterlind, S. J. (2001). Using Multivariate Statistics. New Jersey: Pearson

Tavakol, M,. \& Dennick, R. (2011). Making sense of Cronbach's Alpha. International Journal of Medical Education, 2, 53-55. DOI: 10.5116/ijme.4dfb.8dfd.

Tawfik-Shkor, A. and Khoshnaw, H. (2010). The Impact of Health System Governance and Policy Process on Health Services in Iraqi Kurdistan. BMC International Health and Human Rights, 8 June 2010.

Theron, F. (2008). The developing change agent: a micro-level approach to development. Pretoria: Van Schaik

Timmons, J. F. \& Gorfias, F. (2014). Revealed Corruption, Taxation, and Fiscal Accountability: Evidence from Brazil. World Development, 70, 13-27. http://dx.doi.org/10.1016/j.worlddev.2014.12.011

Tsai, N., Choi, B., \& Perry, M. (2009). Improving the process of e-government initiative: An in-depth case study of web-based GIS implementation. Government Information Quarterly, 26, 368-376.

UNDP. (2009). Budget Execution Support in the Kurdistan Regional Government. Erbil: United Nations Development Program.

UN-HABITAT (2008). Participatory Budgeting in Africa: A training Companion with Cases from Eastern and Southern Africa; Volume 1: Concepts and principles.

Van Cott, D. L. (2008). Radical democracy in the Andes. New York: Cambridge University Press

Wälti, S., Küjbler, D. \& Papadopoulos, Y. (2004). How Democratic Is "Governance"? Lessons from Swiss Drug Policy. Governance, 17 (1), 83-113. DOI: 10.1111/j.0952-1895.2004.00238.x

Wampler, B. (2007). Participatory Budgeting in Brazil: Condensation, Cooperation, and Accountability. Pennsylvania: Pennsylvania State University Press.

Wampler, B. (2008). When does participatory democracy deepen the quality of democracy? Lessons from Brazil. Comparative Politics, 41(1), 61-82.

Weber, R. P. (1990). Basic Content Analysis. Beverly Hills, CA: Sage.

Weeks, E. C. (2000). The practice of deliberative democracy: results from four large-scale trails. Public Administration Review, 60 (4). 360-372. DOI: 10.1111/00333352.00098 
Whitehead, A. L. Sully, B. G. O. \& Campbell, M. J. (2014). Pilot and feasibility studies: Is there a difference from each other and from a randomized controlled trial? Contemporary Clinical Trials, 38, 130-133. http://dx.doi.org/10.1016/j.cct.2014.04.001

Wildavsky, A. (1979). Speaking truth to power: The art and craft of policy analysis. New Brunswick, NJ: Transaction.

Willoughby, K. (2002). Performance Measurement Utility in Public Budgeting:Application in State and Local Governments. The American Society for Public Administration (pp. 1-22).

World Alliance for Citizen Participation (2012). Public Budget and Expenditure. Retrieved, December 23, 2013, from http://www.pgexchange.org/images/toolkits/PGX_G_Public\%20Budgets\%2 0and\%20Expenditures.pdf

World Bank (2011). Chapter V: Strengthening Budgetary institutions for effective Government. Retrieved November 6, 2012, from http://siteresources.worldbank.org/INTTURKEY/Resources/361616$1173282369589 /$ tr_per_c5.pdf

World Bank (2015). Participatory budget formulation. Retrieved April 26, 2015, from http://go.worldbank.org/S9ZD1PNII0 .

World Bank (2015b). Resource Allocation and Investments Prioritization. Retrieved May 23 , 2015 , from http://www.worldbank.org/socialaccountability_sourcebook/Tools/PartBudg et/pb 2.2.html.

Wouters, M., Hardie-Boys, N. \& Wilson, C. (2011). Evaluating public input in National Park Management Plan reviews: Facilitators and barriers to meaningful participation in statutory processes. Wellington: New Zealand Department of Conservation

Yannoukakou, A. \& Araka, I. (2014). Access to Government Information: Right to Information and Open Government Data Synergy. Procedia - Social and Behavioral Sciences, 147, 332-340. Doi: 10.1016/j.sbspro.2014.07.107

Yarnell, P. and Fogg, K. (2007). Mirror, Mirror on the Wall: Parks Canada Reflects on Public Participation in a Recent Planning Initiative for National Historic Sites. International Association for Public Participation. Retrieved at http://static.qwad.com.au/iap2/files/07August_PQ.pdf

Zebari, A. (2013). Opposition Parties Accuse KRG of Mishandling Budget. Al-Monitor. Retrieved November 12, 2013, from http://www.almonitor.com/pulse/iw/contents/articles/originals/2013/02/kurdistanopposition-budget-mismanagement.html\#

Zhang, L. (2008). On Some Common Practices of Systematic Sampling. Journal of Official Statistics, 24 (4), 557-569. 